\title{
DOUBLE-FED ASYNCHRONOUS MOTOR-GENERATOR EQUIPPED WITH A 3-LEVEL VSI CASCADE
}

\author{
THÈSE Nº 2939 (2004) \\ PRÉSENTÉE À LA FACULTÉ SCIENCES ET TECHNIQUES DE L'INGÉNIEUR \\ Institut des sciences de l'énergie \\ SECTION D'ÉLECTRICITÉ \\ ÉCOLE POLYTECHNIQUE FÉDÉRALE DE LAUSANNE \\ POUR L'OBTENTION DU GRADE DE DOCTEUR ÈS SCIENCES TECHNIQUES \\ PAR \\ André HODDER \\ ingénieur électricien diplômé EPF \\ de nationalité suisse et originaire de Cheseaux-sur-Lausanne (VD)
}

acceptée sur proposition du jury:

Prof. J.-J. Simond, directeur de thèse

M. P. Braun, rapporteur

Prof. A.-Ch. Rufer, rapporteur

Dr A. Sapin, rapporteur

Dr A. Schwery, rapporteur

Prof. I.-A. Viorel, rapporteur 



\section{Remerciements}

Par ces quelques lignes, je tiens à remercier les personnes qui ont contribué, d'une manière ou d'une autre, à ce travail de doctorat.

Avant tout j'aimerais faire part de ma reconnaissance au Professeur Jean-Jacques Simond. J'aimerais le remercier de la confiance qu'il m'a témoignée en me permettant de faire ce doctorat au sein de son laboratoire, et de la grande liberté qu'il m'a accordée tout au long de ce travail.

J'aimerais également remercier le Dr Alain Sapin, qui m'a été d'une grande aide lors des premiers pas dans ce travail en me faisant profiter de sa connaissance et de son expérience.

Je remercie les membres du jury qui ont aimablement accepté de prendre du temps à l'analyse du manuscrit, M. Patrick Braun, le Prof. Alfred Rufer, le Dr Alain Sapin, le Dr Alexander Schwery et le Prof. Ioan-Adrian Viorel.

Je tiens à remercier la commission CREE-RDP des électriciens romands, la commission CTI et la firme ALSTOM pour leur soutien financier, sans qui ce travail n'aurait pas été possible.

Je remercie tous mes amis et collaborateurs du "LEME" pour l'extraordinaire ambiance de travail.

Sur un plan plus personnel, j'aimerais prendre le temps de remercier ma p'tite chérie Marie-Laure. Merci pour sa patience, son soutien tout au long de ce travail et merci tout simplement pour son amour.

Un grand merci également à ma maman qui par son amour, son soutien et sa persévérance à me pousser m'a permis d'aller si loin dans mes études. Merci encore à mon papa, et une pensée pour ma soeur Miriam.

Pour finir merci à tous mes amis, voisins et autres connaissances qui comptent pour moi. 



\section{Résumé}

Dans l'optique d'un développement durable, l'utilisation rationnelle de l'énergie électrique impliquera la mise en oeuvre de réseaux capables de transporter sur de longues distances des quantités importantes d'énergie électrique, et d'équipements de stockage d'énergie sous une forme autre qu'électrique.

Cette double exigence est la conséquence du fait que l'énergie électrique doit être simultanément produite et consommée puisqu'il n'est pas possible de la stocker directement en quantité appréciable. En effet, dans la mesure où une part importante de l'énergie électrique est produite par des centrales thermiques ou hydrauliques au fil de l'eau exploitées pratiquement en permanence à leur régime nominal, il n'est pas possible de couvrir une demande fortement variable dans le temps et dans l'espace sans disposer de réseaux de transport performants et de capacités de stockage adéquates. L'appartition récente de sites éoliens conséquents implique des capacités de stockage supplémentaires.

L'inventaire des techniques permettant le stockage de quantités importantes d'énergie fait apparaître la solution "groupes de pompage-turbinage" comme étant globalement la meilleure en termes de potentiel de stockage, de flexibilité et fiabilité d'exploitation, de temps de réponse, de rendement, de risques et de coûts.

Les groupes de pompage-turbinage actuellement en exploitation sont quasiment tous réalisés avec des moto-générateurs synchrones à la fréquence du réseau et par conséquent à vitesse constante. Les performances de tels groupes peuvent être massivement améliorées en recourant à des moto-générateurs à vitesse variable, en particulier à des machines de type asynchrone à rotor bobiné et doté d'une cascade rotorique. Les quelques groupes à vitesse variable de ce type en exploitation à ce jour sont équipés d'une cascade comportant un cyclo-convertisseur.

Le remplacement de la cascade de type cyclo-convertisseur par une cascade de type convertisseur de tension 3-niveaux est l'objectif majeur de ce projet. Les principaux avantages de ce remplacement sont la possibilité de régler la puissance reactive de la cascade rotorique et aucune présence de sous-harmoniques.

Les trois échelons nécessaires à une telle étude, à savoir modélisation, simulation et expérimentation ont permit l'élaboration d'un outil fonctionnel pour le dimensionnement du contrôle d'un tel dispositif. 



\section{Abstract}

In a concern for sustainable development, the rational use of electrical energy implies having transportation networks capable of transmitting large quantities of electrical energy over long distances as well as adequate storage plants.

This double requirement is the consequence of the fact that electrical energy has to be produced and consumed simultaneously, as direct storage of large quantities is not economically feasible. Nowadays, as thermal power plants and run-off river plants are always working at their nominal power for economic reasons; it is not possible to cover the large space and time demand variations without having an efficient transportation network and adequate storage capacities. The recent start up of major windformer sites also implies the need for supplementary storage capacities.

The inventory of large storage plants reveals the solution "pump-storage plant" as being one of the best in terms of storage potential, flexibility, reliability, response time, efficiency, risks and costs.

Nearly all the pump-turbine groups operating today consist of synchronous motorgenerators working at the network frequency and therefore at constant speed. The performance and efficiency of such groups can be significantly improved by using variable speed motor-generators, and more specifically doubly-fed asynchronous motor-generators. The few variable speed units in operation today are equipped with a cyclo-converter cascade.

The purpose of the present thesis is to propose the replacement of the cycloconverter solution by a back to back 3-level VSI cascade and investigate the complete regulation strategy. This solution compared to the former has the advantage of providing the possibility of regulating the reactive power in the rotor cascade as well as not polluting the network with sub-harmonics.

The three steps followed in such a study, modelling, simulation and practical measurements have permitted the elaboration of a functional tool for the design of the control for such a system. 



\section{Table of Contents}

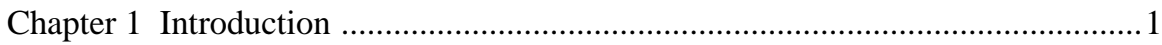

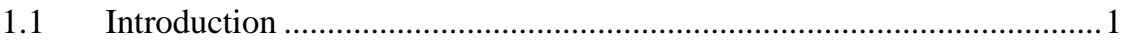

1.2 Comparison between the cyclo-converter and the 3-level VSI solutions

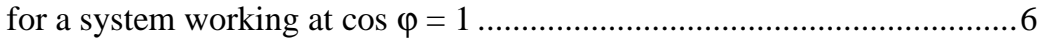

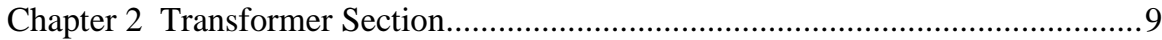

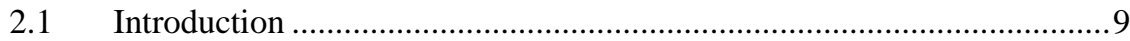

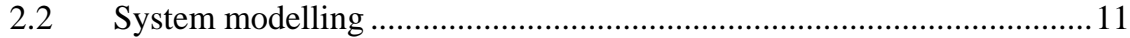

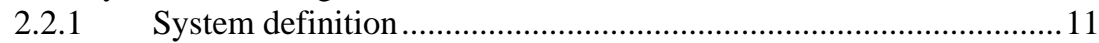

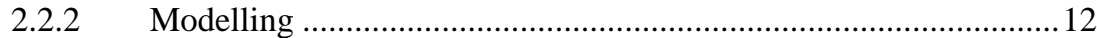

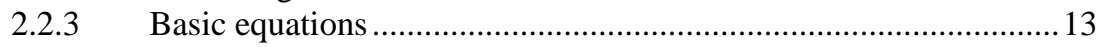

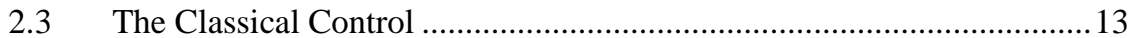

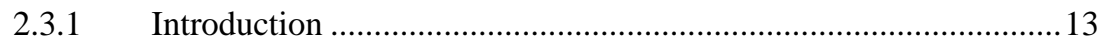

2.3.2 Current Control............................................................................. 14

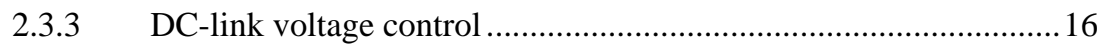

2.3.4 Reactive power control ............................................................. 18

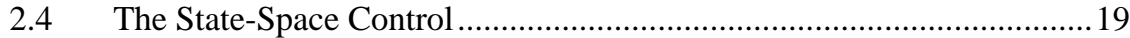

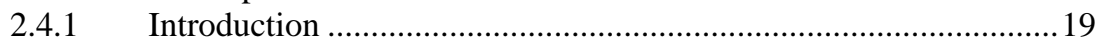

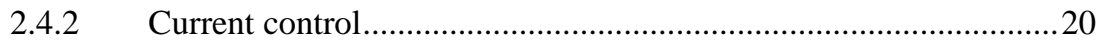

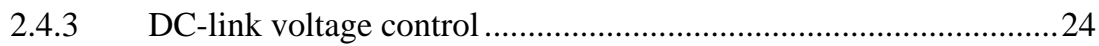

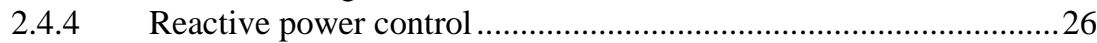

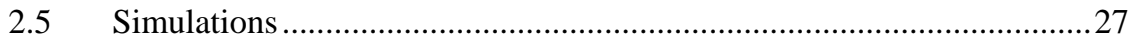

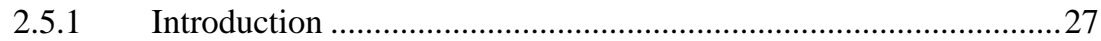

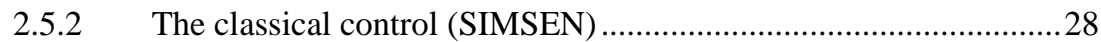

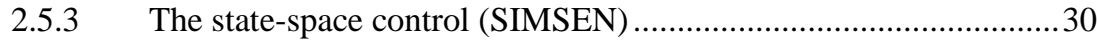

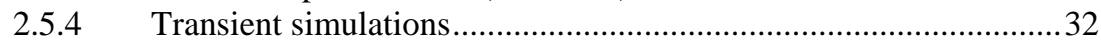

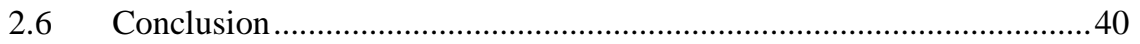


Chapter 3 Machine Section

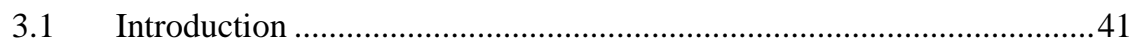

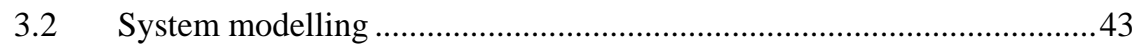

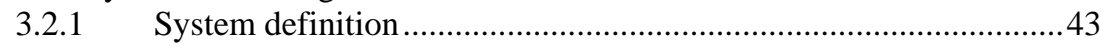

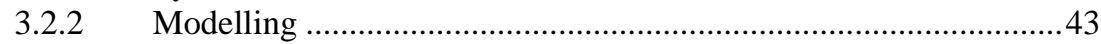

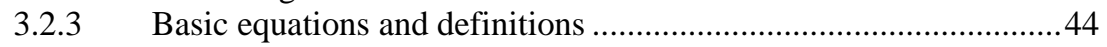

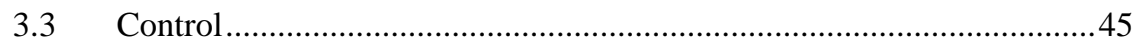

3.3.1 Transfer functions for the rotor and stator current controls ............45

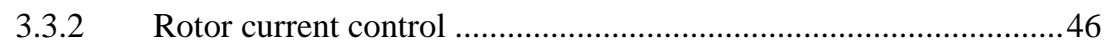

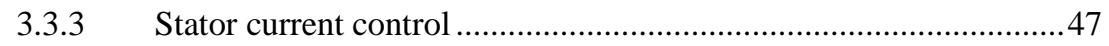

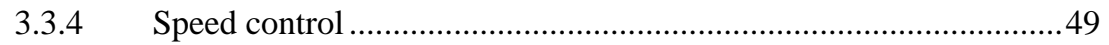

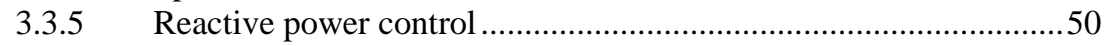

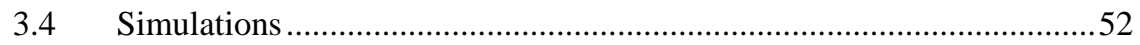

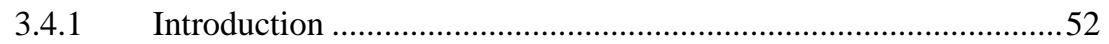

3.4.2 The Machine Control (SIMSEN) ................................................53

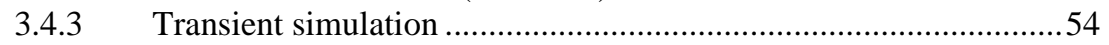

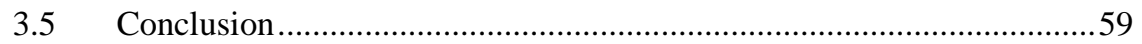

Chapter 4 DC-Link DC Unbalance Control .......................................................61

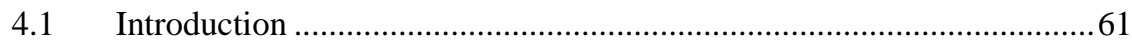

4.2 Basics for the DC-link DC unbalance control .........................................61

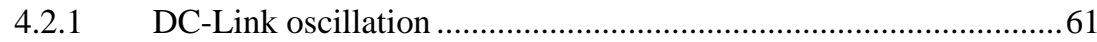

4.2.2 NP-Current $\mathrm{i}_{0}$, driving force for the DC-Side oscillation................62

4.2.3 DC-link DC unbalance and the self balancing ability.....................64

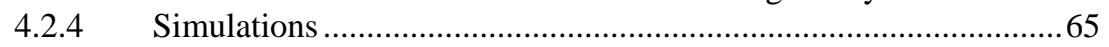

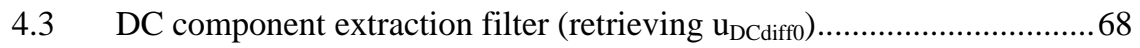

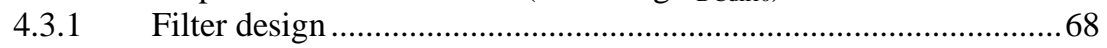

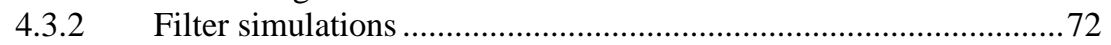

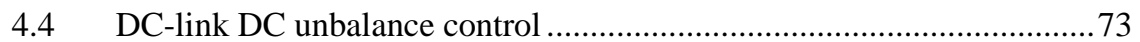

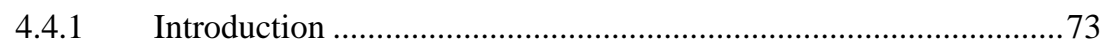

4.4.2 Simulations for the critical point ............................................... 74

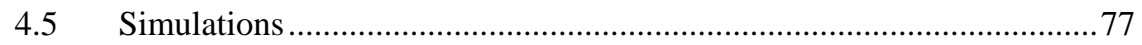

4.6 Influence of a DC unbalance component on the mechanical torque........80

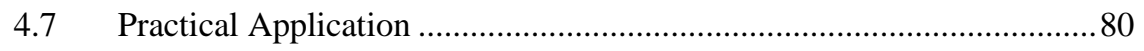

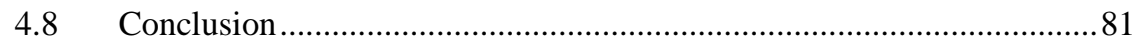




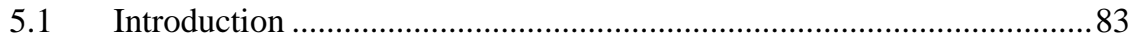

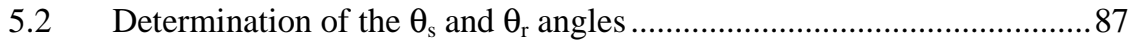

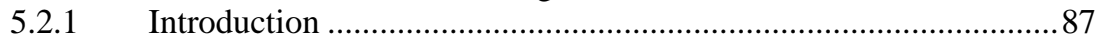

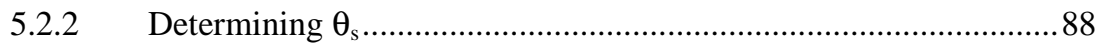

5.2.3 Determining $\theta_{\mathrm{r}}$ with a position observer (Sensorless) ................... 92

5.3 Reactive power steps for the transformer section alone …...................96

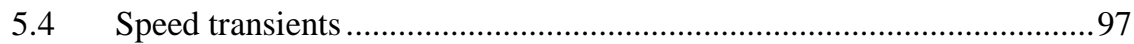

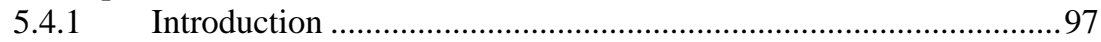

5.4.2 Case (a) - Motor mode speed down step...................................... 100

5.4.3 Case (b) - Motor mode speed up step ............................................ 101

5.4.4 Case (c) - Generator mode speed down step - Flywheel effect.... 103

5.4.5 Case (d) - Generator mode speed up step...................................... 104

5.4.6 Analysis of the results of the speed transients .............................. 106

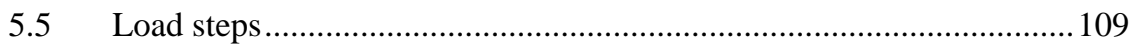

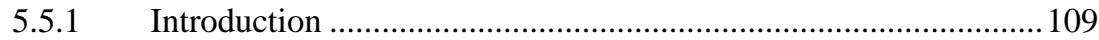

5.5.2 Large load step..................................................................... 109

5.5.3 Load steps with a speed close to the synchronous speed ...............111

5.5.4 Result analysis for the load steps ................................................ 112

5.6 Industrial Application - The size of the capacitors ..............................113

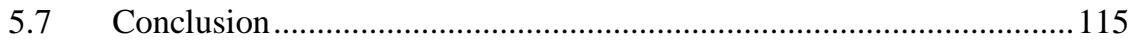

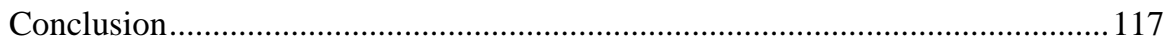

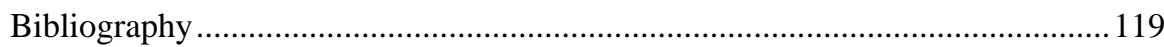

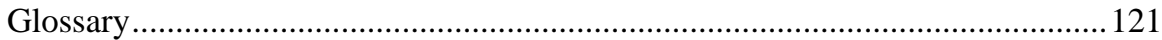

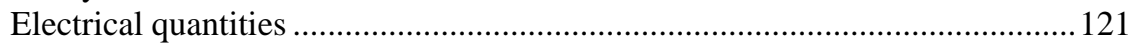

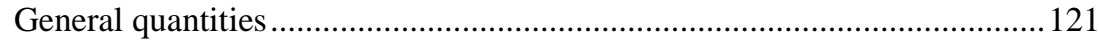

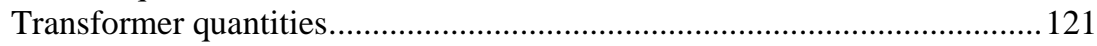

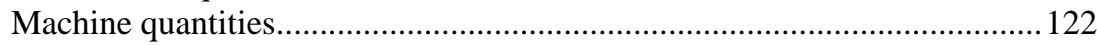

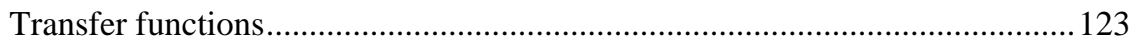

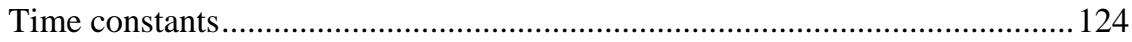

State space control specific quantities .......................................................... 125

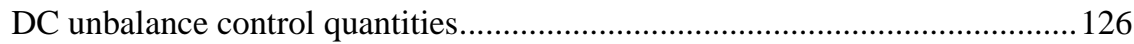





\section{Chapter 1 Introduction}

\subsection{Introduction}

In a concern for sustainable development, the rational use of electrical energy implies having transportation networks capable of transmitting large quantities of electrical energy over long distances as well as adequate storage plants.

This double requirement is the consequence of the fact that electrical energy has to be produced and consumed simultaneously, as direct storage of large quantities is not economically feasible. Nowadays, as thermal power plants and run-off river plants are always working at their nominal power for economic reasons; it is not possible to cover the large space and time demand variations without having an efficient transportation network and adequate storage capacities. The recent startup of major windmill sites also implies the need for supplementary storage capacities.

The inventory of large storage plants reveals the solution "pump-storage plant" as being one of the best in terms of storage potential, flexibility, reliability, response time, efficiency, risks and costs.

The present pump-turbine groups operating are nearly all made of synchronous motor-generators working at the network frequency and therefore at constant speed. The performance and efficiency of such groups can be significantly improved by using variable speed motor-generators, and more specifically doublyfed asynchronous motor-generators. 


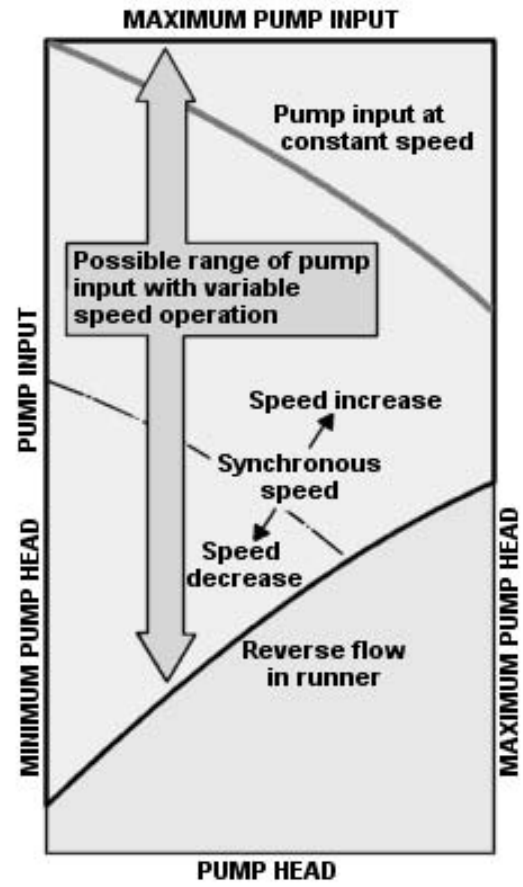

Figure 1.1 : Pump input range with variable speed operation [1]

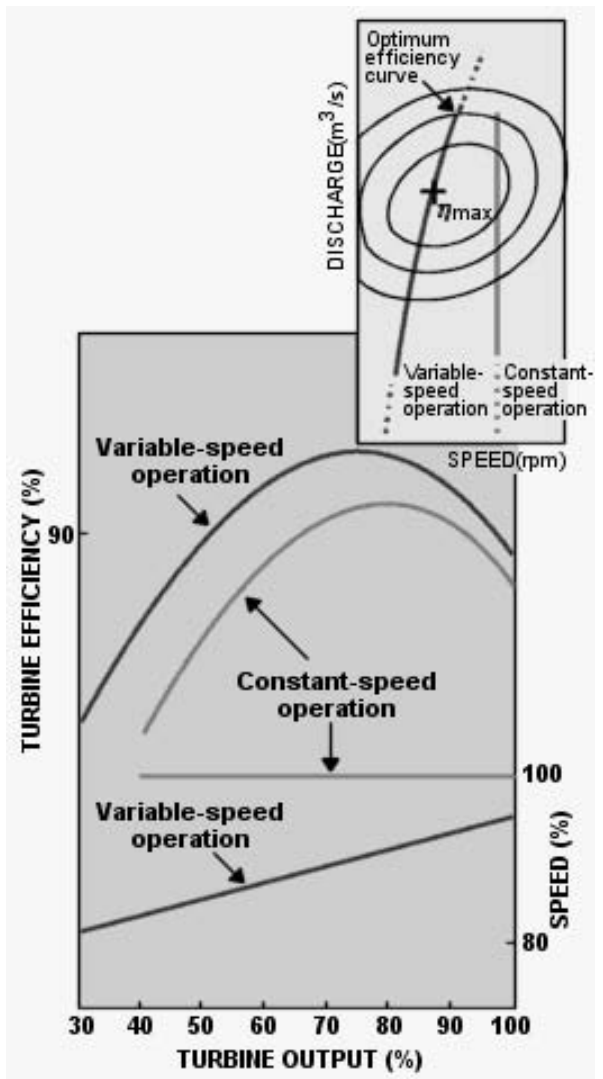

Figure 1.2 : Turbine efficiency comparison for fixed and variable speed operation [1]

The distinctive features of adjustable speed pumped storage are :

- Active power regulation in pump mode. As shown in Figure 1.1, the adjustable speed operation can vary the pump input wherever necessary within a specified range, whereas the pump input in a conventional constant speed system is fixed depending on the available pump head. This also implies a better network frequency regulation under low load conditions leading to an improvement of the network stability.

- High efficiency and wide range of operation in generating mode, especially under partial load (Figure 1.2). The efficiency can be improved of several percent, because the turbine is operated at the optimum speed of each available head. 
- Network stability improvement by rapidly injecting active power (flywheel effect).

- Network stability improvement by reactive power compensation, by using the transformer section of the power electronics as an SVC and/or by magnetising the motor-generator by the rotor.

- Under certain conditions, starting without additional equipment.

For adjustable speed groups, compared to the solution where the power electronics is put on the stator side of the machine (Figure 1.3 (a)), the use of a doubly-fed asynchronous machine (Figure 1.3 (b)) has the advantage that the power electronics only needs to feed the slip energy, and is therefore designed for only $10-15 \%$ of the machine nominal power depending on the required speed range. The network is also less stressed by the power electronics.

In order to exploite the advantages of the variable speed groups, the owner would be obliged to completely change his operating strategies.
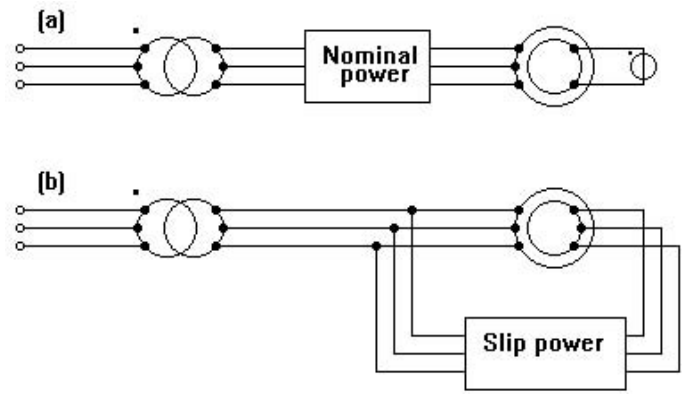

Figure 1.3 : Stator and rotor cascade solutions

The few double-fed adjustable speed pump-storage plants currently in use are equipped with a thyristor cyclo-converter cascade (Figure 1.4 and [2],[3]).

The purpose of the present thesis is to propose the replacement of the cycloconverter solution by a back to back 3-level VSI (Voltage Source Inverter) cascade and investigate the complete regulation strategy.

Figure 1.5 shows the representation of the 3-level VSI slip energy recovery drive. It comprises a wound rotor asynchronous machine (1) and two 3-level VSIs, one on the rotor side (2) and one on the transformer side (3), put back-to-back and connected by a DC-link (4). Also, a transformer (5) at the entry point of the rotor cascade allows the adjustment to the correct voltage required by the power electronics. The overall system is connected to the network (7) via a transformer (6). 


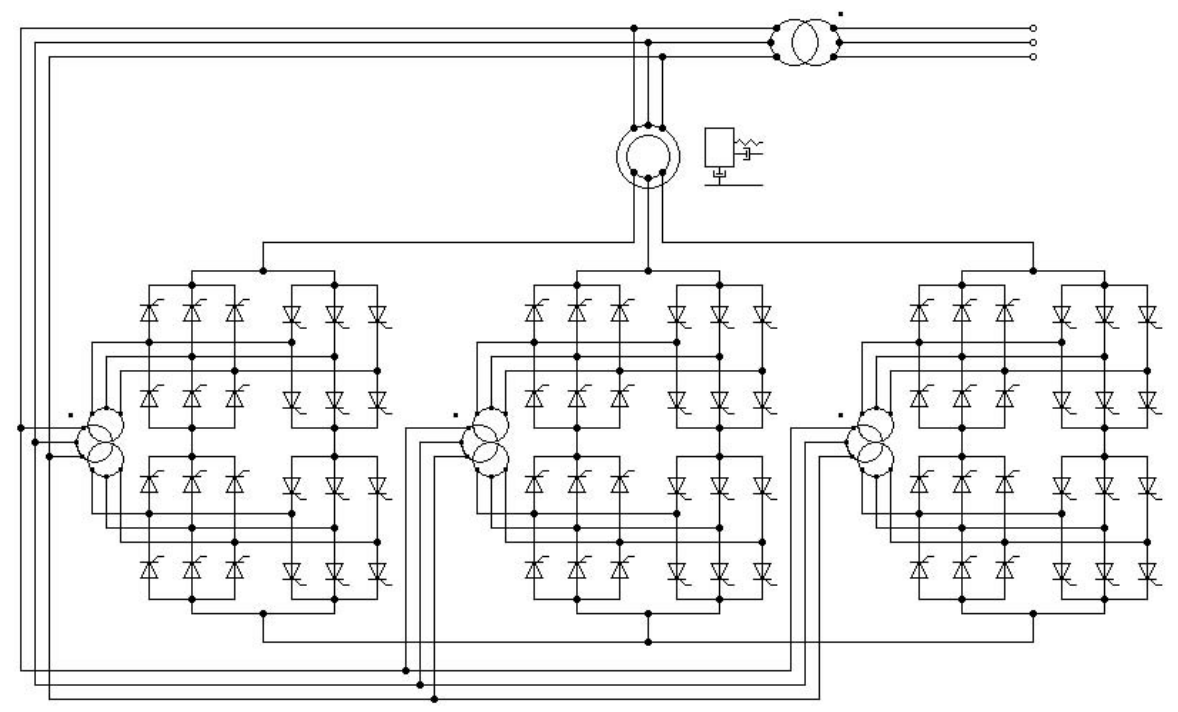

Figure 1.4 : Cyclo-converter slip energy recovery drive

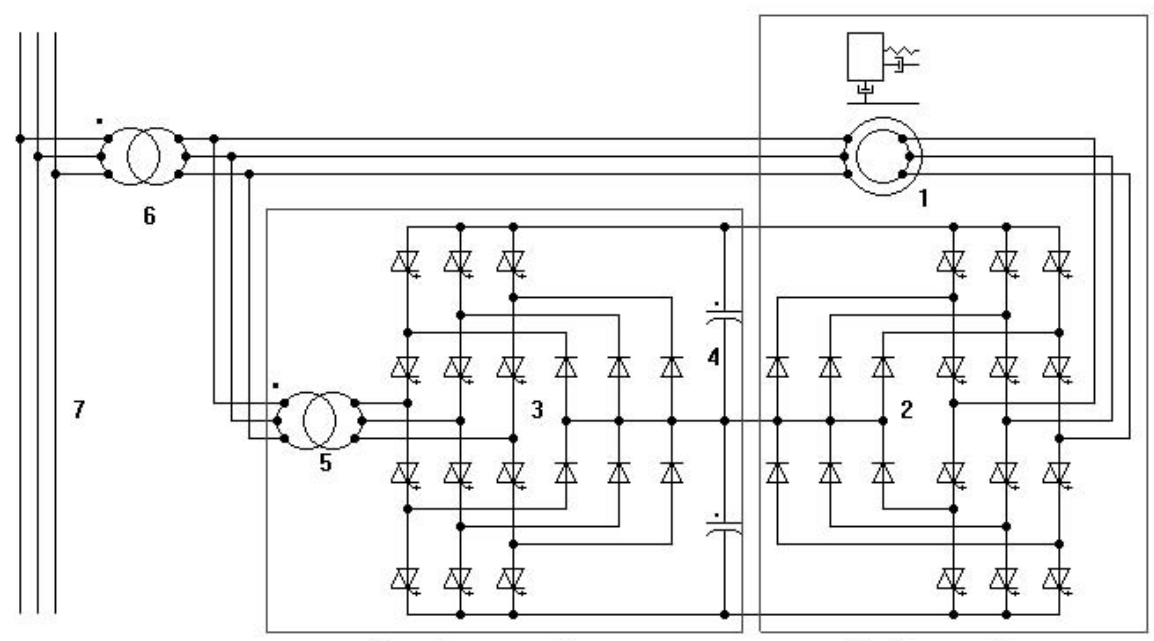

Transformer section

Machine section

Figure 1.5 : 3-level VSI slip energy recovery drive 
The 3-level VSI solution has the following main advantages compared to the cyclo-converter.

- It only requires a single standard transformer, whereas the cyclo-converter needs three multi-winding transformers.

- As the cyclo-converter is made of direct frequency converters, underharmonics are injected in the network, and due to the variable speed, these harmonics will vary with the slip.

- In the case of an installation functioning at $\cos \varphi=1$, the machine is smaller and subsequently costs less with the 3-level VSI solution. This is explained by the fact that the cyclo-converter power electronics always requires feeding with reactive power, whereas the 3-level VSI can produce reactive power. Hence, the machine needs to be less over-excited to compensate the $\cos \varphi$ and is therefore smaller.

These advantages lead to an installtion being up to $10 \%$ cheaper, even if the power electronics is a little bit more expensive.

For the present study, two sections are defined; the transformer section and the machine section (Figure 1.5). Their specific regulation strategies will be investigated in respectively Chapter 2 and Chapter 3.

A specific control for correct voltage dispatching of the DC-link capacitors is investigated in Chapter 4.

Chapter 5 presents the measurements, performed on a low power application, of the behaviour of the system during transients as well as comparison to simulations.

Due to the power generation purpose of the system, carrier based PWM is chosen to control the VSIs. Compared to offline optimized PWM, the carrier based PWM is able to function over the whole range, without predefined operating ranges as required by the offline optimized PWM.

Compared to a 2-level, a 3-level VSI has smaller dv/dt leading to less stress for the machine insulation. Also, the currents THD are nearly four times smaller [4], leading to lower losses in the machine rotor and to smaller or even the suppression of the filter on the transformer side. 


\subsection{Comparison between the cyclo-converter and the 3-level VSI solutions for a system working at $\cos \varphi=1$}

To compare the cyclo-converter and the 3-level VSI solutions for a system working at $\cos \varphi=1$, the system given in Figure 5.3 was used.The comparison is illustrated for a speed of $1.1 \mathrm{pu}$ and an external torque of $0.8 \mathrm{pu}$.

Figure 1.6-Figure 1.8 and Figure 1.7-Figure 1.9 show the line current at the network interconnection point and its Fourier series decomposition for respectively the 3-level VSI and the cyclo-converter solutions.

The equivalent THD is respectively of $1.332 \%$ for the 3-level VSI and of $3.375 \%$ for the cyclo-converter. For the latter, the presence of sub-harmonics are clearly seen. As explained in the previous paragraph, these sub-harmonics are due to the fact that the cyclo-converter is a direct frequency converter.This is illustrated by Figure 1.10 and Figure 1.11 which show the current component injected into the grid by the rotor cascade for respectively the 3-level VSI and the cyclo-converter.

In Figure 1.11, the sub-oscillation of $5 \mathrm{~Hz}$ (for a speed of $1.1 \mathrm{pu}$ ) modulated by the $50 \mathrm{~Hz}$ of the grid is seen. Also, due to the $\cos \varphi=1$, the over-excitation of the machine for the reactive power compensation implies a higher current for the cyclo-converter, leading to more harmonics pollution. In fact, the 3-level VSI current (Figure 1.10) is close to a sinus with an amplitude of about $1.4 \mathrm{pu}$, whereas the cyclo-converter current reaches about $2.3 \mathrm{pu}$.

Figure 1.12-Figure 1.13 and Figure 1.14-Figure 1.15 show the stator and rotor phase currents for respectively the 3-level VSI and the cyclo-converter. For these currents, no major discrepancies are observed.

Finally, Figure 1.16 and Figure 1.17 show the phase voltage for respectively the 3-level VSI and the cyclo-converter. Here, the cyclo-converter offers the advantage of needing less $\mathrm{dv} / \mathrm{dt}$ which may be of importance with older machines.

Two drawbacks of the 3-level VSI solution, linked to the power electronics can be mentioned here. The first one is that even the newer IGCTs imply switching losses which are nearly not present with the thyristors. The second one is that in the 3level VSI, the current passes through two semicondutors, whereas the cycloconverter current only passes through one semiconductor. This leads to more conduction losses for the 3-level VSI solution. In spite of these drawbacks, the 3-level VSI solution appears to be less expensive in case of working at $\cos \varphi=1$ as the economical gain on the machine is higher than the higher cost power electronics. 


\section{VSI Solution}

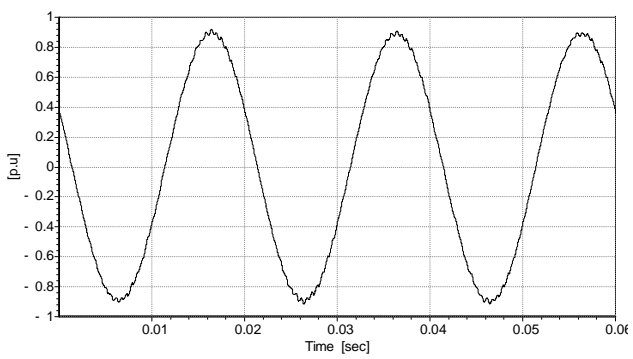

Figure 1.6 : Line current at the network interconnection point for the 3-level VSI

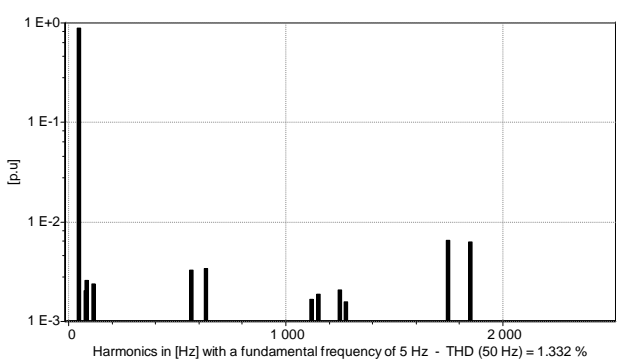

Figure 1.8 : Fourier series decomposition and THD of the line current

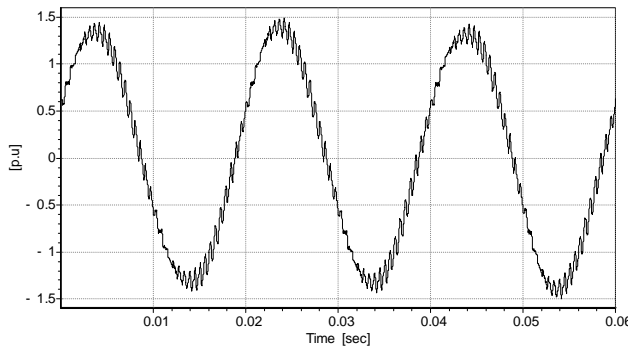

Figure 1.10 : Line current on the primary side of the rotor cascade transformer

\section{Cyclo-converter Solution}

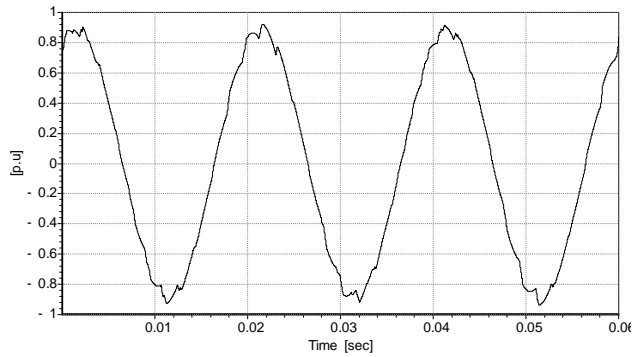

Figure 1.7 : Line current at the network interconnection point for the cyclo-converter

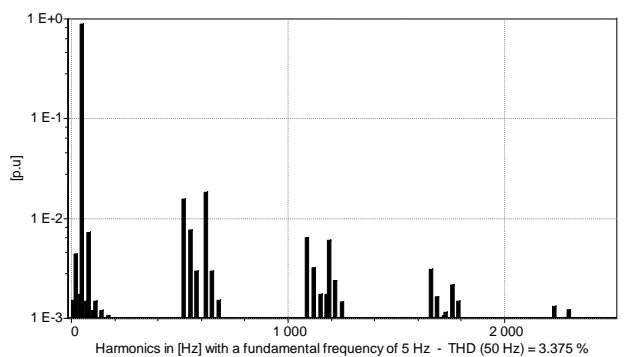

Figure 1.9 : Fourier series decomposition and THD of the line current

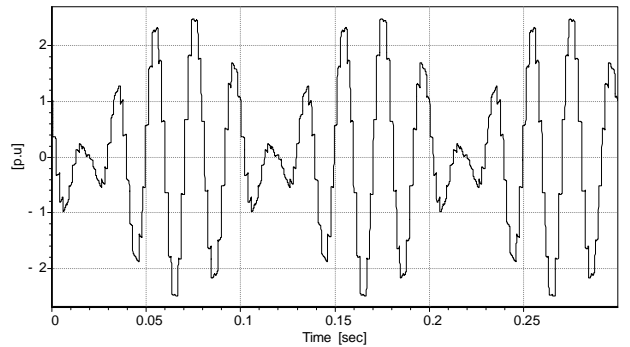

Figure 1.11 : : Line current on the primary side of the rotor cascade transformer 
VSI Solution

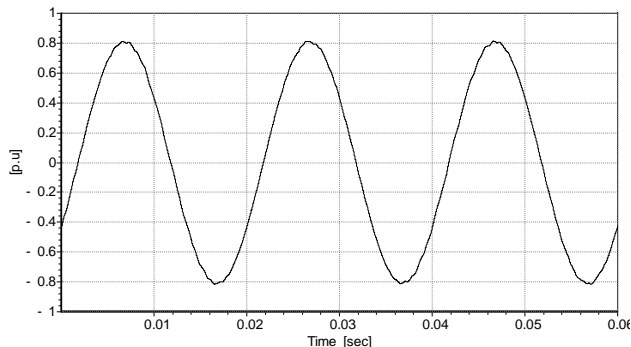

Figure 1.12 : Stator phase current for the VSI solution

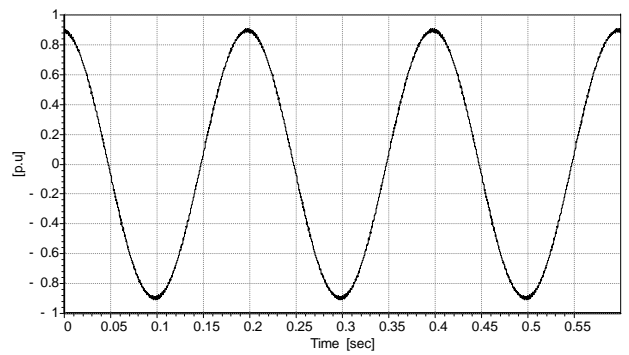

Figure 1.14 : Rotor phase current for the VSI solution

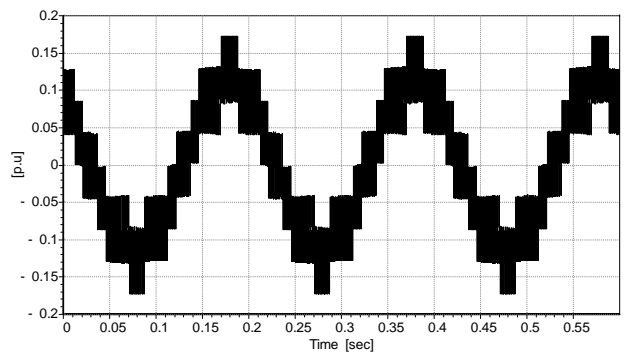

Figure 1.16 : Rotor phase voltage for the VSI solution

\section{Cyclo-converter Solution}

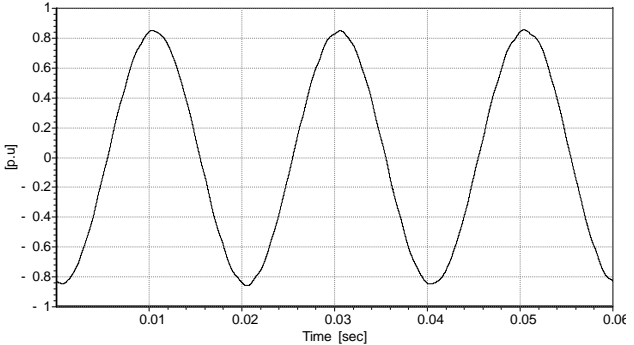

Figure 1.13 : Stator phase current for the cycloconverter solution

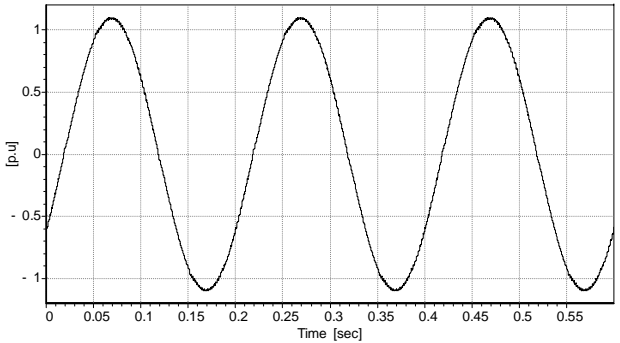

Figure 1.15 : Rotor phase current for the cycloconverter solution

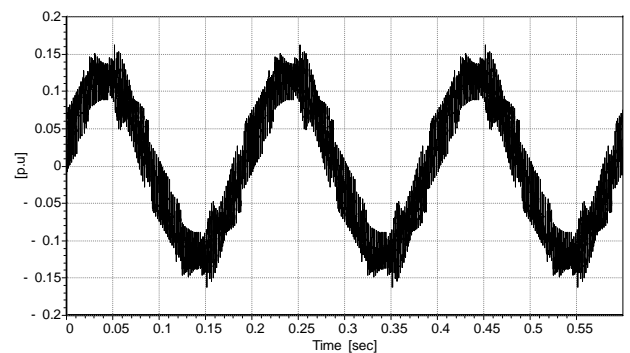

Figure 1.17 : Rotor phase voltage for the cycloconverter solution 


\section{Chapter 2 \\ Transformer Section}

\subsection{Introduction}

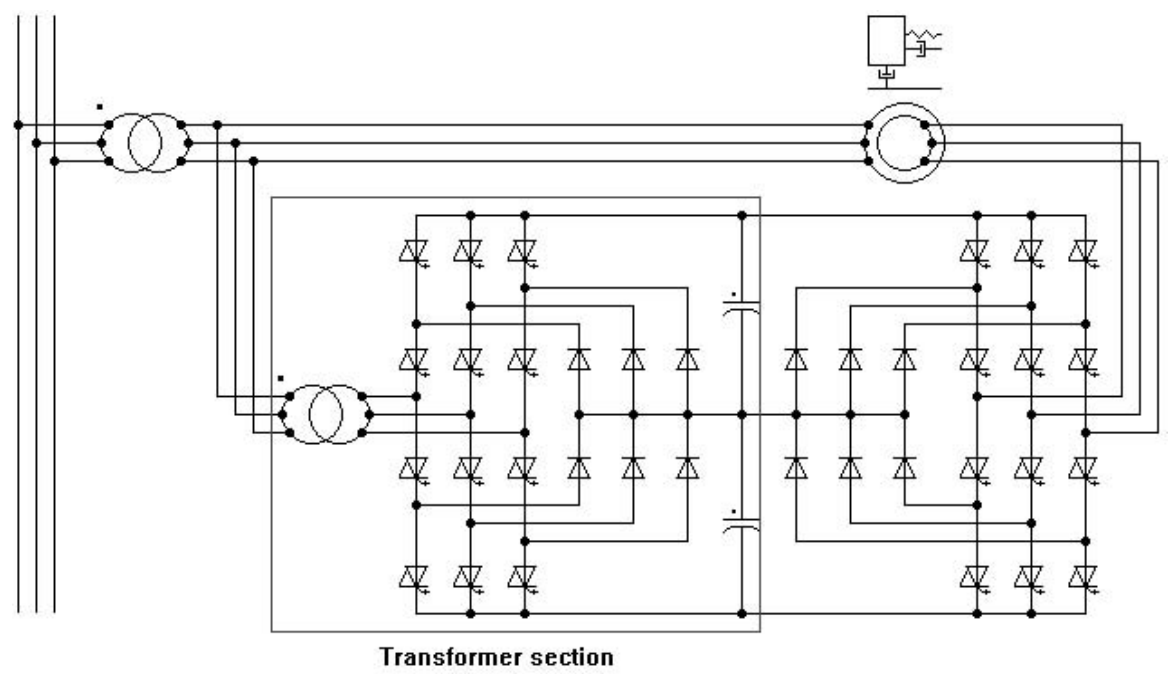

Figure 2.1 : The transformer section

The aim of the transformer section (Figure 2.1) is to regulate the reactive power flow through the rotor cascade transformer (q in Figure 2.3) while keeping the DClink voltage ( $\mathrm{u}_{\mathrm{DC}}$ in Figure 2.3) at a constant value irrespective of the active power flow. These goals can be reached in two different ways, either by using the classical or the state-space control.

The objective is to compare, through simulations, the performances obtained by the two control strategies. Then to make practical tests of the one which would appear to be the best adapted for pump storage plants. To this end, the development presented in [5] will be used for the design of the regulators of the state-space control strategy. 
Both regulation strategies have the same form, which is presented in Figure 2.2. This is a cascade control, with the transformer primary side current being the innermost. The regulation is performed in a reference frame, which lets regulate constant values. A Park transformation is used to achieve this, by changing the 3 phase frame to a 2 axes frame $(\mathrm{d}-\mathrm{q})$, which is locked on the voltage phasor $\underline{\mathrm{u}}_{1}$ in order to have $\mathrm{u}_{1 \mathrm{~d}}=1$ and $\mathrm{u}_{1 \mathrm{q}}=0$. Therefore, the active power and consequently the DC-link voltage are related to the $\mathrm{d}$ axis, and the reactive power to the $\mathrm{q}$ axis.

In a simulation, the value of the locking angle is implicit; in practice it is not the case. Chapter 5 presents multiple practical solutions of the determination of the locking angle.

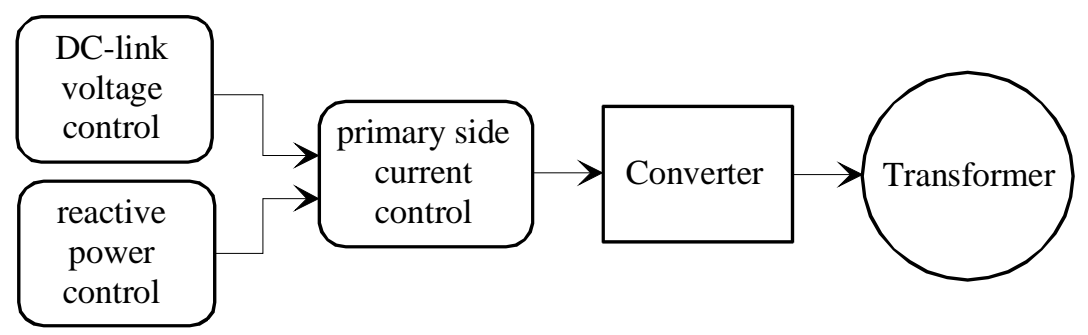

Figure 2.2 : Regulation block diagram for the transformer section

The regulation block diagram of Figure 2.2 includes obvious limitations that guarantee certain limits are not exceeded, in terms of current for example. Furthermore, it appears judicious to give a higher priority to $\mathrm{p}$ than to $\mathrm{q}$ when approaching the limits. 


\subsection{System modelling}

\subsubsection{System definition}

The transformer section system is shown in Figure 2.3. It consists of a standard transformer, which is the system to be regulated and of a 3-level VSI diode clamped, with its 2 capacitors.

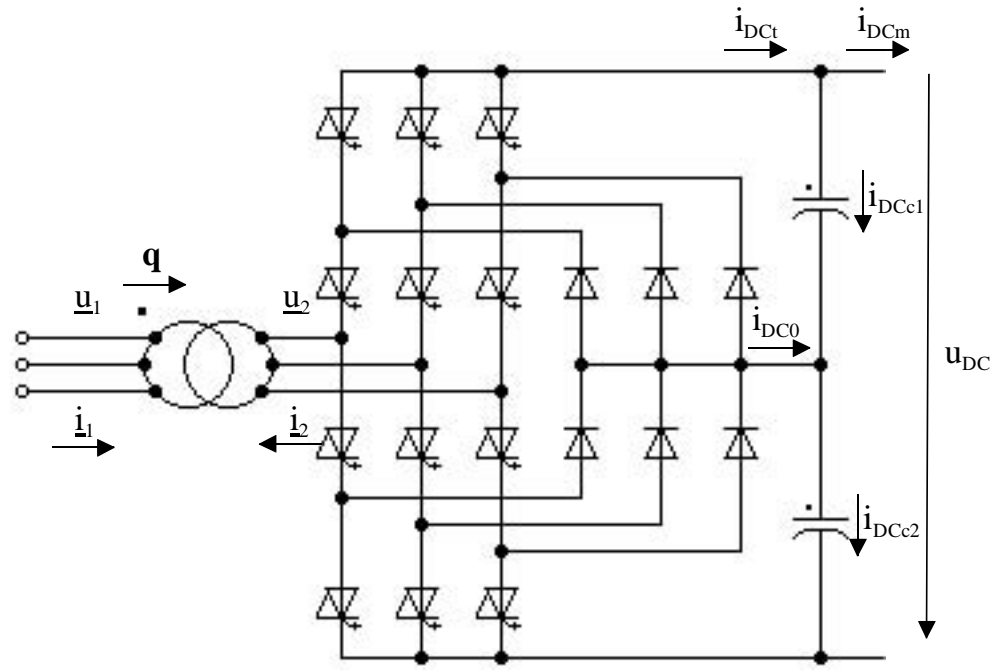

Figure 2.3 : The transformer section system definition

The system is defined by the following items :

- $\underline{\mathrm{u}}_{1}, \underline{\mathrm{i}}_{1}$ : line voltage and current on the primary side of the transformer.

- $\underline{\mathrm{u}}_{2}, \underline{\mathrm{i}}_{2}$ : line voltage and current on the secondary side of the transformer.

- $\mathrm{q}$ : reactive power flowing through the transformer (motor convention).

- $\mathrm{u}_{\mathrm{DC}}$ : DC-link voltage (this is the sum of both capacitor voltages).

- $\mathrm{i}_{\mathrm{DCt}}$ : DC current in the VSI.

- $\mathrm{i}_{\mathrm{DCm}}$ : DC current in the machine rotor side VSI.

- $\mathrm{i}_{\mathrm{DCc} 1}, \mathrm{i}_{\mathrm{DC} 2}$ : DC currents in each capacitor.

- $\mathrm{i}_{\mathrm{DC} 0}$ : neutral point $(\mathrm{NP})$ current.

For the design of the control, it is assumed that $\overline{\mathrm{i}}_{\mathrm{DC} 0}=0$. This aspect will be discussed in Chapter 4, which is dedicated to the unbalance control of the capacitor voltages. Hence, $\mathrm{i}_{\mathrm{DCc} 1}=\mathrm{i}_{\mathrm{DC} 2}$, and we can pass from Figure 2.4(a) to Figure 2.4(c) by considering only one equivalent capacitor $\mathrm{c}_{\mathrm{t}}$. 


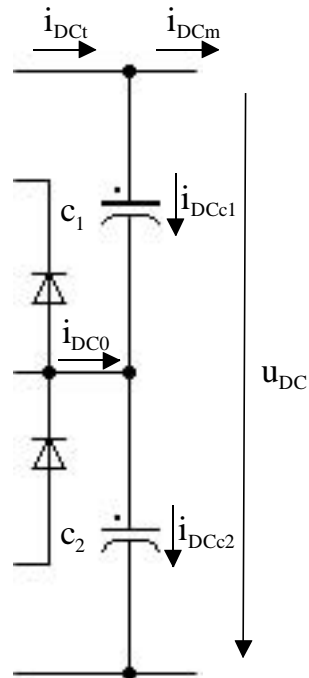

(a)

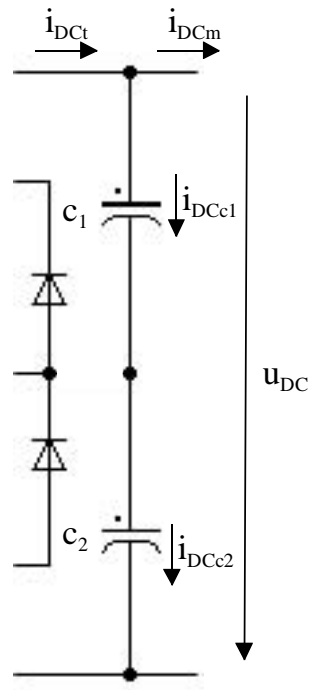

(b)

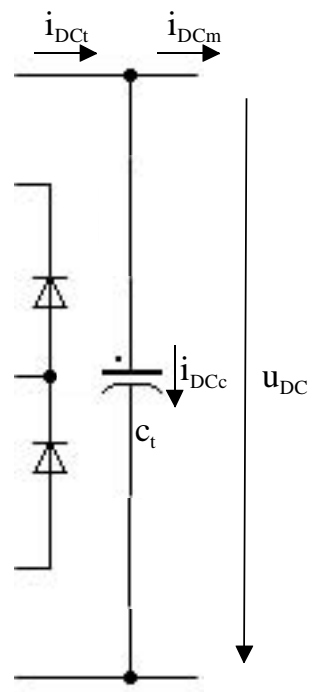

(c)

Figure 2.4 : Assumption on the capacitor current

\subsubsection{Modelling}

The equivalent circuit of the transformer is based on the Kapp hypothesis, as the magnetizing current is negligible for the considered transformers.

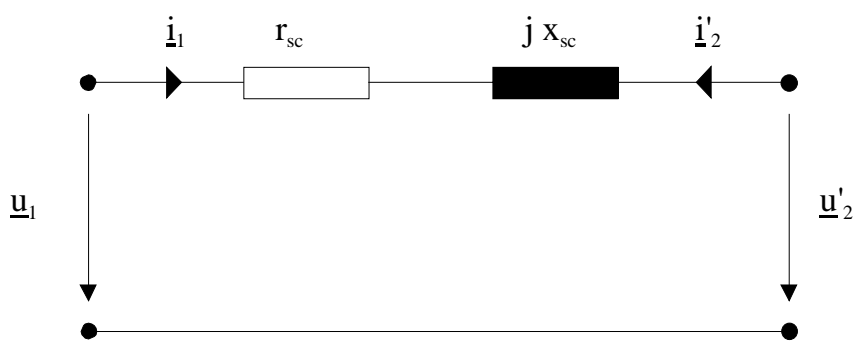

Figure 2.5 : Equivalent circuit with Kapp hypothesis

- $r_{\mathrm{sc}}$ is the short-circuit resistance

- $\mathrm{X}_{\mathrm{sc}}$ is the short-circuit reactance

Per unit (pu) quantities will be used in the transformer reference $S_{n}, U_{n}$. 


\subsubsection{Basic equations}

As explained in $\S 2.1$, as the reference frame is locked on the phasor $\underline{u}_{1}$, with an angle so as to have $\mathrm{u}_{1 \mathrm{~d}}=1$ and $\mathrm{u}_{1 \mathrm{q}}=0$, equation (2.1) can be set.

$$
\hat{\mathrm{u}}_{\mathrm{n}}=\underline{\mathrm{u}}_{1}
$$

The transformer modelling as defined by Figure 2.5, in the chosen reference frame, is given by equation (2.2).

$$
\underline{\mathrm{u}}_{2}=-\mathrm{r}_{\mathrm{sc}} \underline{\mathrm{i}}_{1}-\mathrm{s} \frac{\mathrm{x}_{\mathrm{sc}}}{\omega_{\mathrm{n}}} \underline{\mathrm{i}}_{1}-\mathrm{j} \mathrm{x}_{\mathrm{sc}} \underline{\mathrm{i}}_{1}+\hat{\mathrm{u}}_{\mathrm{n}}
$$

with

$$
\omega_{n}=2 \cdot \pi \cdot f_{n} \quad f_{n} \text { being the network frequency }
$$

By neglecting the losses, we get for the active power :

$$
p=u_{D C} i_{D C t}=u_{1 d} i_{1 d}
$$

and for the reactive power

$$
\mathrm{q}=\mathrm{u}_{1 \mathrm{~d}} \mathrm{i}_{1 \mathrm{q}}
$$

For the equivalent capacitor (Figure 2.4), equation (2.6) can be written

$$
\mathrm{i}_{\mathrm{DCc}}=\mathrm{i}_{\mathrm{DCt}}-\mathrm{i}_{\mathrm{DCm}}=\mathrm{c}_{\mathrm{t}} \mathrm{s} \mathrm{u}_{\mathrm{DC}}
$$

\subsection{The Classical Control}

\subsubsection{Introduction}

The classical control is constituted of standard P, PI, and I regulators. The process to be followed for the design of the regulators is to write the transfer function of the system in open loop and to compensate the largest time constant with the regulator [6].

One of the main drawbacks of the classical control is that the standard regulators used can only compensate 1 pole or 1 pair of complex poles, where the system to be regulated has usually more than 1 pole. The regulation is then a compromise between either following as accurately as possible the set value, or to best rejection 
of the disturbance. Two different methods exist to choose the correct parameters of the different regulators, respectively:

- The Meplat criterion (following of the set value).

- The Symmetric criterion (rejection of the disturbance).

For the regulation, the current control will first be investigated, as it is the innermost one (\$2.3.2), followed by the DC-link voltage control (\$2.3.3) and by the reactive power control $(\S 2.3 .4)$.

Finally, the whole regulation will be implemented and simulated to check the behaviour of the transformer section (\$2.5.2).

\subsubsection{Current Control}

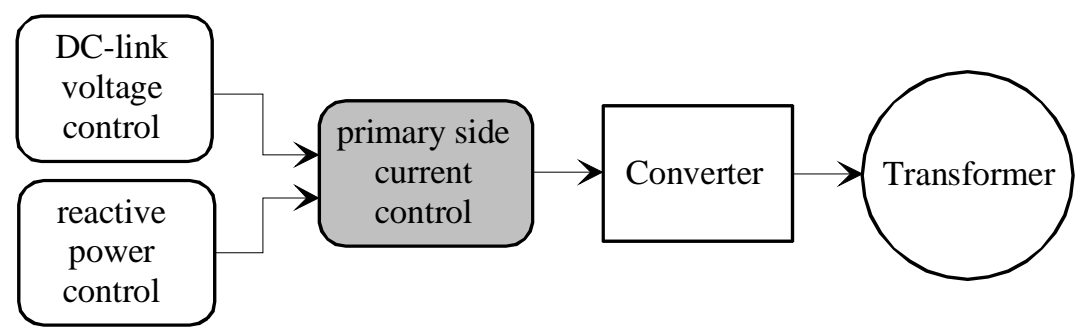

Figure 2.6 : Current control

The current control is the innermost one as shown in Figure 2.6. Figure 2.7 gives its corresponding transfer function block diagram. In this figure, $\underline{G}_{i 1}(s)$ is the system to be regulated, here the transformer defined by (2.2). $\mathrm{G}_{\mathrm{pE} 1}(\mathrm{~s})$ is the command system (3-level VSI) and includes all the small time constants $\left(\mathrm{T}_{\mathrm{pE} 1},(2.9)\right)$. Finally, $\underline{\mathrm{G}}_{\mathrm{R} 1}(\mathrm{~s})$ is the current regulator which will be designed.

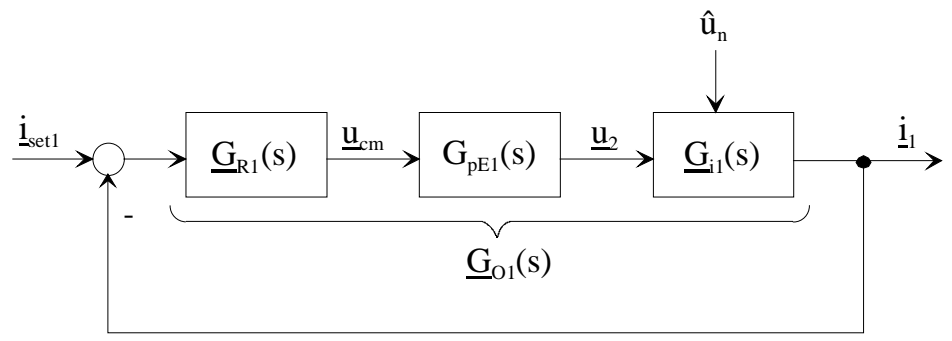

Figure 2.7 : Transfer function block diagram for the current control 
From equation (2.2) we can write :

$$
\underline{\mathrm{i}}_{1}=-\frac{\underline{\mathrm{u}}_{2}}{\mathrm{r}_{\mathrm{sc}}+\mathrm{jf}_{1} \mathrm{x}_{\mathrm{sc}}+\mathrm{s} \frac{\mathrm{x}_{\mathrm{sc}}}{\omega_{\mathrm{n}}}}+\frac{\hat{\mathrm{u}}_{\mathrm{n}}}{\mathrm{r}_{\mathrm{sc}}+\mathrm{jf}_{1} \mathrm{x}_{\mathrm{sc}}+\mathrm{s} \frac{\mathrm{x}_{\mathrm{sc}}}{\omega_{\mathrm{n}}}}
$$

where $\hat{u}_{n}$ is the disturbance and $f_{1}$ is in per unit.

Then we can write the transfer function of block $\underline{G}_{i 1}(s)$ :

$$
\underline{\mathrm{G}}_{\mathrm{i} 1}(\mathrm{~s})=\frac{\underline{\mathrm{i}}_{1}}{\underline{\mathrm{u}}_{2}}=\frac{-1}{\mathrm{r}_{\mathrm{sc}}+\mathrm{jf}_{1} \mathrm{x}_{\mathrm{sc}}+\mathrm{s} \frac{\mathrm{x}_{\mathrm{sc}}}{\omega_{\mathrm{n}}}}=\frac{-\frac{1}{\mathrm{r}_{\mathrm{sc}}}}{1+\left(\mathrm{jf}_{1} \omega_{\mathrm{n}}+\mathrm{s}\right) \frac{\mathrm{x}_{\mathrm{sc}}}{\omega_{\mathrm{n}} \mathrm{r}_{\mathrm{sc}}}}
$$

$\mathrm{G}_{\mathrm{pE}}(\mathrm{s})$ is defined by

$$
\mathrm{G}_{\mathrm{pE1}}(\mathrm{s})=\frac{\underline{\mathrm{u}}_{2}}{\underline{\mathrm{u}}_{\mathrm{cm}}}=\frac{\mathrm{u}_{\mathrm{DC}}}{1+\mathrm{sT}_{\mathrm{pE} 1}}
$$

Note that strictly speaking it is not a transfer function as $\mathrm{u}_{\mathrm{DC}}$ may vary. However, as it will be regulated, it is assumed to be constant.

The regulator must compensate the pole at $\left(1+\left(s+\mathrm{jf}_{1} \omega_{\mathrm{n}}\right) \frac{\mathrm{x}_{\mathrm{sc}}}{\omega_{\mathrm{n}} \mathrm{r}_{\mathrm{sc}}}\right)$. This pole is complex, meaning that a coupling between the $d$ and $q$ axes exist. To ensure a decoupling between the $\mathrm{d}$ and $\mathrm{q}$ axes the regulator must be a multivariable one, compensating this complex pole.

$$
\underline{G}_{\mathrm{R} 1}(\mathrm{~s})=\frac{1+\left(j \mathrm{j}_{1} \omega_{\mathrm{n}}+\mathrm{s}\right) \mathrm{T}_{\mathrm{n} 1}}{\mathrm{~s} \mathrm{~T}_{\mathrm{i} 1}}
$$

All the transfer functions are now defined and the open loop transfer function can be written.

$$
\underline{\mathrm{G}}_{\mathrm{O} 1}(\mathrm{~s})=\frac{1+\left(\mathrm{jf}_{1} \omega_{\mathrm{n}}+\mathrm{s}\right) \mathrm{T}_{\mathrm{n} 1}}{\mathrm{~s} \mathrm{T_{ \textrm {i } 1 }}} \frac{\mathrm{u}_{\mathrm{DC}}}{1+\mathrm{s} \mathrm{T}_{\mathrm{pE} 1}} \frac{-\frac{1}{\mathrm{r}_{\mathrm{sc}}}}{1+\left(j \mathrm{j}_{1} \mathrm{x}_{\mathrm{sc}}+\mathrm{s}\right) \frac{\mathrm{x}_{\mathrm{sc}}}{\omega_{\mathrm{n}} \mathrm{r}_{\mathrm{sc}}}}
$$


As the regulator must follow as accurately as possible the set value, the Meplat criterion (\$2.3.1) is used to calculate $\mathrm{T}_{\mathrm{n} 1}$ and $\mathrm{T}_{\mathrm{i} 1}$.

$$
\begin{aligned}
& \mathrm{T}_{\mathrm{n} 1}=\frac{\mathrm{x}_{\mathrm{sc}}}{\omega_{\mathrm{n}} \mathrm{r}_{\mathrm{sc}}} \\
& \mathrm{T}_{\mathrm{i} 1}=2 \frac{\mathrm{u}_{\mathrm{DC}}}{\mathrm{r}_{\mathrm{sc}}} \mathrm{T}_{\mathrm{pE} 1}
\end{aligned}
$$

\subsubsection{DC-link voltage control}

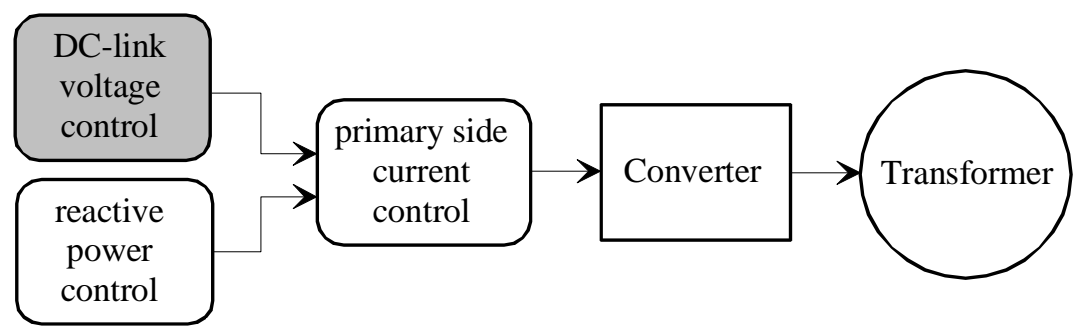

Figure 2.8 : DC-link voltage control

Due to the chosen reference frame, the DC-link regulator only acts in the $\mathrm{d}$ axis of the current regulator (Figure 2.8). Its purpose is to keep the DC-link voltage at a constant value.

Figure 2.9 defines the DC-Link voltage control, where $\mathrm{G}_{\mathrm{u}}(\mathrm{s})$ is the system to be regulated, here the capacitors voltage. $\mathrm{G}_{\mathrm{pEu}}(\mathrm{s})$ is the lag resulting from the sum of all the small time constants $\left(\mathrm{T}_{\mathrm{pEu}},(2.15)\right)$, especially the time constant of the current regulator. Finally, $\mathrm{G}_{\mathrm{Ru}}(\mathrm{s})$ is the DC-link voltage regulator which will be designed.

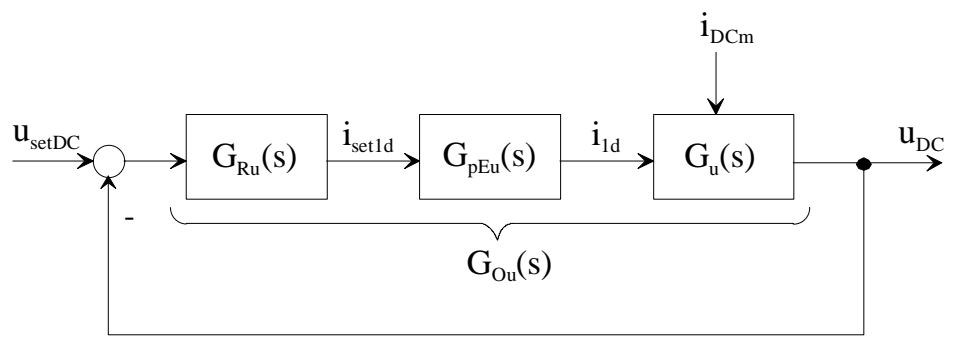

Figure 2.9 : Transfer function block diagram for the DC-link voltage control 
From (2.4), (2.6), with $\mathrm{i}_{\mathrm{DCm}}$ acting as a disturbance, $\mathrm{G}_{\mathrm{u}}(\mathrm{s})$ can be written as

$$
\mathrm{G}_{\mathrm{u}}(\mathrm{s})=\frac{\mathrm{u}_{1 \mathrm{~d}}}{\mathrm{u}_{\mathrm{DC}} \mathrm{sc}_{\mathrm{t}}}
$$

Note that strictly speaking it is not a transfer function as $\mathrm{u}_{\mathrm{DC}}$ may vary. However, as it will be regulated, it is assumed to be constant.

$\mathrm{G}_{\mathrm{pEu}}(\mathrm{s})$ is defined by (2.15), where $\mathrm{T}_{\mathrm{pEl}}$ is the time constant of the current control.

$$
\mathrm{G}_{\mathrm{pEu}}(\mathrm{s})=\frac{1}{1+\mathrm{s} 2 \mathrm{~T}_{\mathrm{pE} 1}}=\frac{1}{1+\mathrm{s} \mathrm{T}_{\mathrm{pEu}}}
$$

From this, the DC-link voltage regulator is chosen as a PI, defined by (2.16)

$$
\mathrm{G}_{\mathrm{Ru}}(\mathrm{s})=\frac{1+\mathrm{s} \mathrm{T}_{\mathrm{nu}}}{\mathrm{s} \mathrm{T}_{\mathrm{iu}}}
$$

where $\left(1+s T_{n u}\right)$ compensate the pole at $\left(1+s T_{p E u}\right)$.

All the transfer functions are now defined and the open loop transfer function can be written.

$$
\mathrm{G}_{\mathrm{Ou}}(\mathrm{s})=\frac{1+\mathrm{s} \mathrm{T}_{\mathrm{nu}}}{\mathrm{s} \mathrm{T}_{\mathrm{iu}}} \frac{1}{1+\mathrm{s} \mathrm{T}_{\mathrm{pEu}}} \frac{\mathrm{u}_{1 \mathrm{~d}}}{\mathrm{u}_{\mathrm{DC}} \mathrm{sc}_{\mathrm{t}}}
$$

As the regulator must at best reject the disturbance, the symmetric criterion is chosen to calculate $\mathrm{T}_{\mathrm{nu}}$ and $\mathrm{T}_{\mathrm{iu}}$.

$$
\begin{aligned}
& \mathrm{T}_{\mathrm{nu}}=4 \mathrm{~T}_{\mathrm{pEu}} \\
& \mathrm{T}_{\mathrm{iu}}=8 \frac{\mathrm{u}_{1 \mathrm{~d}}}{\mathrm{c}_{\mathrm{t}} \mathrm{u}_{\mathrm{DC}}} \mathrm{T}_{\mathrm{pEu}}^{2}
\end{aligned}
$$




\subsubsection{Reactive power control}

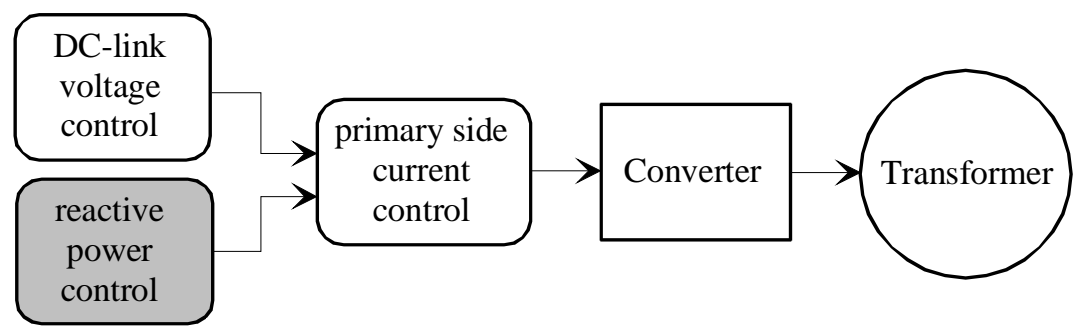

Figure 2.10 : Reactive power control

As was the case for the DC-link voltage control, due to the chosen reference frame, the reactive power regulator only acts in the $\mathrm{q}$ axis of the current regulator.

Figure 2.11 defines the reactive power control, where $\mathrm{G}_{\mathrm{q}}(\mathrm{s})$ is the system to be regulated defined by equation $(2.5) . \mathrm{G}_{\mathrm{pEq}}(\mathrm{s})$ is the lag resulting from the sum of all the small time constants $\left(\mathrm{T}_{\text {peq }},(2.21)\right)$, especially the time constant of the current regulator. Finally, $\mathrm{G}_{\mathrm{Rq}}(\mathrm{s})$ is the reactive power regulator which will be designed.

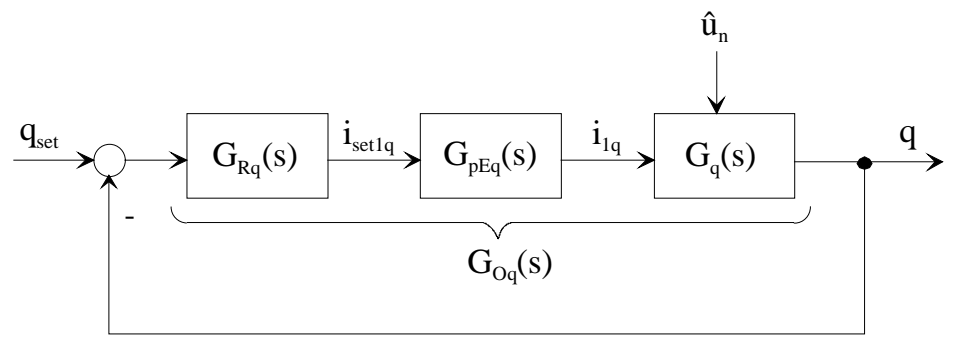

Figure 2.11 : Transfer function block diagram for the reactive power control

From (2.5), (2.1), with $\hat{\mathrm{u}}_{\mathrm{n}}$ acting as a disturbance, $\mathrm{G}_{\mathrm{q}}(\mathrm{s})$ can be written as

$$
\mathrm{G}_{\mathrm{q}}(\mathrm{s})=\frac{\mathrm{q}}{\mathrm{i}_{\mathrm{q}}}=-\mathrm{u}_{1 \mathrm{~d}}
$$

As well as for the DC-link voltage control (\$2.3.3), $\mathrm{G}_{\mathrm{pEq}}(\mathrm{s})$ is defined by (2.21), where $\mathrm{T}_{\mathrm{pE} 1}$ is the time constant of the current control.

$$
\mathrm{G}_{\mathrm{pEq}}(\mathrm{s})=\frac{1}{1+\mathrm{s} 2 \mathrm{~T}_{\mathrm{pE} 1}}=\frac{1}{1+\mathrm{s} \mathrm{T}_{\mathrm{pEq}}}
$$


As the system to be regulated has a proportional behaviour, an I regulator is chosen.

$$
\mathrm{G}_{\mathrm{Rq}}(\mathrm{s})=\frac{1}{\mathrm{~s} \mathrm{~T}_{\mathrm{iq}}}
$$

All the transfer functions are now defined and the open loop transfer function can finally be written.

$$
\mathrm{G}_{\mathrm{Oq}}(\mathrm{s})=\frac{1}{\mathrm{~s} \mathrm{~T}_{\mathrm{iq}}} \frac{1}{1+\mathrm{s} \mathrm{T}_{\mathrm{pEq}}} \mathrm{u}_{1 \mathrm{~d}}
$$

As the regulator must follow as accurately as possible the set value, the Meplat criterion (\$2.3.1) is used to calculate $\mathrm{T}_{\mathrm{iq}}$.

$$
\mathrm{T}_{\mathrm{iq}}=2 \mathrm{~T}_{\mathrm{pEq}}
$$

\subsection{The State-Space Control}

\subsubsection{Introduction}

The main difference between classical and state-space control, is that in the statespace control, disturbances and internal quantities are taken into account in the regulator to compensate all the poles present in the system to be regulated. This usually leads to a better behaviour in terms of dynamic and stability.

The process here is to write the operational equation of the system to be regulated. This equation can be assimilated to the open loop transfer function of the classical control. Then, after choosing the pole placement, the regulator coefficients are determined through identification between the pole placement and the operational equation. This strategy has nevertheless the inconvenience of being more sensitive to variations in the system parameters.

The basics of the state-space control applied to the entry VSI of a frequency converter are described in [5]. However, for clarity and cohesion, the main block diagrams and equations will be recalled here.

As was the case for the classical control, the current control will first be investigated, as it is the innermost one (\$2.4.2), followed by the DC-link control $(\S 2.3 .3)$ and by the reactive power control $(\$ 2.4 .4)$.

Finally the whole regulation will be implemented and simulated (§2.5.3). 


\subsubsection{Current control}

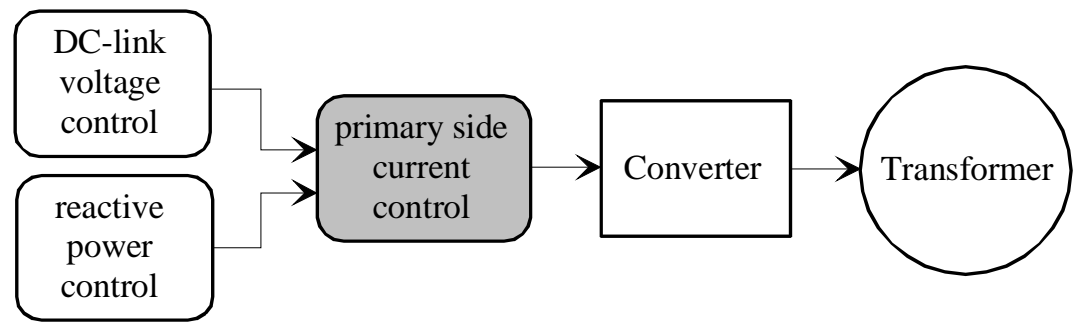

Figure 2.12 : Current control

The current control block diagram for the state-space control is represented in Figure 2.13. The $S_{i}$ block is the system to be regulated, based on equation (2.2), with $\hat{\mathrm{u}}_{\mathrm{n}}$ acting as a disturbance. $\mathrm{S}_{\mathrm{cm}}$ is the command system, here the VSI. In comparison to the classical control, $\mathrm{u}_{\mathrm{DC}}$ is taken into account as a disturbance as it is regulated. The block $\mathrm{R}_{\mathrm{i}}$ represents the current regulator.

The internal structure of the current regulator is given in Figure 2.14. In this figure, $\mathrm{R}_{\mathrm{ss}}$ is the state-space regulator with integral component defined by equation (2.25). The block $S_{\mathrm{pEi}}$ represents, within the current regulator, the lag of the command system (block $\mathrm{S}_{\mathrm{cm}}$ ) as well as all the small time constants. $\mathrm{S}_{\mathrm{pEi}}$ is defined by (2.26).

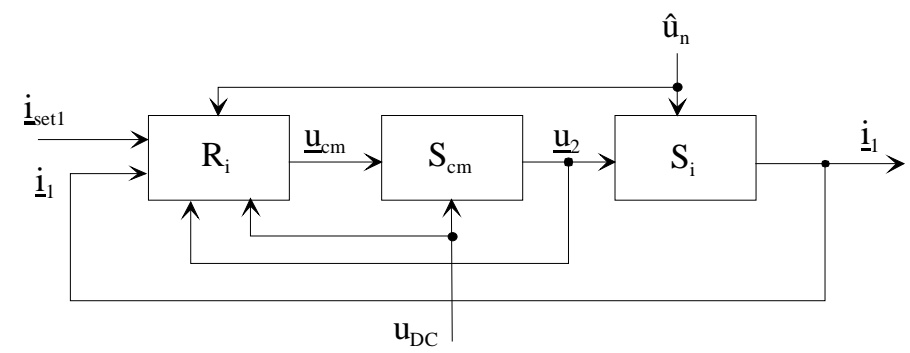

Figure 2.13 : State-space block diagram for the current control

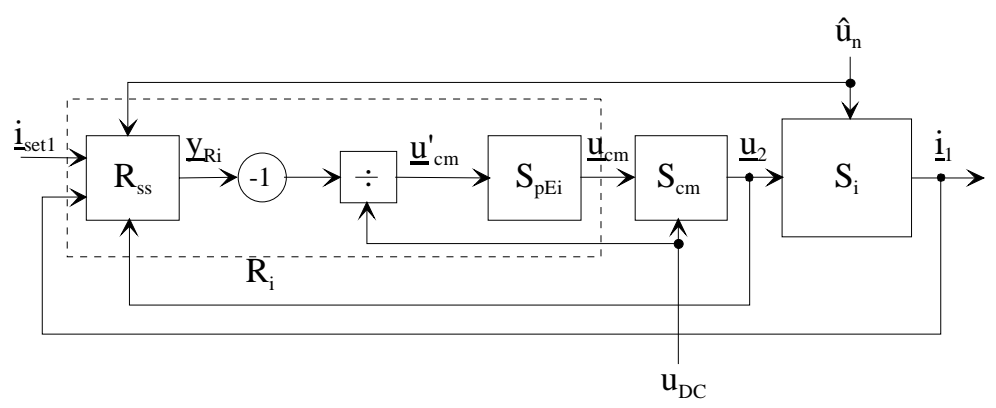

Figure 2.14 : State-space control block diagram, including the current regulator 
The state space current regulator $\mathrm{R}_{\mathrm{ss}}$ with integral component $\left(\underline{x}_{\mathrm{Ri}}\right)$ is defined by equation (2.25).

$$
\left.\begin{array}{l}
\underline{\mathrm{y}}_{\mathrm{Ri}}=-\underline{\mathrm{k}}_{\mathrm{i}} \underline{\mathrm{i}}_{1}-\underline{\mathrm{k}}_{\mathrm{u}} \underline{\mathrm{u}}_{2}+\underline{\mathrm{k}}_{\mathrm{Ri}} \underline{\mathrm{x}}_{\mathrm{Ri}}+\underline{\mathrm{k}}_{\mathrm{wi}} \underline{\mathrm{i}}_{\mathrm{set} 1}-\underline{\mathrm{k}}_{\mathrm{vi}} \hat{\mathrm{u}}_{\mathrm{n}} \\
\frac{\mathrm{d} \underline{\mathrm{x}}_{\mathrm{Ri}}}{\mathrm{dt}}=\frac{1}{\mathrm{~T}_{\mathrm{E}}}\left(\underline{\mathrm{i}}_{\mathrm{set} 1}-\underline{\mathrm{i}}_{1}\right)
\end{array}\right\}
$$

where $\mathrm{T}_{\mathrm{E}}$ is the sampling time.

The $\mathrm{S}_{\mathrm{pEi}}$ block is defined by equation (2.26).

$$
\underline{\mathrm{u}}_{\mathrm{cm}}=\frac{1}{1+\mathrm{sT}_{\mathrm{pEi}}} \underline{\mathrm{u}}_{\mathrm{cm}}^{\prime}
$$

where $\mathrm{T}_{\mathrm{pEi}}$ is the lag of all the small time constants.

For the regulator, not only the current to be regulated is taken into account but also the disturbance $\hat{\mathrm{u}}_{\mathrm{n}}$, as well as the internal value $\underline{\mathrm{u}}_{2}$.

In [5] it is recommended to replace $\underline{\underline{u}}_{2}$ by $\underline{\underline{u}}_{2}{ }^{\prime}$ as given in Figure 2.15 , where $\underline{\mathrm{u}}_{2}{ }^{\prime}$ is the same value as $\underline{\underline{u}}_{2}$ but calculated from $\underline{\underline{u}}_{\mathrm{cm}}$. This recommendation becomes essential in our case as illustrated by Figure 2.16, Figure 2.17, Figure 2.18 for the following reasons.

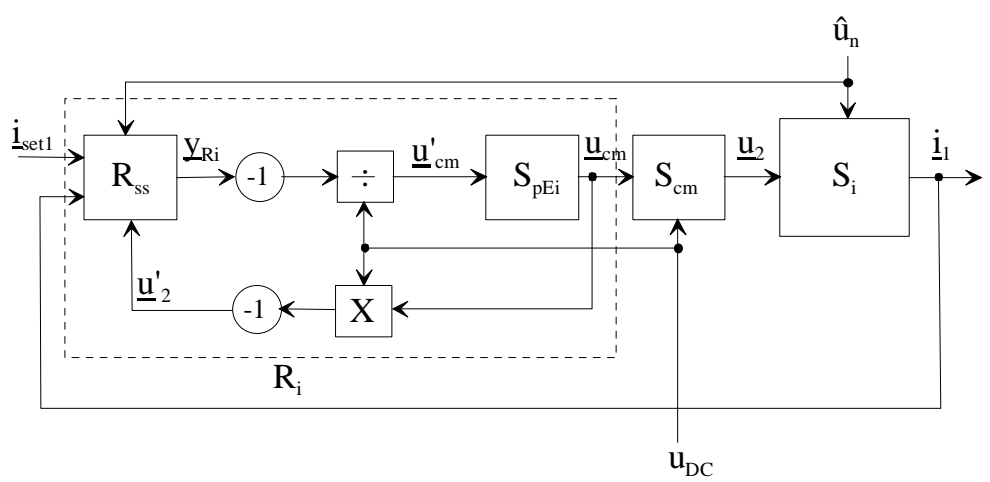

Figure 2.15 : State-space control block diagram for the replacement of $\mathbf{u}_{2}$ by $\mathbf{u}_{2}{ }^{\prime}$

The state space regulator defined by $(2.25)$ uses the VSI output voltage $\underline{\mathrm{u}}_{2}$. This latter is the grey signal shown in Figure 2.16. The Park transformation of $\underline{\underline{u}}_{2}$ in the chosen reference frame is illustrated in Figure 2.17. It is obvious in that case that $\underline{\mathrm{u}}_{2}$ 
is not directly usable by the state-space current regulator without being previously filtered. Due to the significant filtering required, a delay in proportion to the filter time constant is found, and obviously leads to poor performance of the regulator.

The chosen solution consists in using the signal $\underline{\mathbf{u}}_{2}{ }^{\prime}$ as a replacement for $\underline{\mathrm{u}}_{2}$. The former is calculated from $\underline{\mathrm{u}}_{\mathrm{cm}}$ which is the fundamental of $\underline{\underline{u}}_{2}$ (Figure 2.16).

The Park transformation of $\underline{\mathbf{u}}_{2}{ }^{\prime}$ shown in Figure 2.18 is directly usable by the state-space current regulator.

Therefore, it becomes a necessity to use $\underline{\mathrm{u}}_{2}$ instead of $\underline{\mathrm{u}}_{2}$, and this not only because it economizes calculation time and measurement items as stated in [5].

Finally, from (2.25) and (2.26), with the chosen pole placement $\left(\rho_{\mathrm{i}}\right)$, the regulator coefficients can be determined.

$$
\begin{aligned}
& \mathrm{T}_{\mathrm{sc}}=\frac{1_{\mathrm{sc}}}{\mathrm{r}_{\mathrm{sc}}}=\frac{\mathrm{x}_{\mathrm{sc}}}{\mathrm{r}_{\mathrm{sc}} \omega_{\mathrm{n}}} \\
& \rho_{\mathrm{i}}=\frac{1}{3}\left(\frac{1}{\mathrm{~T}_{\mathrm{pEi}}}+\frac{1}{\mathrm{~T}_{\mathrm{sc}}}\right) \\
& \underline{\mathrm{k}}_{\mathrm{u}}=\mathrm{j} \omega \mathrm{T}_{\mathrm{pEi}} \\
& \underline{\mathrm{k}}_{\mathrm{i}}=\left[\left(4 \rho_{\mathrm{i}}^{2}-\omega_{\mathrm{n}}^{2}\right) \mathrm{T}_{\mathrm{pEi}}-\frac{1}{\mathrm{~T}_{\mathrm{sc}}}-\mathrm{j} \omega\left(1-\frac{\mathrm{T}_{\mathrm{pEi}}}{\mathrm{T}_{\mathrm{sc}}}\right)\right] 1_{\mathrm{sc}} \\
& \underline{\mathrm{k}}_{\mathrm{Ri}}=2 \rho_{\mathrm{i}}^{3} 1_{\mathrm{sc}} \mathrm{T}_{\mathrm{pEi}} \mathrm{T}_{\mathrm{E}}=\mathrm{k}_{\mathrm{Ri}} \\
& \underline{\mathrm{k}}_{\mathrm{wi}}=\frac{\underline{\mathrm{k}}_{\mathrm{Ri}}}{\rho_{\mathrm{i}} \mathrm{T}_{\mathrm{E}}}=2 \rho_{\mathrm{i}}^{2} 1_{\mathrm{sc}} \mathrm{T}_{\mathrm{pEi}}=\mathrm{k}_{\mathrm{wi}} \\
& \underline{\mathrm{k}}_{\mathrm{vi}}=1-\underline{\mathrm{k}}_{\mathrm{u}}=1-\mathrm{j} \omega \mathrm{T}_{\mathrm{pEi}}
\end{aligned}
$$

The open loop expression becomes real, leading to a decoupling between the $\mathrm{d}$ and q axes. 


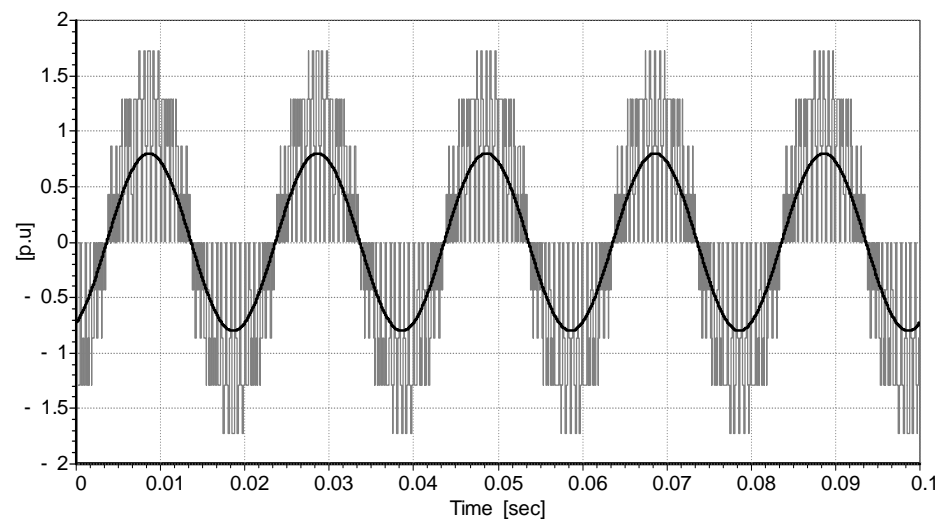

Figure 2.16 : Comparison between $\underline{\underline{u}}_{2}$ (grey) and $\underline{\underline{u}}_{2}{ }^{\prime}$ (black)

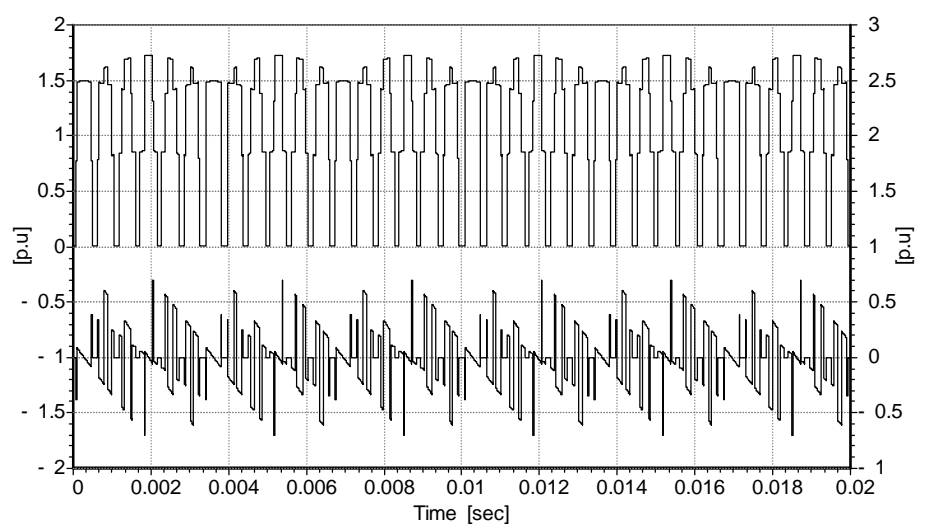

Figure 2.17 : Park transformation of $\underline{\underline{u}}_{2}$

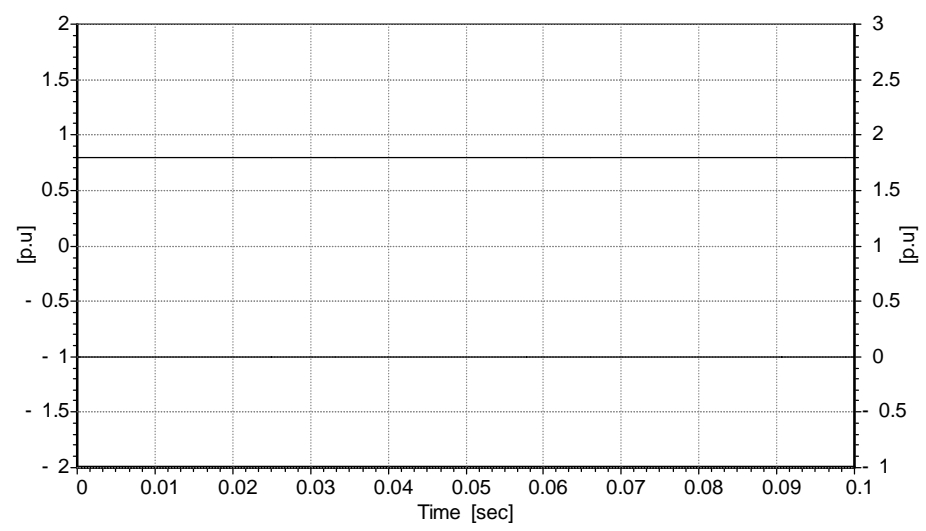

Figure 2.18 : Park transformation of $\underline{\mathrm{u}}_{2}{ }^{\prime}$ 


\subsubsection{DC-link voltage control}

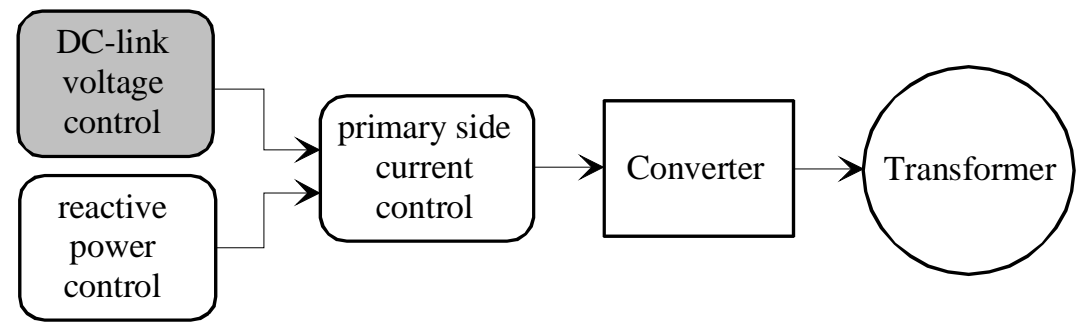

Figure 2.19 : DC-link voltage control

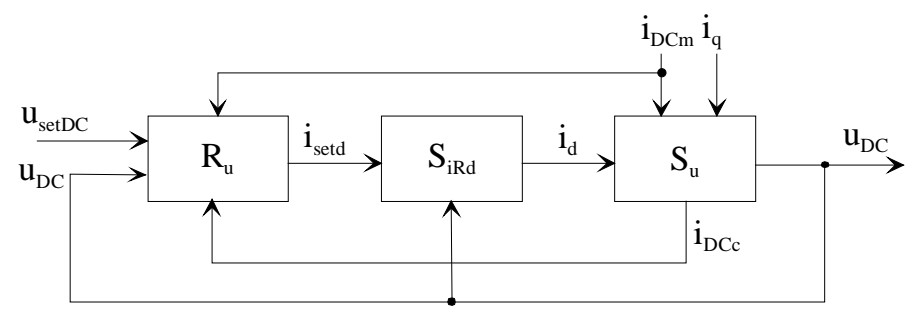

Figure 2.20 : State-space block diagram for the DC-link voltage control

The DC-link voltage control block diagram for the state-space control is represented in Figure 2.20. The $S_{\mathrm{u}}$ block is the system to be regulated defined by equations (2.4) and (2.6), with $\mathrm{i}_{\mathrm{DCm}}$ and $\mathrm{i}_{\mathrm{q}}$ acting as disturbing values. The internal current regulation is taken into account by the $S_{i R d}$ block, and $R_{u}$ represents the DC-link voltage regulator.

The internal structure of the regulator $\left(\mathrm{R}_{\mathrm{u}}\right)$ is shown in Figure 2.21. In this figure, $\mathrm{R}_{\mathrm{ss}}$ is the state-space regulator with integral component defined by (2.34). The block $\mathrm{S}_{\mathrm{pEu}}$ represents, within the DC-link voltage regulator, the lag of the block $\mathrm{S}_{\mathrm{iRd}} \cdot \mathrm{T}_{\mathrm{pEu}}$ is defined by equation (2.35).

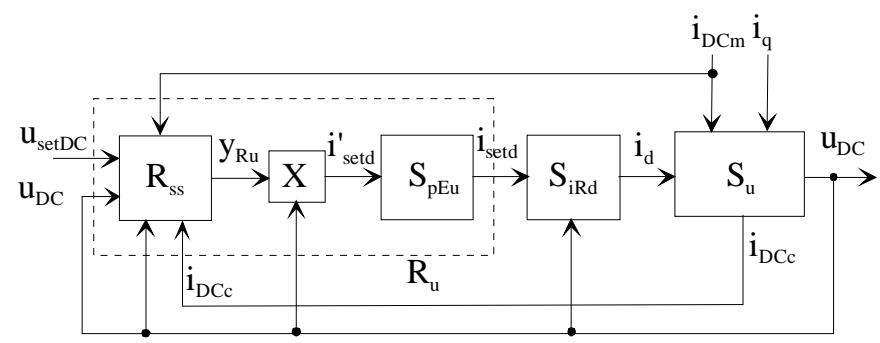

Figure 2.21 : State-space control block diagram, including the DC-link voltage regulator 
The state space DC-link voltage regulator $\mathrm{R}_{\mathrm{ss}}$ with integral component $\left(\mathrm{x}_{\mathrm{Ru}}\right)$ is defined by equation (2.34).

$$
\left.\begin{array}{l}
\mathrm{y}_{\mathrm{Ru}}=-\mathrm{k}_{\mathrm{u}} \mathrm{u}_{\mathrm{DC}}-\mathrm{k}_{\mathrm{i}} \mathrm{i}_{\text {setd }}+\mathrm{k}_{\mathrm{Ru}} \mathrm{x}_{\mathrm{Ru}}+\mathrm{k}_{\mathrm{wu}} \mathrm{u}_{\mathrm{setDC}}-\mathrm{k}_{\mathrm{vu}} \mathrm{i}_{\mathrm{DCm}} \\
\frac{\mathrm{dx}_{\mathrm{Ru}}}{\mathrm{dt}}=\frac{1}{\mathrm{~T}_{\mathrm{E}}}\left(\mathrm{u}_{\mathrm{setDC}}-\mathrm{u}_{\mathrm{DC}}\right)
\end{array}\right\}
$$

where $\mathrm{T}_{\mathrm{E}}$ is the sampling time.

The $S_{\mathrm{pEu}}$ block representing the block $\mathrm{S}_{\mathrm{iRd}}$, is defined by equation (2.35).

$$
\mathrm{i}_{\text {setd }}=\frac{1}{1+\mathrm{sT}_{\mathrm{pEu}}}\left(\mathrm{y}_{\mathrm{Ru}}\right)
$$

where $\mathrm{T}_{\mathrm{pEu}}$ is the lag of all the small time constants, and especially the lag of the current regulator.

From (2.34) and (2.35), with the chosen pole placement $\left(\rho_{\mathrm{u}}\right)$, the regulator coefficients can be determined, with $\mathrm{T}_{\mathrm{ei}}=1 / \rho_{\mathrm{i}}$

$$
\begin{aligned}
& \mathrm{T}_{\mathrm{u}}=\mathrm{T}_{\mathrm{ei}}\left(1+\frac{\hat{\mathrm{u}}_{\mathrm{n}}^{2} \mathrm{~T}_{\mathrm{ei}}^{2}}{2 \mathrm{u}_{\mathrm{DC}}^{2} 1_{\mathrm{sc}} \mathrm{c}_{\mathrm{t}}}\right) \\
& \rho_{\mathrm{u}}=\frac{1}{4}\left(\frac{1}{\mathrm{~T}_{\mathrm{ei}}+\mathrm{T}_{\mathrm{pEu}}}+\frac{1}{\mathrm{~T}_{\mathrm{u}}}+\frac{\mathrm{i}_{\mathrm{DCm}} \mathrm{T}_{\mathrm{ei}}}{\mathrm{u}_{\mathrm{DC}} \mathrm{c}_{\mathrm{t}} \mathrm{T}_{\mathrm{u}}}\right) \\
& \mathrm{k}_{\mathrm{i}}=\left[7 \rho_{\mathrm{u}} \mathrm{T}_{\mathrm{u}}\left(\mathrm{T}_{\mathrm{ei}}+\mathrm{T}_{\mathrm{pEu}}\right)-1-\mathrm{i}_{\mathrm{DCm}} \frac{\left(\mathrm{T}_{\mathrm{pEu}}+2 \mathrm{~T}_{\mathrm{ei}}\right)}{\mathrm{u}_{\mathrm{DC}} \mathrm{c}_{\mathrm{t}}}\right] / \hat{\mathrm{u}}_{\mathrm{n}} \\
& \mathrm{k}_{\mathrm{u}}=\frac{6 \rho_{\mathrm{u}}^{3} \mathrm{c}_{\mathrm{t}} \mathrm{T}_{\mathrm{u}}\left(\mathrm{T}_{\mathrm{pEu}}+\mathrm{T}_{\mathrm{ei}}\right)}{\hat{\mathrm{u}}_{\mathrm{n}}} \\
& \mathrm{k}_{\mathrm{Ru}}=\frac{2 \rho_{\mathrm{u}}^{4} \mathrm{c}_{\mathrm{t}} \mathrm{T}_{\mathrm{u}} \mathrm{T}_{\mathrm{E}}\left(\mathrm{T}_{\mathrm{pEu}}+\mathrm{T}_{\mathrm{ei}}\right)}{\hat{\mathrm{u}}_{\mathrm{n}}} \\
& \mathrm{k}_{\mathrm{vu}}=\frac{\mathrm{k}_{\mathrm{Ru}}}{\rho_{\mathrm{u}}^{4} \mathrm{~T}_{\mathrm{E}}} \\
& \hat{\mathrm{u}}_{\mathrm{n}}
\end{aligned}
$$




\subsubsection{Reactive power control}

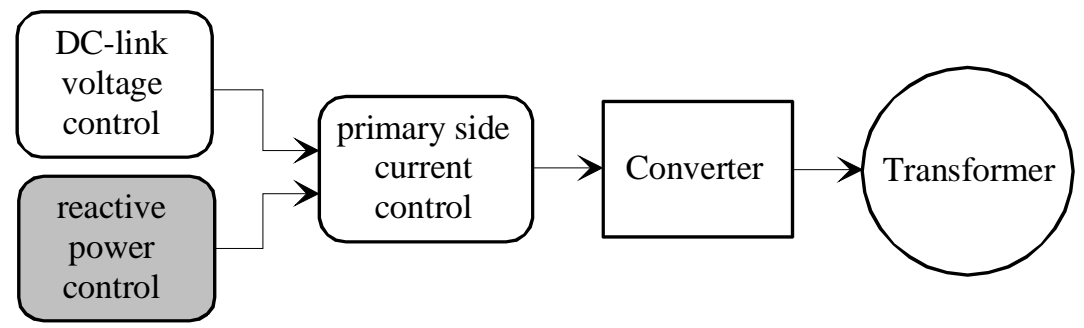

Figure 2.22 : Reactive power control

The reactive power control block diagram for the state-space control is represented in Figure 2.23. The $S_{q}$ block is the system to be regulated and defined by equation (2.5). The internal current regulation is taken into account by the $S_{i R q}$ block, and $\mathrm{R}_{\mathrm{q}}$ represents the reactive power regulator.

The internal structure of the regulator $\left(\mathrm{R}_{\mathrm{q}}\right)$ is shown in Figure 2.24. In this figure, $R_{s s}$ is the state-space regulator with integral component defined by (2.43). The block $S_{\mathrm{pEq}}$ represents, within the reactive power regulator, the lag of the block $S_{\mathrm{iRq}}$. $\mathrm{T}_{\mathrm{pEq}}$ is defined by equation (2.44).

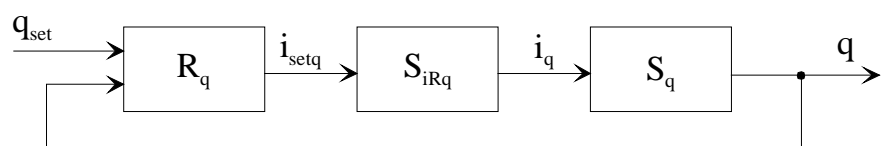

Figure 2.23 : State-space block diagram for the reactive power control

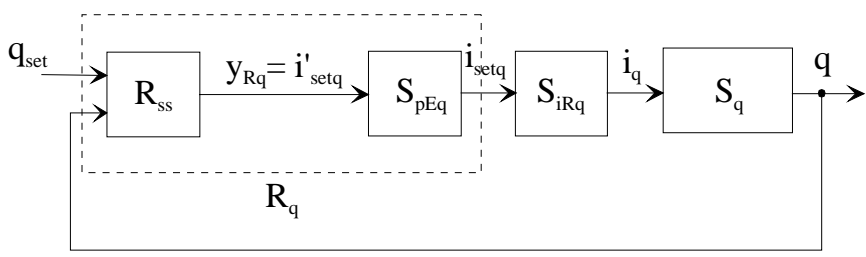

Figure 2.24 : State-space control block diagram, including the reactive power regulator

The state-space reactive power regulator $\mathrm{R}_{\mathrm{ss}}$ with integral component $\left(\mathrm{x}_{\mathrm{Rq}}\right)$ is defined by equation (2.43).

$$
\left.\begin{array}{l}
\mathrm{y}_{\mathrm{Rq}}=\mathrm{k}_{\mathrm{Rq}} \mathrm{x}_{\mathrm{Rq}}+\mathrm{k}_{\mathrm{wq}} \mathrm{q}_{\text {set }} \\
\frac{\mathrm{dx}_{\mathrm{Rq}}}{\mathrm{dt}}=\frac{1}{\mathrm{~T}_{\mathrm{E}}}\left(\mathrm{q}_{\mathrm{set}}-\mathrm{q}\right)
\end{array}\right\}
$$

where $\mathrm{T}_{\mathrm{E}}$ is the sampling time. 
The $S_{\text {peq }}$ block representing the block $S_{\mathrm{iRq}}$, is defined by equation (2.44).

$$
\mathrm{i}_{\mathrm{setq}}=\frac{1}{1+\mathrm{sT}_{\mathrm{pEq}}} \mathrm{y}_{\mathrm{Rq}}
$$

where $\mathrm{T}_{\mathrm{pEq}}$ is the lag of all the small time constants, and especially the lag of the current regulator.

From (2.43) and (2.44), with the chosen pole placement $\left(\rho_{\mathrm{q}}\right)$, the regulator coefficients can be determined.

$$
\begin{aligned}
& \rho_{\mathrm{q}}=\frac{1}{2\left(\mathrm{~T}_{\mathrm{pEq}}+\mathrm{T}_{\mathrm{ei}}\right)} \\
& \mathrm{k}_{\mathrm{Rq}}=\frac{\rho_{\mathrm{q}}^{2} \mathrm{~T}_{\mathrm{E}}\left(\mathrm{T}_{\mathrm{pEq}}+\mathrm{T}_{\mathrm{ei}}\right)}{\hat{\mathrm{u}}_{\mathrm{n}}} \\
& \mathrm{k}_{\mathrm{Ru}}=\frac{\mathrm{k}_{\mathrm{Rq}}}{\rho_{\mathrm{q}}\left(\mathrm{T}_{\mathrm{pEq}}+\mathrm{T}_{\mathrm{ei}}\right)}
\end{aligned}
$$

\subsection{Simulations}

\subsubsection{Introduction}

The aim of the present section is to illustrate and compare the behaviour of the transformer section for both control strategies.

The SIMSEN [7] representation of each control strategy is given in $\$ 2.5 .2$ for the classical control and respectively $\$ 2.5 .3$ for the state-space control. All the different SIMSEN blocks (functions) used for each control are detailed in these sections.

The simulations concern an existing installation in Vianden, with

$$
\begin{array}{ll}
\text { - } & \mathrm{S}_{\mathrm{nT}}=23 \mathrm{MVA} \\
\text { - } & \mathrm{U}_{\mathrm{DCn}}=4220 \mathrm{~V} \\
\text { - } & \mathrm{U}_{1}=15750 \mathrm{~V} \\
\text { - } & \mathrm{U}_{2}=2000 \mathrm{~V} \\
\text { - } & \mathrm{C}_{1,2}=0.3 \mathrm{~F} \text { (chosen according to [5]) } \\
\text { - } & \mathrm{r}_{\mathrm{sc}}=0.005 \mathrm{pu} \\
\text { - } & \mathrm{x}_{\mathrm{sc}}=0.15 \mathrm{pu}
\end{array}
$$




\subsubsection{The classical control (SIMSEN)}

Figure 2.25 shows how the power parts as well as the control system appear in SIMSEN for the classical control.

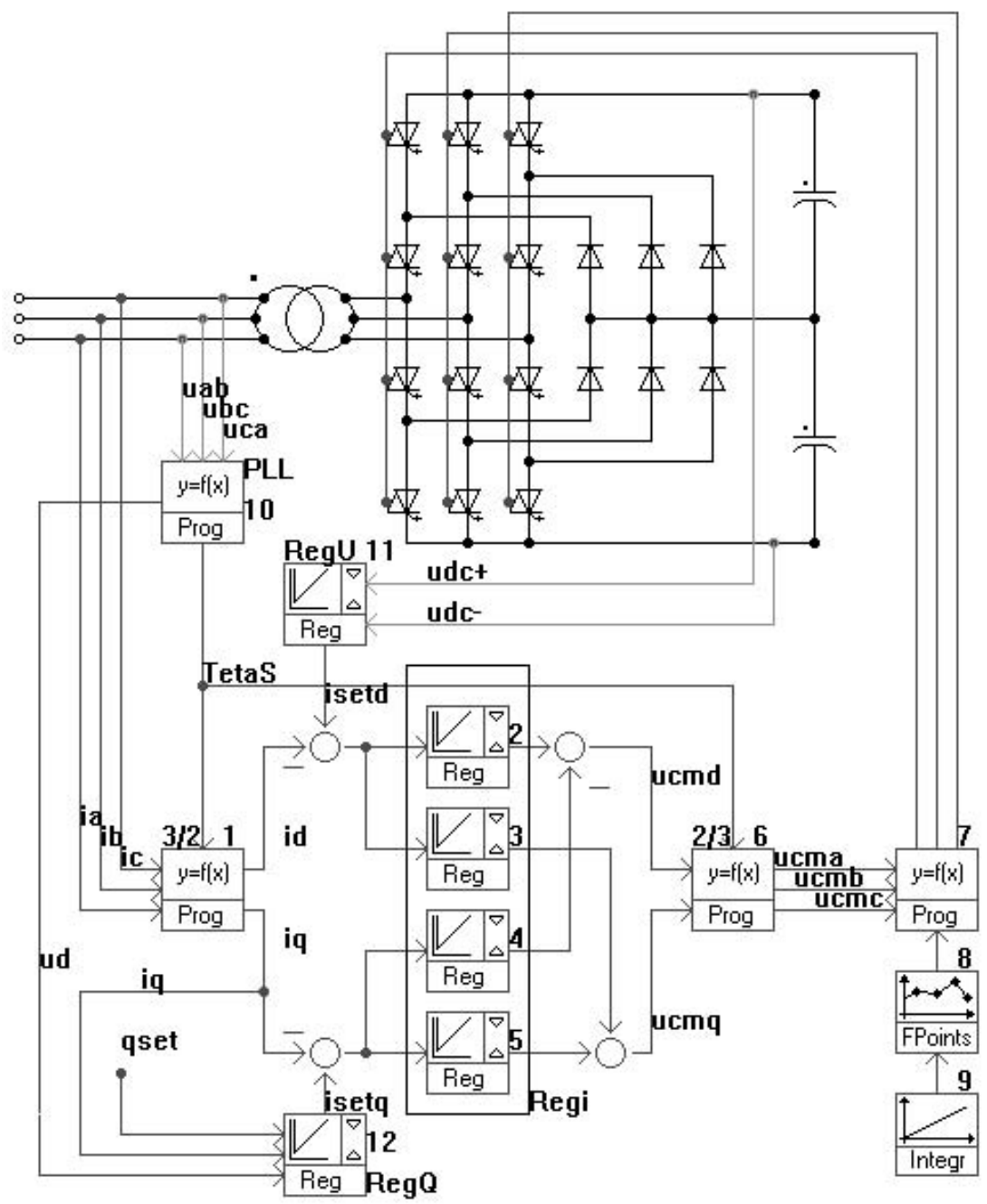

Figure 2.25 : The classical control in SIMSEN 
The 12 blocks in Figure 2.25 correspond to :

1. Park transformation of the primary side currents.

2. PI regulator for the current in the direct $d$ axis.

3. I regulator for the current in the crossed $d-q$ axis.

4. I regulator for the current in the crossed q-d axis.

5. PI regulator for the current in the direct $\mathrm{q}$ axis.

6. Inverse Park transformation generating the command signals.

7. Generation of the gate command switching states.

8. Carrier signal generation.

9. Setting of the carrier signal frequency.

10. PLL (Phase Locked Loop) generating the $\theta_{\mathrm{s}}$ angle (Chapter 5).

11. PI regulator for the DC-link voltage.

12. I regulator for the reactive power.

The phase currents $i_{a}, i_{b}, i_{c}$ are measured on the primary side of the transformer. A Park transformation is applied to these currents (block 1) with the angle $\theta_{\mathrm{s}}$ coming from the PLL (block 10).

The currents $i_{d}$ and $i_{q}$ are then subtracted from their respective set values ( $i_{\text {setd }}, i_{\text {setq }}$ ). $i_{\text {setd }}$ comes from the DC-link voltage regulator (block 11) and $i_{\text {setq }}$ from the reactive power regulator (block 12).

An inverse Park transformation (block 6) is then applied to the outputs $\left(\mathrm{u}_{\mathrm{cmd}}, \mathrm{u}_{\mathrm{cmq}}\right)$ of the current multivariable regulator (blocks 2-3-4-5).

The blocks 8-9 generate the carrier signal, which will be compared to the command signals $\left(\mathrm{u}_{\mathrm{cma}}, \mathrm{u}_{\mathrm{cmb}}, \mathrm{u}_{\mathrm{cmc}}\right)$ in block 7 to produce the GTOs gate switching states. Note that no particular syncronisation of the carrier signal with the command signal is undertaken. 


\subsubsection{The state-space control (SIMSEN)}

Figure 2.26 shows how the power parts as well as the control system appear in SIMSEN for the state-space control.

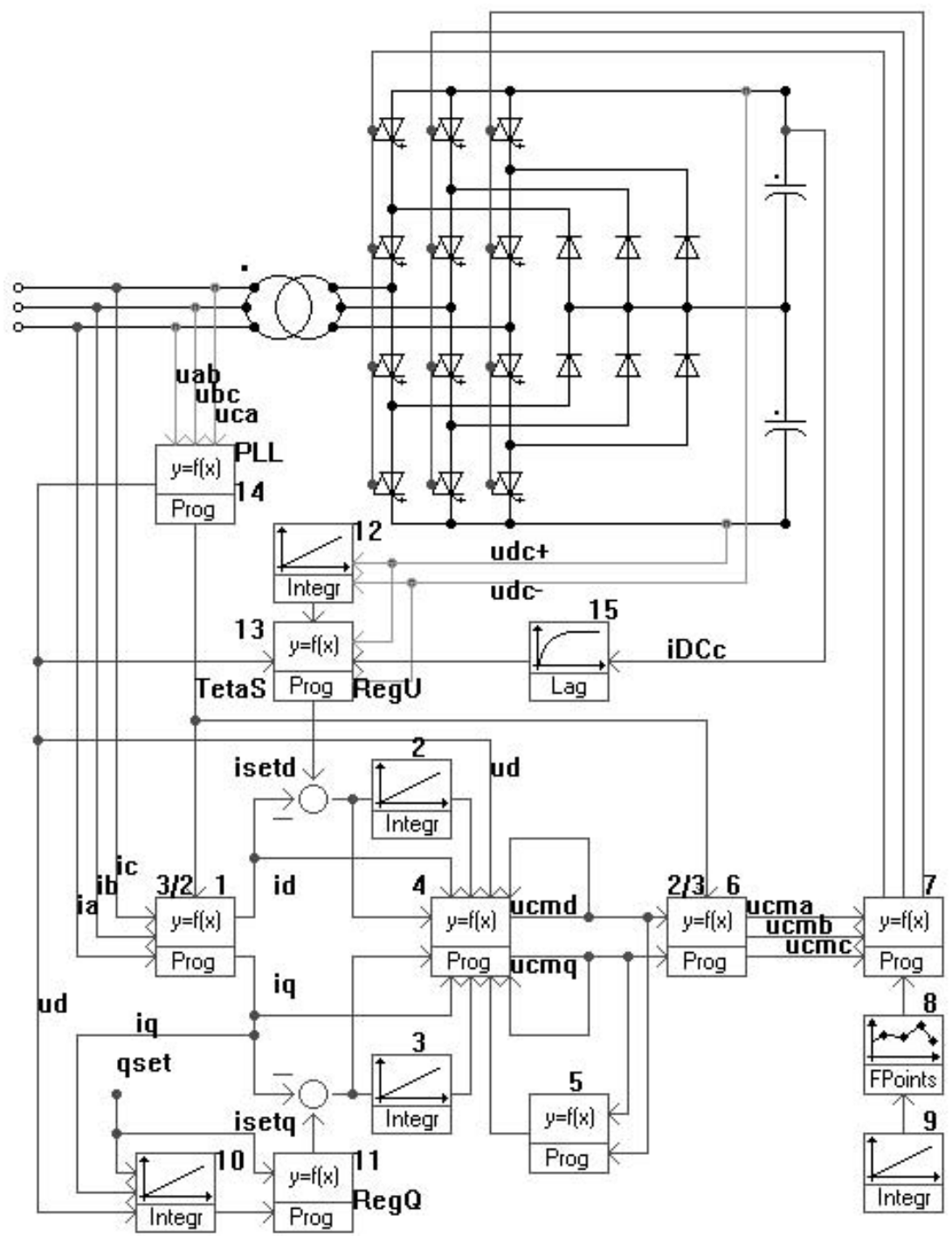

Figure 2.26 : The state-space control in SIMSEN 
The 15 blocks in Figure 2.26 correspond to :

1. Park transformation of the primary side currents.

2. Integrator for the integral component in the $\mathrm{d}$ axis.

3. Integrator for the integral component in the $\mathrm{q}$ axis.

4. State-space current regulator.

5. Feedback of $\underline{\underline{u}}_{2}$ (calculation of $\underline{\underline{u}}_{2}{ }^{\prime}$ ).

6. Inverse Park transformation for the command signals.

7. Generation of the gate command switching states.

8. Carrier signal generation.

9. Setting of the carrier signal frequency.

10. Integrator for the integral component of the reactive power control.

11. State-space regulator for the reactive power.

12. Integrator for the integral component of the DC-link voltage control.

13. State-space regulator for the DC-link voltage.

14. PLL (Phase Locked Loop) generating the $\theta_{\mathrm{s}}$ angle (Chapter 5).

15. Filtering of the capacitors current.

The phase currents $i_{a}, i_{b}, i_{c}$ are measured on the primary side of the transformer. A Park transformation is applied to these currents (block 1) with the angle $\theta_{\mathrm{s}}$ coming from the PLL (block 14).

The currents $i_{d}$ and $i_{q}$ are then subtracted from their respective set values $\left(i_{\text {setd }}, i_{\text {setq }}\right)$ and sent to their respective integrator (block 2-3) for the integral components, as well as to the current multivariable regulator (block 4). $i_{\text {setd }}$ comes from the DC-link voltage regulator (block 13) and $i_{\text {setq }}$ from the reactive power regulator (block 11).

An inverse Park transformation (block 6) is then applied to the outputs $\left(\mathrm{u}_{\mathrm{cmd}}, \mathrm{u}_{\mathrm{cmq}}\right)$ of the current multivariable regulator (blocks 4). These outputs are also fed back to the current regulator after calculating $\underline{\mathrm{u}}_{2}{ }^{\prime}$ in block 5 .

The blocks 8-9 generate the carrier signal, which will be compared to the command signals $\left(\mathrm{u}_{\mathrm{cma}}, \mathrm{u}_{\mathrm{cmb}}, \mathrm{u}_{\mathrm{cmc}}\right)$ in block 7 to produce the GTOs gate switching states. . Note that no particular syncronisation of the carrier signal with the command signal is undertaken. 


\subsubsection{Transient simulations}

The aim of the transient simulations is to validate the proposed control strategies and to allow a comparison between them. According to the design of the control and to the system requirements, three different transient simulations will be performed to validate the behaviour of each regulator as well as the correct decoupling between the reactive power and the DC-link voltage controls. These transient simulations will permit a comparison between the classical and the state-space control strategies with regard to the considered application.

Actually, as the reactive power control must follow set values, reactive power steps are preformed (a). The DC-link voltage must be kept at a constant value and therefore, active power steps are performed (b) by adding a resistor in the DC-link. Finally, the behaviour of the internal current control, in the case of a disturbance $\left(\hat{\mathrm{u}}_{\mathrm{n}},(2.7)\right)$ is checked $(\mathrm{c})$.

\section{a. Reactive power steps}

Reactive power steps are performed while keeping the DC-link voltage constant. Starting from no reactive power $(0 \mathrm{pu})$, the reactive set value is changed to $-1 \mathrm{pu}$ at $0.02 \mathrm{~s}$ and then to $+1 \mathrm{pu}$ at $0.12 \mathrm{~s}$ and finally goes back to $0 \mathrm{pu}$ at $0.3 \mathrm{~s}$.

Figure 2.27 and Figure 2.28 show, for the classical control, the reactive power and its set value, respectively the DC-link voltage and its set value, whereas Figure 2.29 and Figure 2.30 show respectively the same values but for the state-space control.

From this, it can be said that in each case the decoupling between the $\mathrm{d}$ and $\mathrm{q}$ axes, when changing the reactive set value. In fact, under the largest reactive power step ( $2 \mathrm{pu}$ ), the DC-link voltage does not vary more than about $0.5 \%$ in both strategies.

For the reactive power steps, it can be seen that the rise/fall time is nearly the same with each strategy. However, a very slight damped oscillation occurs after the largest reactive power step in the classical control. This is mainly due to the constitution of each strategy. As explained in $\$ 2.3 .1$, the classical control does not compensate all the poles of the system. Therefore, a compromise is made, resulting in damped oscillations appearing in certain cases, which are not present in the state-space control. This oscillation is however not important in terms of amplitude, and can be neglected. 


\section{b. Active power steps}

Active power steps are performed while keeping the reactive power at a constant value. Starting from no active load (DC-link resistor $=\infty$ ), the active load is changed to $1 \mathrm{pu}$ at $0.02 \mathrm{~s}$ and goes back to $0 \mathrm{pu}$ at $0.22 \mathrm{~s}$. Note that the active step is only positive; this is because the active load is simply a resistor put in the DC-link circuit. Of course, in the complete system, active steps can be positive and negative.

Figure 2.31, Figure 2.32 and Figure 2.33 show for the classical control, respectively the reactive power and its set value, the DC-link voltage and its set value, the active current $\left(i_{1 \mathrm{~d}}\right)$, where as Figure 2.34, Figure 2.35 and Figure 2.36 show respectively the same values but for the state-space control.

From this, it can be said, that both strategies react correctly to the steps. Especially, the reactive power is maintained at its correct value.

For the DC-link voltage, the state-space control has a better response as its DC-link voltage only varies about $1 \%$, compared to about $2.5 \%$ for the classical control. This is explained by the fact that the state-space control strategy reacts faster, but with the drawback that the resulting active current has a higher overshoot (1.4 pu). On the other side, the classical control has a slower response, but a lower overshoot too $(1.3 \mathrm{pu})$.

\section{c. Disturbance of $\hat{u}_{n}$}

A disturbance of $\hat{u}_{\mathrm{n}}$ is performed while keeping the reactive power and the DC-link voltage at constant values. A change of $-5 \%$ of $\hat{u}_{n}$ takes place at $0.02 \mathrm{~s}$.

Figure 2.37 and Figure 2.38 show, for the classical control, respectively the reactive power and its set value, the disturbance of $\hat{\mathrm{u}}_{\mathrm{n}}$; the DC-link voltage and its set value, the disturbance of $\hat{\mathrm{u}}_{\mathrm{n}}$. Figure 2.39 and Figure 2.40 show the same values but for the state-space control.

From this, and as expected, in the presence of disturbances the state-space control has a better response, due to the fact that it takes it into account in the regulator.

On the other hand, in the classical control, $\hat{\mathrm{u}}_{\mathrm{n}}$ cannot be taken into account (2.7). This leads to the damped oscillation found in the reactive power for the classical control (Figure 2.37). 


\section{Classical control - Reactive power steps}

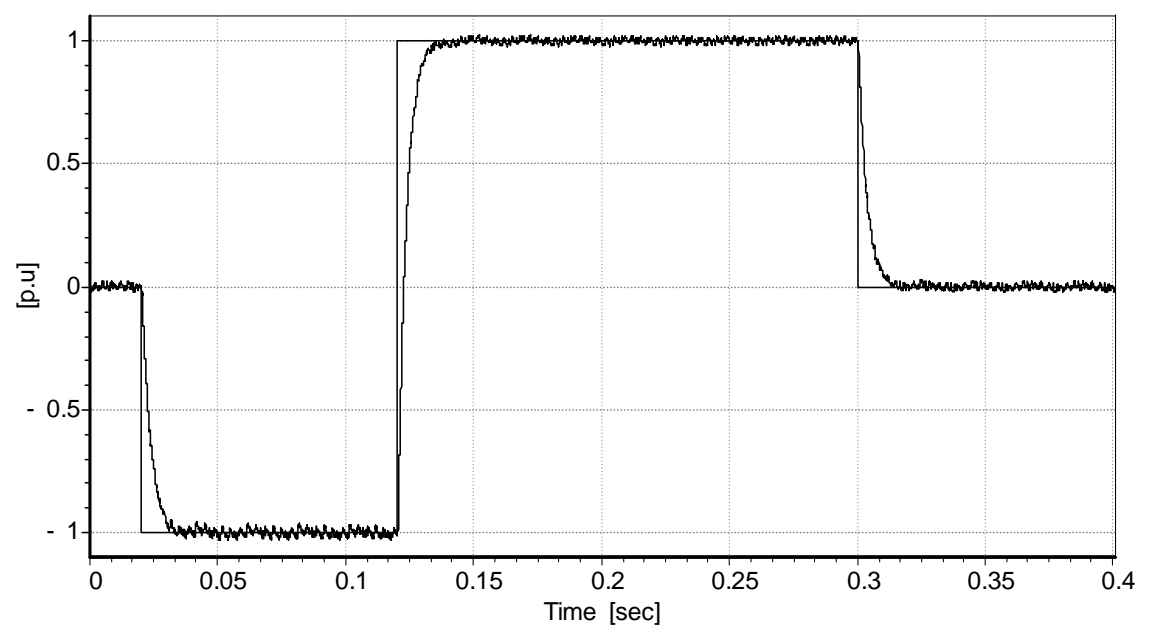

Figure 2.27 : Reactive power and its set value

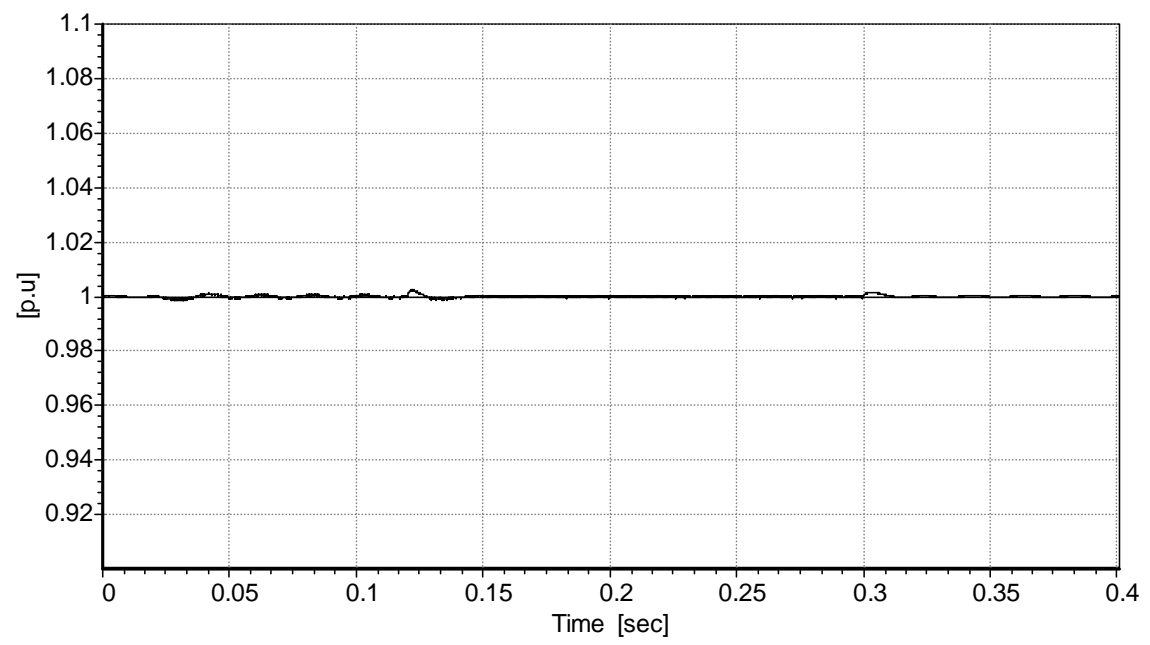

Figure 2.28 : DC-link voltage and its set value 
State-space control - Reactive power steps

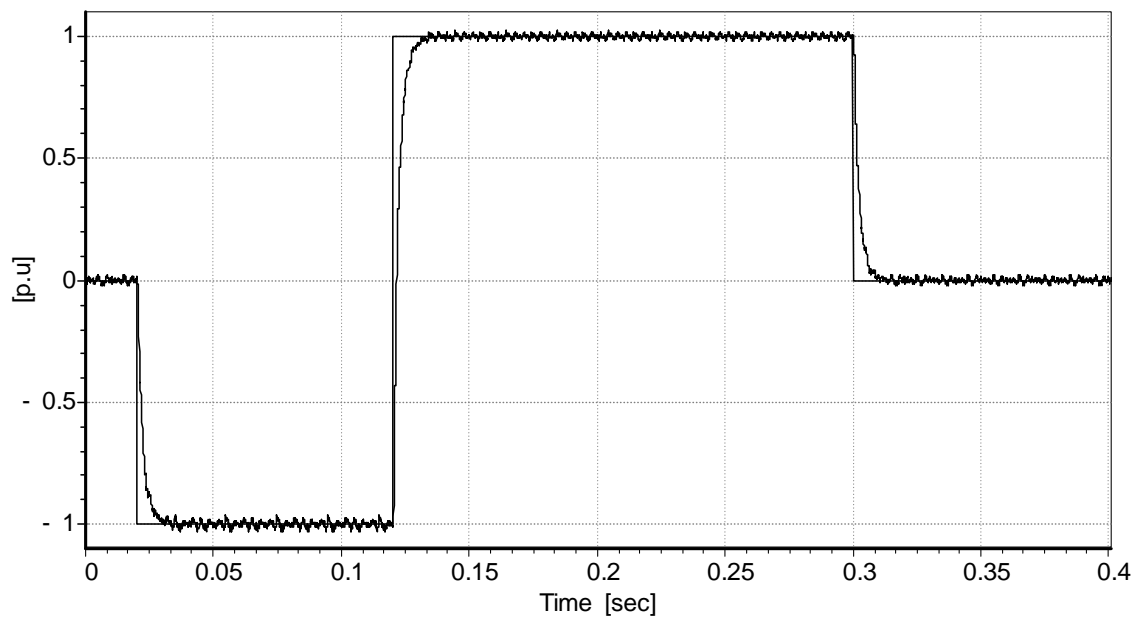

Figure 2.29 : Reactive power and its set value

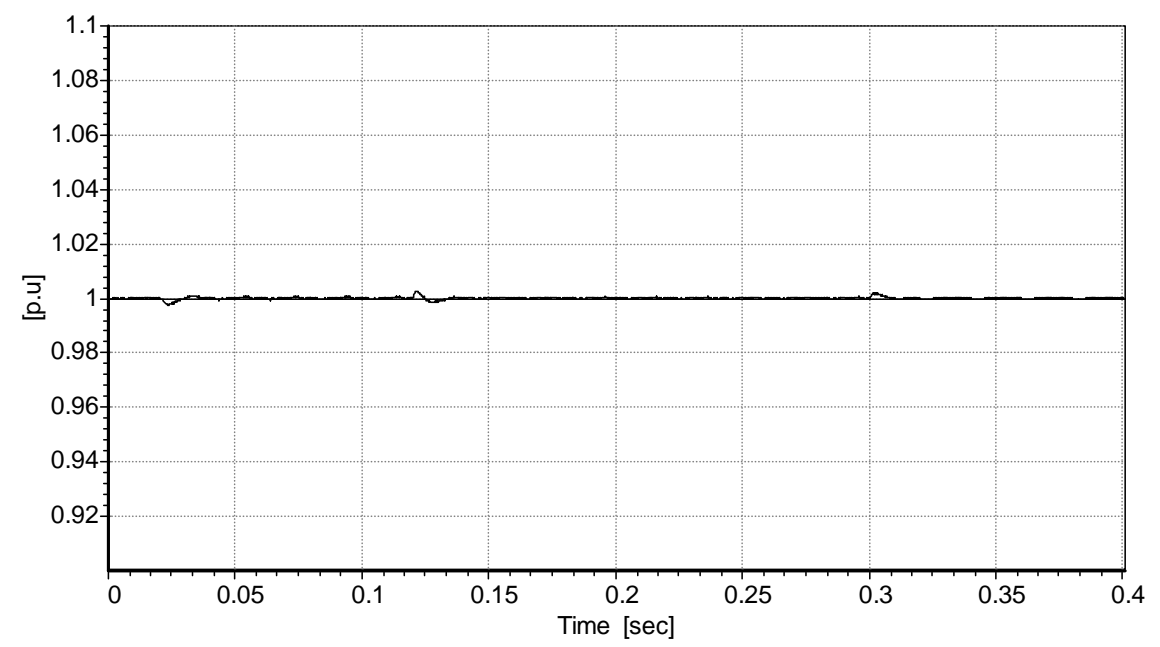

Figure 2.30 : DC-link voltage and its set value 


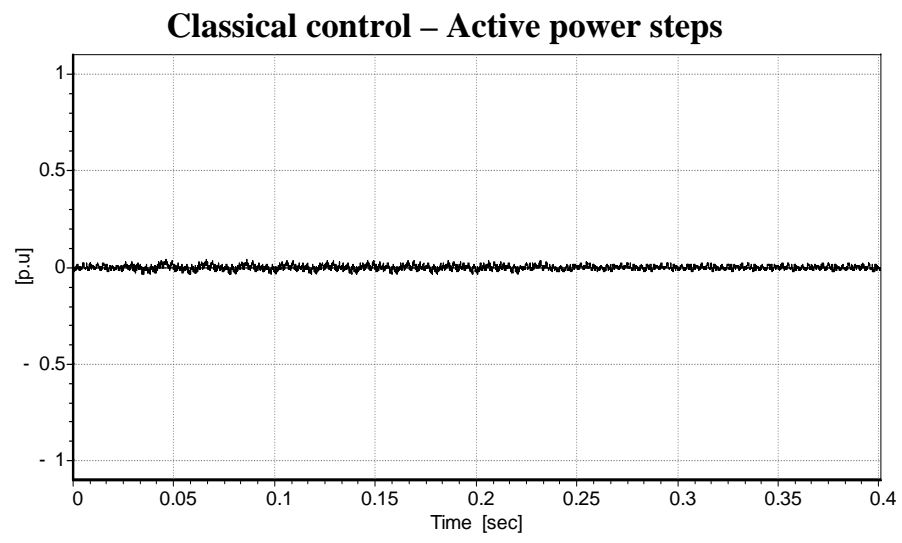

Figure 2.31 : Reactive power and its set value

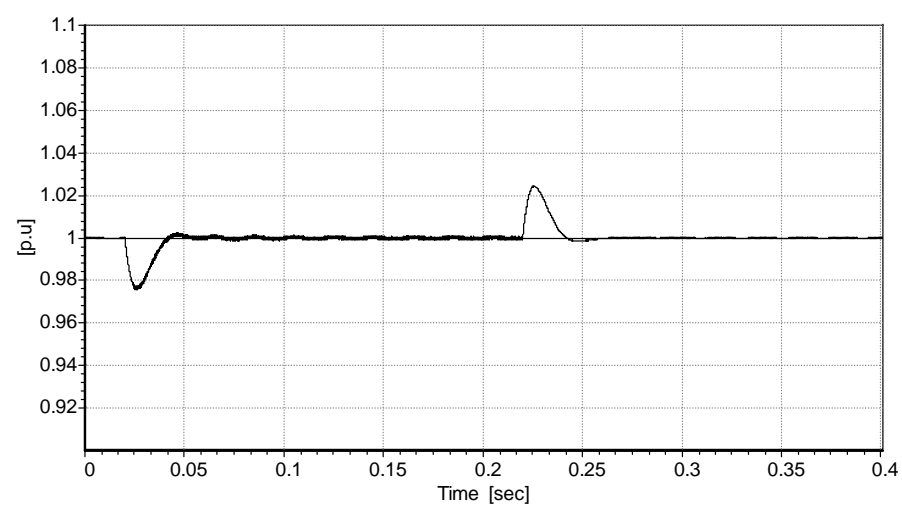

Figure 2.32 : DC-link voltage and its set value

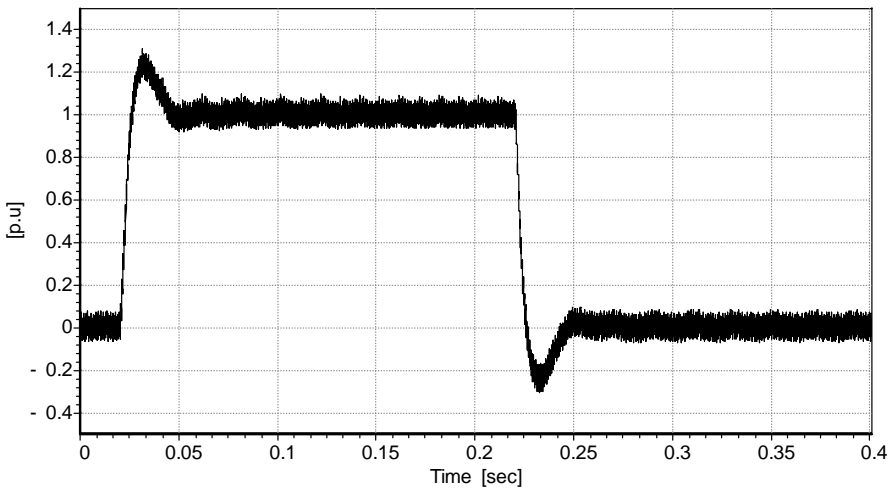

Figure 2.33 : Active current 


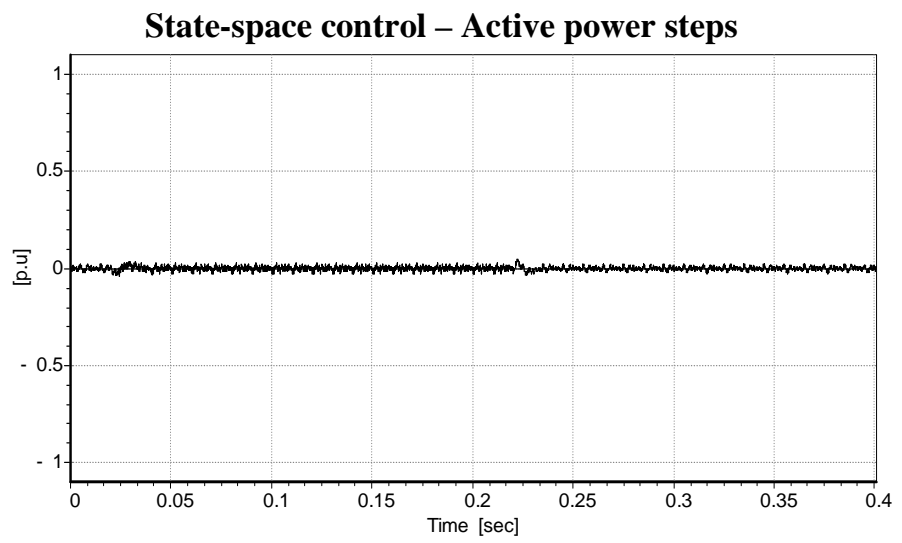

Figure 2.34 : Reactive power and its set value

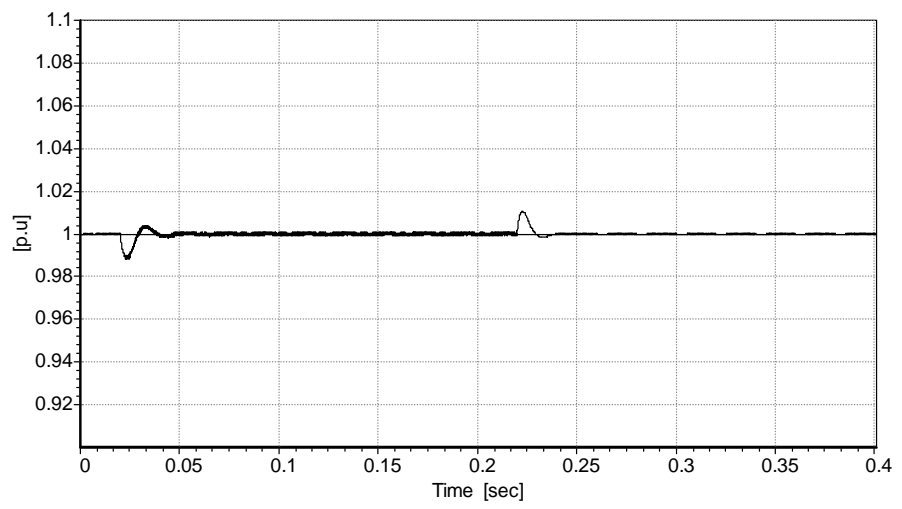

Figure 2.35 : DC-link voltage and its set value

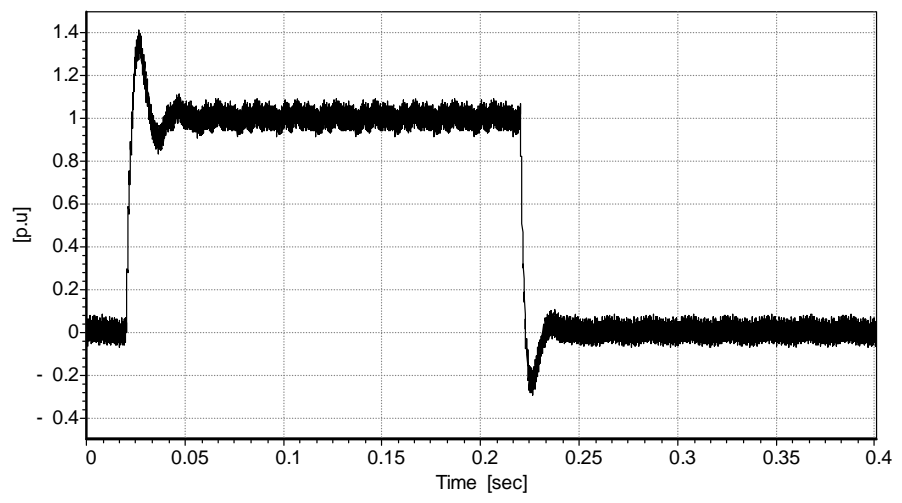

Figure 2.36 : Active current 


\section{Classical control - Disturbance of $\hat{\mathbf{u}}_{\mathbf{n}}$}

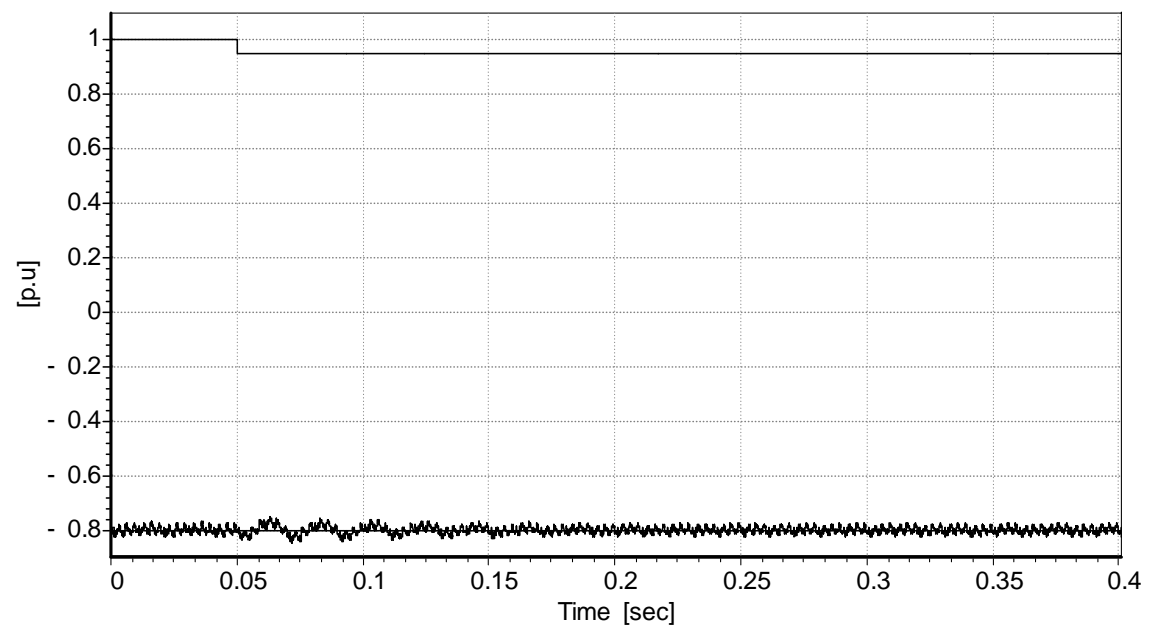

Figure 2.37 : Reactive power and its set value, disturbance of $\hat{\mathbf{u}}_{\mathbf{n}}$

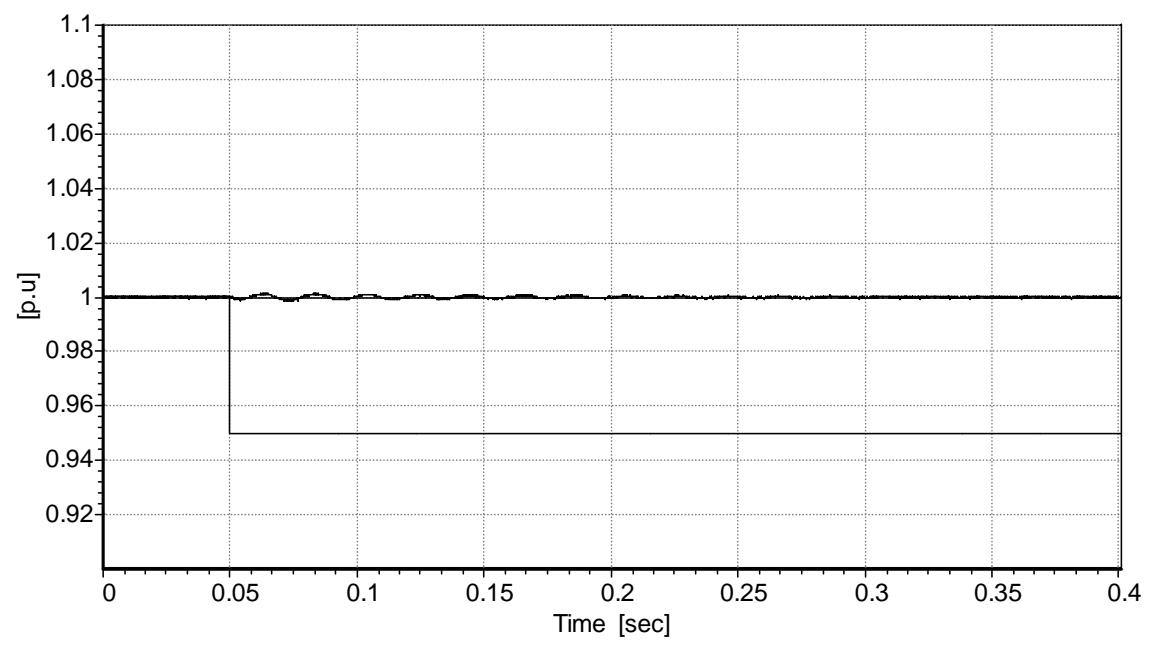

Figure 2.38 : DC-link voltage and its set value, disturbance of $\hat{\mathbf{u}}_{\mathrm{n}}$ 


\section{State-space control - Disturbance of $\hat{\mathbf{u}}_{\mathbf{n}}$}

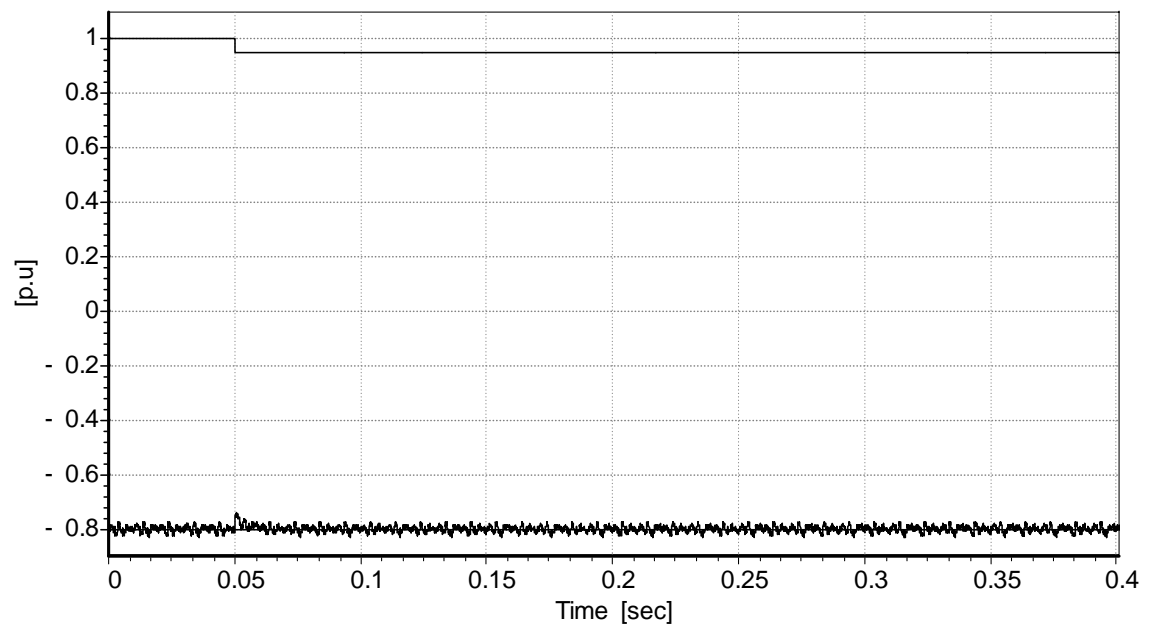

Figure 2.39 : Reactive power and its set value, disturbance of $\hat{\mathbf{u}}_{\mathbf{n}}$

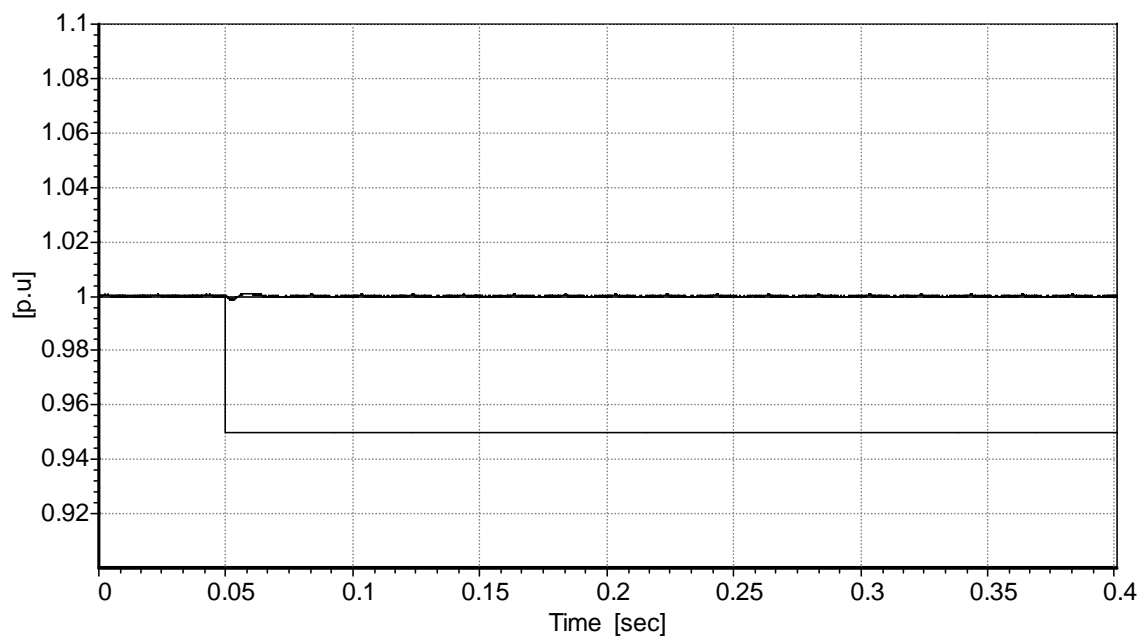

Figure 2.40 : DC-link voltage and its set value, disturbance of $\hat{\mathbf{u}}_{\mathrm{n}}$ 


\subsection{Conclusion}

The application presented in this chapter has allowed a comparison in terms of performance between the classical and the state-space control. The comparison shows that only few differences are found, however this cannot be generalized to all cases. In other terms, a comparison must be done in each particular application, to choose one or the other regulation strategy, according to the needs of the particular system (stability, speed, response time, ...).

Generally speaking, as the state-space control uses more variables, it requires more values to be measured as well. This, in regard of the total investment for the application, is usually negligible. However, this can become a technical problem in some cases.

More specifically, in the present application, the dynamic behaviour is limited by the hydraulic section for the active power steps. Furthermore, in this power range, the voltage is constant and does only vary very slowly or in presence of faults, such as short circuits. In the light of this, the classical control appears to cover all the requirements, with the advantage of having a control less dependant on the system parameters (c.f. §2.3.1). This solution would probably be the chosen one. At least, it will be the chosen solution for the practical section (Chapter 5). 


\section{Chapter 3 \\ Machine Section}

\subsection{Introduction}

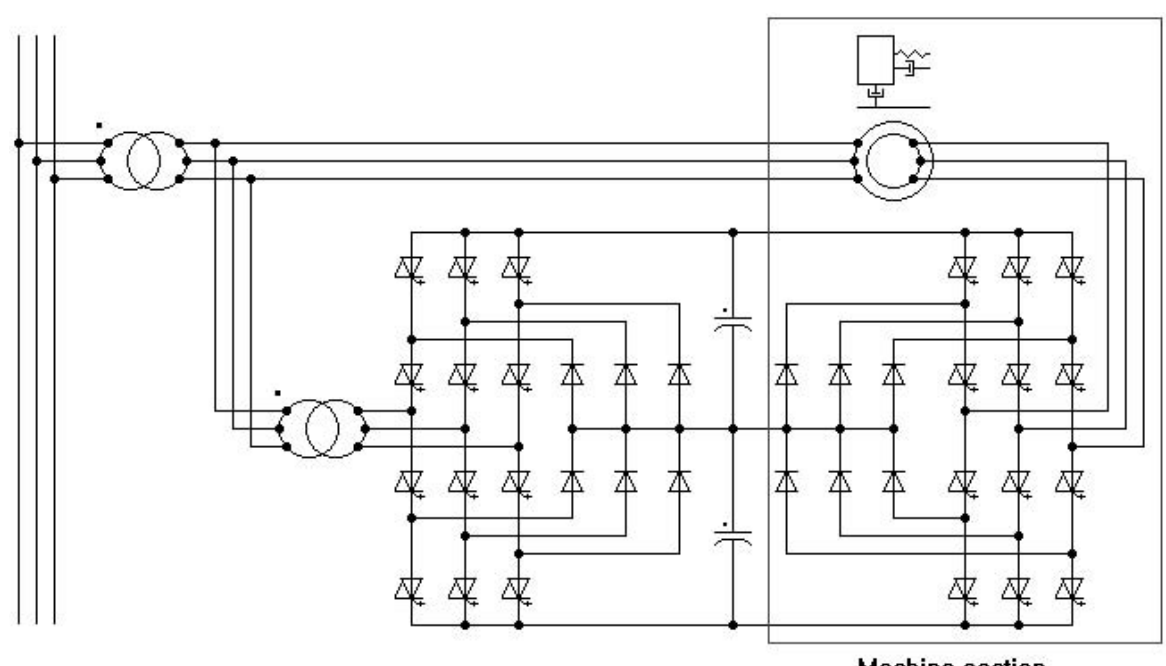

Figure 3.1 : The machine section

The aim of the machine section (Figure 3.1) is to regulate the machine in pump and turbine modes, respectively in motor and generator mode. Usually, in pump mode, the speed and reactive power are regulated, whereas in turbine mode the active and reactive powers are regulated. In the latter mode, the speed is controlled by the turbine itself. Note that the stator and the rotor of the machine offer completely decoupled magnetizing sources.

Compared to the transformer section (Chapter 2), where two different control strategies were investigated, only the classical control will be studied in this section. This is justified for two main reasons. 
The first one is that the rapidity of the classical control appears to be fast enough compared to the hydraulic part time constants. The second one is that a state-space control would require the measurement of $\underline{u}_{s}$ and an estimation of the flux $\underline{\psi}_{s}$. The former is easy to measure, whereas the estimation of the latter is out of the scope of this thesis. Furthermore, small variations of $\underline{\underline{u}}_{s}$ in terms of amplitude are only very slow except in the presence of disturbances such as short circuits, requiring specific protections which will not be discussed here.

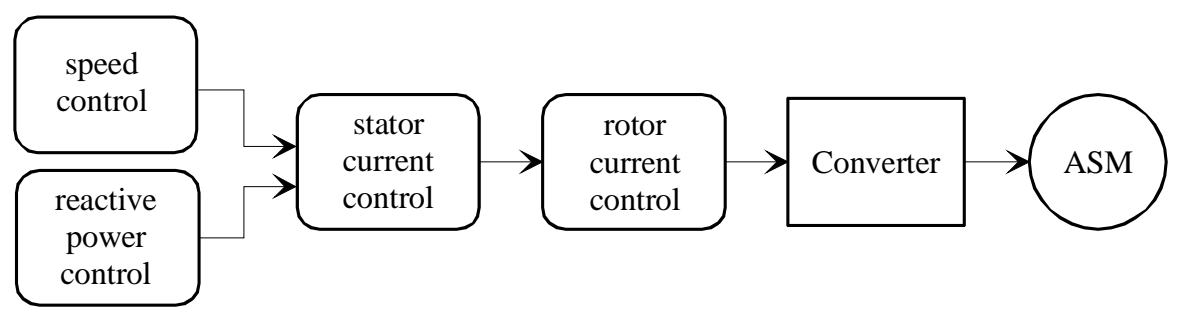

Figure 3.2 : Regulation block diagram for the machine section

The machine speed and reactive power control are achieved by controlling the machine rotor currents (Figure 3.2). Therefore, two different reference frames are to be used, one for the stator control and one for the rotor control. Chapter 5 investigates strategies for the determination of these reference frames.

The stator control is performed in the same d-q axes frame as for the transformer section, which is locked on the voltage phasor $\underline{u}_{s}$. Hence, the active power is on the $\mathrm{d}$ axis, whereas the reactive power is on the q axis. At the same time, the rotor control is performed in a d-q axes frame locked on the voltage phasor $\underline{u}_{r}$, resulting in the rotor active power being on the $\mathrm{d}$ axis and the rotor reactive power being on the $\mathrm{q}$ axis. 


\subsection{System modelling}

\subsubsection{System definition}

The machine section system is shown in Figure 3.3. It consists of a wound rotor asynchronous machine and of a pump-turbine.

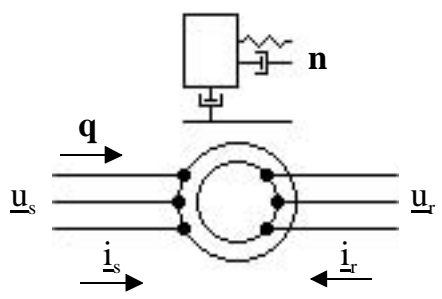

Figure 3.3 : The machine section system definition

The system is defined by the following items :

- $\underline{\underline{u}}_{s}, \underline{i}_{s}:$ line voltage and current on the stator side of the machine.

- $\underline{\mathrm{u}}_{\mathrm{r}}, \underline{\mathrm{i}}_{\mathrm{r}}$ : line voltage and current on the rotor side of the machine.

- $\mathrm{q}$ : reactive power on the stator side of the machine (motor convention).

- $\mathrm{n}$ : speed of the rotor of the machine.

\subsubsection{Modelling}

The equivalent circuit of the machine is shown in Figure 3.4.

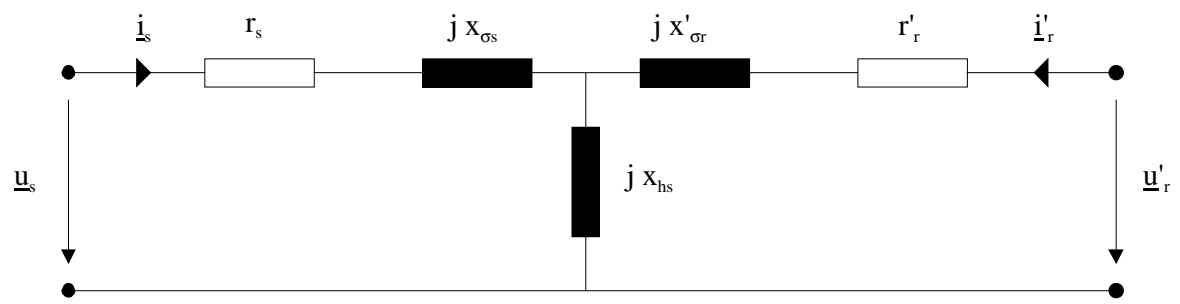

Figure 3.4 : Equivalent circuit of a wound rotor asynchronous machine

- $r_{s}$ : stator resistance.

- $\mathrm{r}_{\mathrm{r}}^{\prime}$ : rotor resistance referred to the stator.

- $\mathrm{x}_{\sigma \mathrm{s}}$ : stator leakage reactance.

- $\mathrm{x}_{\sigma \mathrm{r}}^{\prime}$ : rotor leakage reactance referred to the stator.

- $\mathrm{x}_{\mathrm{h}}$ : main field reactance

The mechanical section modelling is an inertia and an external torque applied on it.

- Inertia $\quad \mathrm{J} \quad\left[\mathrm{kg} \mathrm{m}^{2}\right]$

- External torque $\mathrm{T}_{\text {ext }}[\mathrm{Nm}]$

Per unit (pu) quantities will be used in the stator reference $\left(S_{n}, U_{n}\right)$. 


\subsubsection{Basic equations and definitions}

The machine modelling as defined by Figure 3.3, in the chosen reference frame, enables us to write the equations (3.1) and (3.2)

$$
\begin{aligned}
& \underline{\mathrm{u}}_{\mathrm{s}}=\mathrm{r}_{\mathrm{s}} \underline{\mathrm{i}}_{\mathrm{s}}+\mathrm{jf} \mathrm{f}_{\mathrm{s}} \underline{\psi}_{\mathrm{s}}+\frac{1}{\omega_{\mathrm{n}}} \frac{\mathrm{d} \underline{\psi}_{\mathrm{s}}}{\mathrm{dt}} \\
& \underline{\mathrm{u}}_{\mathrm{r}}^{\prime}=\mathrm{r}_{\mathrm{r}}^{\prime} \underline{\mathrm{i}}_{\mathrm{r}}^{\prime}+\mathrm{j} \mathrm{f}_{\mathrm{r}} \underline{\psi}_{\mathrm{r}}^{\prime}+\frac{1}{\omega_{\mathrm{n}}} \frac{\mathrm{d} \underline{\psi}_{\mathrm{r}}^{\prime}}{\mathrm{dt}}
\end{aligned}
$$

with $\mathrm{f}_{\mathrm{s}}$ and $\mathrm{f}_{\mathrm{r}}$ being in per unit and the fluxes defined by

$$
\begin{array}{ll}
\underline{\psi}_{\mathrm{s}}=\mathrm{x}_{\mathrm{s}} \underline{\mathrm{i}}_{\mathrm{s}}+\mathrm{x}_{\mathrm{h}} \underline{\mathrm{i}}_{\mathrm{r}}^{\prime} & \text { with } \mathrm{x}_{\mathrm{s}}=\mathrm{x}_{\mathrm{h}}+\mathrm{x}_{\sigma \mathrm{s}} \\
\underline{\Psi}_{\mathrm{r}}^{\prime}=\mathrm{x}_{\mathrm{r}} \underline{\mathrm{i}}_{\mathrm{r}}^{\prime}+\mathrm{x}_{\mathrm{h}} \underline{\mathrm{i}}_{\mathrm{s}} & \text { with } \mathrm{x}_{\mathrm{r}}^{\prime}=\mathrm{x}_{\mathrm{h}}+\mathrm{x}_{\sigma \mathrm{r}}{ }^{\prime}
\end{array}
$$

From now on, the time derivation $\mathrm{d} / \mathrm{dt}$ will be replace by the Laplace operator 's', and the indices omitted.

Other useful terms are to be defined here

$$
\begin{array}{ll}
\sigma_{\mathrm{M}}=1-\frac{\mathrm{x}_{\mathrm{h}}^{2}}{\mathrm{x}_{\mathrm{s}} \mathrm{x}_{\mathrm{r}}} & \text { with } \mathrm{T}_{\mathrm{s}}=\frac{1_{\mathrm{s}}}{\mathrm{r}_{\mathrm{s}}}=\frac{\mathrm{x}_{\mathrm{s}}}{\omega_{\mathrm{s}} \mathrm{r}_{\mathrm{s}}}=\sigma_{\mathrm{M}} \mathrm{T}_{\mathrm{s}} \\
\mathrm{T}_{\mathrm{r}}^{\prime}=\sigma_{\mathrm{M}} \mathrm{T}_{\mathrm{r}} & \text { with } \mathrm{T}_{\mathrm{r}}=\frac{1_{\mathrm{r}}}{\mathrm{r}_{\mathrm{r}}}=\frac{\mathrm{x}_{\mathrm{r}}}{\omega_{\mathrm{n}} \mathrm{r}_{\mathrm{r}}}
\end{array}
$$

For the mechanical torque [8] we have

$$
\mathrm{T}_{\mathrm{j}} \frac{\mathrm{dn}}{\mathrm{dt}}=\mathrm{t}_{\mathrm{e}}-\mathrm{t}_{\mathrm{ext}} \quad \text { with } \mathrm{T}_{\mathrm{j}} \text { the inertia constant }
$$

with $t_{e x t}$ the external torque, and the electromagnetic torque $t_{e}$ defined by (3.9).

$$
\mathrm{t}_{\mathrm{e}}=\left(\psi_{\mathrm{sd}} \mathrm{i}_{\mathrm{sq}}-\psi_{\mathrm{sq}} \mathrm{i}_{\mathrm{sd}}\right)
$$

And finally for the machine powers :

$$
\begin{aligned}
& \mathrm{p}=\mathrm{u}_{\mathrm{sd}} \mathrm{i}_{\mathrm{sd}} \\
& \mathrm{q}=-\mathrm{u}_{\mathrm{sd}} \mathrm{i}_{\mathrm{sq}}
\end{aligned}
$$




\subsection{Control}

\subsubsection{Transfer functions for the rotor and stator current controls}

By replacing the flux in equations (3.1) and (3.2) by (3.3) and (3.4) we obtain:

$$
\begin{aligned}
& \underline{u}_{s}=\left(r_{s}+j f_{s} x_{s}+s \frac{1}{\omega_{n}} x_{s}\right) \underline{i}_{s}+\left(j f_{s} x_{h}+s \frac{1}{\omega_{n}} x_{h}\right) \underline{i}_{r} \\
& \underline{u}_{r}=\left(r_{r}+j f_{r} x_{r}+s \frac{1}{\omega_{n}} x_{r}\right) \underline{i}_{r}+\left(j f_{r} x_{h}+s \frac{1}{\omega_{n}} x_{h}\right) \underline{i}_{s}
\end{aligned}
$$

From these equations, the transfer functions needed for the rotor and stator current controls are

$$
\begin{aligned}
& \underline{\mathrm{i}}_{\mathrm{r}}=\underline{\mathrm{G}}_{\mathrm{ir}}(\mathrm{s}) \underline{\mathrm{u}}_{\mathrm{r}}-\underline{\mathrm{G}}_{\mathrm{ur}}(\mathrm{s}) \underline{\mathrm{u}}_{\mathrm{s}} \\
& \underline{\mathrm{i}}_{\mathrm{s}}=\mathrm{G}_{\mathrm{is}}(\mathrm{s}) \underline{\mathrm{i}}_{\mathrm{r}}+\underline{\mathrm{G}}_{\mathrm{us}}(\mathrm{s}) \underline{\mathrm{u}}_{\mathrm{s}}
\end{aligned}
$$

with

$$
\begin{aligned}
& \underline{G}_{i r}(s)=\frac{\omega_{n} T_{r}^{\prime}}{\sigma_{M} x_{r}} \frac{1}{1+\left(s+j f_{r} \omega_{n}\right) T_{r}^{\prime}} \\
& \underline{G}_{u r}(s)=\frac{\left(1-\sigma_{M}\right) \omega_{n} T_{r}^{\prime}}{\sigma_{M} x_{h}} \frac{1}{1+\left(s+j f_{r} \omega_{n}\right) T_{r}^{\prime}} \frac{s+j f_{r} \omega_{n}}{s+j f_{s} \omega_{n}}
\end{aligned}
$$

and

$$
\begin{aligned}
& \underline{G}_{u s}(s)=\frac{\omega_{n}}{x_{s}} \frac{1}{s+j f_{s} \omega_{n}} \\
& G_{i s}(s)=-\frac{x_{h}}{x_{s}}
\end{aligned}
$$

In these transfer functions, the $\underline{\underline{u}}_{s}$ term is the disturbance in both cases (rotor and stator). 


\subsubsection{Rotor current control}

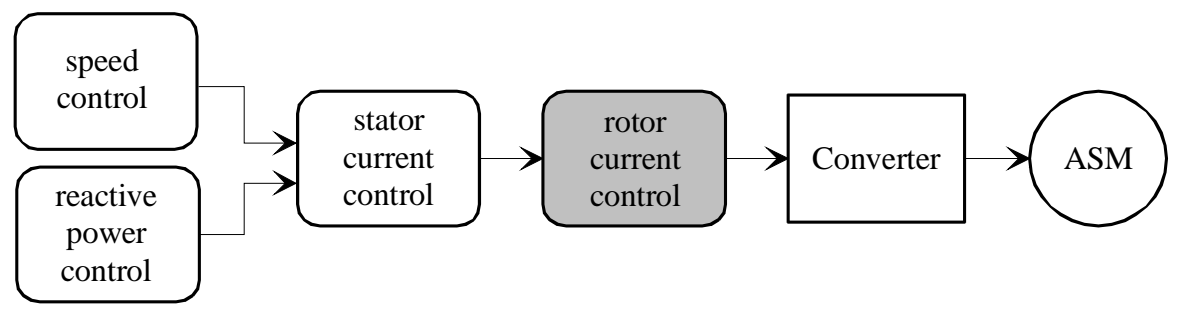

Figure 3.5 : Rotor current control

The rotor current control is the innermost one as shown in Figure 3.5. Figure 3.6 gives its corresponding transfer function block diagram. In this figure, $\underline{G}_{i r}(s)$ is the system to be regulated, here the rotor side of the machine defined by (3.16). $\mathrm{G}_{\mathrm{pEr}}(\mathrm{s})$ is the command system (3-level VSI) and includes all the small time constants $\left(T_{\mathrm{pEr}},(3.20)\right)$. Finally $\underline{\mathrm{G}}_{\mathrm{Rr}}(\mathrm{s})$ is the rotor current regulator which will be designed.

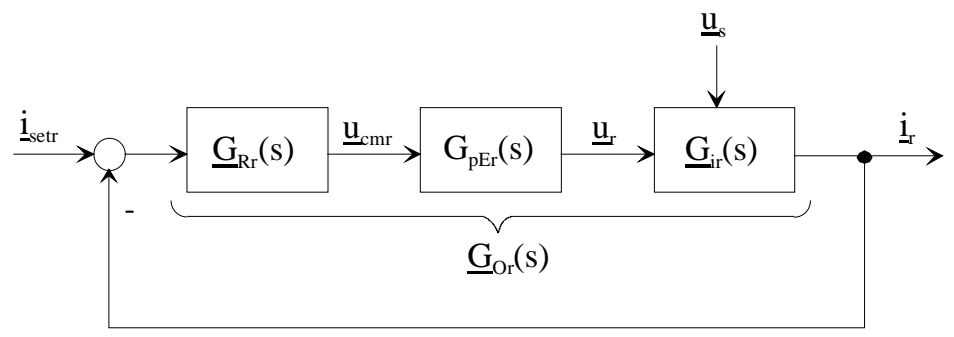

Figure 3.6 : Transfer function block diagram of the rotor current control

$\mathrm{G}_{\mathrm{pEr}}(\mathrm{s})$ is given by

$$
\mathrm{G}_{\mathrm{pEr}}(\mathrm{s})=\frac{\mathrm{u}_{\mathrm{DCr}}}{1+\mathrm{sT}_{\mathrm{pEr}}}
$$

with $\mathrm{u}_{\mathrm{DCr}}$ being the $\mathrm{DC}$-link voltage value referred to the rotor side of the machine.

As was the case in the transformer section (\$2.3.2), the regulator must compensate the complex pole at $1+\left(\mathrm{s}+\mathrm{jf}_{\mathrm{r}} \omega_{\mathrm{n}}\right) \mathrm{T}_{\mathrm{r}}^{\prime}$, and therefore has to be a multivariable one in order to ensure a correct decoupling between the $\mathrm{d}$ and $\mathrm{q}$ axes.

$$
\underline{G}_{\mathrm{Rr}}(\mathrm{s})=\frac{1+\left(\mathrm{jf}_{\mathrm{r}} \omega_{\mathrm{n}}+\mathrm{s}\right) \mathrm{T}_{\mathrm{nr}}}{\mathrm{s} \mathrm{T} \mathrm{T}_{\mathrm{ir}}}
$$


Note that as stated in [8], the coupling I regulators [9] can be suppressed. The former demonstrates that standard PIs with an increased gain give nearly the same performance than a multivariable regulator. This is mainly due to the fact that, because of the low slip of the rotor, the coupled I regulators have little influence. Hence, the I regulators have almost no effect as is the case at synchronous speed.

All the transfer functions are now defined and the open loop transfer function can finally be written.

$$
\underline{G}_{\mathrm{Or}}(\mathrm{s})=\frac{1+\left(\mathrm{jf}_{\mathrm{r}} \omega_{\mathrm{n}}+\mathrm{s}\right) \mathrm{T}_{\mathrm{nr}}}{\mathrm{s} \mathrm{T}_{\mathrm{ir}}} \frac{\mathrm{u}_{\mathrm{DCr}}}{1+\mathrm{s} \mathrm{T}_{\mathrm{pEr}}} \frac{\omega_{\mathrm{n}} \mathrm{T}_{\mathrm{r}}^{\prime}}{\sigma_{\mathrm{M}} \mathrm{x}_{\mathrm{r}}} \frac{1}{1+\left(\mathrm{s}+\mathrm{jf}_{\mathrm{r}} \omega_{\mathrm{n}}\right) \mathrm{T}_{\mathrm{r}}^{\prime}}
$$

As the regulator must follows as accurately as possible the set value, the Meplat criterion is used (\$2.3.1) to calculate $\mathrm{T}_{\mathrm{nr}}$ and $\mathrm{T}_{\mathrm{ir}}$.

$$
\begin{aligned}
& \mathrm{T}_{\mathrm{nr}}=\mathrm{T}_{\mathrm{r}}^{\prime} \\
& \mathrm{T}_{\mathrm{ir}}=2 \frac{\mathrm{u}_{\mathrm{DCr}} \omega_{\mathrm{n}} \mathrm{T}_{\mathrm{r}}^{\prime}}{\sigma_{\mathrm{M}} \mathrm{x}_{\mathrm{r}}} \mathrm{T}_{\mathrm{pEr}}
\end{aligned}
$$

\subsubsection{Stator current control}

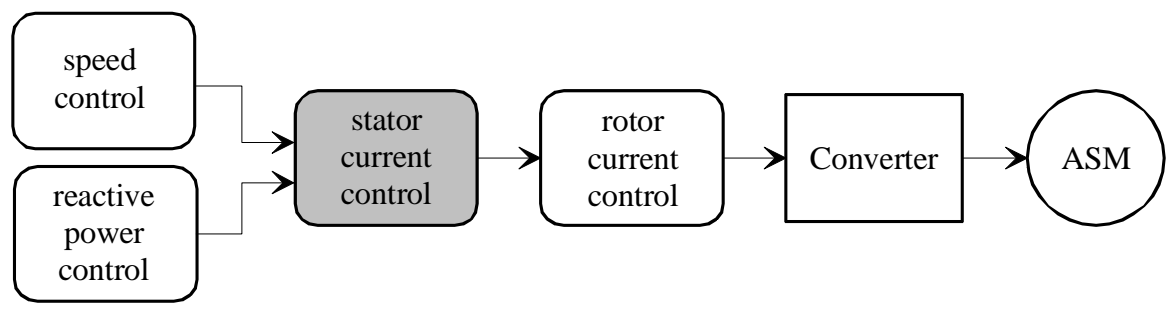

Figure 3.7 : Stator current control

The stator current control is the second internal control as shown in Figure 3.7. Figure 3.8 gives its corresponding transfer function block diagram. In this figure, $\underline{\mathrm{G}}_{\mathrm{is}}(\mathrm{s})$ is the system to be regulated, here the stator side of the machine given by equation (3.19). $\underline{G}_{\mathrm{pEs}}(\mathrm{s})$ is the lag resulting from the sum of all the small time constants, especially the time constant of the rotor current regulator $\left(\mathrm{T}_{\mathrm{pEs}},(3.25)\right)$. Finally, $\underline{G}_{\mathrm{Rs}}(\mathrm{s})$ is the stator current regulator which will be designed. 


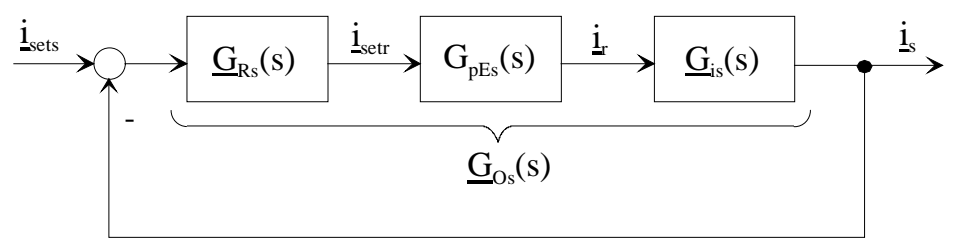

Figure 3.8 : Transfer function block diagram for the stator current control

$\mathrm{G}_{\mathrm{pEs}}(\mathrm{s})$ is defined by (3.25), where $\mathrm{T}_{\mathrm{pEr}}$ is the time constant of the rotor current control.

$$
\mathrm{G}_{\mathrm{pEs}}(\mathrm{s})=\frac{1}{1+\mathrm{s} 2 \mathrm{~T}_{\mathrm{pEr}}}=\frac{1}{1+\mathrm{s} \mathrm{T}_{\mathrm{pEs}}}
$$

From this, as the system has a proportional behaviour, the regulator is chosen as a simple integrator, defined by equation (3.26).

$$
\underline{\mathrm{G}}_{\mathrm{Rs}}(\mathrm{s})=\mathrm{G}_{\mathrm{Rs}}(\mathrm{s})=\frac{1}{\mathrm{~s} \mathrm{~T}_{\mathrm{is}}}
$$

All the transfer functions are now defined and the open loop transfer function can finally be written.

$$
\underline{\mathrm{G}}_{\mathrm{Os}}(\mathrm{s})=\frac{1}{\mathrm{~s} \mathrm{~T}_{\mathrm{is}}}\left(-\frac{\mathrm{x}_{\mathrm{h}}}{\mathrm{x}_{\mathrm{s}}}\right)\left(\frac{1}{1+\mathrm{s} \mathrm{T} \mathrm{T}_{\mathrm{pEs}}}\right)
$$

As the regulator must follow at best the set value, the Meplat criterion (§2.3.1) is used to calculate $\mathrm{T}_{\text {is. }}$.

$$
\mathrm{T}_{\mathrm{is}}=2 \frac{\mathrm{x}_{\mathrm{h}}}{\mathrm{x}_{\mathrm{s}}} \mathrm{T}_{\mathrm{pEs}}
$$




\subsubsection{Speed control}

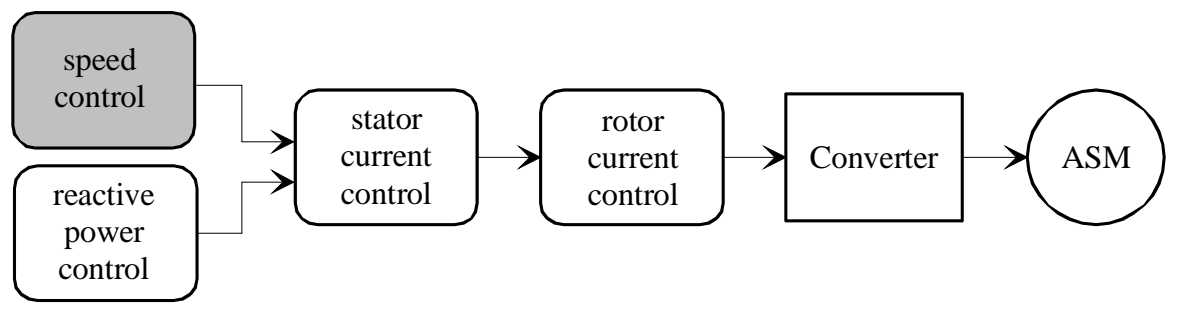

Figure 3.9 : Speed control

Due to the chosen reference frame, the speed regulator only acts in the $\mathrm{d}$ axis of the stator current regulator (Figure 3.9).

Figure 3.10 defines the speed control, where $G_{n}(s)$ is the system to be regulated. $\mathrm{G}_{\mathrm{pEn}}(\mathrm{s})$ is the lag resulting from the sum of all the small time constants, especially the time constant of the stator current regulator $\left(T_{p E n},(3.30)\right)$. Finally, $G_{R n}(s)$ is the speed regulator which will be designed.

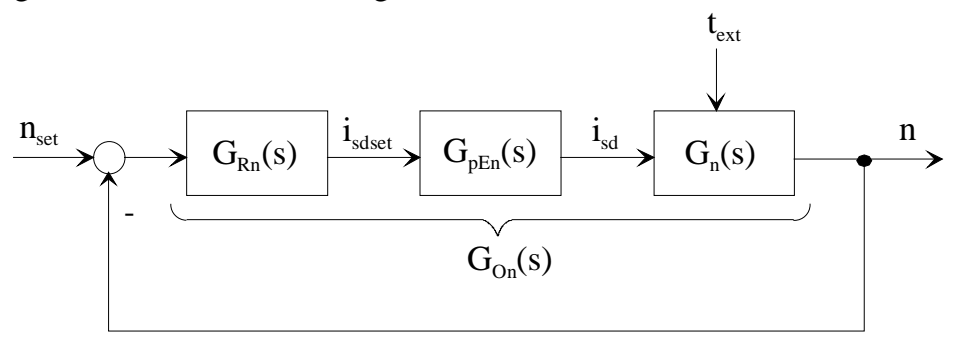

Figure 3.10 : Transfer function block diagram for the speed control

From (3.8)-(3.10), in steady state, by neglecting the ohmic losses, and with $t_{\text {ext }}$ acting as a disturbance, $\mathrm{G}_{\mathrm{n}}(\mathrm{s})$ can be written as

$$
\mathrm{G}_{\mathrm{n}}(\mathrm{s})=\frac{\mathrm{n}}{\mathrm{i}_{\mathrm{sd}}}=\frac{\mathrm{u}_{\mathrm{sd}}}{\mathrm{s} \mathrm{T}_{\mathrm{j}}}
$$

$\mathrm{G}_{\mathrm{pEn}}(\mathrm{s})$ is defined by equation (3.30), where $\mathrm{T}_{\mathrm{pEs}}$ is the time constant of the stator current control.

$$
\mathrm{G}_{\mathrm{pEn}}(\mathrm{s})=\frac{1}{1+\mathrm{s} 2 \mathrm{~T}_{\mathrm{pEs}}}=\frac{1}{1+\mathrm{s} \mathrm{T}_{\mathrm{pEn}}}
$$


From this, the speed regulator is chosen as a PI, and defined by (3.31)

$$
\mathrm{G}_{\mathrm{Rn}}(\mathrm{s})=\frac{1+\mathrm{s} \mathrm{T}_{\mathrm{nn}}}{\mathrm{s} \mathrm{T}_{\mathrm{in}}}
$$

All the transfer functions are now defined and the open loop transfer function can finally be written.

$$
\mathrm{G}_{\mathrm{On}}(\mathrm{s})=\frac{1+\mathrm{s} \mathrm{T}_{\mathrm{nn}}}{\mathrm{s} \mathrm{T}_{\mathrm{in}}} \frac{1}{1+\mathrm{sT}_{\mathrm{pEn}}} \frac{\mathrm{u}_{\mathrm{sd}}}{\mathrm{s} \mathrm{T}_{\mathrm{j}}}
$$

As the system has an integral behaviour, the symmetric criterion (\$2.3.1) is chosen to calculate $\mathrm{T}_{\mathrm{nn}}$ and $\mathrm{T}_{\mathrm{in}}$.

$$
\begin{aligned}
& \mathrm{T}_{\mathrm{nn}}=4 \mathrm{~T}_{\mathrm{pEn}} \\
& \mathrm{T}_{\mathrm{in}}=8 \frac{\mathrm{u}_{\mathrm{sd}}}{\mathrm{T}_{\mathrm{j}}} \mathrm{T}_{\mathrm{pEn}}^{2}
\end{aligned}
$$

\subsubsection{Reactive power control}

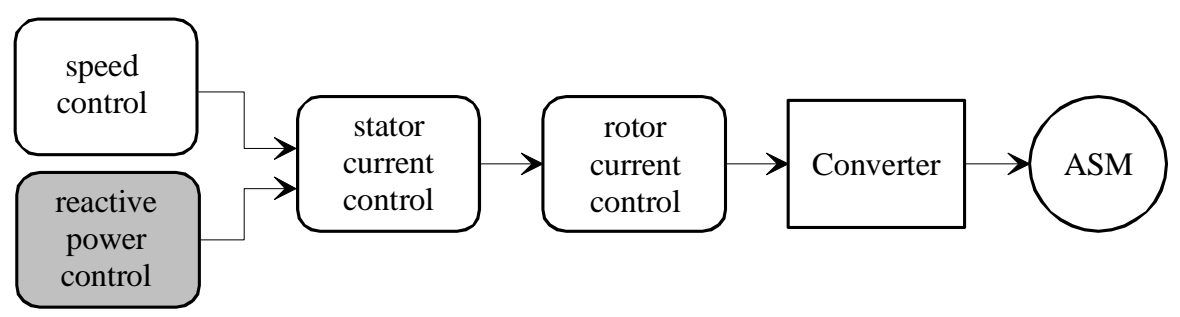

Figure 3.11 : Reactive power control

As was the case for the speed control, due to the chosen reference frame the reactive power regulator only acts in the $\mathrm{q}$ axis of the stator current regulator.

Figure 2.11 defines the reactive power control, where $\mathrm{G}_{\mathrm{q}}(\mathrm{s})$ is the system to be regulated defined by equation (3.11). $\mathrm{G}_{\mathrm{pEq}}(\mathrm{s})$ is the lag resulting from the sum of all the small time constant, especially the time constant of the stator current regulator $\left(\mathrm{T}_{\mathrm{pEq}},(3.36)\right)$. Finally, $\mathrm{G}_{\mathrm{Rq}}(\mathrm{s})$ is the reactive power regulator which will be designed. 


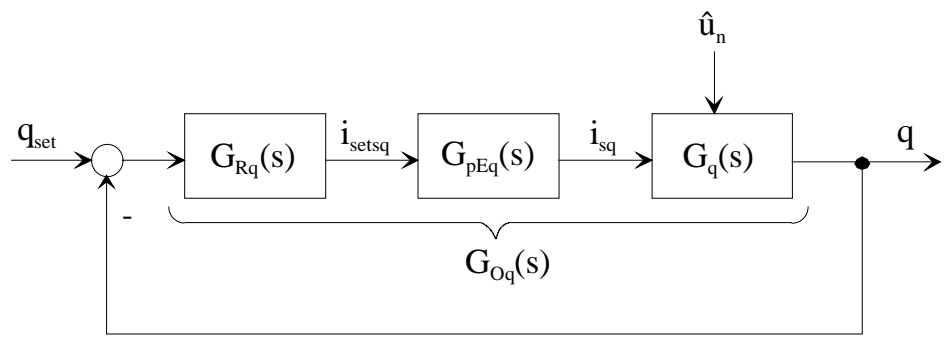

Figure 3.12 : Transfer function block diagram for the reactive power control

From (3.11), with $\hat{u}_{n}$ acting as a disturbance, $\mathrm{G}_{\mathrm{q}}(\mathrm{s})$ can be written as

$$
\mathrm{G}_{\mathrm{q}}(\mathrm{s})=\frac{\mathrm{q}}{\mathrm{i}_{\mathrm{sq}}}=\mathrm{u}_{\mathrm{sd}}
$$

As well as for the speed control (\$3.3.4), $\mathrm{G}_{\mathrm{pEq}}(\mathrm{s})$ is defined by equation (3.36), where $\mathrm{T}_{\mathrm{pEs}}$ is the time constant of the stator current control.

$$
\mathrm{G}_{\mathrm{pEq}}(\mathrm{s})=\frac{1}{1+\mathrm{s} 2 \mathrm{~T}_{\mathrm{pEs}}}=\frac{1}{1+\mathrm{s} \mathrm{T}_{\mathrm{pEq}}}
$$

As the system to be regulated has a proportional behaviour, an I regulator is chosen.

$$
\mathrm{G}_{\mathrm{Rq}}(\mathrm{s})=\frac{1}{\mathrm{~s} \mathrm{~T}_{\mathrm{iq}}}
$$

All the transfer functions are now defined and the open loop transfer function can finally be written.

$$
\mathrm{G}_{\mathrm{Oq}}(\mathrm{s})=\frac{1}{\mathrm{~s} \mathrm{~T}_{\mathrm{iq}}} \frac{1}{1+\mathrm{s} \mathrm{T}_{\mathrm{pEq}}} \mathrm{u}_{\mathrm{sd}}
$$

As the regulator must follow at best the set value, the Meplat criterion (§2.3.1) is used to calculate $\mathrm{T}_{\mathrm{i} 1}$.

$$
\mathrm{T}_{\mathrm{iq}}=2 \mathrm{~T}_{\mathrm{pEq}}
$$




\subsection{Simulations}

\subsubsection{Introduction}

The aim of the present section is to illustrate the behaviour of the machine section control strategy.

After performing different tests with the statement of $\$ 3.3 .2$ relating to the use of standard PIs instead of a multivariable regulator, it appeared that the quality of the decoupling was directly proportional to the gain improvement. The drawback being oscillations of the output command signals in the d-q frame due to the high gain, resulting in non sinusoidal signals in the three phase plane. Hence, depending on the application the gain should be adapted to match as closely as possible the desired performance as a compromise between decoupling and oscillation.

In the following simulation, the transformer side VSI, which should supply the DC-link, is not used. It is replaced by DC sources to ensure a correct testing of the machine side control alone.

The simulation concerns an existing installation in Vianden, with :

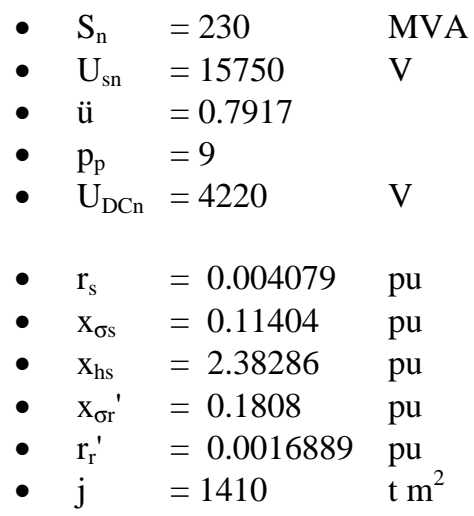




\subsubsection{The Machine Control (SIMSEN)}

Figure 3.13 shows, in SIMSEN, the power parts as well as the control system.

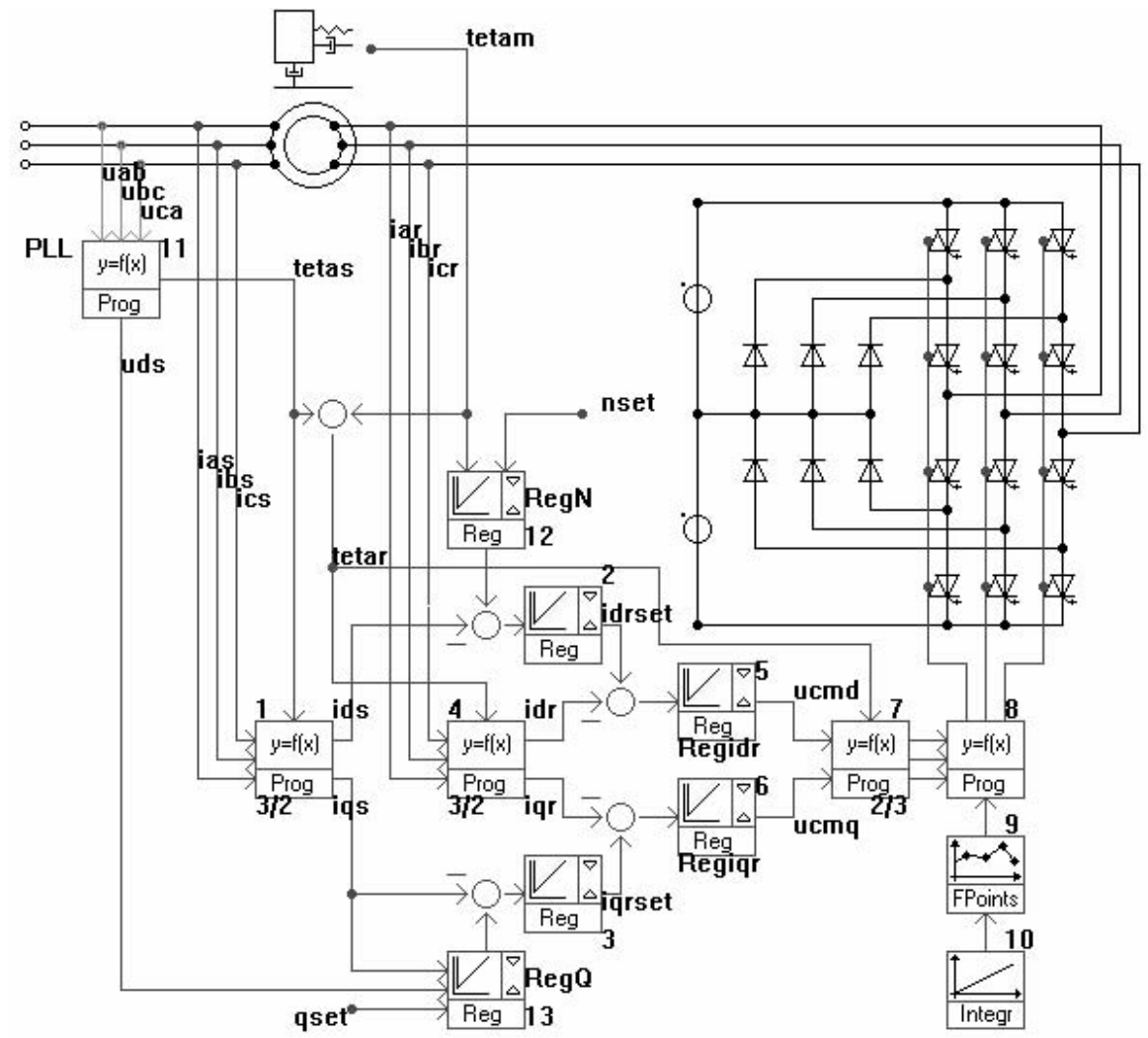

Figure 3.13 : Machine Control in SIMSEN

The 13 blocks in Figure 3.13 correspond to :

1. Park transformation of the stator currents.

2. I regulator for the stator current in the $\mathrm{d}$ axis.

3. I regulator for the stator current in the q axis.

4. Park transformation of the rotor side currents.

5. PI regulator for the rotor current in the $\mathrm{d}$ axis.

6. PI regulator for the rotor current in the $\mathrm{q}$ axis.

7. Inverse Park transformation generating the command signals.

8. Generation of the gate command switching states.

9. Carrier signal generation.

10. Setting of the carrier signal frequency.

11. PLL (Phase Locked Loop) generating the $\theta_{\mathrm{s}}$ angle (Chapter 5).

12. PI regulator for the speed control.

13. I regulator of the reactive power control. 
The phase currents $i_{\mathrm{as}}, i_{\mathrm{bs}}, i_{\mathrm{cs}}$ are measured on the stator side of the machine. A Park transformation is applied to these currents (block 1) with the angle $\theta_{\mathrm{s}}$ coming from the PLL (block 11).

The currents $i_{d s}$ and $i_{q s}$ are subtracted from their respective set value ( $i_{\text {setds }}, i_{\text {setqs }}$ ). $i_{\text {setds }}$ comes from the speed regulator (block 12) and $i_{\text {setqs }}$ from the reactive power regulator (block 13).

The phase currents $i_{a r}, i_{b r}, i_{c r}$ are measured on the rotor side of the machine. A Park transformation is applied to these currents (block 4) with the angle $\theta_{\mathrm{r}}$ coming from the PLL (block 11).

The currents $i_{d r}$ and $i_{q r}$ are subtracted from their respective set value ( $i_{\text {setdr }}, i_{\text {setqr }}$ ). $i_{\text {setdr }}$ comes from the stator current regulator in the d-axis (block 2) and $i_{\text {setgr }}$ from the stator current regulator in the q-axis (block 3).

An inverse Park transformation (block 7) is applied to the outputs $\left(\mathrm{u}_{\mathrm{cmd}}, \mathrm{u}_{\mathrm{cmq}}\right)$ of the rotor current regulators (block 5-6).

The blocks 9-10 generate the carrier signal, which will be compared to command signals $\left(\mathrm{u}_{\mathrm{cma}}, \mathrm{u}_{\mathrm{cmb}}, \mathrm{u}_{\mathrm{cmc}}\right)$ in block 8 to produce GTOs gate switching states.

\subsubsection{Transient simulation}

The aim of the transient simulations is to validate the proposed control strategy. According to the design of the control and to the system requirements, three different transients will be performed to validate the behaviour of each regulator as well as the correct decoupling between the speed and the reactive power controls with the statement of \$3.3.2.

Actually, as the speed and reactive power regulators must follow set values, a speed down step and reactive power steps are performed. The latter being performed while the former is still acting. Finally, the behaviour of the speed regulator in the case of a disturbance $\left(\mathrm{t}_{\mathrm{ext}},(3.8)\right)$ is checked.

The steady state starting point is in pump mode at a speed of $1.1 \mathrm{pu}$, with an external torque of $0.5 \mathrm{pu}$, a stator reactive power of $0 \mathrm{pu}$. At $0.05 \mathrm{~s}$ the speed set value changes from 1.1 to $0.9 \mathrm{pu}$. Then at $0.2 \mathrm{~s}$ the reactive power set value goes from 0 to $-0.25 \mathrm{pu}$ and back to 0 at time $1.4 \mathrm{~s}$.

Finally, at $1.6 \mathrm{~s}$ the external torque changes from 0.5 to $-0.5 \mathrm{pu}$. This means that the machine goes from pump to turbine mode. Obviously this is not possible in practice where a change in the rotation direction must be made. Anyhow, this permits the verification of the response of the system to a large external torque variation $(1 \mathrm{pu})$. 


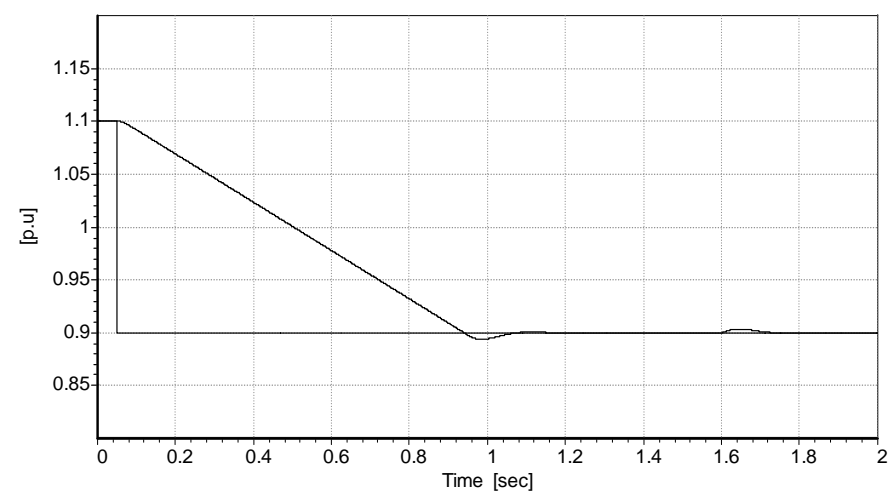

Figure 3.14 : Speed and its set value

Figure 3.14 shows the speed and its set value. When changing the set value to $0.9 \mathrm{pu}$, the speed follows it through a ramp. This is due to the fact that the available mechanical torque is limited and therefore, once the maximum torque available reached, under a constant torque, speed can only vary constantly.

The speed variation found at about $1.6 \mathrm{~s}$ comes from the change in the external torque. This is assimilated to a disturbance for the speed regulator, which rejects it quickly ensuring that the speed stays nearly constant.

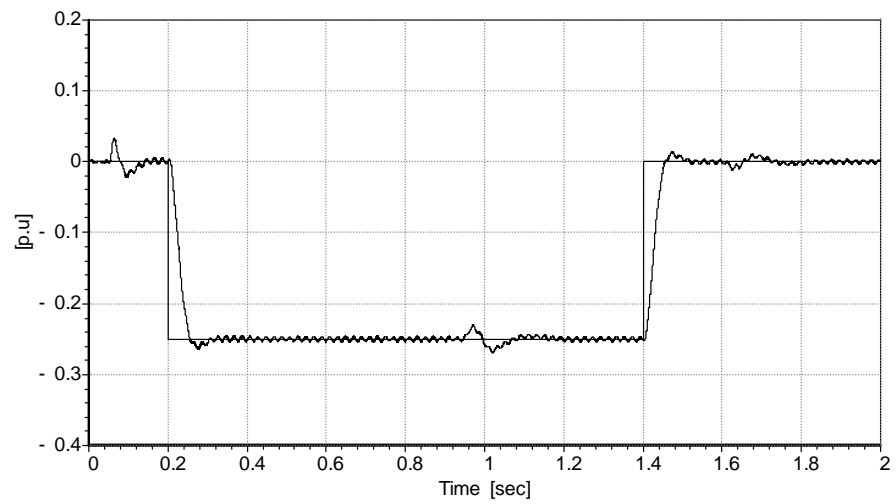

Figure 3.15 : Reactive power and its set value

Figure 3.15 shows the reactive power and its set value. Remember that the reactive power steps are performed during the speed down step. When changing the set value, the reactive power follows it correctly, rapidly, and with nearly no overshoot. Furthermore, it can be seen that even by using standard PIs (\$3.3.2), the decoupling is correct, with only a small variation of $\mathrm{q}$ under very large active power variations (Figure 3.16). A look back at Figure 3.14 confirms this, as no speed variation is found when varying the reactive power. 


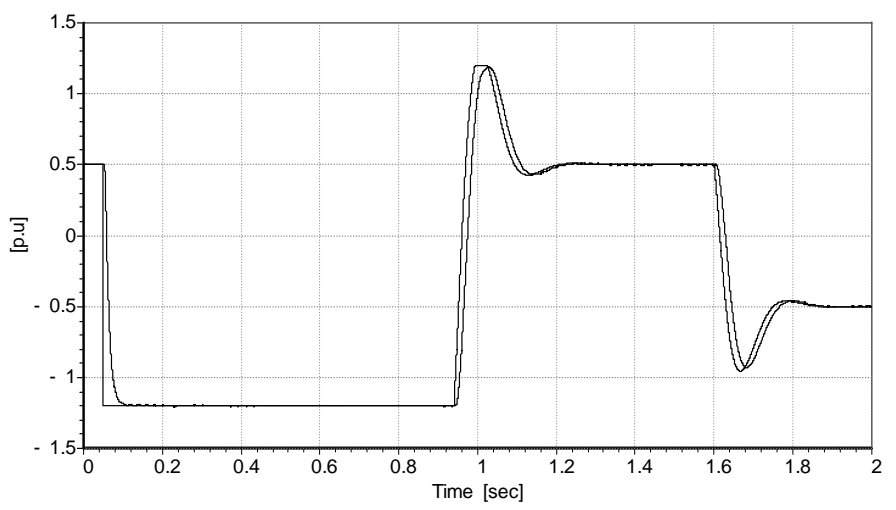

Figure 3.16 : Active stator current (d axis) and its set value

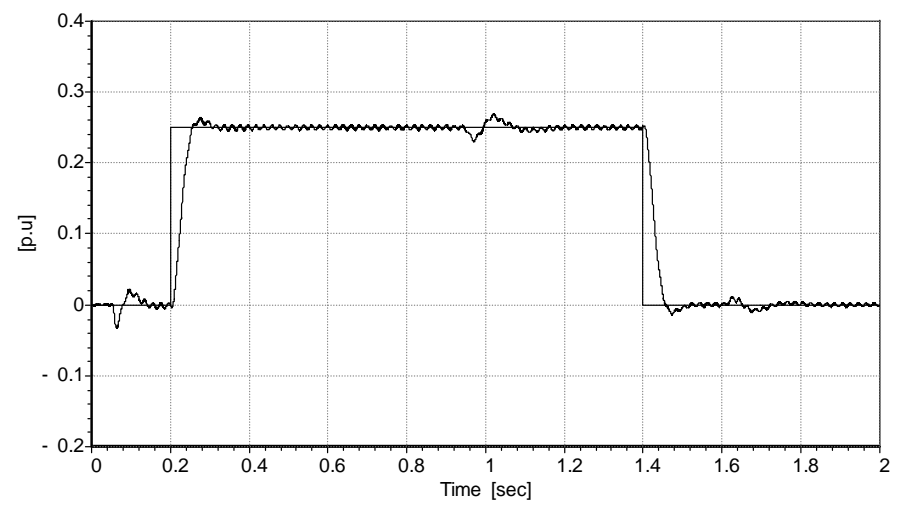

Figure 3.17 : Reactive stator current (q axis) and its set value

Figure 3.16 and Figure 3.17 show respectively the active and reactive stator currents.

In Figure 3.17 it can be seen, as expected from equation (3.11), that under nominal conditions, the reactive power is equal to minus the reactive stator current.

From equation (3.10), the active current equals the active power under nominal conditions. Therefore, Figure 3.16 also represents the active power, which is also the same as the air-gap torque (Figure 3.21). 


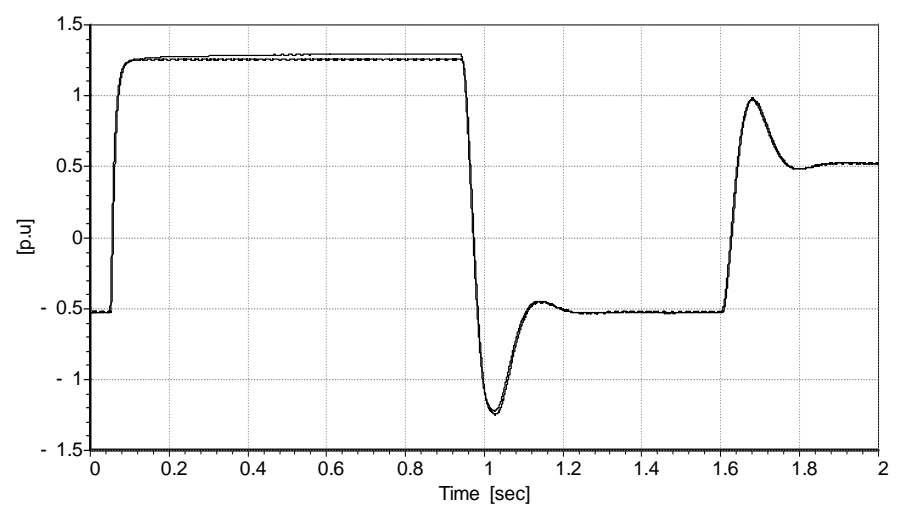

Figure 3.18 : Active rotor current (d axis) and its set value

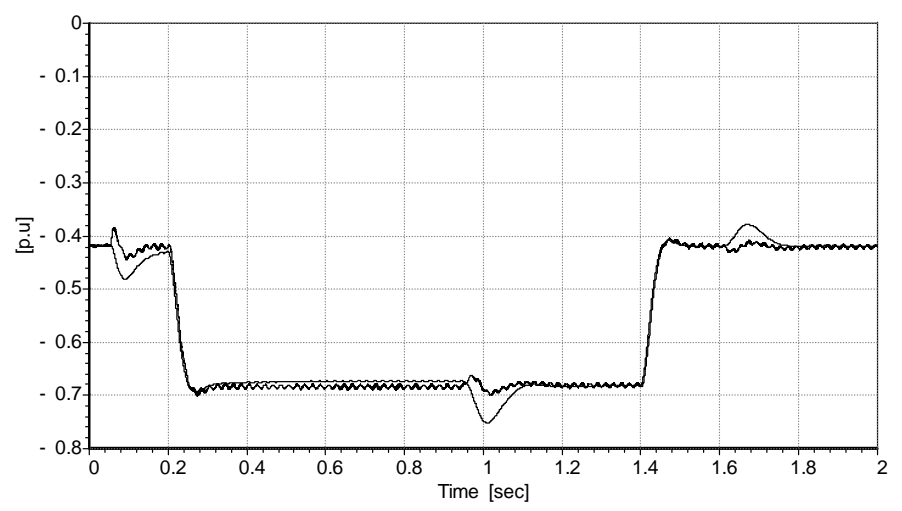

Figure 3.19 : Reactive rotor current (q axis) and its set value

Figure 3.18 and Figure 3.19 show respectively the active and reactive rotor currents. In both axes, the regulators react correctly to either set value changes or to disturbances. This proves to be correct, even in large slip, validating the simplification of the multivariable regulator to two single PIs done in §3.3.2.

Figure 3.20 shows the rotor phase currents. This figure is interesting as it shows the decrease of the rotor currents frequency down to the synchronous speed, as it is linked to the mechanical speed and to the slip. When this point is reached, at about $0.5 \mathrm{~s}$, the machine passes from a hyper-synchronous mode to a sub-synchronous mode. Therefore, the rotor currents change their phase succession as the slip changes its sign. This means that the rotor current phasor changes its rotation direction. Past this point, the rotor currents frequency increases again. 


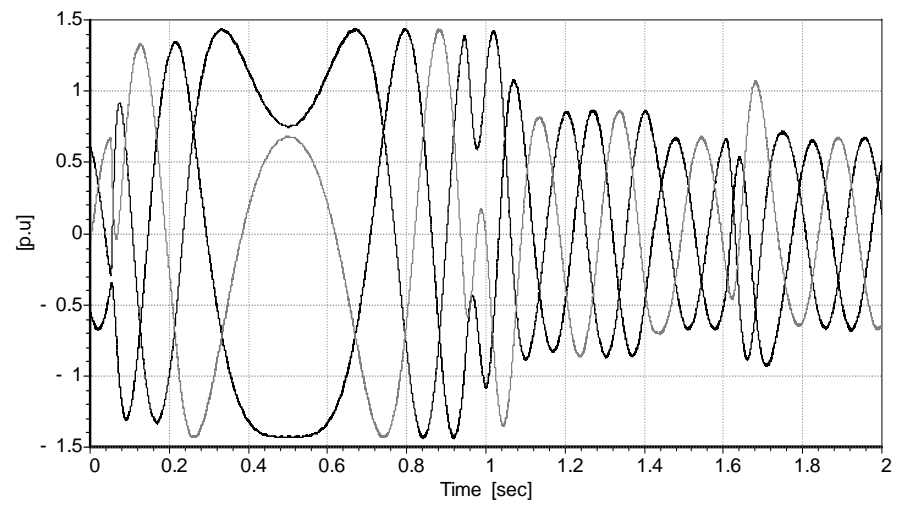

Figure 3.20 : Rotor phase currents

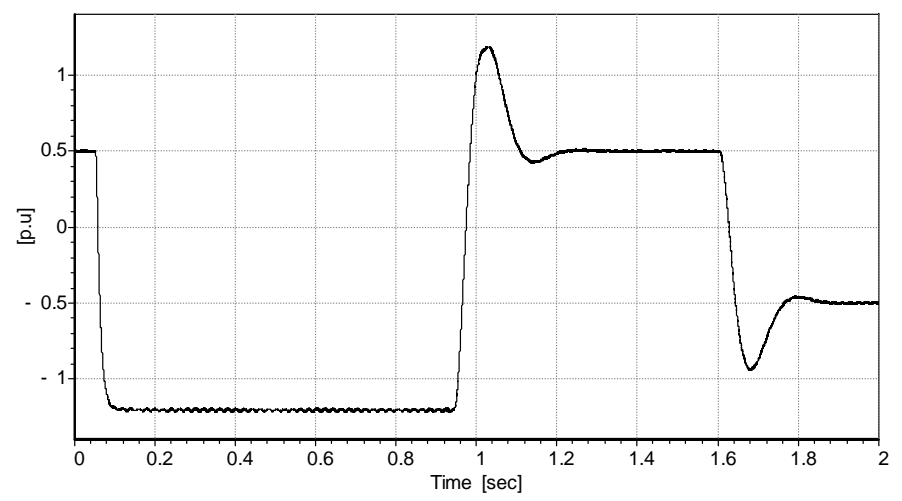

Figure 3.21 : Air gap torque

The electromagnetic torque is given in Figure 3.21. When the speed set value changes at $0.1 \mathrm{~s}$, the torque reverts to -1.2 pu to slow down the machine as quickly as possible. Then, at about 0.95 , when the speed reaches its set value, the torque increase and exceeds the external torque $(0.5 \mathrm{pu})$ to stop the machine speed decrease. Finally, the torque stabilizes at about $1.2 \mathrm{~s}$ at the same value as at the start.

At $1.6 \mathrm{~s}$ the mode changes virtually from pump to turbine. The regulator corrects this perturbation in about $250 \mathrm{~ms}$. Even though such variations in the external torque are not found in practice, due to the very large time constants of the hydraulic parts, it validates the designed regulators. 


\subsection{Conclusion}

The simulation results validate the correct design of the regulators. Even by using the simplification for the multivariable regulator to two PIs, an acceptable decoupling is found between the speed and the reactive power controls.

The speed and reactive power regulators react rapidly to the set values changes. Even under a rapid large disturbance of the external torque (1pu) the speed is kept to a constant value, even if such kind of disturbances are not possible in practice as they are limited by the hydraulic time constants. Therefore, a previous statement which was that the use of the classical control was matching the needed requirement is validated.

As the DC-link was supplied by DC sources, the whole system behaviour must still be checked as problems of interactions between the transformer and the machine controls may occur. This will be done in the practical section (Chapter 5), where simulations of the overall system will be compared to measurements. 


\section{Chapter 4 \\ DC-link DC Unbalance Control}

\subsection{Introduction}

The present chapter deals with the DC-link DC unbalance control, which is the active regulation of the voltage dispatching between the DC-link capacitors.

\subsection{Basics for the DC-link DC unbalance control}

\subsubsection{DC-Link oscillation}

One of the main drawbacks of the 3-level VSI is the possibility of having, in the presence of asymmetries, the creation of an unbalanced DC component present in each capacitor of the DC link, which must be distinct from the natural DC-link oscillation. In fact, an oscillation (pulsating component) between the capacitors of the DC-link is always present, and is assumed as being "natural", not removable, inversely proportional to the capacitors size (see equation (4.2)) and dependant on the operating point [4].

The oscillation of a VSI is composed of frequencies being all the odd multiples of the AC side $3^{\text {rd }}$ harmonic, with decreasing amplitudes. As in the present study two VSIs are put back-to-back with different AC-side frequencies; the resulting DClink oscillation is composed of frequencies being the odd multiples of both AC-side $3^{\text {rd }}$ harmonics as given in equation (4.1) and illustrated by Figure 4.6 to Figure 4.9 in $\$ 4.2 .4$.

$$
\mathrm{f}_{\text {DCside }}=\sum_{\mathrm{i}} 3 \cdot \mathrm{f}_{\mathrm{n}} \cdot \mathrm{i}+\sum_{\mathrm{i}} 3 \cdot \mathrm{f}_{\mathrm{n}} \cdot|1-\mathrm{n}| \cdot \mathrm{i} \quad \text { with } \mathrm{i}=1,3,5,7 \ldots
$$

where $\mathrm{n}$ is the machine mechanical speed in $\mathrm{pu}$.

It is important to note that for a motor speed close to the synchronous speed, voltage pulsating components with very low frequencies appear. As shown later, these very low frequencies components must not be considered as a DC component by the control strategy proposed. 


\subsubsection{NP-Current $i_{0}$, driving force for the DC-Side oscillation}

The generation of the NP (Neutral Point) current is widely discussed in [4]. As a recall, it can be said that the NP current is built out of the convolution between the NP switching states with the phase currents. The NP switching states are when the VSI voltages are linked to the NP (when higher and lower GTOs are "off"). Hence, the NP current is dependant on the operating point of the system, as the phase shift between the voltages and the currents depends on the operating point.

As an illustration, Figure 4.2 shows the NP current generation of one phase for a simple command, for a pure reactive operating point. The light grey signal is the voltage, the black signal the current and the black bold signal the NP current generated by this phase. Figure 4.3 shows the overall NP current (black bold signal) resulting from the sum of all three phase NP currents. The same example is given in Figure 4.4 and Figure 4.5 for a carrier based PWM.

The NP current $i_{0}$ is the driving force for the oscillation in the DC-link voltages $\mathrm{u}_{\mathrm{DC} 1}$ and $\mathrm{u}_{\mathrm{DC} 2}$, given by equation (4.2). The integration ratio between the current and the voltage in this equation implies that the DC-link oscillation is usually only of low amplitude.

$$
\begin{aligned}
& \mathrm{u}_{\mathrm{DC} 1}=\frac{\mathrm{u}_{\mathrm{DC}}}{2}-\frac{1}{2} \cdot \frac{1}{\mathrm{c}} \int \mathrm{i}_{0} \mathrm{dt}+\text { const } \\
& \mathrm{u}_{\mathrm{DC} 2}=\frac{\mathrm{u}_{\mathrm{DC}}}{2}+\frac{1}{2} \cdot \frac{1}{\mathrm{c}} \int \mathrm{i}_{0} \mathrm{dt}+\text { const }
\end{aligned}
$$

Also note that obviously, the third harmonic generation in the DC-link is self explanatory by the NP current generation shown in Figure 4.3 and Figure 4.5. Of course, in steady state and by assuming that the switching shape has symmetry of a quarter of a period, the NP current is periodic with no DC component $\left(\overline{\mathrm{i}}_{0}=0\right)$.

As Figure 4.1 shows it, and due to Kirchoff's law, if $\overline{\mathrm{i}}_{\mathrm{DCc} 1} \neq \overline{\mathrm{i}}_{\mathrm{DC} 2}$ then $\overline{\mathrm{i}}_{0} \neq 0$. Also, $\overline{\mathrm{u}}_{\mathrm{DC} 1} \neq \overline{\mathrm{u}}_{\mathrm{DC} 2}$ as the respective capacitor charging and/or discharging currents $\overline{\mathrm{i}}_{\mathrm{DCc} 1}$ and $\overline{\mathrm{i}}_{\mathrm{DCc} 2}$ are not equal.

Therefore, a DC component is present in $\mathrm{i}_{0}$ only in presence of an unbalanced DC component in the DC-link voltages.

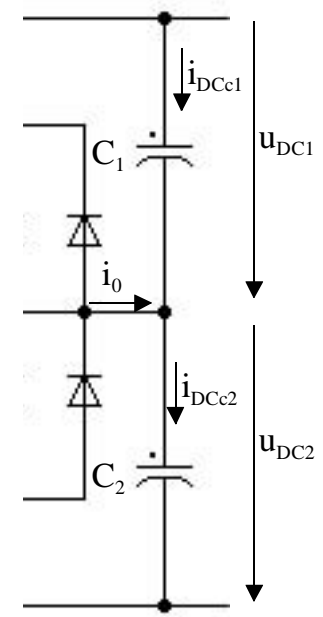

Figure 4.1 


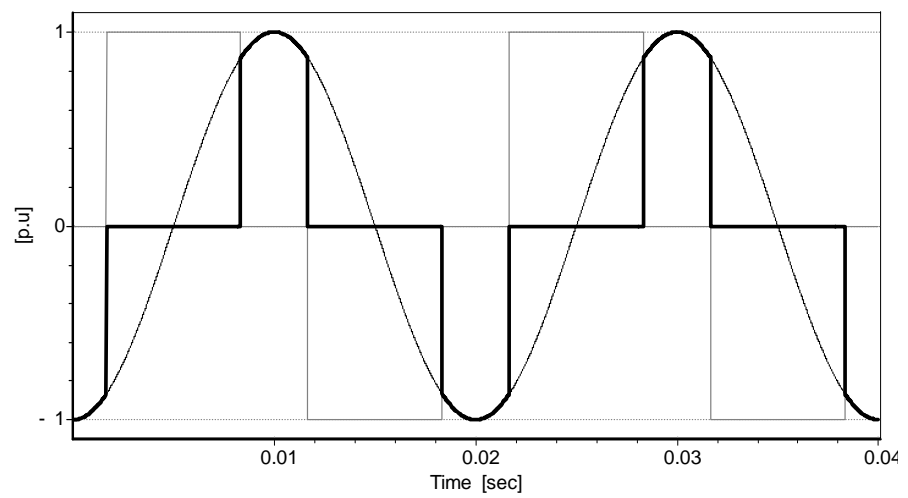

Figure 4.2 : NP current generation of one phase for a simple command

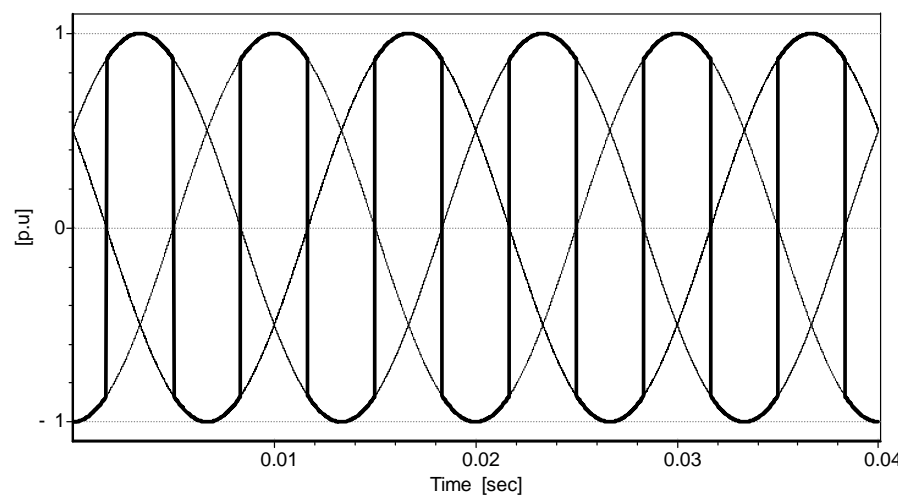

Figure 4.3 : NP current generated by the sum of the 3 phase NP currents

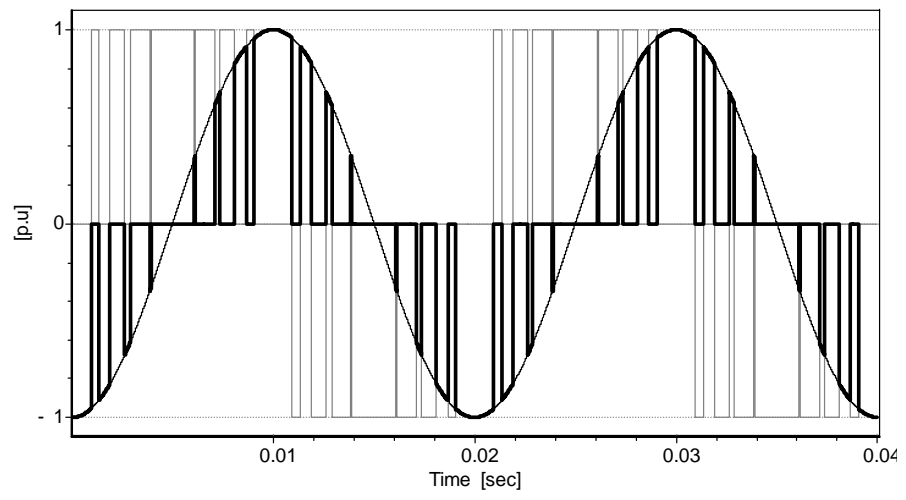

Figure 4.4 : NP current generation of one phase for a PWM command 


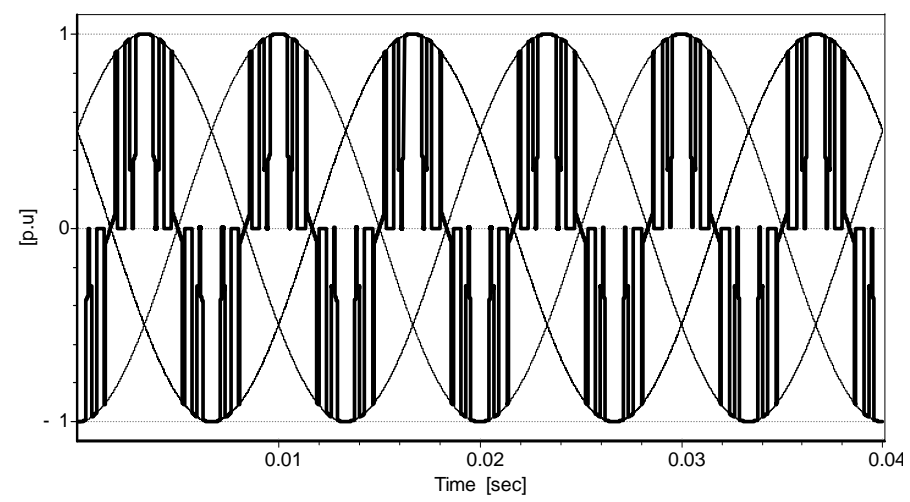

Figure 4.5 : NP current generated by the sum of the 3 phase NP currents

\subsubsection{DC-link DC unbalance and the self balancing ability}

As stated in $\$ 4.2 .1$, the oscillation between the capacitors is considered to be irremovable, assumed as being balanced (symmetrical), and with its amplitude dependant on the capacitors size and on the operating point.

Hence, the real drawback is found when over this natural oscillation, an unbalanced DC component appears between each capacitor. The 3-level VSI naturally compensates such an unbalanced DC component by causing a negative sequence $2^{\text {nd }}$ AC side current harmonic to occur, which will counteract its driving force. Note that multiples of that $2^{\text {nd }}$ harmonic are also found with decreasing amplitudes.

It can be said that an unbalanced DC component is predominantly caused by :

- Transient load steps.

- Transients in the AC-system line voltages.

- Even numbered AC-system line voltages harmonics.

- Switching inaccuracies or dissymmetry.

Due to the power range of the present application, the main source for an unbalance DC component are transient load steps, caused by the machine (rotor) control.

Note that even numbered AC-system line voltages harmonics cause the largest unbalance DC component source. 
In case of low power drive systems, the natural self-balancing ability is effective enough. This is due to the relative high values of the resistances present in low power systems. For large power units, this natural effect is too weak, and must be amplified. This is the aim of the regulation strategy proposed later on.

The control algorithms of the overall DC-link voltage and of the DC unbalance between both capacitor voltages are completely separated. For the overall DC-link voltage control (Chapter 2), the sum of both capacitor voltages is used, whereas the difference $\left(\mathrm{u}_{\mathrm{DC} 1}-\mathrm{u}_{\mathrm{DC} 2}\right)$ is used for the DC unbalance control, and more precisely the $\mathrm{DC}$ value of this difference $\left(\mathrm{u}_{\mathrm{DCdiffo}}\right)$.

$$
\mathrm{u}_{\mathrm{DCdiff}}=\mathrm{u}_{\mathrm{DC} 1}-\mathrm{u}_{\mathrm{DC} 2} \quad \mathrm{u}_{\mathrm{DCdiff}}=\mathrm{DC} \text { component of } \mathrm{u}_{\mathrm{DCdiff}}
$$

$\mathrm{u}_{\mathrm{DCdiff}}$ includes the same harmonics with the same frequencies as $\mathrm{u}_{\mathrm{DC} 1}$ and $\mathrm{u}_{\mathrm{DC} 2}$. In the case of a DC unbalance between $\mathrm{u}_{\mathrm{DC} 1}$ and $\mathrm{u}_{\mathrm{DC} 2}$, a DC component ( $\mathrm{u}_{\mathrm{Dcdiff} 0}$ ) appears in $\mathrm{u}_{\text {Dcdiff. }}$

\subsubsection{Simulations}

Two simulations of the whole drive are presented in this section. Figure 4.6 and Figure 4.7 correspond to a pump operation (mechanical torque $-0.6 \mathrm{pu}$, speed of $1.1 \mathrm{pu}$, machine and transformer reactive powers zero), whereas Figure 4.8 and Figure 4.9, correspond to a generator operation (mechanical torque $0.8 \mathrm{pu}$, speed of $0.98 \mathrm{pu}$, machine reactive power $-0.4 \mathrm{pu}$ and no transformer reactive power).

Figure 4.6 and Figure 4.8 show $\mathrm{u}_{\mathrm{DC} 1}, \mathrm{u}_{\mathrm{DC} 2}$ and $\mathrm{u}_{\mathrm{DCdiff}}$ for both cases, whereas Figure 4.7 and Figure 4.9 show the corresponding Fourier analysis of $u_{D C d i f f}$.

As expected, the Fourier analysis of Figure 4.7 shows the $3^{\text {rd }}$ harmonic coming from the transformer side $(150 \mathrm{~Hz})$, as well as the $3^{\text {rd }}$ harmonics coming from the rotor side. For a speed of $1.1 \mathrm{pu}: 15 \mathrm{~Hz}, 45 \mathrm{~Hz}, 75 \mathrm{~Hz} \ldots$

The Fourier analysis of Figure 4.9 shows the $3^{\text {rd }}$ harmonic coming from the transformer side $(150 \mathrm{~Hz})$, and the $3^{\text {rd }}$ harmonics coming from the rotor side. For a speed of $0.98 \mathrm{pu}: 3 \mathrm{~Hz}, 9 \mathrm{~Hz}, 15 \mathrm{~Hz} \ldots$ 
Operating point for case 1

speed of $1.1 \mathrm{pu}$ - torque of $0.6 \mathrm{pu}$

machine reactive power of $0 \mathrm{pu}$ - transformer reactive power of $0 \mathrm{pu}$

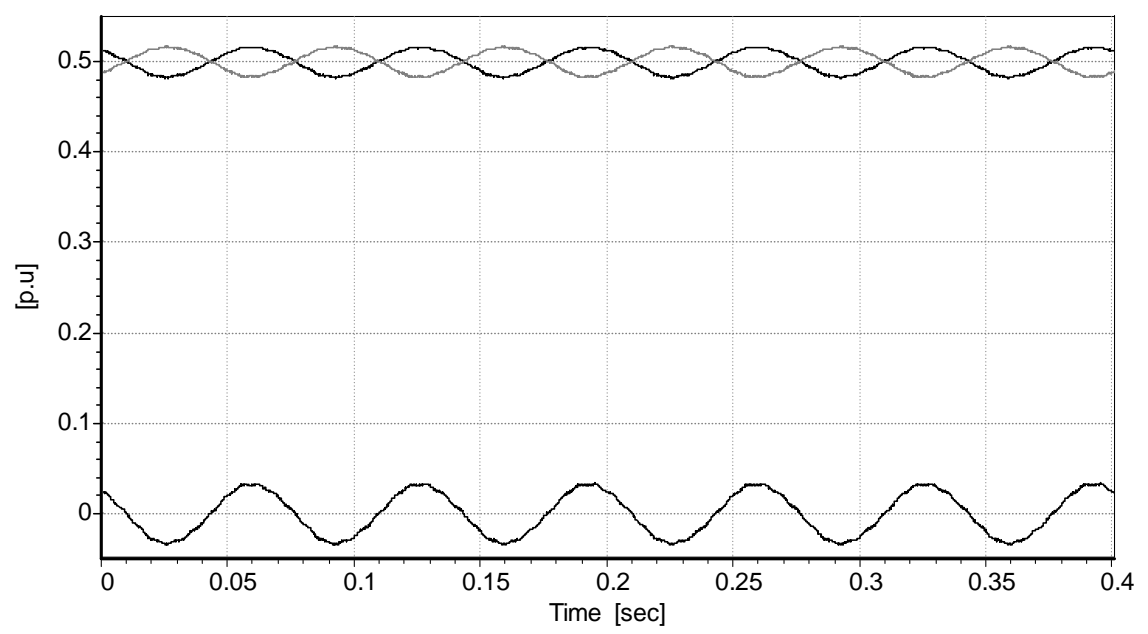

Figure 4.6 : $\mathrm{u}_{\mathrm{DC} 1}$ and $\mathrm{u}_{\mathrm{DC} 2}$ (top), and $\mathrm{u}_{\mathrm{Dcdiff}}$ (bottom)

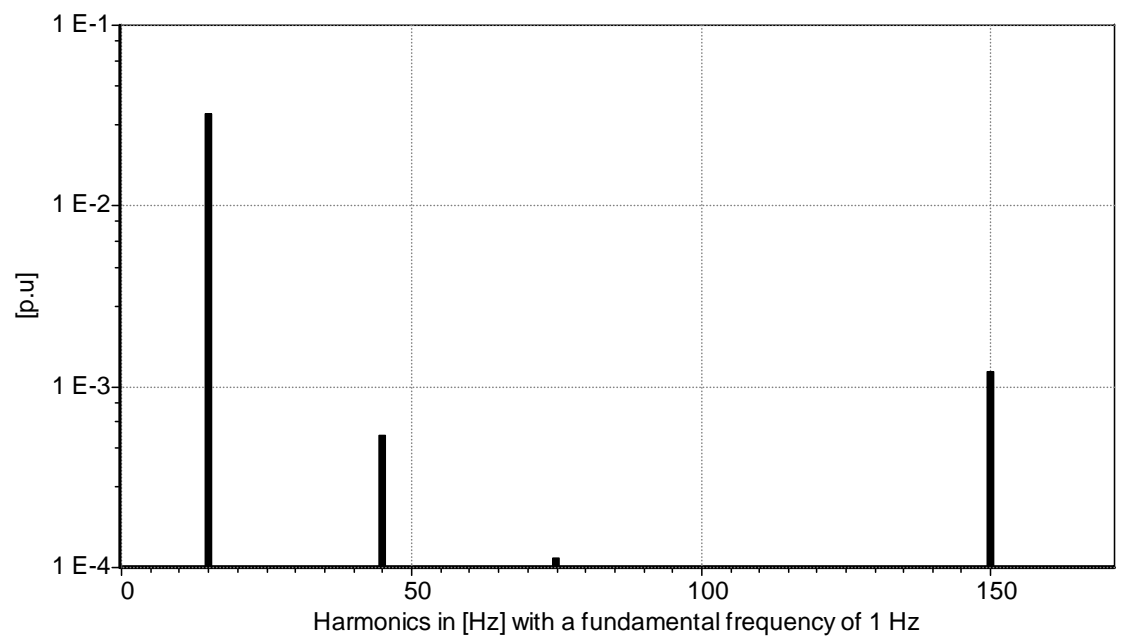

Figure 4.7 : Fourier series decomposition of $u_{\text {Dcdiff }}$ 
Operating point for case 2

speed of $0.98 \mathrm{pu}$ - torque of $0.8 \mathrm{pu}$

machine reactive power of $-0.8 \mathrm{pu}$ - transformer reactive power of $0 \mathrm{pu}$

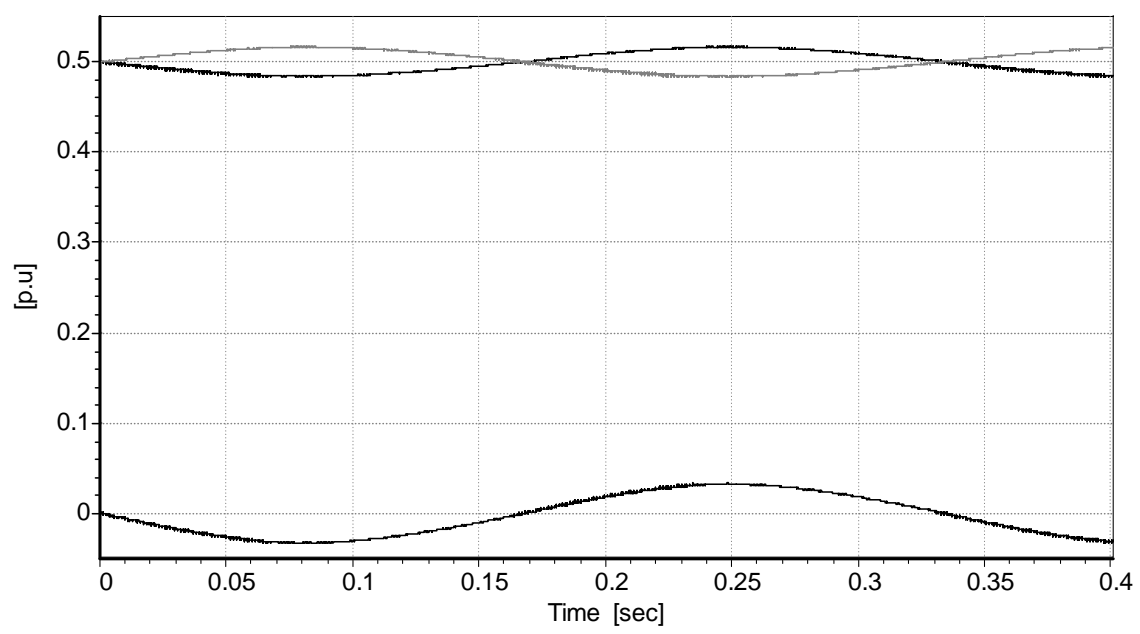

Figure $4.8: \mathrm{u}_{\mathrm{DC} 1}$ and $\mathrm{u}_{\mathrm{DC} 2}(\mathrm{top})$, and $\mathrm{u}_{\mathrm{Dcdiff}}$ (bottom)

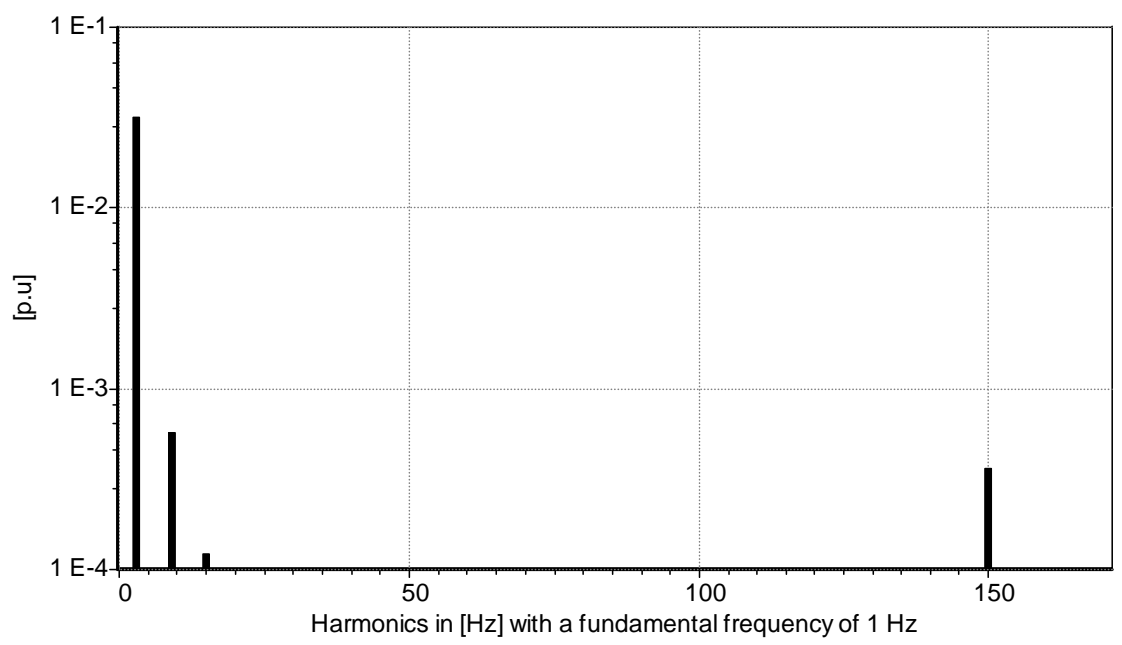

Figure 4.9 : Fourier series decomposition of $\mathbf{u}_{\text {Dediff }}$ 


\subsection{DC component extraction filter (retrieving $\left.u_{D C d i f f o}\right)$}

\subsubsection{Filter design}

This section presents the method used to correctly extract $\mathrm{u}_{\text {DCdiffo }}$ from $\mathrm{u}_{\text {DCdiff }}$. In order to economise calculation time and to ensure an easy implementation in a DSP, the filters used here are only of low order.

Due to the fact that the frequencies on both sides are not in the same range, the problem is decomposed in two steps : filtering the frequencies coming from the transformer side $(a)$, and filtering of the frequencies coming from the rotor side $(b)$.

It is important to say that the extraction of $\mathrm{u}_{\mathrm{DCdiff}}$ must be performed as quickly as possible to ensure a rapid regulation. It is therefore not possible to apply an FFT or to use a simple low pass filter, as both methods would require a large time constant especially at mechanical speeds close to the synchronous speed, which would not match the requirements of short time constants needed for acceptable regulation.

Step (a) (transformer side) : first order low pass filter

For the frequencies coming from the transformer side, a simple first order low pass filter can be used as the frequencies are fixed. It is defined by equation (4.4).

$$
\mathrm{H}_{\text {lowpass }}(\mathrm{s})=\frac{1}{1+\mathrm{s} \mathrm{T}_{\mathrm{lp}}}
$$

where $\mathrm{T}_{\mathrm{lp}}$ is the low pass time constant and $\frac{1}{\mathrm{~T}_{\mathrm{lp}}}$ the cut-off frequency.

In the case of a $50 \mathrm{~Hz}$ network frequency, a $\mathrm{T}_{\mathrm{lp}}$ of $0.02 \mathrm{~s}$ is chosen to remove 150 $\mathrm{Hz}$ and higher frequencies (Figure 4.10). This is a good compromise between cut-off and regulation speed. 


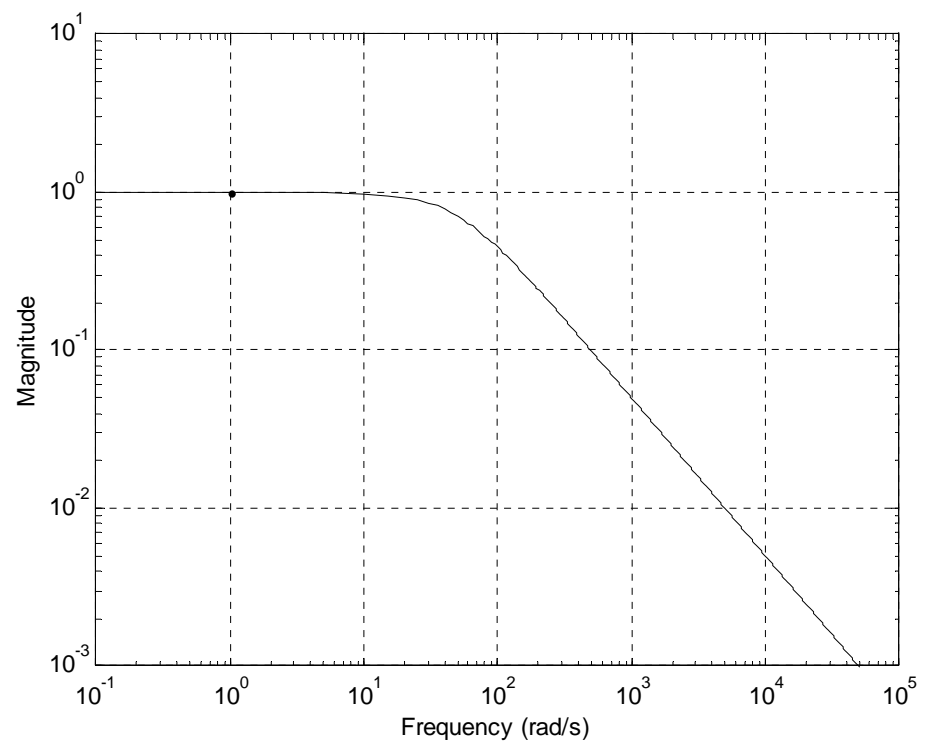

Figure 4.10 : Frequency response of the low pass filter with a time constant of $0.02 \mathrm{~s}$

Step (b) (rotor side) : adaptable notch filter

As already mentioned in $\$ 4.2 .1$, the DC link voltages $u_{\mathrm{DC} 1}$ and $\mathrm{u}_{\mathrm{DC} 2}$ contain pulsating components with very low frequencies at speeds close to the synchronous speed. Therefore, an adaptable notch filter is used. It is defined by equation (4.5).

$$
\mathrm{H}_{\text {notch }}(\mathrm{s})=\frac{\mathrm{s}^{2}+\omega_{0}^{2}}{\mathrm{~s}^{2}+\mathrm{s} \mathrm{K} \omega_{0}+\omega_{0}^{2}}
$$

where $\omega_{0}$ is the central or also stopped angular frequency, and $\mathrm{K}$ the depth as well as the width of the stopped angular frequency, as shown in Figure 4.11.

The frequency response of the notch filter defined by equation (4.5), with different $\mathrm{K}$ and $\mathrm{f}_{0}$ is given in Figure 4.11 and Figure 4.12. 


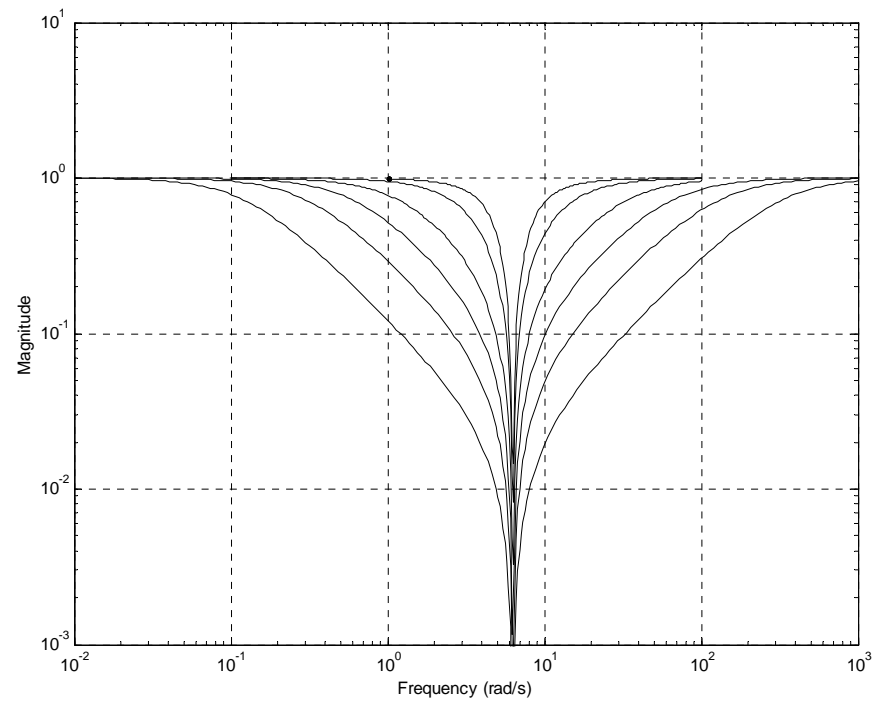

Figure 4.11 : Frequency response of the notch filter with a variation of $K$ $f_{0}=1 \mathrm{~Hz}$ and $\mathrm{K}=1,2,5,10,20,50$

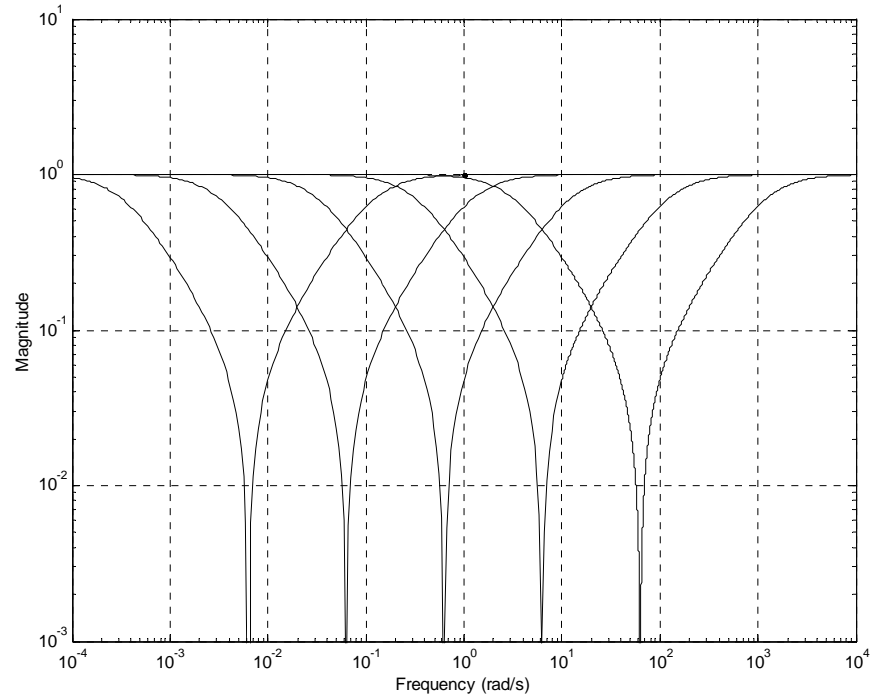

Figure 4.12 : Frequency response of the notch filter with a variation of $f$ $\mathrm{K}=20$ and $\mathrm{f}_{0}=0.001,0.01,0.1,1,10 \mathrm{~Hz}$ 
Both filters are combined by multiplying their transfer functions. This leads to the proposed filter according to equation (4.6).

$$
\mathrm{H}_{\text {filter }}(\mathrm{s})=\frac{\mathrm{s}^{2}+\omega_{0}^{2}}{\mathrm{~T}_{\mathrm{lp}} \mathrm{s}^{3}+\left(1+\mathrm{T}_{\mathrm{lp}} \mathrm{K} \omega_{0}\right) \mathrm{s}^{2}+\left(\omega_{0} \mathrm{~K}+\omega_{0}^{2} \mathrm{~T}_{\mathrm{lp}}\right) \mathrm{s}+\omega_{0}^{2}}
$$

Of course more complicated filters (Chebyshev, Butterworth, ...) could be designed. However, the current $3^{\text {rd }}$ order filter appears to be an easy solution fulfilling the requirements, with the advantage of taking only a short calculation time for the implementation in a DSP, as well as giving an accurate adaptable filtering in the light of the result presented in §4.3.2.

Figure 4.13 shows the frequency response of equation (4.6).

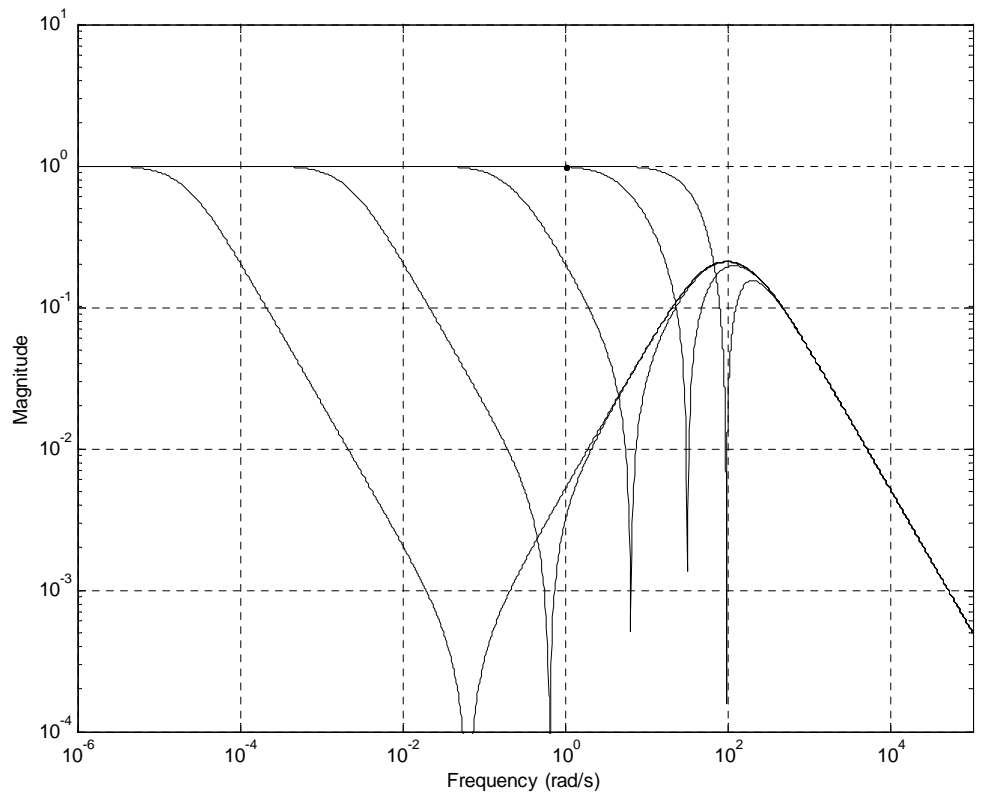

Figure 4.13 : Frequency response of the combination of both filters with a varying $f$

$$
T_{l p}=0.02 \mathrm{~s} \mathrm{~K}=30 \cdot 2 \cdot \pi f_{0}=0.01,0.1,1,5,15 \mathrm{~Hz}
$$




\subsubsection{Filter simulations}

Two preliminary tests can be performed. The first one is to apply the filter to the $\mathrm{u}_{\text {DCdiff }}$ voltages represented in Figure 4.7 and Figure 4.9. As expected, the result is that no amplitude higher than $10^{-4}$ is obtained. With the second test, a DC component of $0.1, \pm 0.05$ and $0.01 \mathrm{pu}$ is artificially added to $\mathrm{u}_{\mathrm{DCdiff}}$ for different steady-state load conditions. Table 4.1 summarizes the results. The last column validates the designed filter.

The last two lines in Table 4.1 correspond to a very low slip value (0.001). In these cases $\mathrm{u}_{\mathrm{DCdiff}}$ contains a pulsating component with a frequency of $0.15 \mathrm{~Hz}$, which is almost a DC component. For the filter, this low frequency pulsating component must not be confused with a DC component, and the filter output must be zero in that case. The last two lines in Table 4.1 validate that the designed filter fulfilled this requirement.

In practice, this could lead to the need of inhibiting the filter with speeds close to the synchronous speed. In spite of this, no inhibition had to be set for the practical application presented in Chapter 5.

\begin{tabular}{|l|l|l|l|l|l|}
\hline Speed & Torque & DC comp. & Measurement & Gap & Precision \\
\hline 1.1 & -0.6 & 0.1 & 0.099808 & 0.000192 & $0.19 \%$ \\
\hline 0.98 & 0.8 & 0.1 & 0.10007 & 0.00007 & $0.07 \%$ \\
\hline 1.1 & -0.6 & -0.05 & -0.050184 & 0.000184 & $0.37 \%$ \\
\hline 0.98 & 0.8 & -0.05 & -0.049926 & 0.000074 & $0.15 \%$ \\
\hline 1.1 & -0.6 & 0.01 & 0.0098227 & 0.0001773 & $0.18 \%$ \\
\hline 0.98 & 0.8 & 0.01 & 0.010054 & 0.000054 & $0.54 \%$ \\
\hline 1.001 & -0.6 & 0.1 & 0 & 0.1 & - \\
\hline 0.999 & 0.8 & 0.1 & 0 & 0.1 & - \\
\hline
\end{tabular}

Table 4.1 : Simulations results summary 


\subsection{DC-link DC unbalance control}

\subsubsection{Introduction}

A DC component in $u_{\text {DCdiff }}$ naturally generates a $2^{\text {nd }}$ harmonic on the AC side which counteracts its driving force [4]. Therefore, as proposed in [10], deliberately inserting this $2^{\text {nd }}$ harmonic with large amplitude compared to the natural $2^{\text {nd }}$ harmonic, helps to remove the unbalanced DC component faster than the selfbalancing abilities of the 3-level VSI. The regulator acts by inserting a negative sequence $2^{\text {nd }}$ harmonic in the gate command voltages $\left(\mathrm{u}_{\mathrm{cma}}, \mathrm{u}_{\mathrm{cmb}}, \mathrm{u}_{\mathrm{cmc}}\right)$, creating the desired negative sequence $2^{\text {nd }}$ harmonic.

As explained in detail in [4], the exact transfer function of the system to be regulated by the DC unbalance controller is difficult to achieve, because the equations defining the input and output are written in different reference frames, as one is rotating at $\omega_{\mathrm{n}}$ (input) and the other at $-2 \omega_{\mathrm{n}}$ (output).

Therefore, the design of the regulator is made on the basis of some representative simulations. It appears that an acceptable configuration is found when using a $\mathrm{P}$ regulator, with its output bounded within $-0.1 \mathrm{pu}$ and $0.1 \mathrm{pu}$ and its gain set to 1 . This limitation is mainly required to not pollute the network too much.

The injection of a $2^{\text {nd }}$ harmonic in the gates command can simply be explained by the fact that it will create an asymmetric pulse pattern which will result in the creation of an asymmetric current $\underline{i}_{0}$ and thus to the appearance of a DC component in $i_{0}$, which in the light of $\S 4.2 .2$ will either contribute to or counteract the DC unbalance component present in the DC-link capacitors voltages. That latter statement obviously implies that the sign of the injected $2^{\text {nd }}$ harmonic is not fixed and may invert depending on the operating point because of the convolution between the voltages and currents creating $\mathrm{i}_{0}$. The particular moment found when the DC component in $\mathrm{i}_{0}$ reverses its sign, while the DC-link DC component remains the same, is called the "critical point". As stated above, the transfer function of the system is difficult to establish, making it hard to define the equation of the critical point especially over the whole power range (active and reactive power varying from -1 to 1 ).

The critical point depends on parameters [4], which can unfortunately not be used to ensure that the critical point is out of the system power range. This because they either cannot be changed (line voltages, network impedance) or cannot be changed significantly (capacitors size, stray inductance of the transformer). 
Therefore, the critical point has to be determined through some representative simulations, and confirmed through tests performed over the whole power range. The simulation tool used for simulations must match several requirements in the overall system simulation including the network, the machine, the power electronics and the regulation strategy, to be able to use the simulations performed as a basis for the analysis of the critical point. SIMSEN [7] was chosen as the simulation tool.

An important point in the present study involves another consideration, which is that the system will rarely work under full reactive power (positive or negative) on the transformer side. In fact, as active power can flow through the system, and to avoid over-sizing the transformer and the VSI, only a small amount of current will be dedicated to reactive power. The critical point is usually reached with operating points that are close to pure reactive mode and which are only rarely used in the present particular application. Hence, in most cases, the implementation of the reverse sign in the regulator can be avoided.

\subsubsection{Simulations for the critical point}

For a quick determination of the critical point through simulations, a parameterized model has been built in SIMSEN. Once the specified operating points are reached and stabilized, the model checks the action of the DC unbalance control by inserting a $2^{\text {nd }}$ order harmonic in the gates command signals with a reference frame rotating at $-2 \omega_{1}$. Then, a look at the results tells which voltage between $\mathrm{u}_{\mathrm{DC} 1}$ and $\mathrm{u}_{\mathrm{DC} 2}$ is rising for each operating point and therefore if the critical point has been reached.

To enable a correct checking of all the operating points, the DC-link voltage control is replaced by a DC source, as can be seen in Figure 4.14. Thus, the active power can easily be modified by changing the set value of the active current, to cover all the available power range.

In Figure 4.14, the main change compared to Figure 2.25 is that the DC-link voltage regulator (11) is removed and DC sources are put in the DC-link. Blocks 12-13 are also added, which are respectively for the generation of the reference frame $\left(-2 \omega_{1}\right)$, for the addition of the $2^{\text {nd }}$ harmonic $(12)$, and for adding that $2^{\text {nd }}$ harmonic directly into the command signals (13). The reference angle used for the generation of the $2^{\text {nd }}$ harmonic is $\theta_{\mathrm{s}}$.

Table 4.2 summarizes the results for the simulations performed and shows which voltage is rising when injecting the $2^{\text {nd }}$ harmonics. When the rising voltage is different, then a sign reversal has occurred. The grey cells represent an overall current of more than $1 \mathrm{pu}$. 


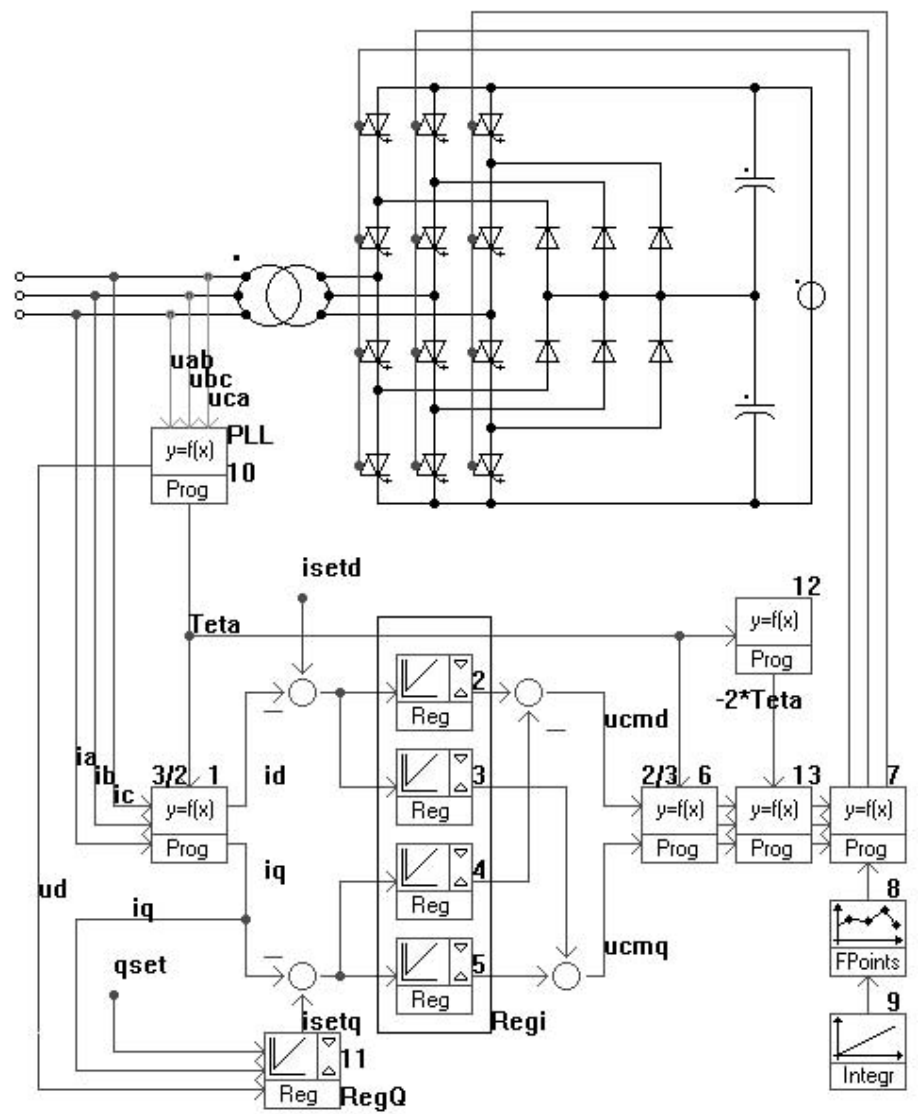

Figure 4.14 : The critical point determination in SIMSEN

The 13 blocks in Figure 4.14 correspond to :

1. Park transformation of the primary side currents.

2. PI regulator for the current in the direct $d$ axis.

3. I regulator for the current in the crossed $d-q$ axis.

4. I regulator for the current in the crossed q-d axis.

5. PI regulator for the current in the direct $\mathrm{q}$ axis.

6. Inverse Park transformation generating the command signals.

7. Generation of the gate command switching states.

8. Carrier signal generation.

9. Setting of the carrier signal frequency.

10. PLL (Phase Locked Loop) generating the $\theta_{\mathrm{s}}$ angle (Chapter 5).

11. I regulator for the reactive power.

12. Generation of the angle $-2 \theta_{\mathrm{s}}$.

13. Addition of $2^{\text {nd }}$ harmonic to the command signals. 


\begin{tabular}{|c|c|c|c|c|c|c|c|c|c|}
\hline $\mathbf{d} / \mathbf{q}$ & $\mathbf{- 1}$ & $\mathbf{- 0 . 7 5}$ & $\mathbf{- 0 . 5}$ & $\mathbf{- 0 . 2 5}$ & $\mathbf{0}$ & $\mathbf{0 . 2 5}$ & $\mathbf{0 . 5}$ & $\mathbf{0 . 7 5}$ & $\mathbf{1}$ \\
\hline $\mathbf{1}$ & & & $\mathrm{u}_{\mathrm{DC}} 1$ & & $\mathrm{u}_{\mathrm{DC}} 1$ & & $\mathrm{u}_{\mathrm{DC}} 1$ & & \\
\hline $\mathbf{0 . 7 5}$ & & $\mathrm{u}_{\mathrm{DC}} 1$ & & $\mathrm{u}_{\mathrm{DC}} 1$ & & $\mathrm{u}_{\mathrm{DC}} 1$ & & $\mathrm{u}_{\mathrm{DC}} 1$ & \\
$\mathbf{0 . 5}$ & & & $\mathrm{u}_{\mathrm{DC}} 1$ & & $\mathrm{u}_{\mathrm{DC}} 1$ & & $\mathrm{u}_{\mathrm{DC}} 1$ & & \\
\hline $\mathbf{0 . 2 5}$ & & $\mathrm{u}_{\mathrm{DC}} 1$ & & $\mathrm{u}_{\mathrm{DC}} 1$ & & $\mathrm{u}_{\mathrm{DC}} 1$ & & $\mathrm{u}_{\mathrm{DC}} 1$ & \\
\hline $\mathbf{0}$ & $\mathbf{u}_{\mathrm{DC}} \mathbf{2}$ & & $\mathrm{u}_{\mathrm{DC}} 1$ & & $\mathrm{u}_{\mathrm{DC}} 1$ & & $\mathrm{u}_{\mathrm{DC}} 1$ & & $\mathrm{u}_{\mathrm{DC}} 1$ \\
\hline $\mathbf{- 0 . 2 5}$ & & $\mathrm{u}_{\mathrm{DC}} 1$ & & $\mathrm{u}_{\mathrm{DC}} 1$ & & $\mathrm{u}_{\mathrm{DC}} 1$ & & $\mathrm{u}_{\mathrm{DC}} 1$ & \\
\hline $\mathbf{- 0 . 5}$ & & & $\mathrm{u}_{\mathrm{DC}} 1$ & & $\mathrm{u}_{\mathrm{DC}} 1$ & & $\mathrm{u}_{\mathrm{DC}} 1$ & & \\
\hline $\mathbf{- 0 . 7 5}$ & & $\mathrm{u}_{\mathrm{DC}} 1$ & & $\mathrm{u}_{\mathrm{DC}} 1$ & & - & & $\mathbf{u}_{\mathrm{DC}} \mathbf{2}$ & \\
\hline $\mathbf{- 1}$ & & & - & & $\mathrm{u}_{\mathrm{DC}} 1$ & & $\mathbf{u}_{\mathbf{D C}} \mathbf{2}$ & & \\
\hline
\end{tabular}

Table 4.2 : Simulation results for the determination of the critical point

As can be seen from the results in Table 4.2 and as expected from the last statement of $\$ 4.3 .1$, the regulator always acts in the same way, meaning that for the current application no sign reversal has to be applied to the regulator or in other words that the critical point is out of the system operating range.

In fact, only three cells are found to have the sign reversed (bold $\mathrm{u}_{\mathrm{DC} 2}$ ), but are either out of the acceptable overall current (grey cells) or in the case of full reactive mode of -1 pu which will practically never be used.

Two cells are found with a "-" meaning that in that case, no particular rise or fall of any voltage is found, or that the time constant is very large (nearly the same as the self balancing time constant).

Of course, these simulations would have to be verified in practice as some parameters are not exactly known. However, these former are an accurate basis on which to determine where problems may arise. Furthermore, the simulations could be performed with the parameters varying within an acceptable range and checking in the overall set of simulations if any particular attention must be paid in any of these cases. 


\subsection{Simulations}

Transient simulations of the overall system defined by $\S 2.5 .1$ and $\S 3.4 .1$ have been performed with the regulator and the filter designed in the previous sections. Figure 4.15 is the same as Figure 2.25 to which the DC unbalance control is added (blocks 13-14-15-16). In block 13, $\mathrm{u}_{\mathrm{DC} \text { sum }}$ and $\mathrm{u}_{\mathrm{DCdiff}}$ are calculated. The latter is then sent to block 14 which filters it to extract $\mathrm{u}_{\mathrm{DCdiffo}}$. Block 15 is the DC unbalance regulator using $\mathrm{u}_{\mathrm{DCdiff} 0}$ as input and block 16 does the addition of the $2^{\text {nd }}$ harmonic (angle $-2 \theta_{\mathrm{S}}$ ) with the VSI command signals.

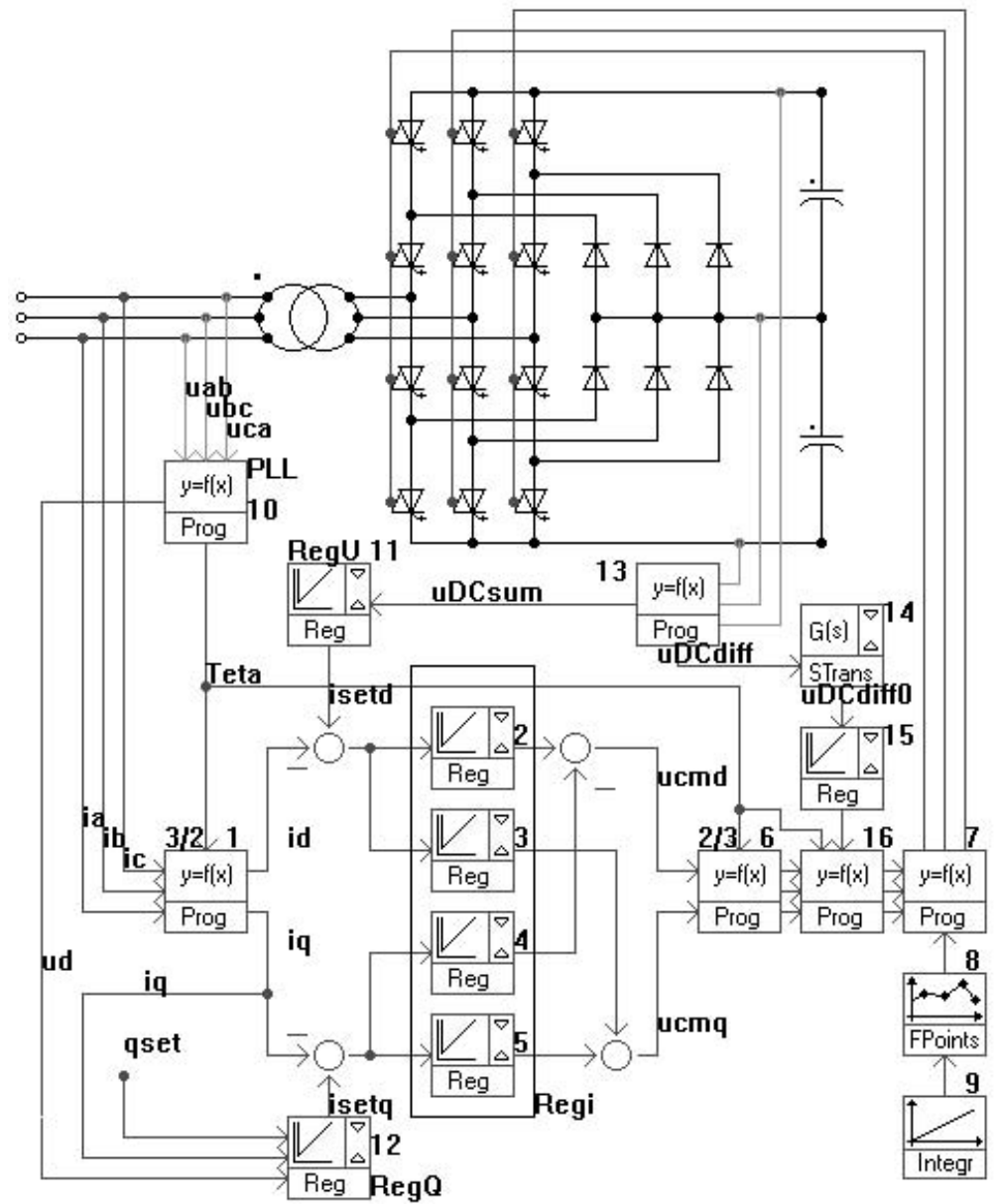

Figure 4.15 : The DC unbalance control in SIMSEN 
The 16 blocks in Figure 4.15correspond to :

1. Park transformation of the primary side currents.

2. PI regulator for the current in the direct $d$ axis.

3. I regulator for the current in the crossed $d-q$ axis.

4. I regulator for the current in the crossed q-d axis.

5. PI regulator for the current in the direct $\mathrm{q}$ axis.

6. Inverse Park transformation generating the command signals.

7. Generation of the gate command switching states.

8. Carrier signal generation.

9. Setting of the carrier signal frequency.

10. PLL (Phase Locked Loop) generating the $\theta_{\mathrm{s}}$ angle (Chapter 5).

11. PI regulator for the DC-link voltage.

12. I regulator for the reactive power.

13. Calculation of $u_{D C s u m}$ and $u_{D C d i f f}$.

14. Filtering of $u_{D C d i f f}$ to extract $u_{D C d i f f o}$.

15. DC unbalanced regulator.

16. Addition of $2^{\text {nd }}$ harmonic to the command signals.

The case presented is obtained after manually setting an unbalanced DC component of $\pm 7 \%$ (14\% overall) between $u_{\mathrm{DC} 1}$ and $\mathrm{u}_{\mathrm{DC} 2}$. The steady-state point reached before inserting the unbalanced DC component is defined as follows: without reactive power on the transformer side as well as on the machine stator, the mechanical torque at $-0.6 \mathrm{pu}$ and the speed at $1.1 \mathrm{pu}$.

Figure 4.16 and Figure 4.17 show the response of the capacitors voltages $\mathrm{u}_{\mathrm{DC} 1}$ and $\mathrm{u}_{\mathrm{DC} 2}$ without and with regulation. From the simulation it can be seen that natural self-balancing occurs and tends to slowly remove the DC unbalance after about 5 seconds (Figure 4.16), whereas the controller corrects the DC unbalance in less than 500 milliseconds (Figure 4.17). Note that the regulator could be set to react faster by increasing the gain factor or raising the output limits, but with the drawback of injecting an undesirable $2^{\text {nd }}$ harmonic of higher amplitude into the grid.

Figure 4.18 shows $\mathrm{u}_{\mathrm{DCdiff}}$ (light grey) and $\mathrm{u}_{\mathrm{DCdiff}}$ (black). Actually, the filtering appears to be correct, even in transient state, and $u_{\text {DCdiffo }}$ tends to reach zero as the regulator is acting. It is important to note that the injection of the $2^{\text {nd }}$ order harmonic current of 0.1 pu takes only about $0.1 \mathrm{~s}$ for such a large unbalanced DC component. Furthermore, as the transformer side power is about $10 \%$ of the machine power and that the $2^{\text {nd }}$ order harmonic current is maximally $10 \%$ the transformer nominal current. Under nominal conditions, this current is about $1 \%$ of the current injected into the grid and this only for a very short time. Therefore it can be said that no major drawback is seen by the network. 


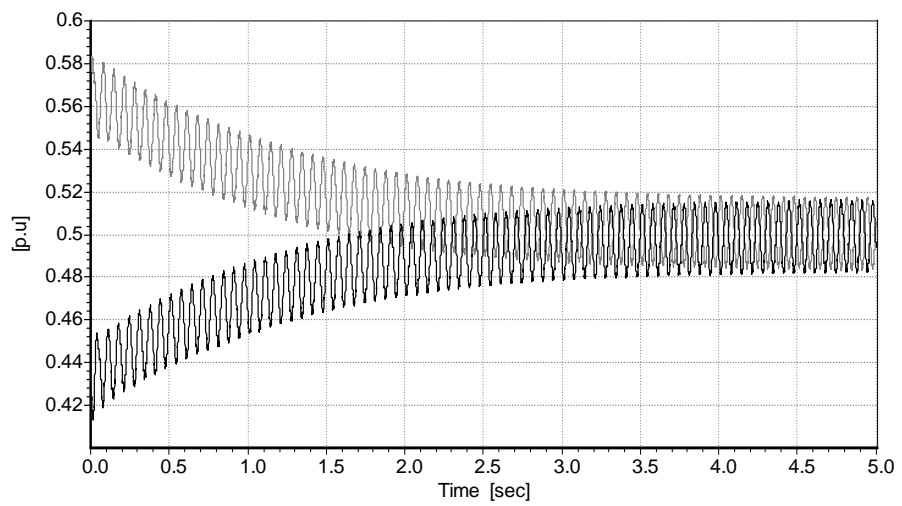

Figure 4.16 : Self balancing (without regulation)

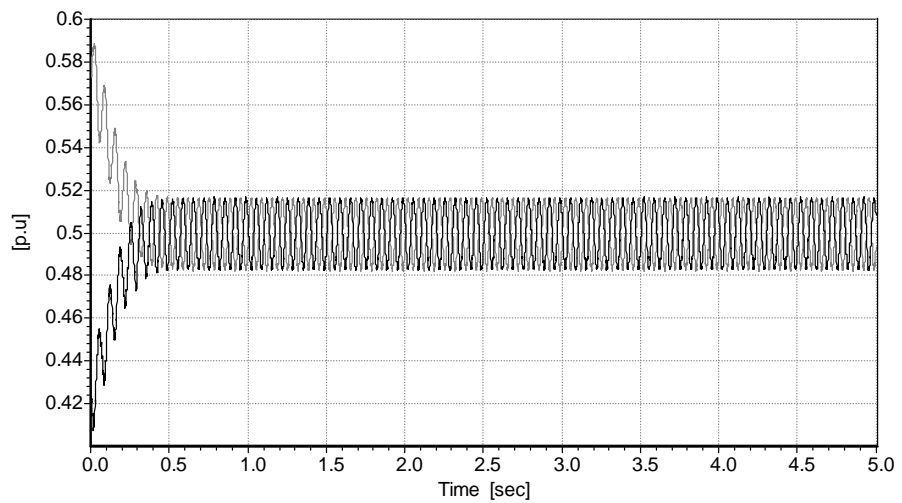

Figure 4.17 : Balancing with regulation

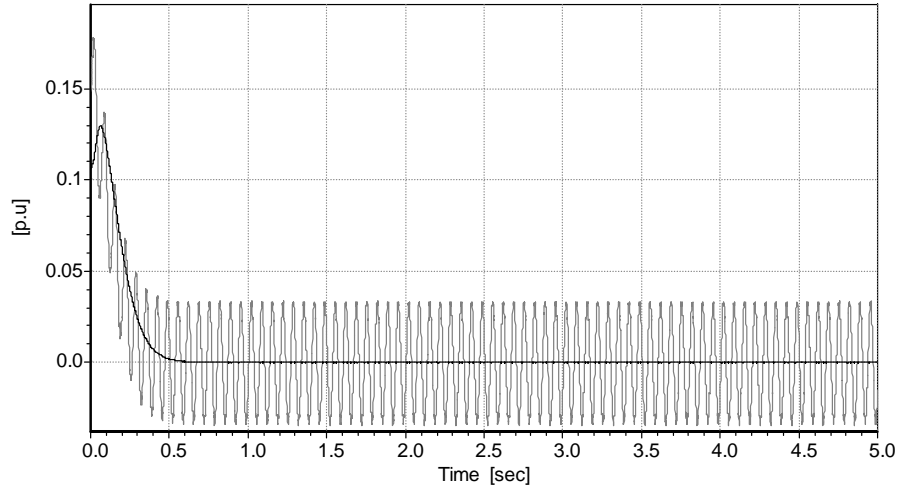

Figure $4.18: u_{\text {DCdiff }}$ and $u_{\text {DCdiffo }}$ 


\subsection{Influence of a DC unbalance component on the mechanical torque}

Beyond the electrical problems linked to a DC unbalance component, the influence of such a component on the machine torque is of high interest.

The $2^{\text {nd }}$ order current harmonic resulting from a DC unbalance component creates a mechanical frequency 3 times the rotor current fundamental frequency. This is explained by the fact that the negative $2^{\text {nd }}$ order harmonic is seen as a $3^{\text {rd }}$ harmonic by the rotor current creating the electromechanical torque. This mechanical harmonic is of major interest as it can excite low mechanical frequencies. Note that all odd multiple harmonics of the current fundamental are found.

In spite of this, the mechanical harmonics generated are only of low amplitude. Simulations have shown that for a DC unbalance component of $10 \%$ in each capacitor voltage, the resulting harmonic generated is never higher than $0.7 \%$ for the worst case. From this it can be said that a DC unbalance component has little influence on the mechanical torque.

\subsection{Practical Application}

To illustrate the behaviour of the DC unbalance control, measurements have been made on the low power system presented in Chapter 5.

In this low power system, the machine saturation level is such that high level $2^{\text {nd }}$ order current harmonics are present. As discussed in $\S 4.2 .3$, these harmonics create an unbalance DC component. Therefore, even in steady-state, the DC unbalance control has to work.

Figure 4.19 illustrates this statement. At about $2 \mathrm{~s}$ the DC unbalance control is disabled and the two capacitors voltages are slowly diverging. Before this, the capacitors voltages are kept balanced by the DC unbalance control. 


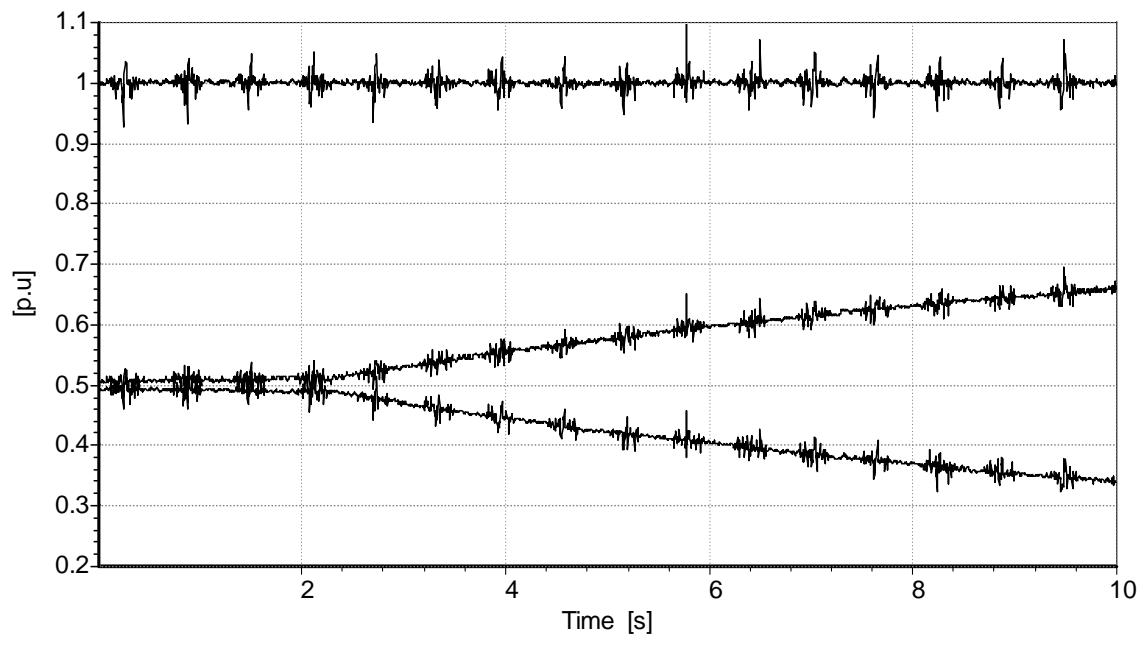

Figure 4.19 : DC unbalance control measurements

\subsection{Conclusion}

The major problem of the DC-link DC unbalance control in back-to-back 3-level VSI converters applied to doubly-fed induction motor generator has been discussed. The solution used for PWM control is based on the injection of a $2^{\text {nd }}$ order harmonic which tends to remove the unbalanced DC component for selfbalancing.

The measurement of the DC-unbalance component ( $\mathrm{u}_{\mathrm{DC} \text { diffo }}$ ) is done by using a specific adaptable filter. This filter has been designed with a concern for practical applications and is therefore only of $3^{\text {rd }}$ order. Simulations show that the design of the filter is accurate and effective.

The critical point has been discussed and even if a check of this point in simulation and practice must be performed, it proves to be out of the power range of the present application.

The simulation results show the accuracy of the designed filter as well as the correct behaviour of the regulator. 


\section{Chapter 5 \\ The Overall System \\ Practical Application}

\subsection{Introduction}

The present chapter deals with the practical application of the overall system, performed with a low power system.

Figure 5.1 shows the 3-level VSI designed and built in the laboratory of the EPFL, whereas Figure 5.2 shows the DC-machine used as a pump-turbine, the wound rotor asynchronous machine, the transformer, and the I/O and DSP cards controlling the 3-level VSIs.

It is important to say that the pratical programmation of the DSPs aked for a translation of the control design performed in the analogical world to the digital world. The bilinear transformation was used for the adaptative filter presented in $\S 4.3$, whereas the regulators were translated using the methods presented in [15].

Figure 5.3 shows the overall system used for the comparison between simulations and measurements presented in the following sections.

The system presented is constituted of the three control strategies defined in $\$ 2.5 .2$ Figure 2.25 for the transformer section, in $\$ 3.4 .2$ Figure 3.13 for the machine section and in $\$ 4.5$ Figure 4.15 for the DC unbalance control. 
The system has the following parameters :

The transformer :

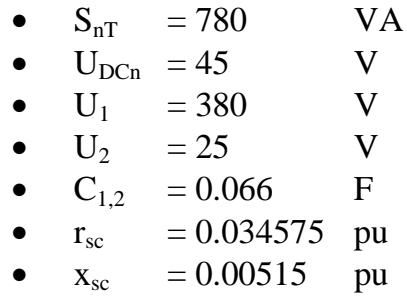

Additional inductance

- $\mathrm{r}_{\mathrm{sc}}=0.08 \quad \mathrm{pu}$

- $\mathrm{x}_{\mathrm{sc}}=0.935 \quad \mathrm{pu}$

The machine

- $\begin{array}{ccc}\mathrm{S}_{\mathrm{n}} & =3.3 \quad \mathrm{kVA}\end{array}$

- $\mathrm{U}_{\mathrm{sn}}=380 \quad \mathrm{~V}$

- $\ddot{\mathrm{u}} \quad=4.0992$

- $\mathrm{p}_{\mathrm{p}}=2$

- $\mathrm{U}_{\mathrm{DCn}}=45$

V

- $\mathrm{r}_{\mathrm{s}}=0.1 \quad \mathrm{pu}$

- $\mathrm{x}_{\sigma \mathrm{s}}=0.12 \quad \mathrm{pu}$

- $\mathrm{x}_{\mathrm{hs}}=2.34 \quad \mathrm{pu}$

- $\mathrm{x}_{\sigma \mathrm{r}}{ }^{\prime}=0.12 \quad \mathrm{pu}$

- $\mathrm{r}_{\mathrm{r}}{ }^{\prime}=0.075 \mathrm{pu}$

- $\mathrm{j}=0.34 \quad \mathrm{~kg} \mathrm{~m}^{2}$ (including additional inertia)

Note that due to the very low reactance of the transformer, an inductance has been added on the primary side. Thus, the transformer reactive power is measured on the network side of this inductance and not on the transformer primary side. 


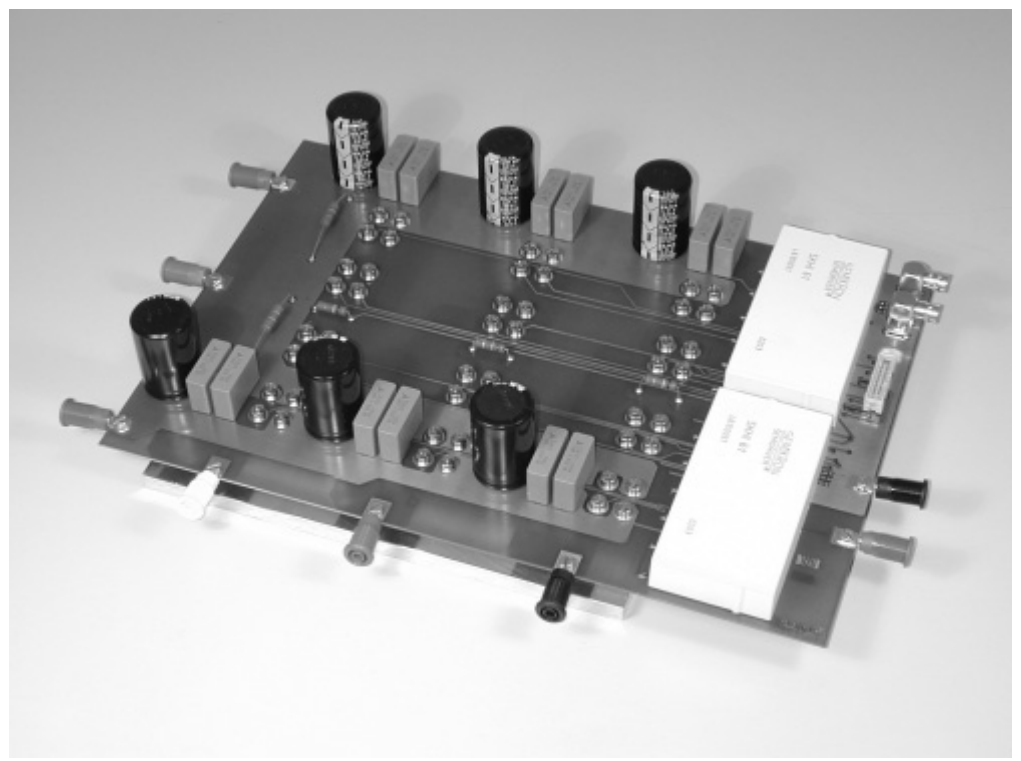

Figure 5.1 : The 3-level VSI

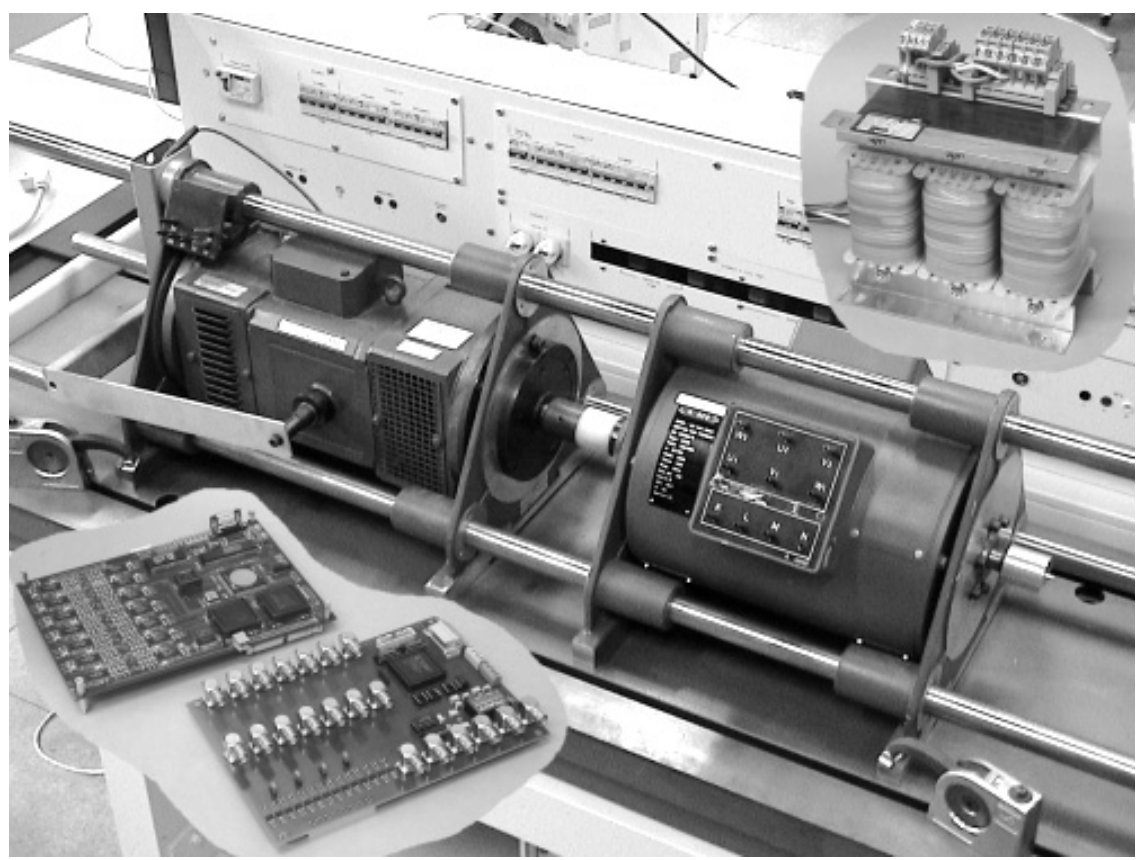

Figure 5.2 : The system hardware 


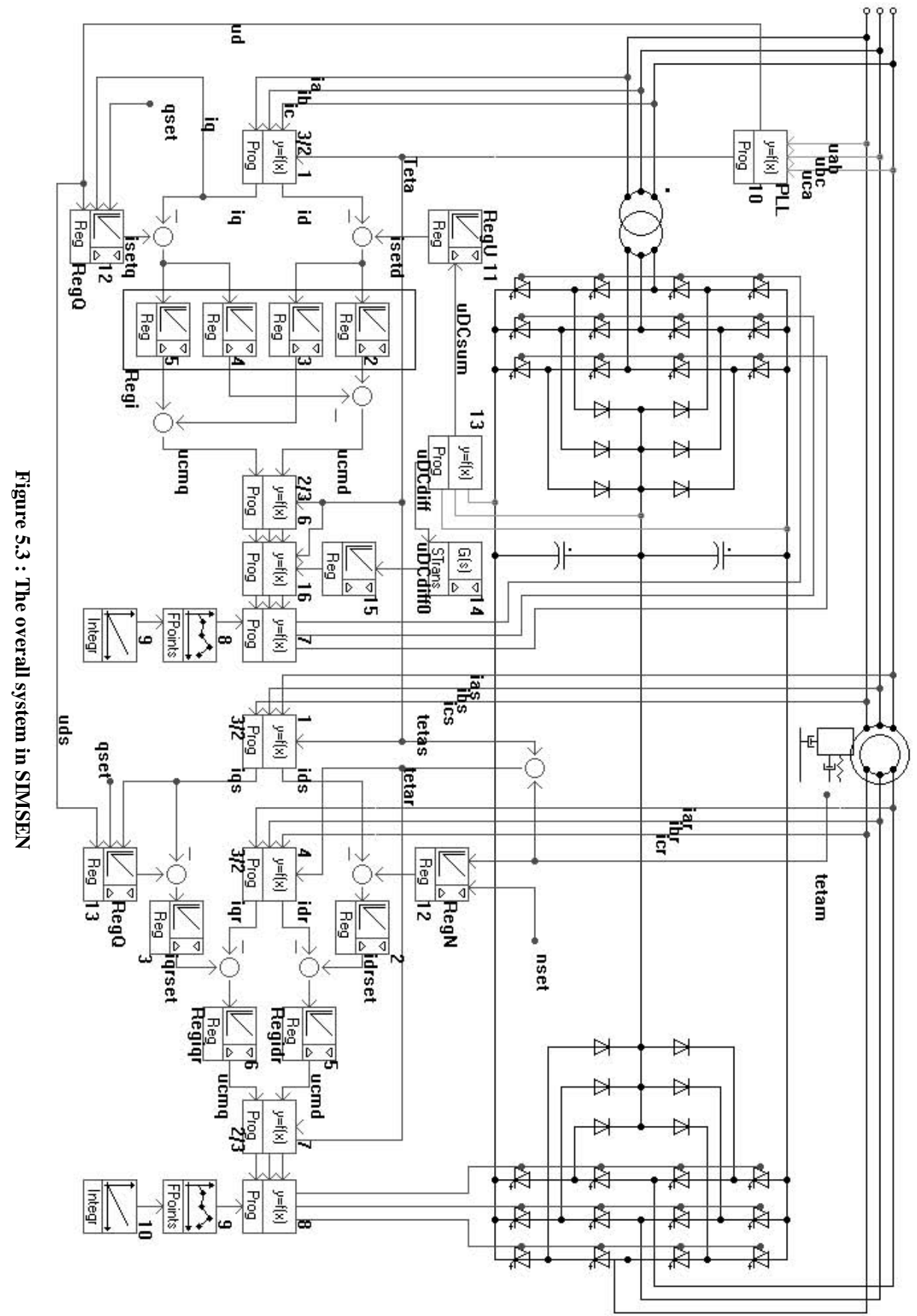




\subsection{Determination of the $\theta_{\mathrm{s}}$ and $\theta_{\mathrm{r}}$ angles}

\subsubsection{Introduction}

In practice, the knowledge of the $\theta_{\mathrm{s}}$ and $\theta_{\mathrm{r}}$ angles is not implicit, and they must be determined. The present section presents two methods for determining $\theta_{\mathrm{s}}$ and a sensorless method for determining $\theta_{\mathrm{r}}$.

The relationship between the different angles present in the system is given by equation (5.1), and illustrated by Figure 5.4.

$$
\theta_{\mathrm{r}}=\theta_{\mathrm{s}}+\left(\theta_{\mathrm{m}} \cdot \mathrm{p}_{\mathrm{p}}\right)
$$

where $p_{p}$ is the number of pairs of poles of the machine, $\theta_{\mathrm{s}}$ the stator voltage phasor angle, $\theta_{\mathrm{r}}$ the rotor voltage phasor angle and $\theta_{\mathrm{m}}$ the mechanical angle.

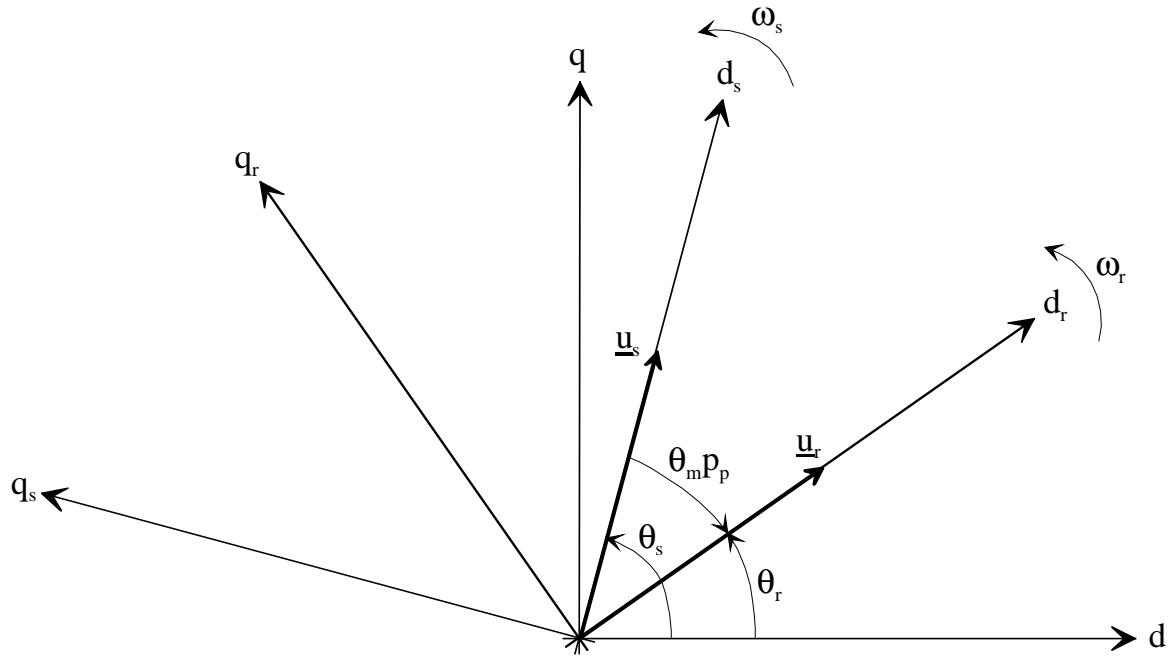

Figure 5.4 : Relationship between the stator and rotor reference frames 


\subsubsection{Determining $\theta_{\mathrm{s}}$}

\section{a. fixed method}

In this method, a fixed reference frame is used. The block diagram given in Figure 5.5 shows that after measuring the line voltages, a first Park transformation applied to $\underline{u}_{s}$ is performed in a fixed reference frame, and therefore with an angle of 0 $\left(\theta_{\mathrm{P}}=0\right)$. From this fixed reference frame, $\theta_{\mathrm{s}}$ is calculated with equation (5.2), and is illustrated by Figure 5.7.

$$
\theta_{\mathrm{s}}=\arctan \left(\frac{\mathrm{u}_{\mathrm{sq}}}{\mathrm{u}_{\mathrm{sd}}}\right)
$$

\section{b. rotating method}

In this method, a rotating frame is used. The block diagram given in Figure 5.6 shows that after measuring the line voltages, a first Park transformation of $\underline{\underline{u}}_{s}$ is performed in a rotating reference, meaning that the angle used for this transformation is the last calculated angle $\theta_{\mathrm{s}}$. In the digital world, that previously calculated angle is simply denoted $\theta_{\mathrm{s}}(\mathrm{k}-1)$, where $\mathrm{k}$ represents the actual time step, and $(\mathrm{k}-1)$ the previous time step. Therefore, the Park transformation angle is $\theta_{\mathrm{P}}=\theta_{\mathrm{s}}(\mathrm{k}-1)$. From this rotating reference frame, $\theta_{\mathrm{s}}$ at the time $(\mathrm{k})$ is given by equation (5.3), and is illustrated by Figure 5.8.

$$
\theta_{\mathrm{s}}(\mathrm{k})=\theta_{\mathrm{s}}(\mathrm{k}-1)+\Delta \theta_{\mathrm{s}}=\theta_{\mathrm{s}}(\mathrm{k}-1)+\arctan \left(\frac{\mathrm{u}_{\mathrm{sq}}}{\mathrm{u}_{\mathrm{sd}}}\right)
$$
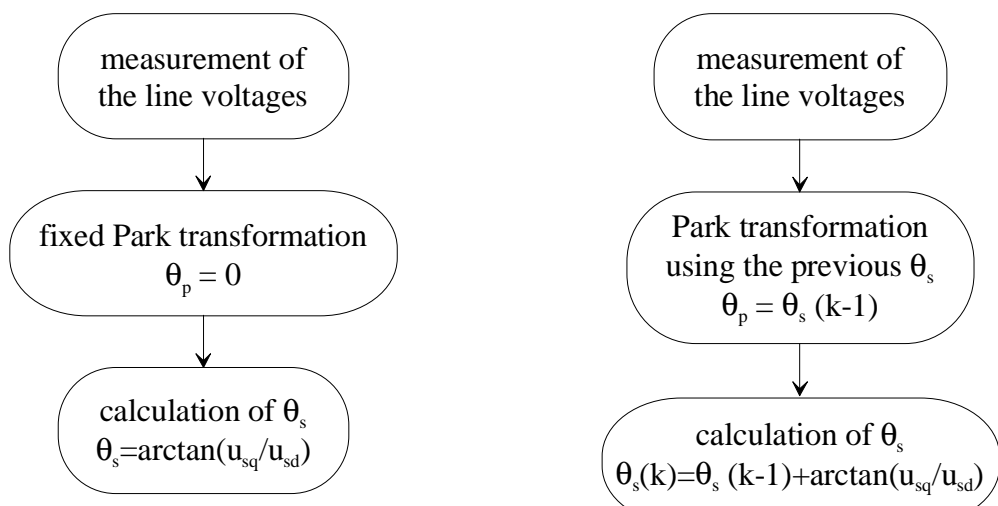

Figure 5.5 : The fixed method block diagram Figure 5.6 : The rotating method block diagram 88 


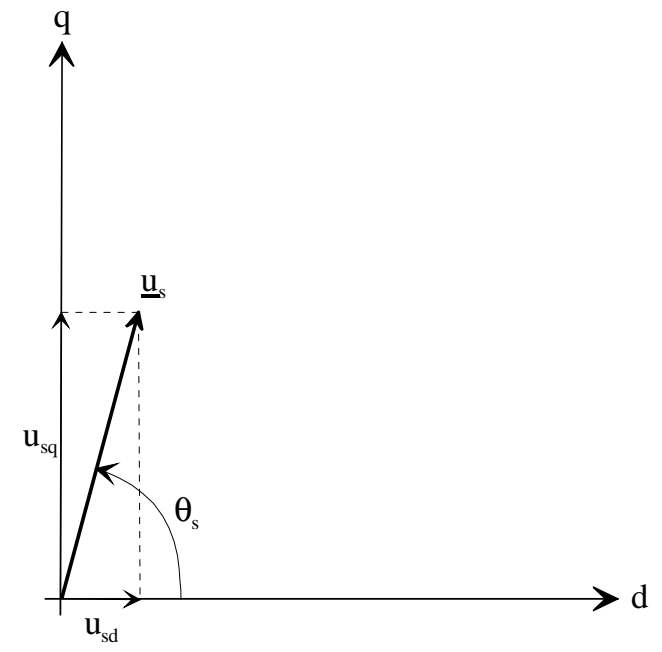

Figure 5.7 : The fixed method

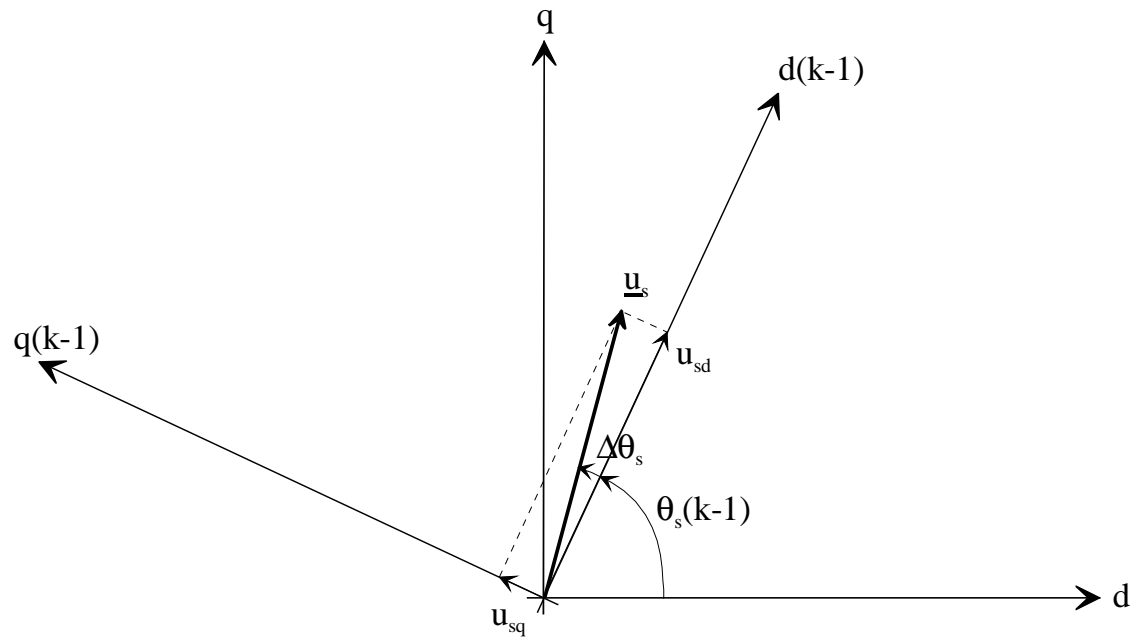

Figure 5.8 : The rotating method

It is obvious that both methods give the same accuracy. However, the fixed method $\left(\theta_{\mathrm{P}}=0\right)$ requires less calculation time, and is the solution adopted for the practical application. 
To check the accuracy of these methods, simulations were performed. In these simulations, three-phase sinus waves are generated. The amplitudes are changed and noise and offsets are added to these sinus waves. Then, after determining $\theta_{\mathrm{s}}$ with the fixed method, the accuracy is given by comparing $\theta_{\mathrm{s}}$ to the original angle used for the generation of the sinus waves.

Various tests were performed by changing the amplitudes and offsets differently in each phase. As an example, Figure 5.9 and Figure 5.10 show respectively the original sinus waves and the sinus waves after changing the amplitude in phase ' $b$ ' and ' $c$ ' to $0.95 \mathrm{pu}$, and changing the offset by $0.05 \mathrm{pu}$, negatively in phase ' $a$ ' and positively in phase 'c'. The results, which can be generalized to each possible case, are given in Figure 5.11 for four different signal to noise ratios (SNR [db]), and show that in the worst case, the maximum error is less than $2.5 \%$.

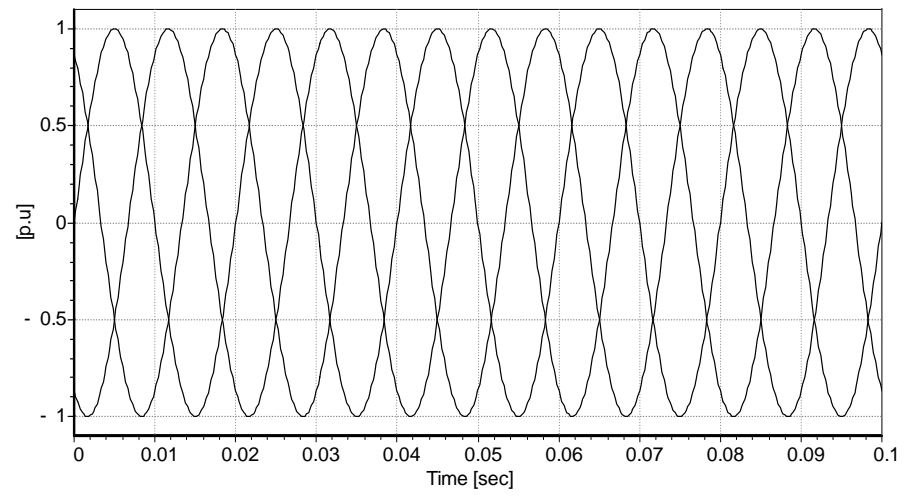

Figure 5.9 : Original sinus waves

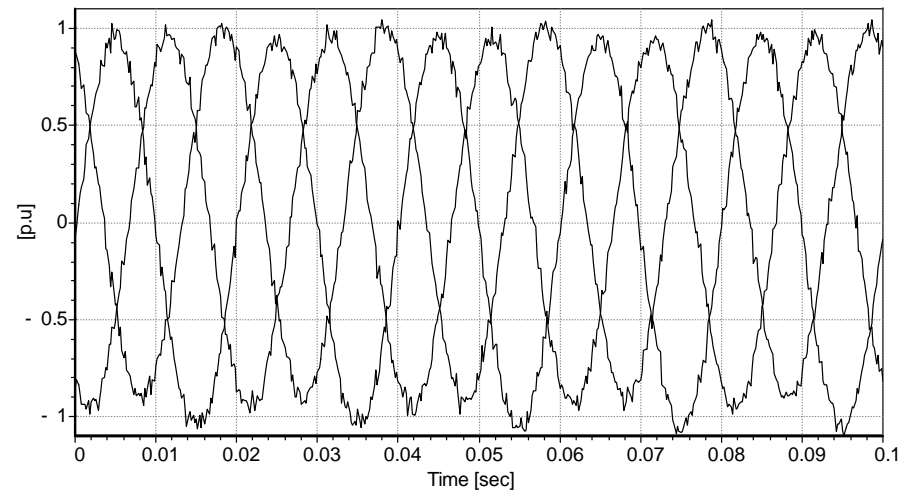

Figure 5.10 : Sinus waves after modifications 

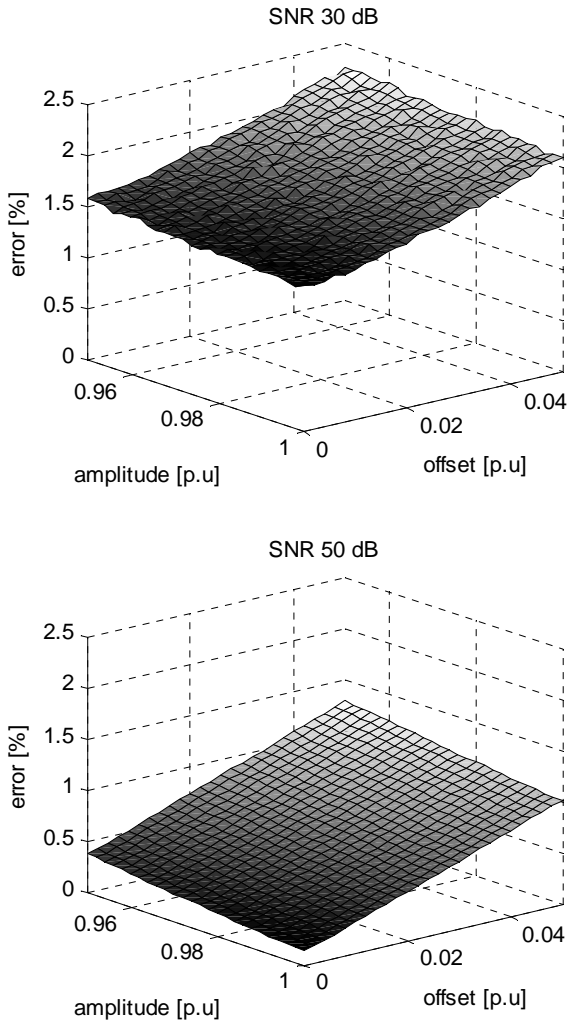
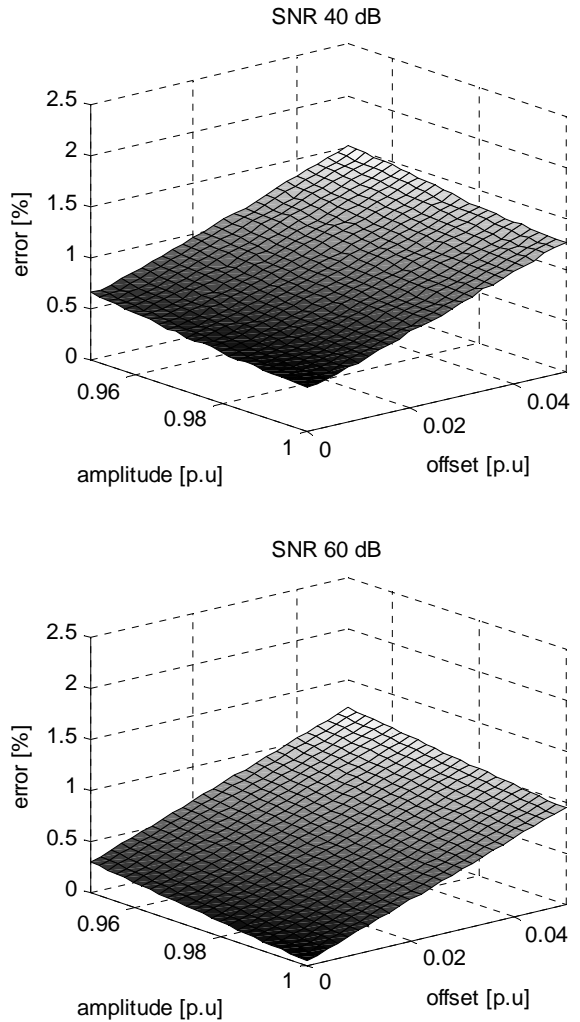

Figure 5.11 : Simulation result for the accuracy of the fixed method.

with the amplitude varying from 0.95 to $1 \mathrm{pu}$ in phase $\mathrm{b}$ and $\mathrm{c}$ with the offset varying from 0 to $-0.05 \mathrm{pu}$ in phase a and from 0 to 0.05 in phase $\mathrm{c}$ 


\subsubsection{Determining $\theta_{\mathrm{r}}$ with a position observer (Sensorless)}

Instead of using an absolute position encoder, the determination of the rotor angle $\theta_{\mathrm{r}}$ can be done with a sensorless method or in other words with a position observer.

The new method is inspired by [11] and [12]. However, no flux estimation is performed as a well known equivalent diagram (Figure 3.4) is used and assumed as being precise enough. From the latter, $\theta_{\mathrm{r}}$ is deduced by the principle defined here under. The new method proposed is only based on the use of values already measured or known for regulation purposes, which are the stator voltages as well as the stator and rotor currents.

The principle is : (Figure 5.12) An estimation of $\underline{i}_{r}$ projected in the rotor reference frame is done at a time $(\mathrm{k})$, based on the actual measured stator voltages and currents at that time $(\mathrm{k})$. The estimated rotor current $\underline{i}_{\mathrm{re}}$ ('e' standing for estimated), is then compared to $\underline{i}_{r}$ based on the actual rotor currents at time $(\mathrm{k})$, but projected in the rotor reference frame for the time $(\mathrm{k}-1)$, and called $\underline{i}_{r m}(' m$ ' standing for measured). Then, the actual angle $\theta_{\mathrm{r}}(\mathrm{k})$ is determined by the old $\theta_{\mathrm{r}}(\mathrm{k}-1)$ plus the difference between the angles $\left(\Delta \theta_{\mathrm{r}}\right)$ of the estimated frame $\left(\theta_{\mathrm{re}}\right)$ and of the $(\mathrm{k}-1)$ frame $\left(\theta_{\mathrm{rm}}\right)$. This method is illustrated by Figure 5.12 and summarized in the block diagram of Figure 5.13.

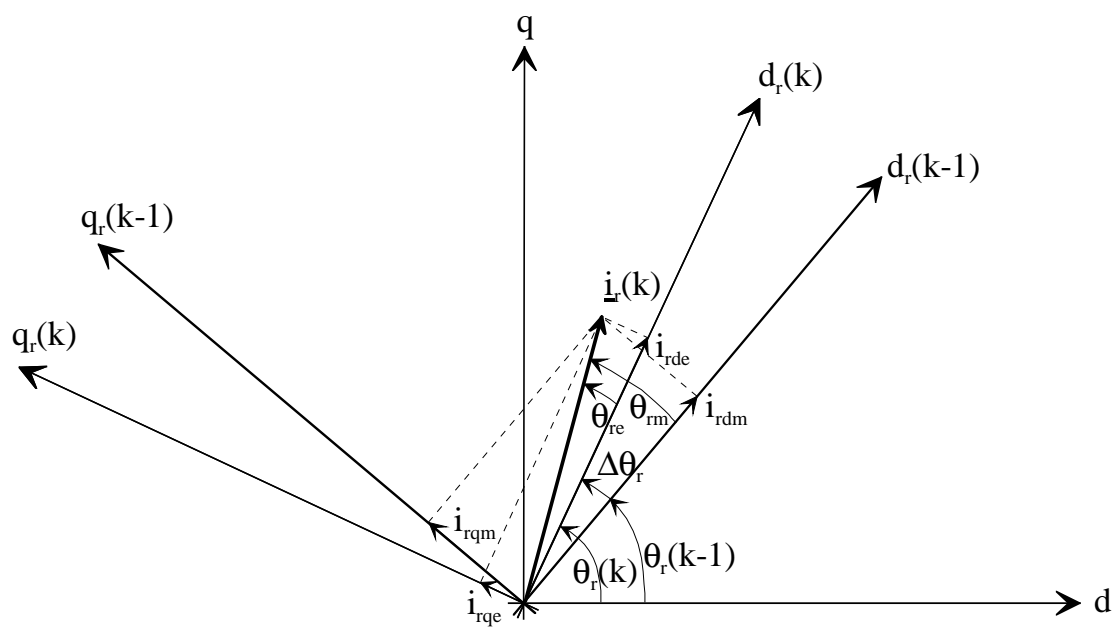

Figure 5.12 : Sensorless method 
measurement of the line voltages

\section{measurement of} the stator currents measurement of

the rotor currents

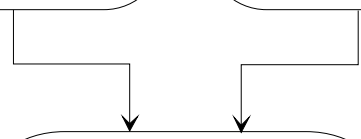

Estimation of $i_{\text {rde }}$ and $i_{\text {rqe }}$<smiles>C[V]</smiles>

Calculation of $\theta_{\text {re }}$
Calculation of $i_{\text {rdm }}$ and $i_{\text {rqm }}$

Calculation of $\theta_{\text {rm }}$

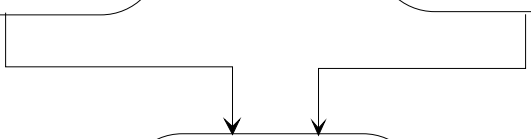

Determination $\theta_{\mathrm{r}}$

Figure 5.13 : Sensorless block diagram

On the basis of Figure 3.4 and equation (3.12), and assuming a steady state operation, the rotor current $\underline{i}_{r}$ can be expressed, in the rotor reference frame, by equations (5.4) and (5.5).

$$
\begin{aligned}
& i_{\text {rde }}=\frac{\left(u_{s q}-r_{s} i_{s q}-x_{s} i_{s d}\right)}{x_{h}} \\
& i_{\text {rqe }}=\frac{\left(-u_{\text {sd }}+r_{s} i_{s d}-x_{s} i_{s q}\right)}{x_{h}}
\end{aligned}
$$

Assuming that $\mathrm{r}_{\mathrm{s}}$ is small, that $\mathrm{x}_{\mathrm{s}} \cong \mathrm{x}_{\mathrm{h}}$ and that $\mathrm{u}_{\mathrm{sd}}=1$ and $\mathrm{u}_{\mathrm{sq}}=0$, which is correct for the power range of the current study, equations (5.4)-(5.5) can be reduced to (5.6)-(5.7).

$$
\begin{aligned}
& \mathrm{i}_{\text {rde }}=-\mathrm{i}_{\text {sd }} \\
& \mathrm{i}_{\text {rqe }}=-\left(\frac{1}{\mathrm{x}_{\mathrm{h}}}+\mathrm{i}_{\mathrm{sq}}\right)
\end{aligned}
$$


Using either equations (5.4)-(5.5) or (5.6)-(5.7), the estimation of the angle that the estimation of $\underline{i}_{r}$ has in the rotor reference frame at the time $(\mathrm{k})$ is given by

$$
\theta_{\text {re }}=\arctan \left(\frac{i_{\text {rqe }}}{i_{\text {rde }}}\right)
$$

Also, the angle that the measurement of $\underline{i}_{r}$ at the time (k) has in the rotor reference frame at the time (k-1) is given by

$$
\theta_{\mathrm{rm}}=\arctan \left(\frac{\mathrm{i}_{\mathrm{rqm}}}{\mathrm{i}_{\mathrm{rdm}}}\right)
$$

The angle between these two reference frames is given by

$$
\Delta \theta_{\mathrm{r}}=\theta_{\text {rm }}-\theta_{\text {re }}=\arctan \left(\frac{i_{\text {rqm }}}{i_{\text {rdm }}}\right)-\arctan \left(\frac{i_{\text {rqe }}}{i_{\text {rde }}}\right)
$$

Finally,

$$
\theta_{\mathrm{r}}(\mathrm{k})=\theta_{\mathrm{r}}(\mathrm{k}-1)+\Delta \theta_{\mathrm{r}}
$$

Of course the parameters $r_{s}, r_{r}^{\prime}, x_{\sigma s}, x_{\sigma r}^{\prime}$ and $x_{h}$ of the equivalent diagram used (Figure 3.4), are to be measured using for example [13] or [14].

Figure 5.14 and Figure 5.15 show the comparison between the sensorless method in grey and an absolute position encoder in black, for respectively a speed up and a speed down steps.

The worst case found in Figure 5.14 shows, for the present application in transient, a maximum error of less than $10^{\circ}$. This validates the sensorless method proposed. Note that in high power systems, with smoother currents, a better precision has to be expected. 


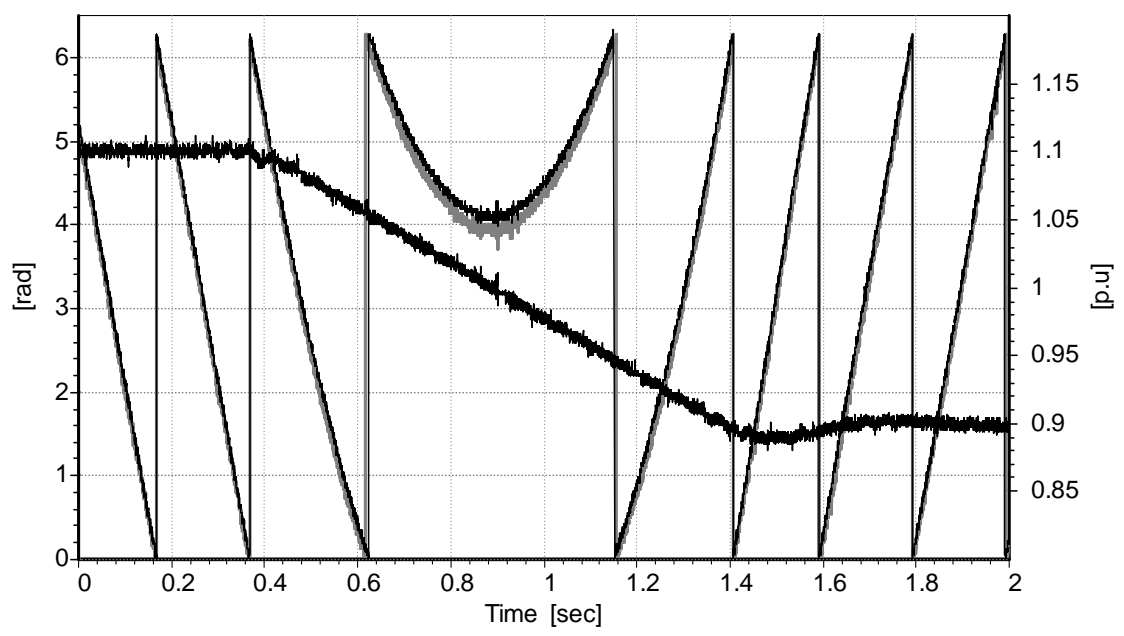

Figure 5.14 : Comparison between the sensorless method (grey) and an absolute position encoder (black) for a speed down step.

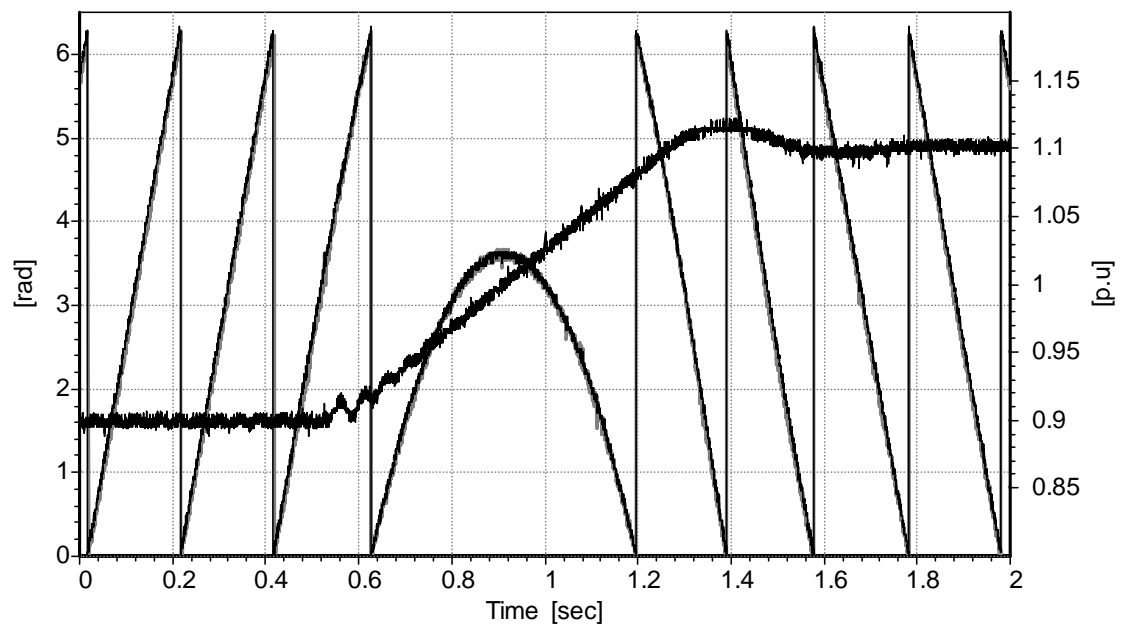

Figure 5.15 : Comparison between the sensorless method (grey) and an absolute position encoder (black) for a speed up step. 


\subsection{Reactive power steps for the transformer section alone}

Reactive power steps are performed for the transformer section alone, to illustrate the correct decoupling between the reactive power and the DC-link voltage (c.f $\$ 2.5 .4 a)$.

Starting from $0.2 \mathrm{pu}$, the reactive power set value is changed to $0.9 \mathrm{pu}$ at $0.1 \mathrm{~s}$ and then back to $0.2 \mathrm{pu}$ at $1.1 \mathrm{~s}$.

Figure 5.16 shows in grey the simulation and in black the measurements. From top to bottom the signals are the DC-link voltage, the reactive power and the active power.

As expected, a correct decoupling is found between the reactive power and the DClink voltage.

The active power increase during the reactive power step is due to the relative importance of the semi-conductors losses in the present low power application.

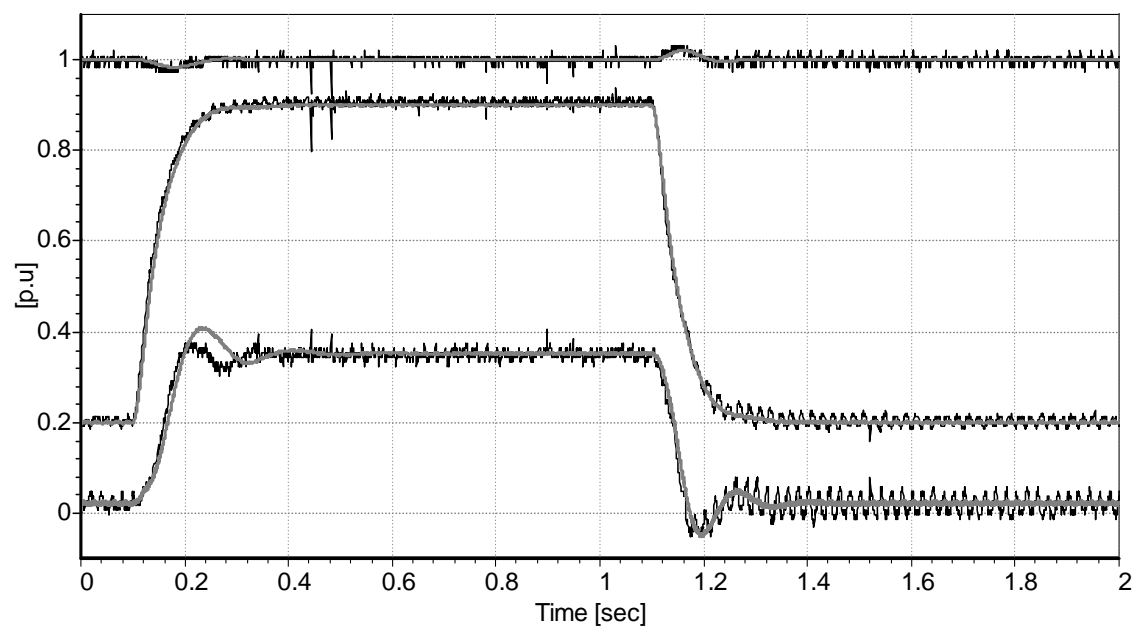

Figure 5.16

Reactive power steps - simulation (grey), measurements (black) from to bottom, the DC-link voltage, the reactive power and the active power 


\subsection{Speed transients}

\subsubsection{Introduction}

Figure 5.17 summarizes the different possible steady state operating modes. Note that in this section all the values are referred to the machine nominal power, and from now on, the speed will always be regulated by the machine.
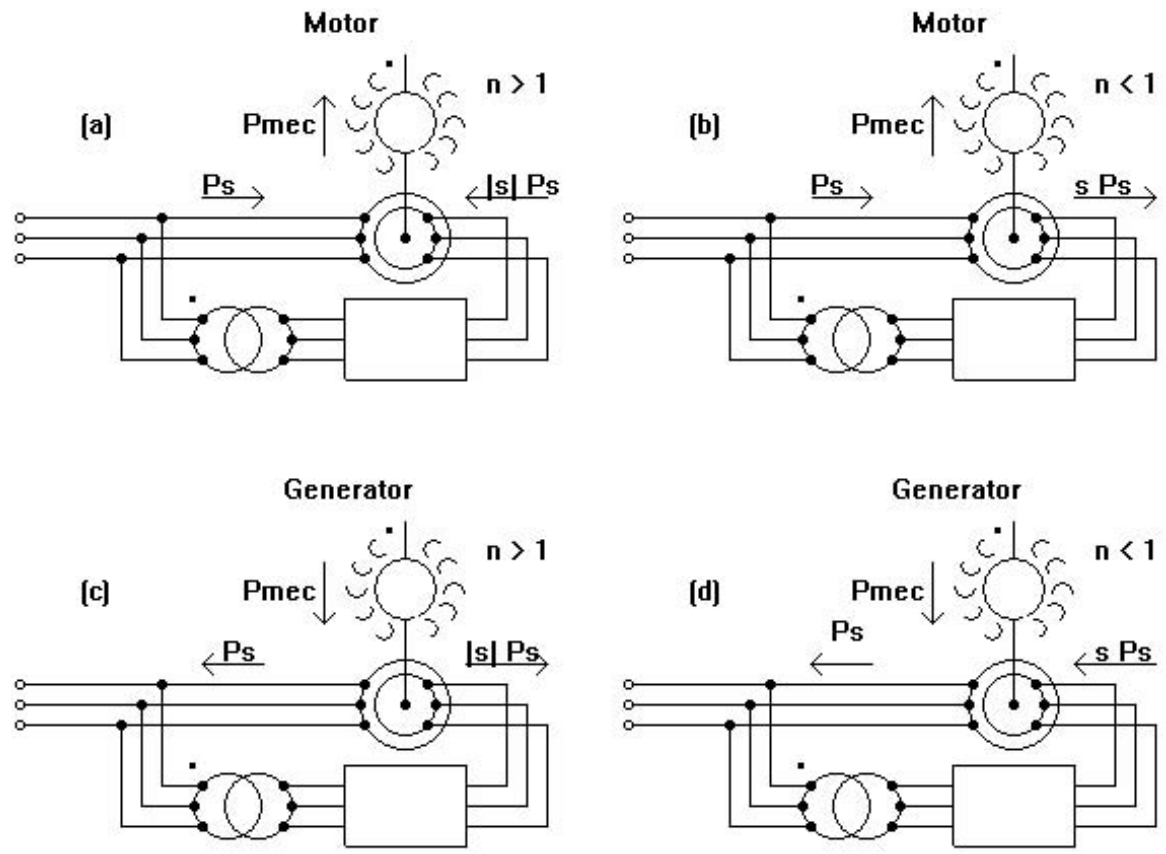

Figure 5.17 : The different possible operating modes

The speed transients presented in Figure 5.18 are deduced from Figure 5.17, by assuming that the external torque $\left(\mathrm{t}_{\mathrm{ext}}\right)$ is constant, and that the cascade losses are negligible $\left(\mathrm{p}_{\text {transformer }}=\mathrm{p}_{\text {rotor }}\right)$.

The starting and ending speeds are chosen symmetrically over the synchronous speed $(1.1 \rightarrow 0.9,0.9 \rightarrow 1.1)$, and the transients are performed in motor and in generator mode, leading to the four possible cases a-b-c-d.

As the power reference is the machine nominal power, the cascade is at its nominal power when $s= \pm s_{\max }$.

When the speed set value changes, the stator power uses the full available variation range, and the rotor power follows in the ratio s. Figure 5.19 illustrates the rotor power flow during transients. 
(a)

Motor $\mathrm{n}>\mathbf{1}$
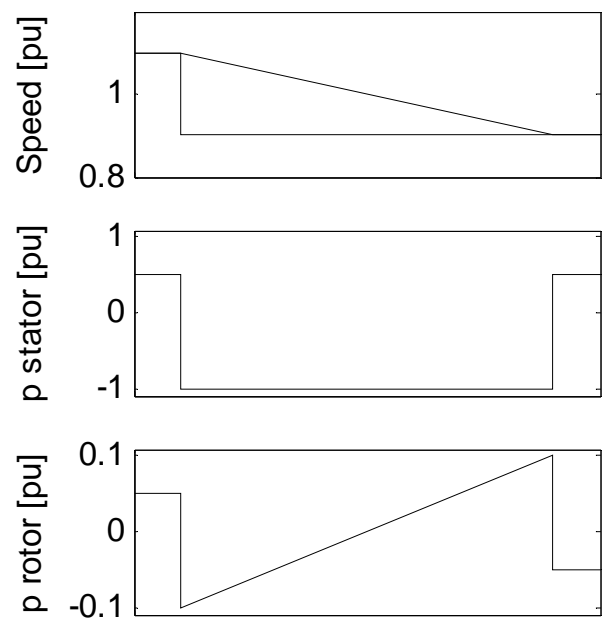

Time

(c)
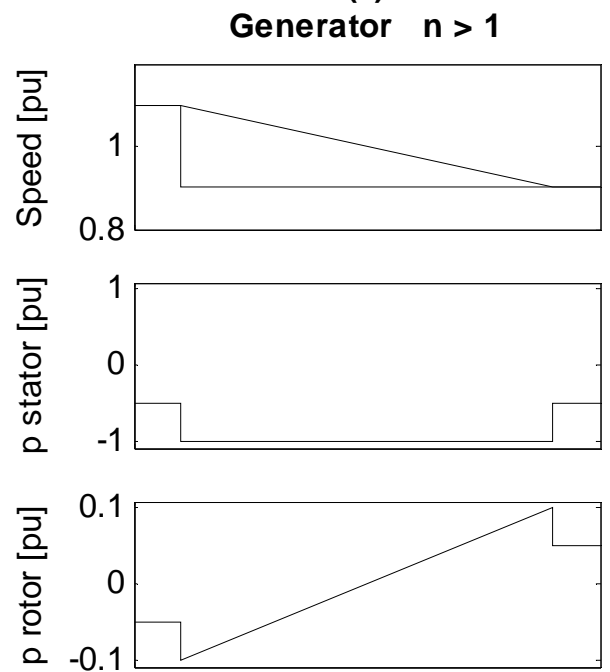

Time (b)

Motor $\mathrm{n}<1$
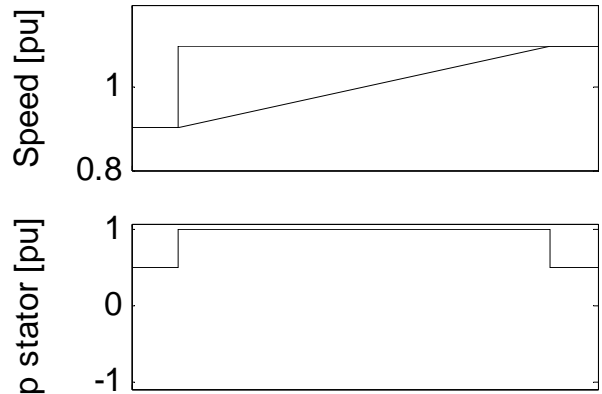

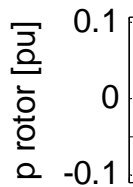

Time

(d)

Generator $\mathrm{n}<1$
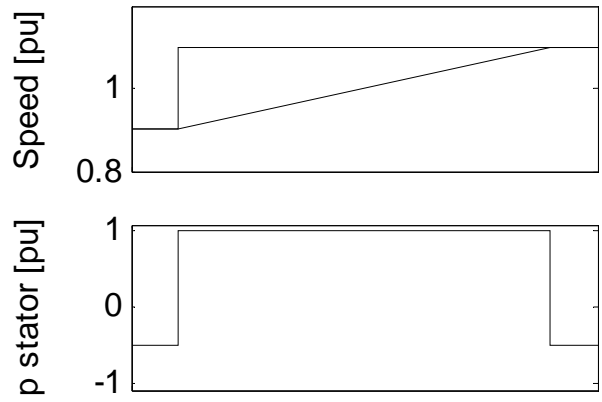

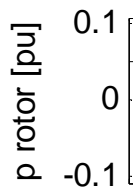

Time

Figure 5.18 : Transients with speed mode change 


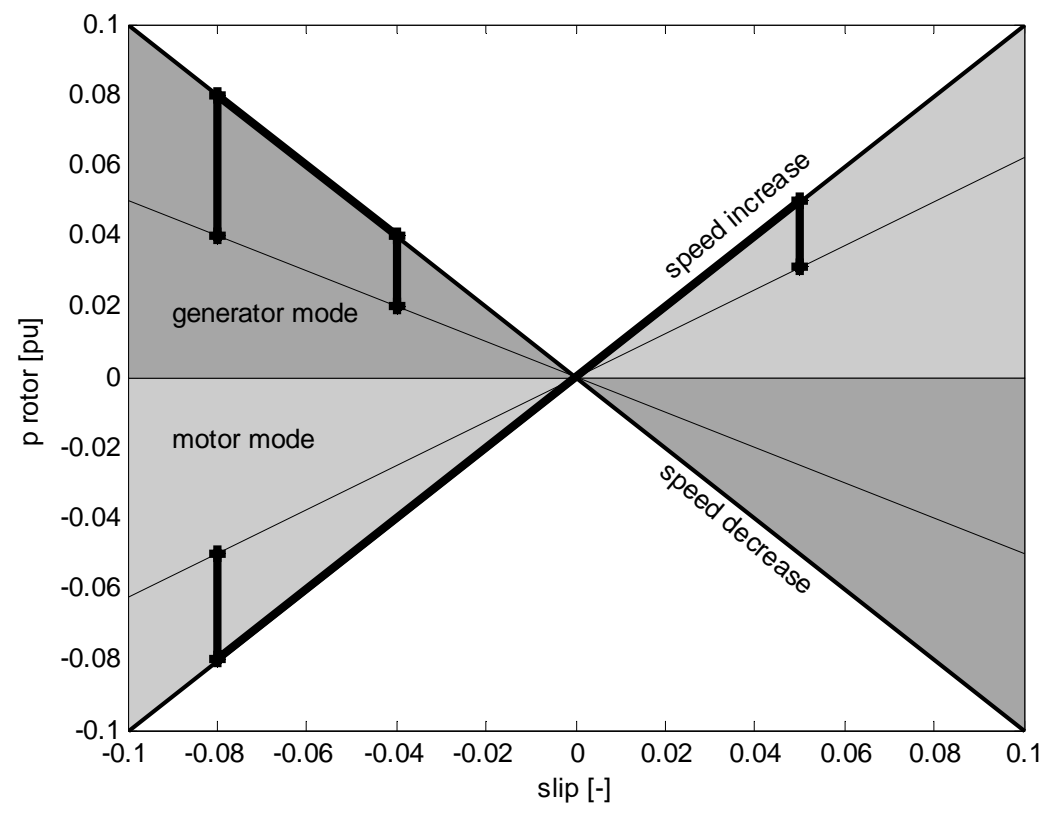

Figure 5.19 : The rotor active power in transient

The four transients shown in Figure 5.18 are presented and compared to simulations in the following sub-sections. In each presented transient, the speed set value change occurs at $0.1 \mathrm{~s}$. Three figures are presented in each transient. The first one shows the speed, the stator active and reactive powers. The second one shows the transformer active and reactive powers, and the third one the DC-link voltage and the capacitors voltages. In each and every figure, the simulations results are in grey, whereas the measurements are in black.

Note that due to the losses in the power electronics, the stator power limit is set to $\pm 0.7 \mathrm{pu}$ and the transformer power limit to $\pm 0.09 \mathrm{pu}$.

These speed steps are performed under constant external torque, and with the machine stator reactive power set value kept constant. A supplementary inertia has also been added to slow down the speed variations and allow a correct analysis of the results. 


\subsubsection{Case (a) - Motor mode speed down step}

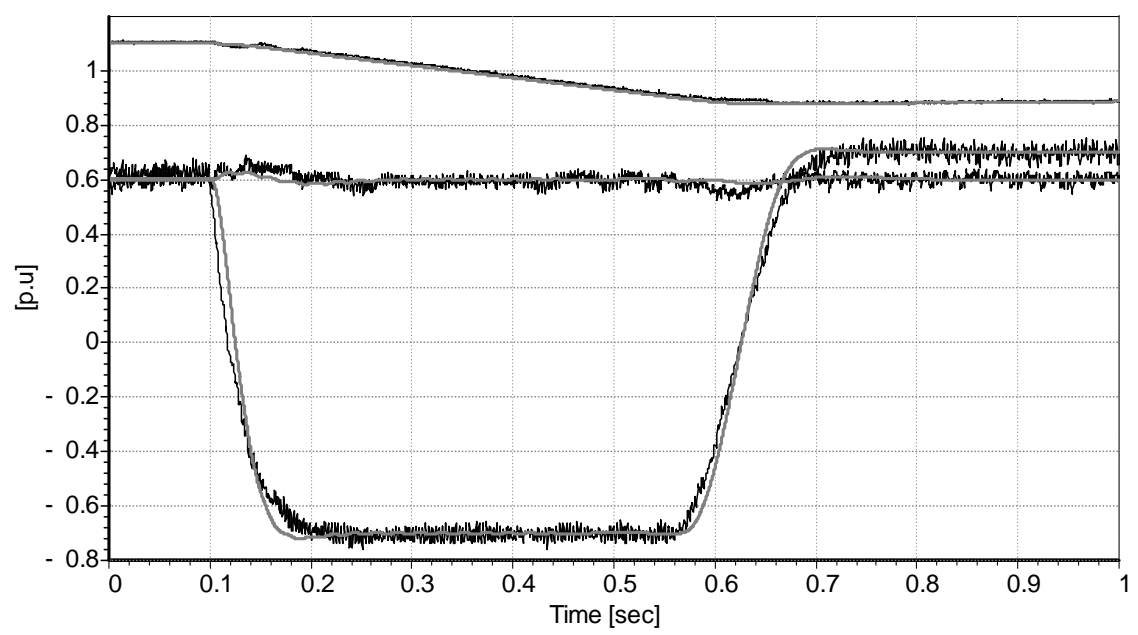

Figure 5.20 : Case (a)

Motor mode speed down step - simulation (grey), measurements (black)

Speed, stator active and reactive powers

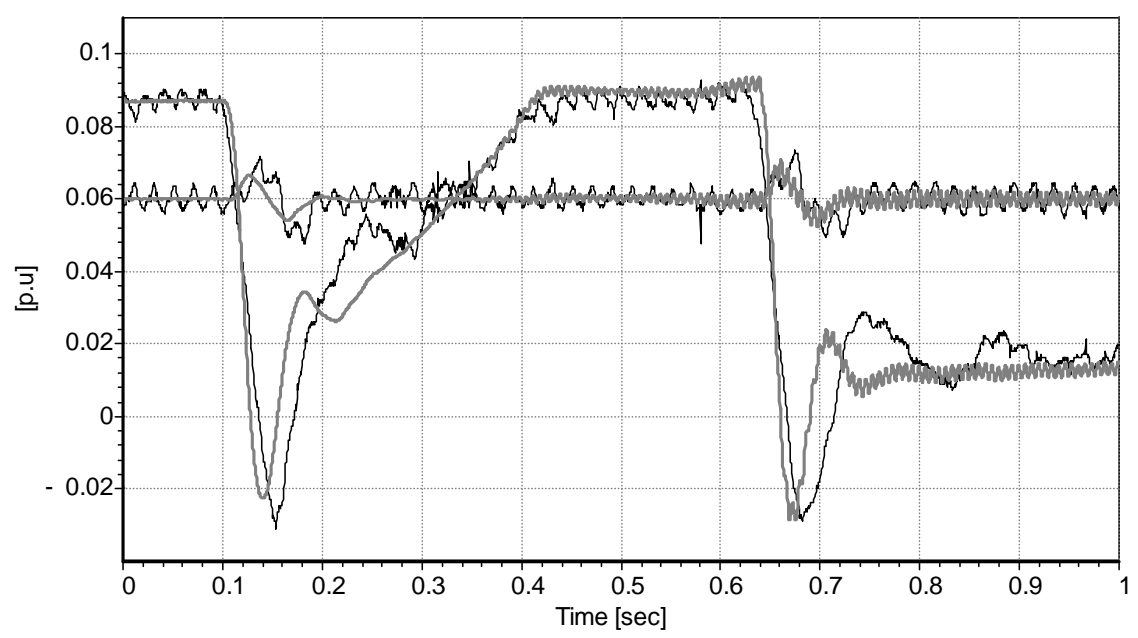

Figure 5.21 : Case (a)

Motor mode speed down step - simulation (grey), measurements (black)

Transformer active and reactive powers 


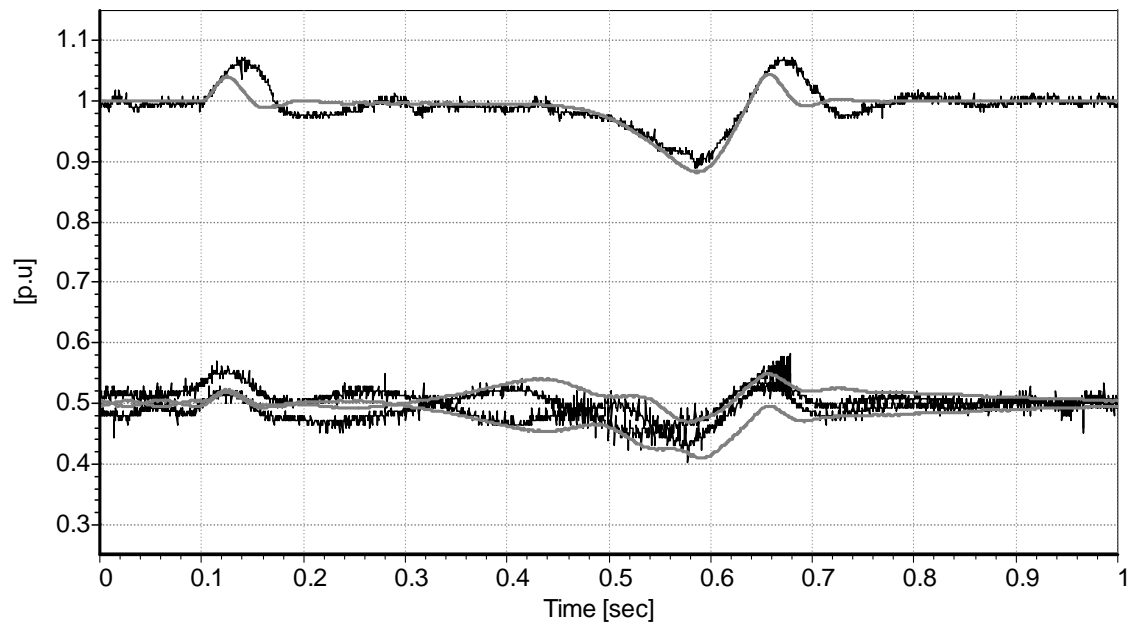

Figure 5.22 : Case (a)

Motor mode speed down step - simulation (grey), measurements (black)

DC-link and capacitors voltages

\subsubsection{Case (b) - Motor mode speed up step}

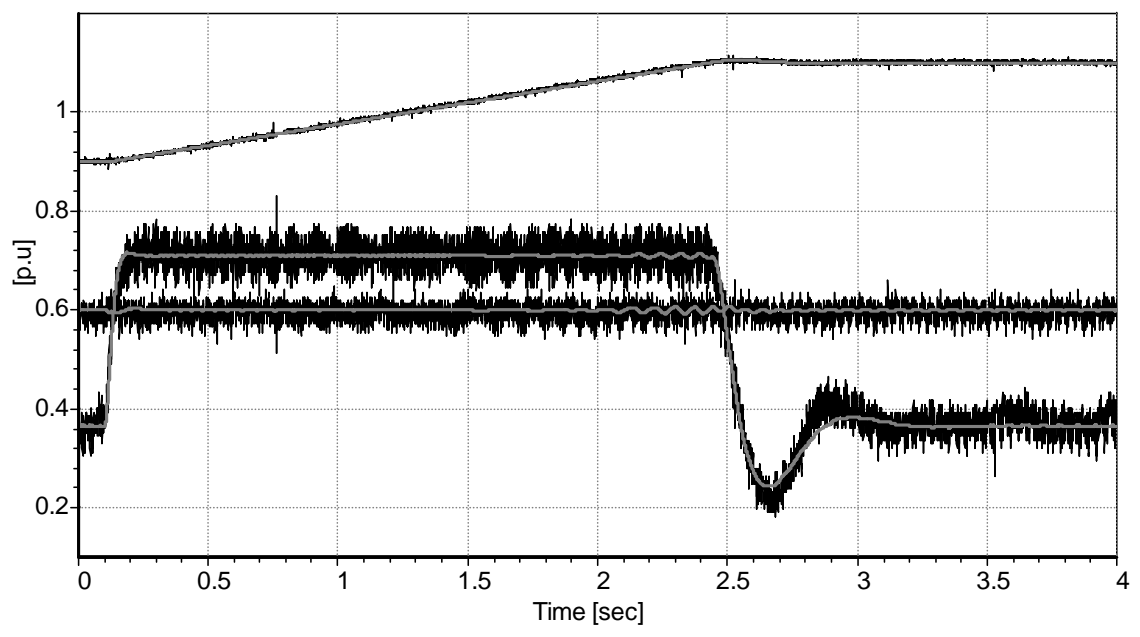

Figure 5.23 : Case (b)

Motor mode speed up step - simulation (grey), measurements (black)

Speed, stator active and reactive powers 


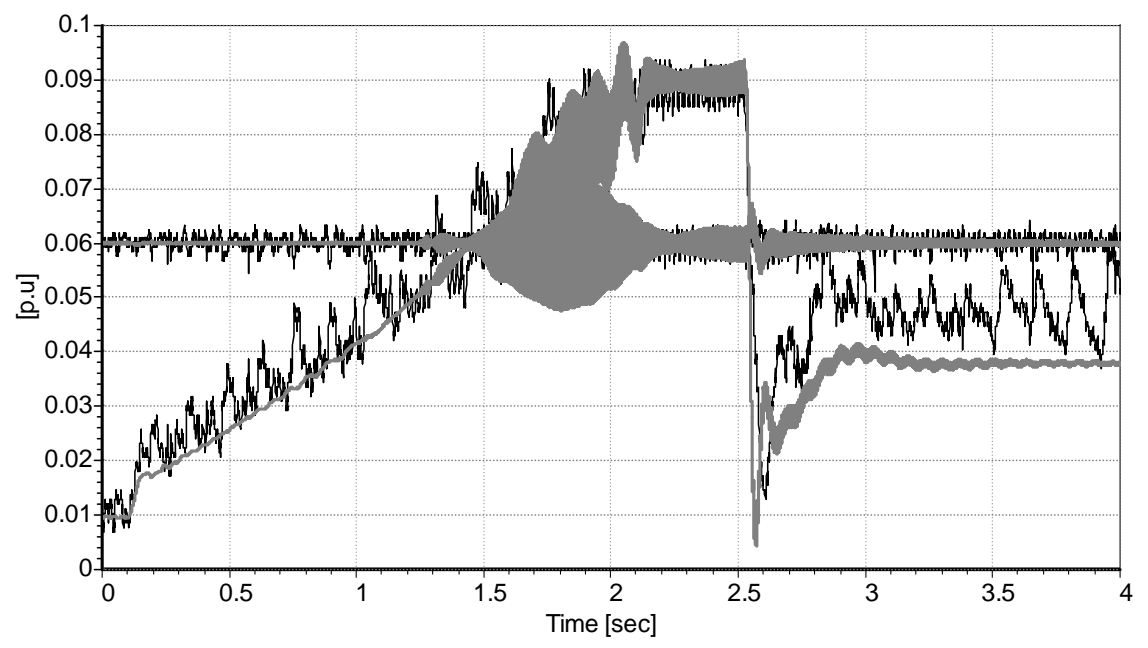

Figure 5.24 : Case (b)

Motor mode speed up step - simulation (grey), measurements (black)

Transformer active and reactive powers

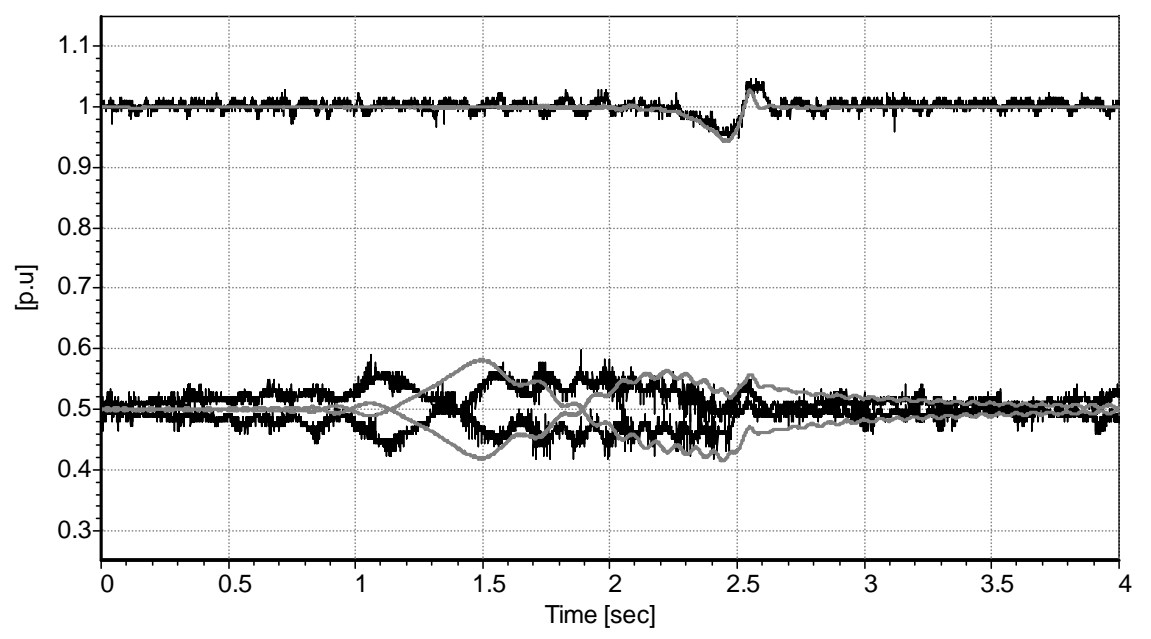

Figure 5.25 : Case (b)

Motor mode speed up step - simulation (grey), measurements (black)

DC-link and capacitors voltages 


\subsubsection{Case (c) - Generator mode speed down step - Flywheel effect}

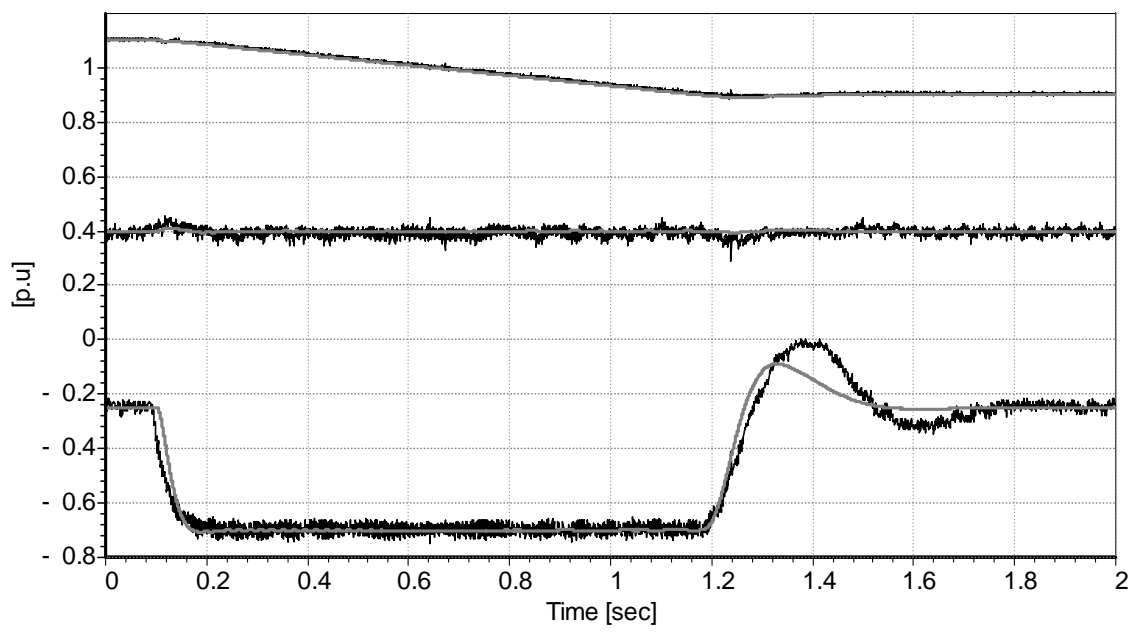

Figure 5.26 : Case (c)

Flywheel effect - simulation (grey), measurements (black)

Speed, stator active and reactive powers

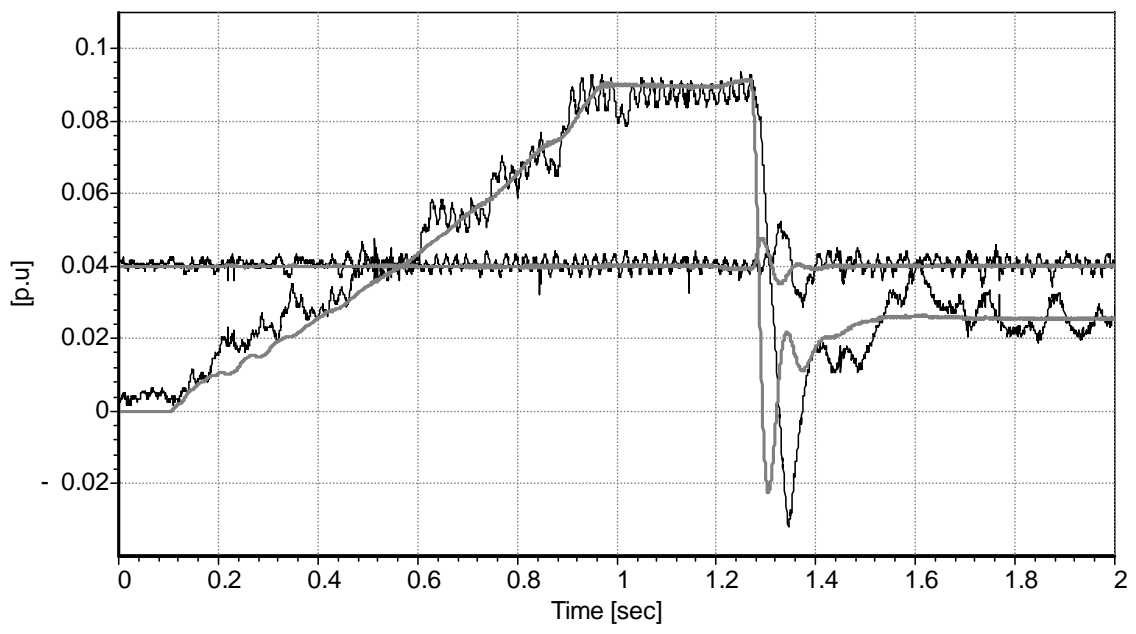

Figure 5.27 : Case (c)

Flywheel effect - simulation (grey), measurements (black)

Transformer active and reactive powers 


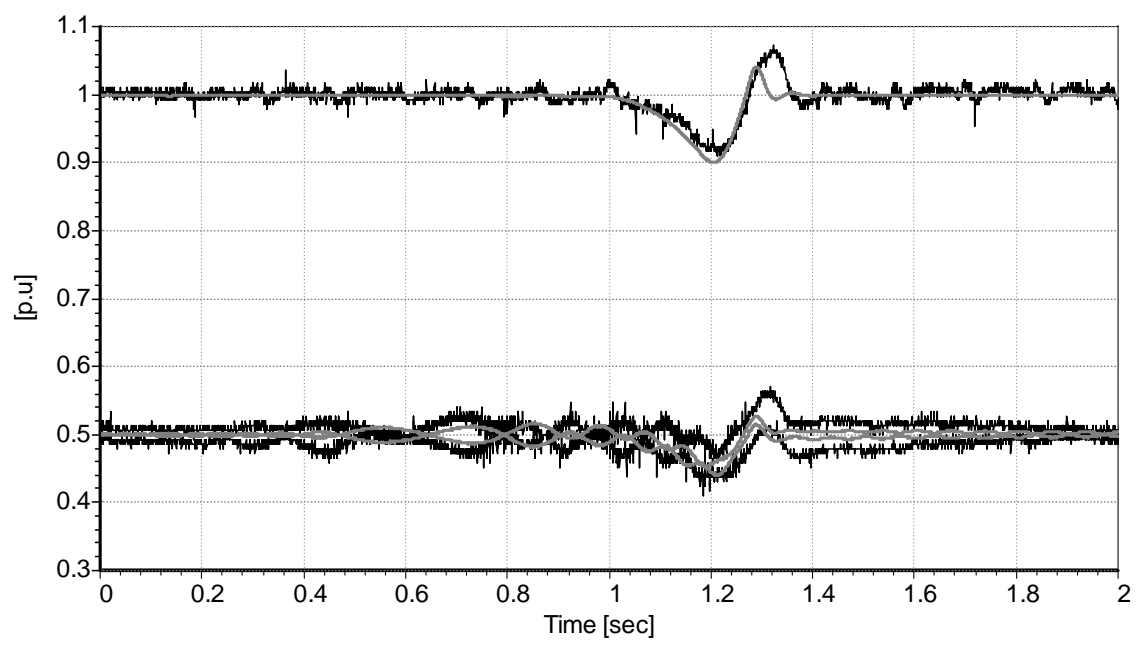

Figure 5.28 : Case (c)

Flywheel effect - simulation (grey), measurements (black)

DC-link and capacitors voltages

\subsubsection{Case (d) - Generator mode speed up step}

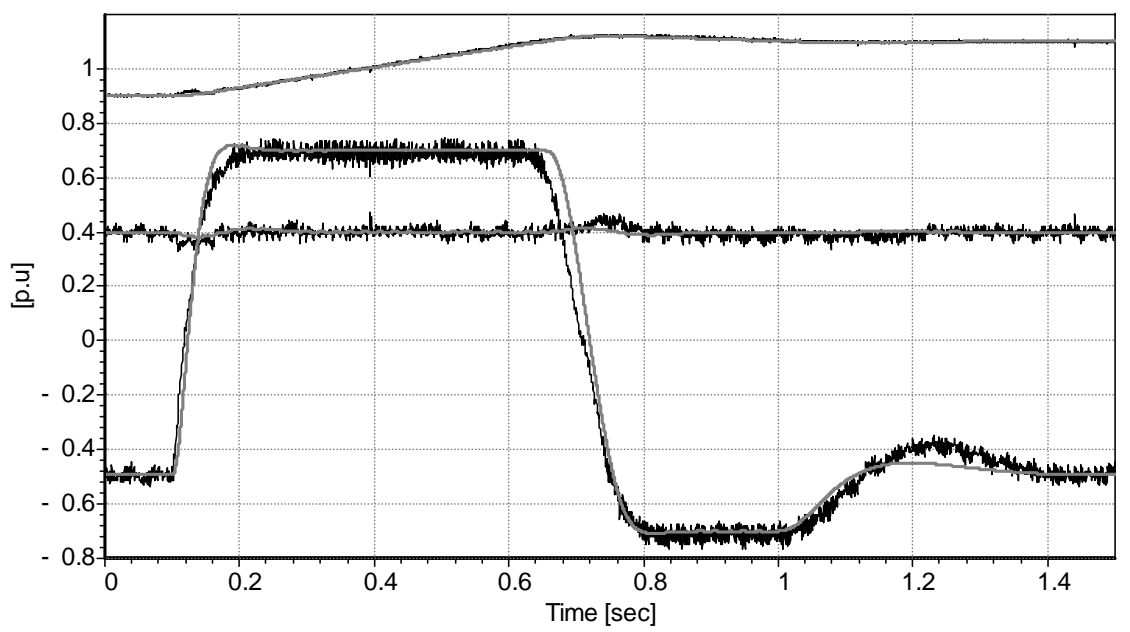

Figure 5.29 : Case (d)

Generator mode speed up step - simulation (grey), measurements (black) Speed, stator active and reactive powers 


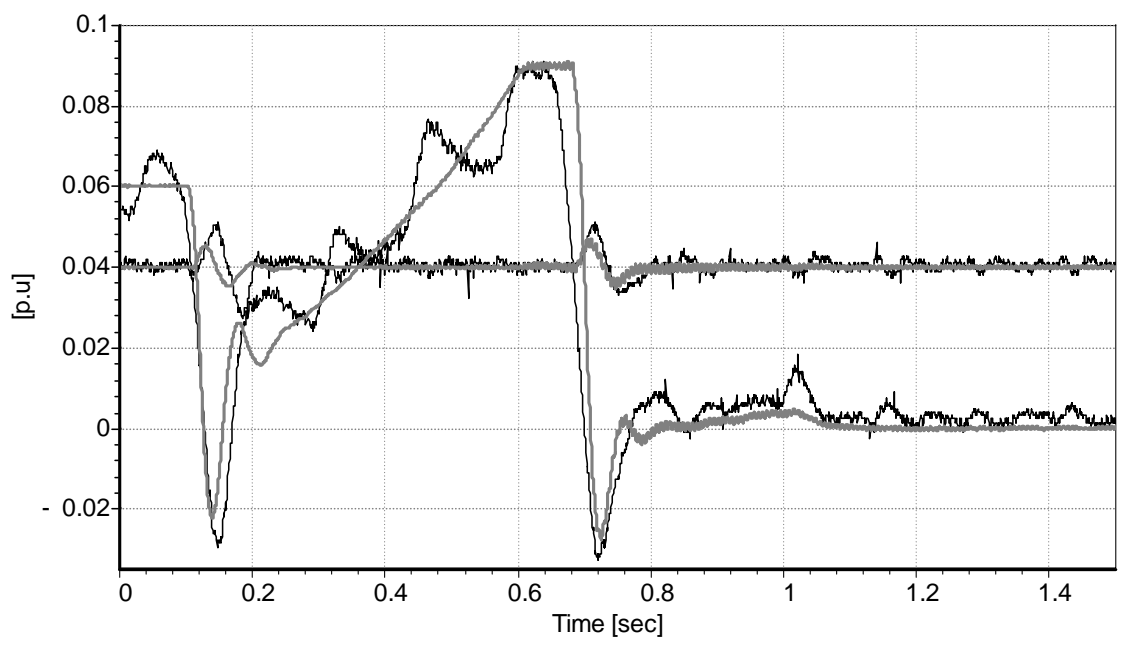

Figure 5.30 : Case (d)

Generator mode speed up step - simulation (grey), measurements (black) Transformer active and reactive powers

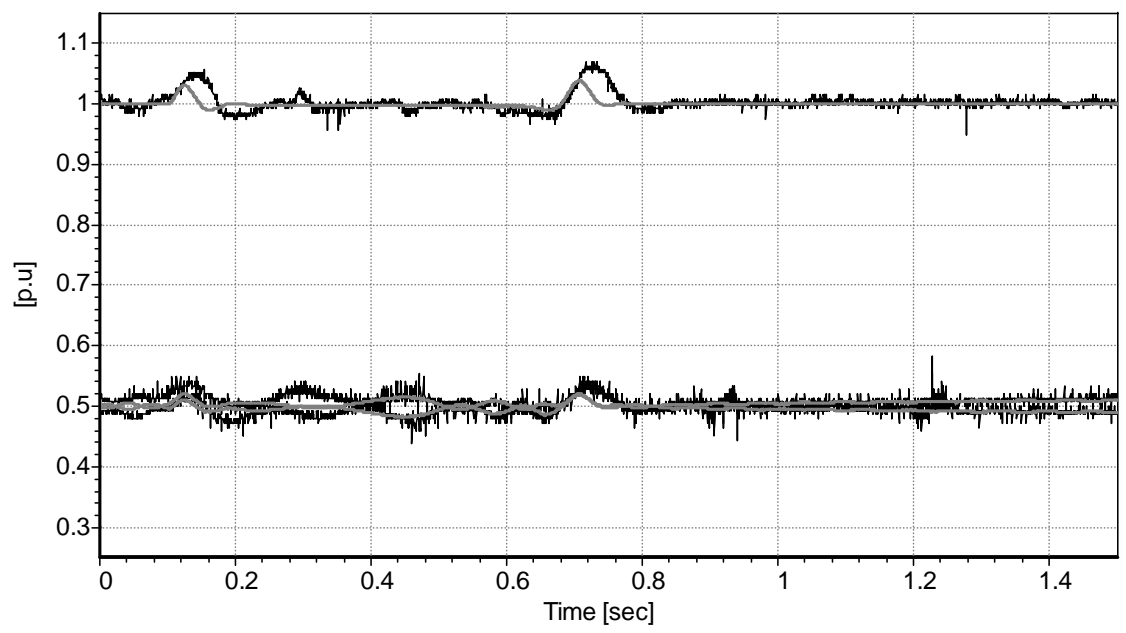

Figure 5.31 : Case (d)

Generator mode speed up step - simulation (grey), measurements (black)

DC-link and capacitors voltages 


\subsubsection{Analysis of the results of the speed transients}

From the figures presenting the transients it can be said that a correct decoupling is found between the speed (active power) and reactive power for the machine and between the DC-link voltage (active power) and the reactive power for the transformer.

For the stator active power, it acts exactly as expected from $§ 5.4 .1$ and Figure 5.18.

For the DC-link, the voltage drop found in the transients is due to the fact that once the transformer active power has reached its limit $( \pm 0.09 \mathrm{pu})$, the missing energy is supplied by the capacitors, leading to the voltage drop (for example Figure 5.22 and Figure 5.28).

The generation of even numbered harmonics due to a relatively high saturation level of the machine leads to a constant action of the DC-unbalance controller, which results in the ripple of $150 \mathrm{~Hz}$ found in the transformer primary side reference frame, especially in the measurements (Figure 5.21). This effect is particularly visible in the simulations of the case (b) (Figure 5.24), where the action of the DC-unbalance controller, and also the quite large DC unbalance component, lead to quite large oscillations in the transformer active and reactive powers. However, this has nearly no effect on the machine (Figure 5.23). In spite of this, it can be said that during the transients the capacitors voltage is kept balanced, as it never exceeds $7-8 \%$.

It is also obvious from the results that the DC-link voltage and the DC unbalance controls are completely decoupled.

Table 5.1 summarizes the starting and ending operating points for the four transients presented in the previous sub-sections. Remember that the losses in the power electronics of the present low power system are high. The results show that as expected the stator active and reactive powers, as well as the transformer reactive power, match the expected results and no difference is seen before and after the transient.

\begin{tabular}{|r|c|c|c|c|c|c|c|c|}
\cline { 2 - 10 } \multicolumn{1}{c|}{} & \multicolumn{2}{c|}{ Case a } & \multicolumn{2}{c|}{ Case b } & \multicolumn{2}{c|}{ Case c } & \multicolumn{2}{c|}{ Case d } \\
\cline { 2 - 10 } \multicolumn{1}{c|}{} & start & end & start & end & start & end & Start & End \\
\hline Speed & 1.1 & 0.9 & 0.9 & 1.1 & 1.1 & 0.9 & 0.9 & 1.1 \\
\hline Stator active power & 0.6 & 0.6 & 0.35 & 0.35 & -0.25 & -0.25 & -0.5 & -0.5 \\
\hline Stator reactive power & 0.6 & 0.6 & 0.6 & 0.6 & 0.4 & 0.4 & 0.4 & 0.4 \\
\hline Transfo. active power & 0.085 & 0.015 & 0.01 & 0.04 & 0.005 & 0.03 & 0.06 & 0 \\
\hline Transfo. reactive power & 0.06 & 0.06 & 0.06 & 0.06 & 0.04 & 0.04 & 0.04 & 0.04 \\
\hline
\end{tabular}

Table 5.1 : Speed transients results 
For the transformer active power, a sign reversal of the starting value was expected. However, due to the high level of losses in the power electronics, the transformer active power is not even negative, because when the rotor active power is negative, it is completely dissipated in the power electronics. This explains the values found in Table 5.1 for the transformer active power. Actually, by neglecting the losses, the transformer active power should have, in the ratio s, the same absolute value as the stator active power.

The flywheel effect :

A flywheel effect occurs when the system is working in generator mode, that the speed is regulated by the machine, and results in the possibility of quickly supplying the network with the rotating energy. This corresponds to the case (c).

When performing a flywheel effect, the important point is the power that the system can supply to the network. Figure 5.32 shows the machine stator power in grey and the overall power supplied to the network in black. It can be seen that the overall power supplied quickly reaches its maximum value and slowly decreases. This decrease is due to the high level of the losses in the power electronics.

To have a better idea of the flywheel effect in high power systems, a simulation has been performed with the system defined in $\S 2.5, \S 3.4$ and $\S 4.5$. Figure 5.33 shows the machine stator power in grey and the overall power supplied to the network in black. Compared to Figure 5.32, at the beginning, and as expected, the rotor cascade supplies the network with an active power of $\left(-s \cdot p_{s}\right)$, explaining why the network power reaches $-1.32 \mathrm{pu}$ (the machine stator power limit is set to $1.2 \mathrm{pu}$ ). Then, the overall power supplied to the network decreases with the speed to $-1.08 \mathrm{pu}$, before reaching its final value once the speed limit is reached. 


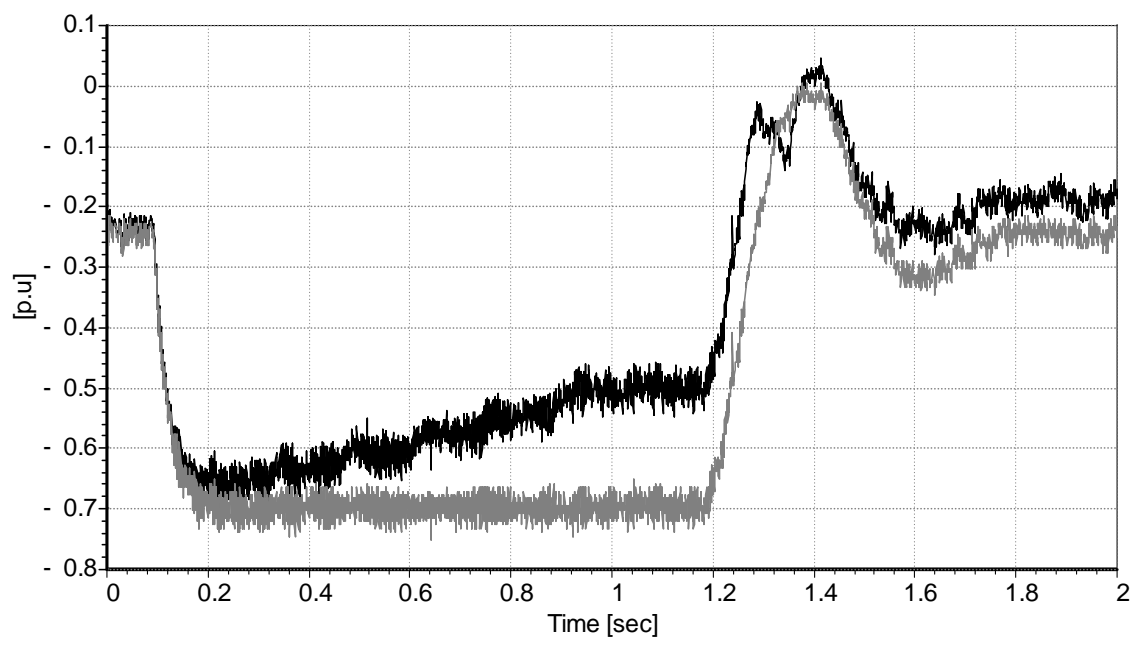

Figure 5.32 : Case (c) - Flywheel effect measurement

Machine stator active power (grey) - Network active power (black)

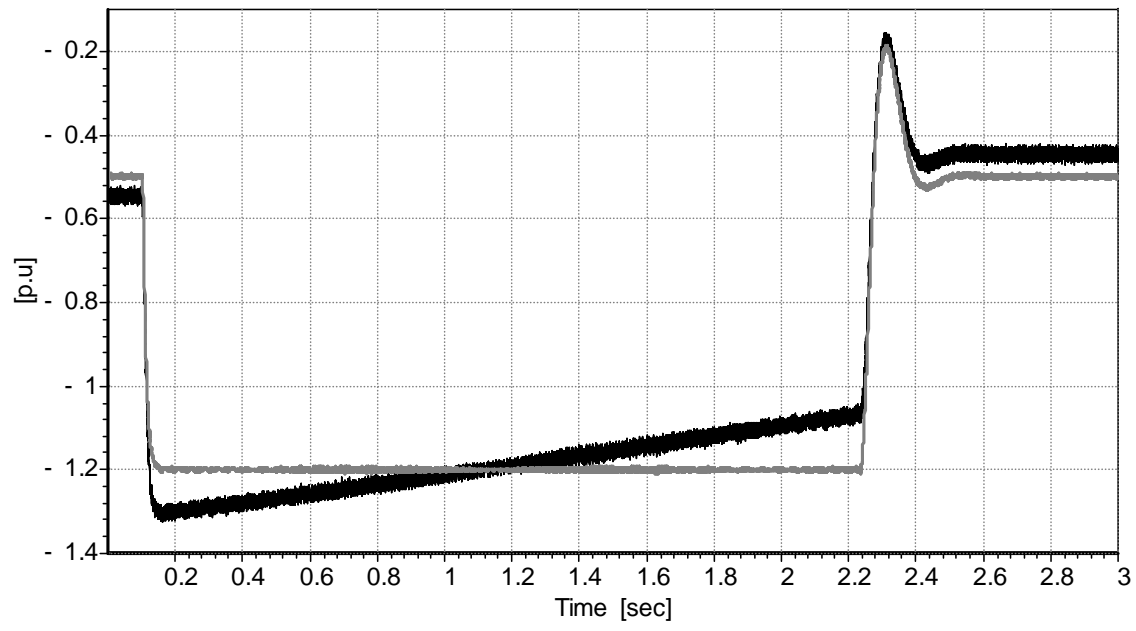

Figure 5.33 : high power system flywheel effect

Machine stator active power (grey) - Network active power (black) 


\subsection{Load steps}

\subsubsection{Introduction}

To check the system behaviour in the presence of rapid load variations, two different transients have been measured.

Both transients are performed under constant speed, constant stator reactive power and constant transformer reactive power.

The first transient is at a speed of $1.1 \mathrm{pu}$, and the external torque changes from about $0.5 \mathrm{pu}$ to $-0.5 \mathrm{pu}$. The second transient is at a speed of $0.995 \mathrm{pu}$, and the external torque changes from 0 pu to about $0.5 \mathrm{pu}$ and back to $0 \mathrm{pu}$.

In both cases three figures are presented, respectively Figure 5.34, Figure 5.35 and Figure 5.36 for the first one and Figure 5.37, Figure 5.38 and Figure 5.39 for the second one. In each case, the first figure shows the speed, the stator active and reactive powers, the second figure the transformer active and reactive powers, and the third figure the DC-link voltage and the capacitors voltages.

\subsubsection{Large load step}

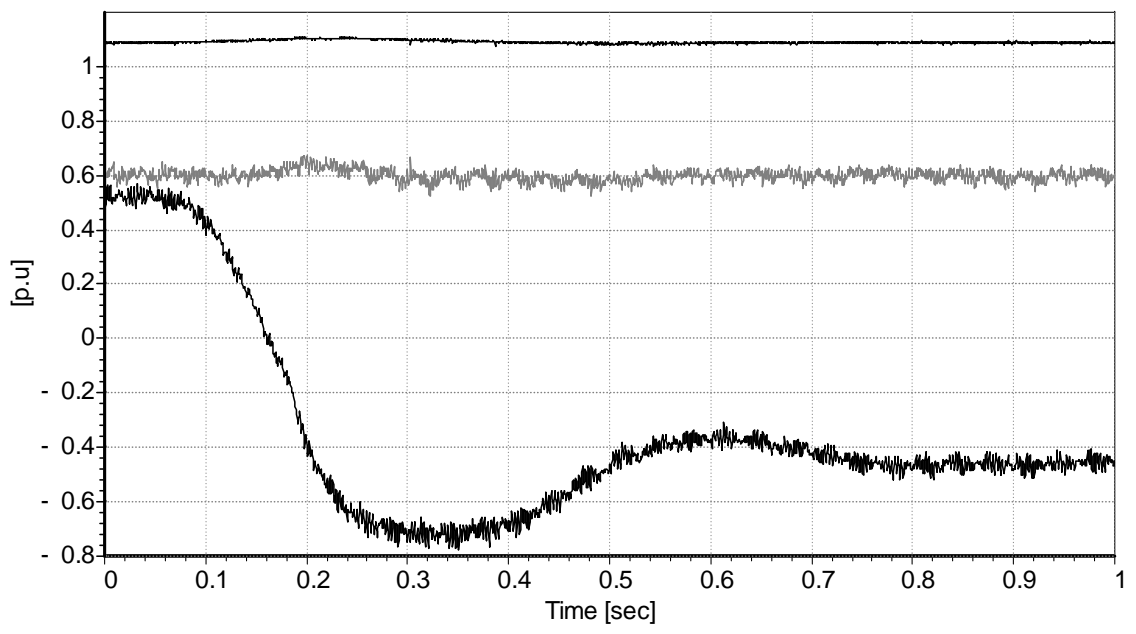

Figure 5.34 : Large load step - Speed, stator active and reactive powers 


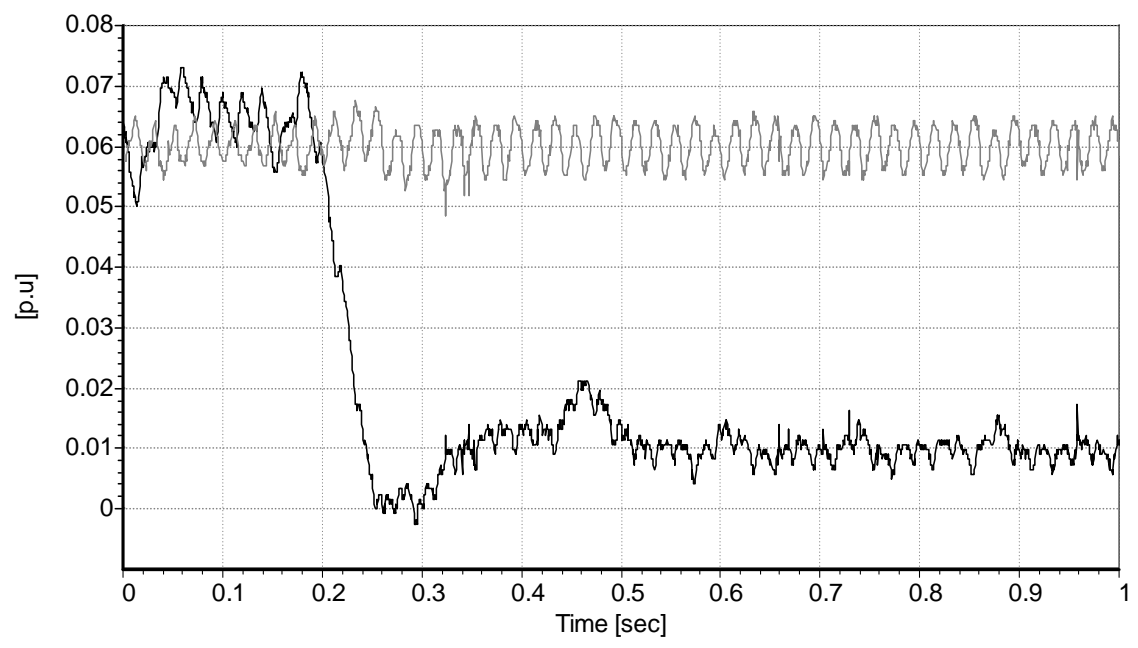

Figure 5.35 : Large load step - Transformer active and reactive powers

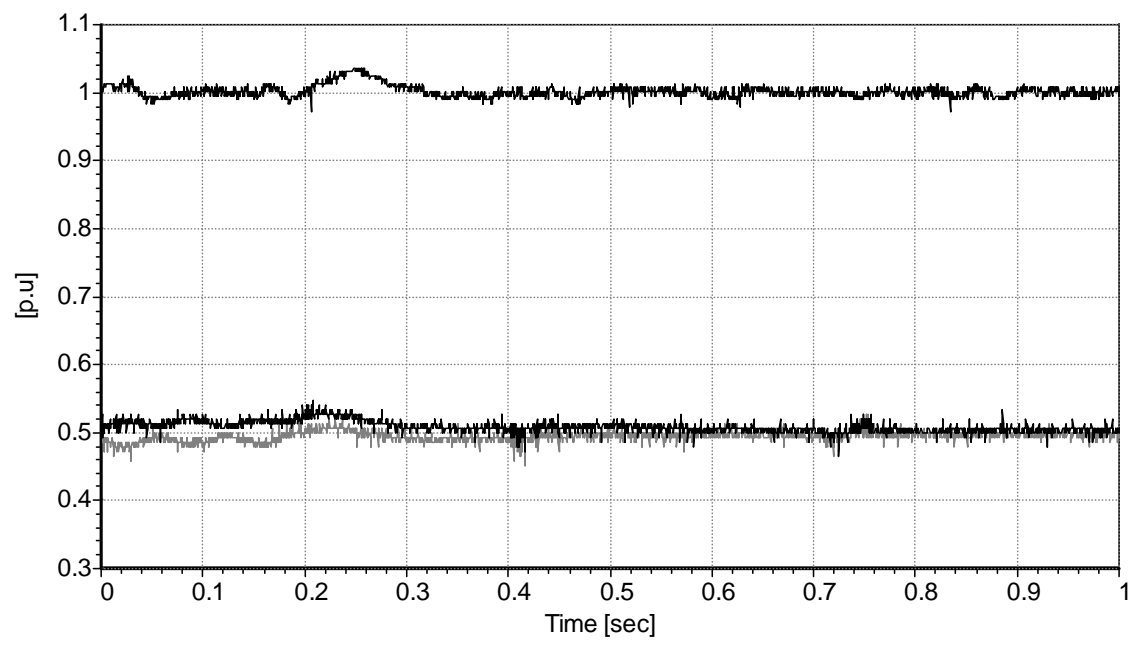

Figure 5.36 : Large load step - DC-link and capacitors voltages 


\subsubsection{Load steps with a speed close to the synchronous speed}

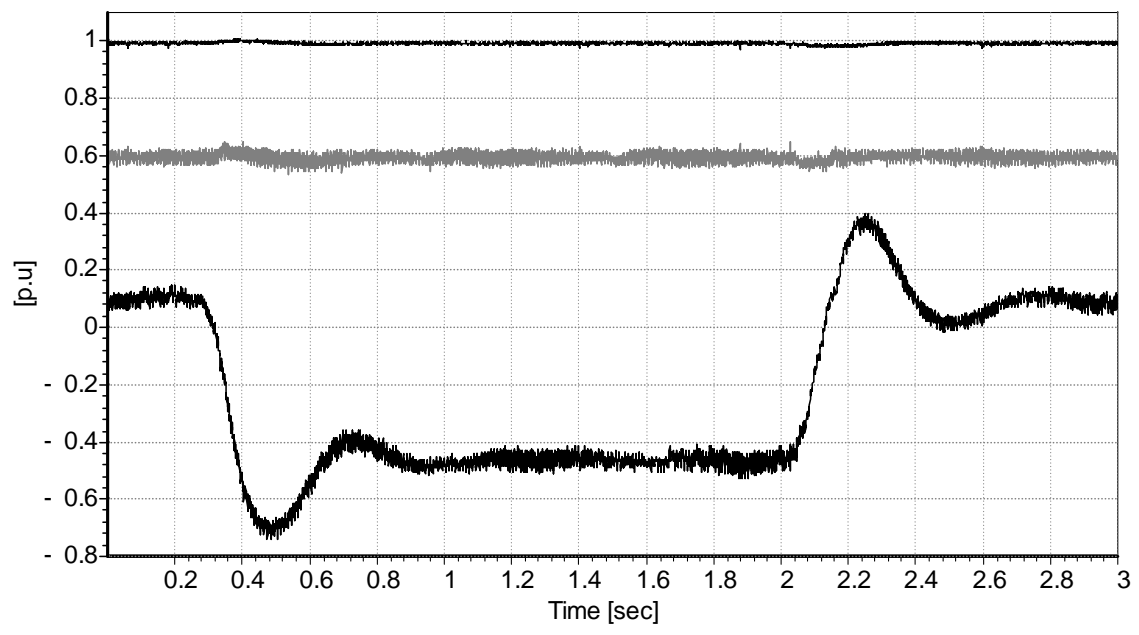

Figure 5.37 : Close to synchronous speed load steps - Speed, stator active and reactive powers

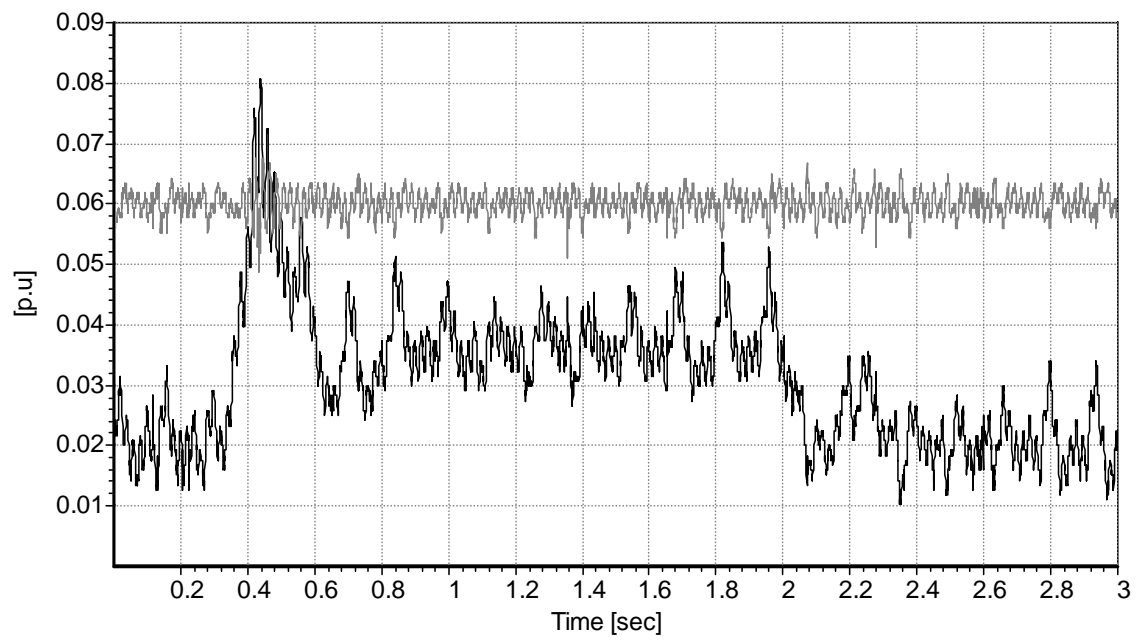

Figure 5.38 : Close to synchronous speed load steps - Transformer active and reactive powers 


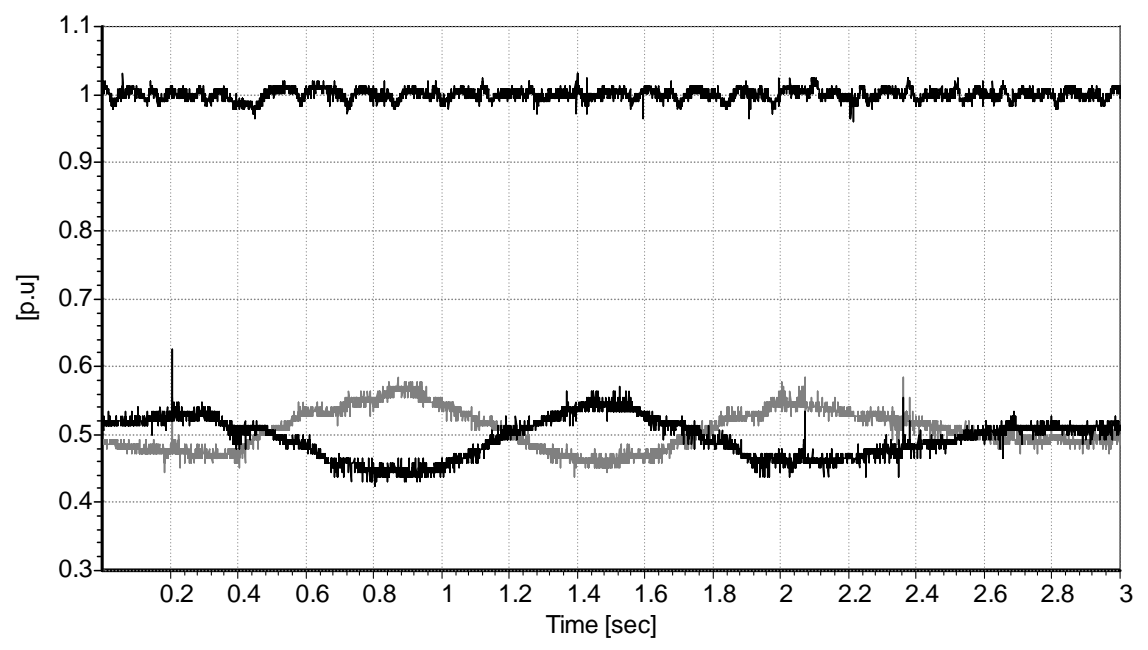

Figure 5.39 : Close to synchronous speed load steps - DC-link and capacitors voltages

\subsubsection{Result analysis for the load steps}

Both transient show the correct decoupling between the disturbances (external torque) and the machine and transformer controls.

Actually, the machine and transformer reactive powers are kept constant as is the DC-link voltage. Also, the capacitors voltages are kept balanced.

The stator power follows correctly the external torque variations, ensuring that the speed is kept constant. Note that the overall offset found in the stator active power, which is particularly seen in Figure 5.37, is due to the electrical losses in the semiconductors.

The transformer active power acts correctly as the DC-link voltage is kept constant even though the losses in the power semiconductors are high.

Hence it can be said that the overall system acts correctly in the presence of a disturbance (external torque). 


\subsection{Industrial Application - The size of the capacitors}

As stated in $\$ 4.2 .1$, the natural DC-link oscillation is inversely proportional to the capacitors size. For an industrial application, using the smallest capacitors becomes a necessity in terms of price. In the present system, the DC-link oscillation amplitude is mainly dependant on the rotor side, due to its low frequencies. Therefore, replacing the rotor side 3-level VSI by a 2-level VSI, as shown in Figure 5.40, allows a reduction of the capacitors size.

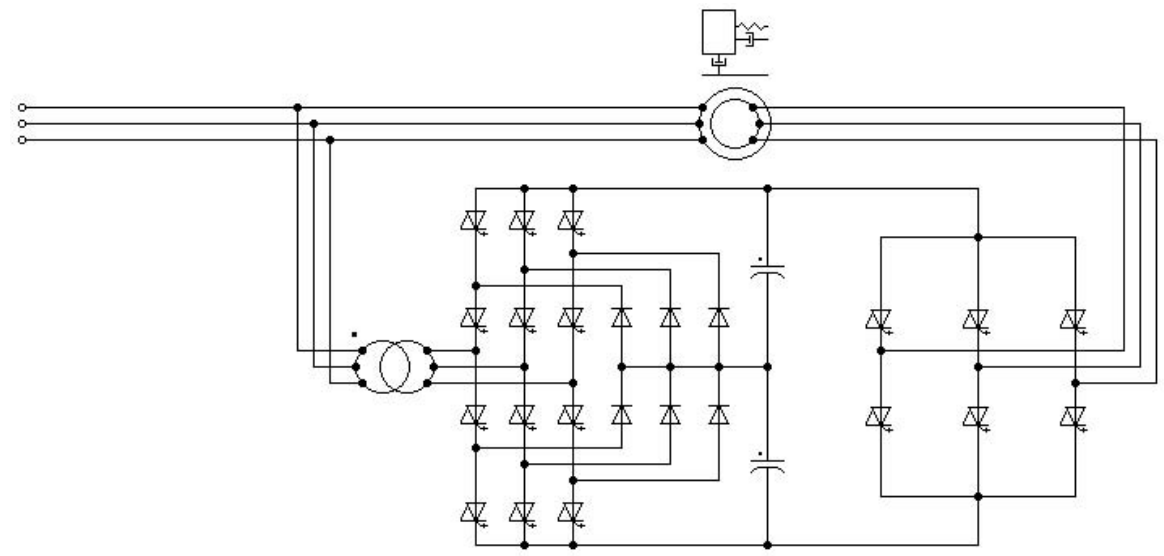

Figure 5.40 : The 3-2 level configuration

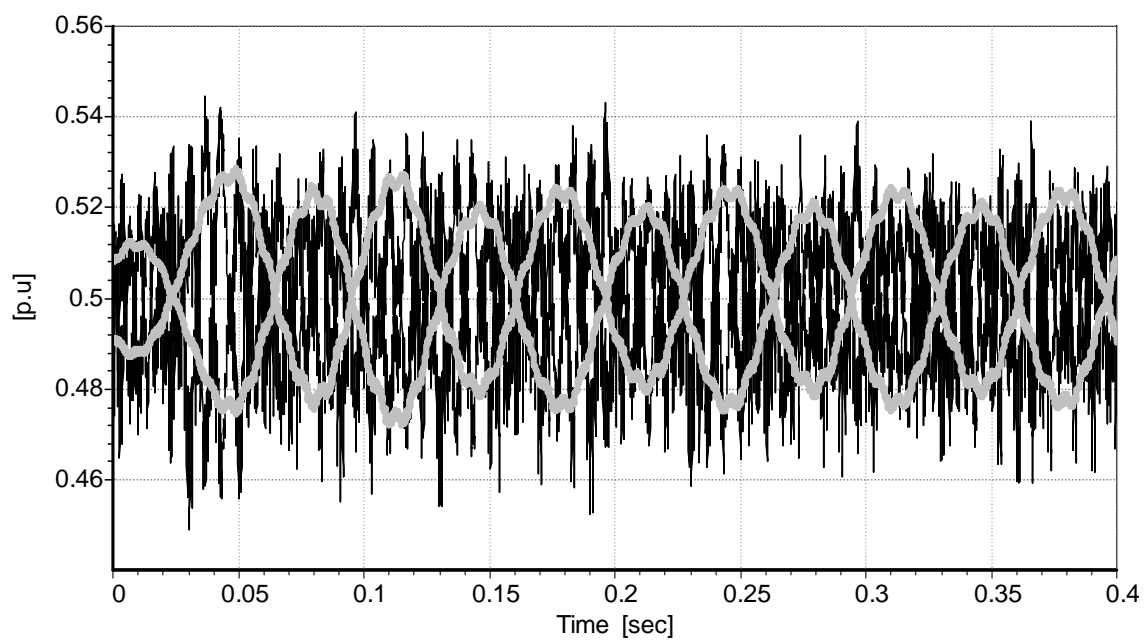

Figure 5.41 : Comparison between 3-level and 2-level for a capacitors size 20 times smaller 
In Figure 5.41, a simulation presents the comparison between the use of a 2 and 3 -level VSI on the rotor side, for the system defined in $\S 2.5, \S 3.4$ and $\S 4.5$. This figure shows, that for the present system, a significant reduction of the capacitors size leads to the same natural DC-link oscillation amplitude. Practical measurements validate the statement that the capacitors size can be significantly reduced.

However it must not be forgotten that the relation between the DC-link oscillation amplitude and the capacitor size is also depending on the modulation strategy. Especially, for low output frequencies and in the the case of corresponding low output amplitudes, the DC current modulation can be improved by using an adequate modulation strategy using redundant phasors [16].

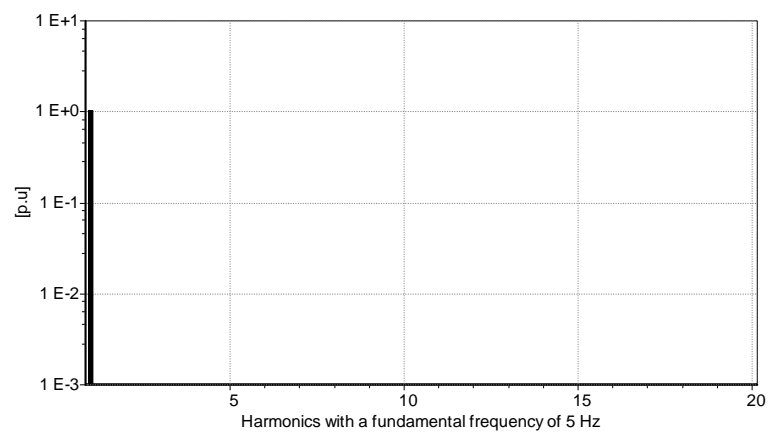

Figure 5.42 : Rotor current 3-level

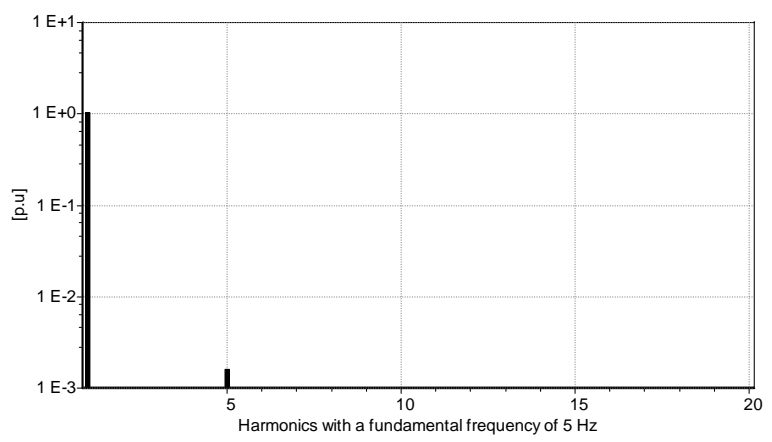

Figure 5.43 : Rotor current 2-level 
The use of a 2-level VSI on the rotor side has some drawbacks. One of them is a higher current THD (Total Harmonic Distortion) [4]. However, due to the low frequency found on the rotor side, this effect is only of little importance. One of the main drawbacks is more constraints on the machine insulation due to higher $\mathrm{dv} / \mathrm{dt}$, and the necessity of using a power electronics being able to handle the whole DClink voltage.

Figure 5.42 to Figure 5.43 show the Fourier analysis comparison for the rotor currents in the case of using a 3-level (Figure 5.42) or a 2-level (Figure 5.43). From this it can clearly be seen that no harmonics higher than $1 \mathrm{E}-3$, except the $5^{\text {th }}$ rotor side harmonic, are found in any case. The stator currents show no harmonics higher than $1 \mathrm{E}-3$ in both cases.

\subsection{Conclusion}

The present chapter has dealt with the practical application of the overall system performed with a low power installation.

First of all, methods for retrieving the required angles $\theta_{\mathrm{s}}$ and $\theta_{\mathrm{r}}$ are proposed and investigated. For the latter, a sensorless method had been proposed and discussed, and validated by measurements.

The entire transients presented validate the different choices made in the control design. In the light of the results, the use of the classical control for the transformer section (\$2.6), appears to be a correct solution for the present application.

The choice of replacing the rotor side 3-level VSI by a 2-level VSI cannot be generalised, and must be related to a more specific design of the machine rotor. 


\section{Conclusion}

The present thesis comprises all the necessary steps for the design of a double fed asynchronous motor-generator equipped with a 3-level VSI cascade.

The system under studywas decomposed into two sections: the transformer and the machine sections. In each of them the aim was to set a correct decoupling between the defined $d$ and $q$ axes while offering the desired regulation values. The values for the transformer section being the DC-link voltage and the reactive power on the primary side. The values for the machine section being, the speed (stator active power) and the stator reactive power.

In the case of the transformer section, two different strategies have been presented and compared, these being the classical and the state-space controls. The comparison showed that in regard to the current application, the classical control matches the requirements.

In both sections, the correct decoupling between the $\mathrm{d}$ and $\mathrm{q}$ axes was validated by simulations. Also, the major disturbances and the eventual drawbacks on the regulation strategy have been presented and discussed.

In a second step, the problem of interfacing the transformer and the machine sections through the DC-link, and more specifically the DC unbalance was investigated. This appears to be the major drawback of the use of a 3-level VSI cascade, compared to a 2-level VSI cascade. This specific problem of the current application has been discussed and a solution was proposed.

The solution required the design of a specific adaptable third order filter. The filter was designed to allow easy incorporation in a DSP. Furthermore, the action of the DC unbalance regulator was investigated and a parameterized model was built to allow easy research of the critical point.

The overall system was tested in practice on a low power system. This was possible after building the 3-level VSIs and implementing the control strategies in DSPs. This has revealed practical problems which had to be solved. 
For example, the problem of measuring the stator and rotor voltage angles has been investigated. As all the strategy is based on the knowledge of these angles, their determination was essential. Two methods have been proposed for the determination of the stator angle. For the rotor angle, an original sensorless method has been proposed and is of significant interest as no other sensors than voltage and current sensors already required by the control are necessary.

Practical measurements of transients performed on the low power system have been discussed and compared to simulations. The measurements performed matched the expected results, and their accurate concordance with simulations, have permitted the validation of the three different control strategies (transformer, machine, DC unbalance).

Finally, the possibility of replacing the rotor side 3-level VSI by a 2-level for a reduction of the DC-link capacitor size is discussed. Even though this reduction is economically interesting, it cannot technically be generalised and should be investigated in each specific case.

As a conclusion it can be said that double fed asynchronous motor-generators equipped with a 3-level VSI cascade are now technically investigated. Their economic implementation in a network must still be evaluated, however the major advantages of the variable speed and of the reactive power compensation seems at first sight to be of significant importance. 


\section{Bibliography}

[1] http://www.toshiba.co.jp/f-ene/hydro/english/products/pump/index02_2.htm

[2] "Adjustable speed asynchronous machine in hydro power plants and its advantages for the electric grid stability", D. Schafer, J.-J. Simond, CIGRE 98.

[3] "Optimized Design on Variable-Speed Drives Based on Numerical Simulation", J.-J. Simond, A. Sapin, B. Kawkabani, D. Schafer, M. Tu Xuan, B. Willy, EPE 97 Trondheim.

[4] "Investigation of the 3-level Voltage Source Inverter (VSI) for flexible ACTransmission Systems (FACTS) exemplified on a Static Var Compensator (SVC)", G. Scheuer, 1997, Diss. ETH N 12389.

[5] "Réglage de systèmes d'électronique de puissance Vol. 3", H. Bühler, PPUR.

[6] "Réglage de systèmes d'électronique de puissance Vol. 1", H. Bühler, PPUR.

[7] "Logiciel modulaire pour la simulation et l'étude des systèmes d'entrainement et des réseaux électriques", A. Sapin , Thèse N¹346, EPFL, 1995.

[8] "Untersuchung der unter-/übersynchronen Kaskade mit einem Spannungszwischenkreis Umrichter", A. Omlin, 1997, Diss. ETH Nr. 12203.

[9] "Réglage de systèmes d'électronique de puissance Vol. 2", H. Bühler, PPUR.

[10] "Static Var Compensator using neutral-point-clamped PWM inverter and its control scheme", M. Matsui, International Power Electronics Conference, IPEC Yokohama 1995, pp488-493.

[11] "Double-fed induction machine: converter optimisation and field oriented control without a position sensor", L. Morel, H. Godfroid, A. Mirzaian, J.M. Kauffmann, IEE Proceedings online no. 19981982.

[12] "Sensorless Multiscalar Control of Double Fed Machine for Wind Power Generators", Zbigniew Krzeminski, IEEE 2002.

[13] "Détermination des paramèters de machines", J. Dos Ghali, Fascicule LME.

[14] "Les Machines Electriques", F.Lucas, P. Charruault, Delagrave.

[15] "Conception de systèmes automatiques", H. Bühler, PPUR.

[16] "Switching Frequency Optimal PWM control of a Three-Level Inverter", J. Steinke, IEEE transaction on power electronics, Vol 7, NO. 3, July 1992. 


\section{Glossary}

\section{Electrical quantities}

General quantities

$\omega_{n} \quad$ nominal angular frequency

13,44

$f_{n} \quad$ nominal frequency

13,61

$\mathrm{p} \quad$ active power

13,44

$\mathrm{q}$ reactive power

$11,13,43,44$

$\mathrm{S}_{\mathrm{n}} \quad$ nominal apparent power

$\underline{\mathrm{u}}_{\mathrm{cm}} \quad$ command signal

$14,15,20$

$\mathrm{U}_{\mathrm{n}} \quad$ nominal line voltage

\section{Transformer quantities}

$c_{t} \quad$ equivalent capacitor

$f_{1} \quad$ primary side frequency in per unit

$\underline{\mathrm{i}}_{1} \quad$ primary side current phasor

$11,13,14$

$\mathrm{i}_{1 \mathrm{~d}} \quad$ primary side active current

$\mathrm{i}_{1 \mathrm{q}} \quad$ primary side reactive current

$\underline{\mathrm{i}}_{2} \quad$ secondary side current phast

11,13

$\mathrm{i}_{\mathrm{DC} 0} \quad$ current in the NP

mean value of the current in the NP

$\mathrm{i}_{\mathrm{DCc} 1}$

current in the capacitor $\mathrm{c}_{1}$

$\mathrm{i}_{\mathrm{DCc} 2} \quad$ current in the capacitor $\mathrm{c}_{1}$

$\mathrm{i}_{\mathrm{DCm}}$

machine side DC-link current

$\mathrm{i}_{\mathrm{DCt}}$ transformer side DC-link current

$\underline{\mathrm{i}}_{\text {set1 }}$ primary side current complex set value primary side reactive current set value

$r_{\mathrm{sc}}$ short-circuit resistance

$\underline{\mathrm{u}}_{1} \quad$ primary side voltage phasor

$\mathrm{u}_{1 \mathrm{~d}} \quad$ primary side active voltage

$\mathrm{u}_{1 \mathrm{q}} \quad$ primary side reactive voltage

$\underline{\mathrm{u}}_{2} \quad$ secondary side complex voltage

$\mathrm{u}_{\mathrm{DC}} \quad$ overall $\mathrm{DC}$-link voltage

$\hat{\mathrm{u}}_{\mathrm{n}} \quad$ peak value of $\underline{\mathrm{u}}_{1}$

13,14

$\mathrm{u}_{\mathrm{setDC}} \quad$ DC-link voltage set value

$\mathrm{X}_{\mathrm{Sc}}$ short-circuit reactance 


\section{Machine quantities}

$\begin{array}{lll}\Psi_{\mathrm{r}}^{\prime} & \text { reported complex rotor flux } & 44\end{array}$

$\Psi_{\text {s }} \quad$ complex stator flux $\quad 44$

$\psi_{\text {sd }} \quad$ active stator flux $\quad 44$

$\psi_{\mathrm{sq}} \quad$ reactive stator flux $\quad 44$

$\mathrm{f}_{\mathrm{r}} \quad$ rotor frequency in per unit $\quad 44$

$\mathrm{f}_{\mathrm{s}} \quad$ stator frequency in per unit $\quad 44$

$\underline{i}_{\mathrm{r}} \quad$ complex rotor current $\quad 43,44,45,47$

$\underline{i}_{\text {s }} \quad$ complex stator current $\quad 43,44,45,47$

$\mathrm{i}_{\mathrm{sd}} \quad$ active stator current $\quad 44$

$\begin{array}{lll}i_{\mathrm{sd}} & \text { reactive stator current } & 47\end{array}$

$\begin{array}{lll}i_{\text {sdset }} & \text { active stator current set value } & 47\end{array}$

$\underline{\mathrm{i}}_{\text {setr }} \quad$ complex rotor current set value $\quad 46,47$

$\begin{array}{lll}\underline{i}_{\text {sets }} & \text { complex stator current set value } & 47\end{array}$

$i_{\mathrm{sq}} \quad$ reactive stator current 44

$\begin{array}{lll}\mathrm{i}_{\mathrm{sqset}} & \text { reactive stator current set value } & 51\end{array}$

J inertia 43

$\begin{array}{lll}\mathrm{n} & \text { speed } & 43,61\end{array}$

$\begin{array}{lll}\mathrm{n}_{\text {set }} & \text { speed set value } & 49\end{array}$

$\mathrm{p}_{\mathrm{p}} \quad$ number of pairs of poles $\quad 51$

$r_{r}^{\prime} \quad$ rotor resistance in the stator reference 43, 44, 45

$r_{s} \quad$ stator resistance 43, 44, 45

$t_{\mathrm{e}} \quad$ electromechanical (air-gap) torque 44

$t_{\text {ext }} \quad$ external torque 43, 44

$\ddot{\mathrm{u}} \quad$ transformation ratio $\quad 51$

$\mathrm{U}_{\mathrm{DCn}} \quad$ nominal DC-link voltage $\quad 51$

$\mathrm{u}_{\mathrm{DCr}} \quad$ DC-link voltage in the rotor reference system 46

$\underline{u}_{\mathrm{r}} \quad$ complex rotor voltage $43,44,45$

$\underline{\mathrm{u}}_{\mathrm{s}} \quad$ complex stator voltage $\quad 43,44,45$

$\mathrm{u}_{\mathrm{sd}} \quad$ active stator voltage $\quad 44$

$\mathrm{U}_{\mathrm{sn}} \quad$ nominal stator line voltage $\quad 51$

$\mathrm{x}^{\prime}{ }_{\sigma \mathrm{r}} \quad$ rotor leakage reactance in the stator reference 43,44

$\mathrm{x}_{\sigma \mathrm{s}} \quad$ stator leakage reactance $\quad 43,44$

$\mathrm{x}_{\mathrm{h}}$ main field reactance 43, 44, 45 


\section{Transfer functions}

$\underline{\mathrm{G}}_{\mathrm{i} 1}(\mathrm{~s}) \quad$ transformer primary side current transfer function

$\mathrm{G}_{\mathrm{ir}}(\mathrm{s}) \quad$ rotor side current transfer function

$\mathrm{G}_{\text {is }}(\mathrm{s}) \quad$ stator side current transfer function

$\mathrm{G}_{\mathrm{n}}(\mathrm{s}) \quad$ speed transfer function

$\underline{\mathrm{G}}_{\mathrm{O} 1}(\mathrm{~s}) \quad$ transformer primary side open loop transfer function

$\mathrm{G}_{\mathrm{On}}(\mathrm{s}) \quad$ speed open loop transfer function

$\mathrm{G}_{\mathrm{Oq}}(\mathrm{s}) \quad$ reactive power open loop transfer function

$18,19,51$

$\underline{\mathrm{G}}_{\mathrm{Or}}(\mathrm{s})$ rotor side open loop transfer function

$\underline{\mathrm{G}}_{\mathrm{Os}}(\mathrm{s}) \quad$ stator side open loop transfer function

$\mathrm{G}_{\mathrm{Ou}}(\mathrm{s}) \quad$ DC-link voltage open loop transfer function

$\mathrm{G}_{\mathrm{pE} 1}(\mathrm{~s}) \quad$ transformer primary side small time constants transfer function

$\mathrm{G}_{\mathrm{pEn}}(\mathrm{s}) \quad$ speed small time constants transfer function

$\mathrm{G}_{\mathrm{pEq}}(\mathrm{s}) \quad$ reactive power small time constants transfer function

18,51

$\mathrm{G}_{\mathrm{pEr}}(\mathrm{s}) \quad$ rotor side small time constants transfer function

$\mathrm{G}_{\mathrm{pEs}}(\mathrm{s})$ rotor side small time constants transfer function

$\mathrm{G}_{\mathrm{pEu}}(\mathrm{s}) \quad$ DC-link small time constants transfer function

$\mathrm{G}_{\mathrm{q}}(\mathrm{s})$ reactive power transfer function

$\mathrm{G}_{\mathrm{R} 1}(\mathrm{~s}) \quad$ transformer primary side current regulator transfer function

$\mathrm{G}_{\mathrm{Ru}}(\mathrm{s}) \quad$ DC-link voltage regulator transfer function

$\mathrm{G}_{\mathrm{u}}(\mathrm{s}) \quad$ DC-link voltage transfer function

16,17

$\mathrm{H}_{\text {filter }}(\mathrm{s}) \quad$ filter transfer function

$\mathrm{H}_{\text {lowpass }}(\mathrm{s})$ low pass filter transfer function

$\mathrm{H}_{\text {notch }}(\mathrm{s})$ notch filter transfer function 


\section{Time constants}

$\mathrm{T}_{\mathrm{E}}$

$\mathrm{T}_{\mathrm{i} 1}$

$T_{\text {in }}$

$\mathrm{T}_{\mathrm{iq}}$

$\mathrm{T}_{\mathrm{iq}}$

$\mathrm{T}_{\mathrm{ir}}$

$T_{\text {is }}$

$T_{\text {iu }}$

$\mathrm{T}_{\mathrm{j}}$

$\mathrm{T}_{\mathrm{lp}}$

$\mathrm{T}_{\mathrm{n} 1}$

$\mathrm{T}_{\mathrm{nn}}$

$\mathrm{T}_{\mathrm{nr}}$

$\mathrm{T}_{\mathrm{nu}}$

$\mathrm{T}_{\mathrm{pE} 1}$

$\mathrm{T}_{\mathrm{pEi}}$

$\mathrm{T}_{\mathrm{pEn}}$

$\mathrm{T}_{\mathrm{pEq}}$

$\mathrm{T}_{\mathrm{pEr}}$

$\mathrm{T}_{\mathrm{pEs}}$

$\mathrm{T}_{\mathrm{pEu}}$

$\mathrm{T}_{\mathrm{sc}}$ sampling time

primary side classical current control integral time constant

$21,25,26$

speed control integral time constant

16

reactive power classical control integral time constant

50

machine reactive power integral time constant

19

51

rotor current classical control integral time constant

47

classical control stator current time constant

47

DC-link voltage classical control integral time constant

17 inertia time constant

44

low pass filter time constant $\quad 68$

primary side classical current control proportional time constant 16

speed control proportional time constant 50

rotor current classical control proportional time constant

47

DC-link voltage classical control proportional time constant

17

17

21

47

27

46

47

25

DC-link voltage classical control small equivalent time constant

19 


\section{State space control specific quantities}

$\rho_{\mathrm{i}} \quad$ state-space current control pole placement $\quad 24$

$\rho_{\mathrm{q}} \quad$ state-space reactive power control pole placement $\quad 27$

$\rho_{\mathrm{u}} \quad$ state-space DC-link voltage control pole placement 25

$\underline{\mathrm{i}}^{\prime}$ setd $\quad$ state-space active current set value $\quad 24$

$\mathrm{i}_{\text {setq }} \quad$ state-space reactive current set value 26

$\begin{array}{lll}\underline{k}_{\mathrm{i}} & \text { state-space current regulator current coefficient } & 21,24\end{array}$

$\mathrm{k}_{\mathrm{i}} \quad$ state-space DC-link voltage regulator set value coefficient 25

$\underline{\mathrm{k}}_{\mathrm{Ri}} \quad$ state-space current regulator integral component coefficient $\quad 21,24$

$\mathrm{k}_{\mathrm{Rq}} \quad$ state-space reactive power reg. integral component coefficient 26,27

$\mathrm{k}_{\mathrm{Ru}} \quad$ state-space DC-link voltage reg. integral component coefficient

$\underline{\mathrm{k}}_{\mathrm{u}}$

$\mathrm{k}_{\mathrm{u}}$

state-space current regulator command signal coefficient

state-space DC-link voltage regulator voltage coefficient

21,24

state-space current regulator perturbation coefficient 21,24

$\begin{array}{llr}\underline{\mathrm{k}}_{\mathrm{vi}} & \text { State-space current regulator perturbation coefficient } & 21,24 \\ \mathrm{k}_{\mathrm{vu}} & \text { state-space DC-link voltage regulator perturbation coefficient } & 25\end{array}$

21,24

$\underline{\mathrm{k}}_{\mathrm{wi}}$

$\mathrm{k}_{\mathrm{wq}}$

$\mathrm{k}_{\mathrm{wu}}$

$\mathrm{R}_{\mathrm{i}}$

state-space current regulator set value coefficient

26, 27

state-space reactive power regulator perturbation coefficient

state-space DC-link voltage regulator set value coefficient

state-space current regulator

$\mathrm{R}_{\mathrm{q}}$

state-space reactive power regulator

$20,24,26$

state-space regulator

$\mathrm{R}_{\mathrm{u}}$

$\mathrm{S}_{\mathrm{cm}}$

state-space DC-link voltage regulator

$\mathrm{S}_{\mathrm{i}}$

state-space command system

20,21

$\mathrm{S}_{\mathrm{iRd}}$

$\mathrm{S}_{\mathrm{iRq}}$

state-space current system

state-space active current system

state-space reactive current system

$\mathrm{S}_{\mathrm{pEi}}$

state-space reactive power system

20,21

$\mathrm{S}_{\mathrm{pEq}}$

$\mathrm{S}_{\mathrm{q}}$

state-space current small time constant equivalent system

state-space reactive power small time constant equivalent system

state-space reactive power system

$\mathrm{S}_{\mathrm{u}}^{\prime}$
$\mathrm{u}_{\mathrm{cm}}$

state-space DC-link voltage system

20,21

command signal

state-space current regulator integral component
state-space reactive power regulator integral component

state-space DC-link voltage regulator integral component 


\section{DC unbalance control quantities}

$\begin{array}{lll}\omega_{0} & \text { notch filter cut off frequency } & 69\end{array}$

$\begin{array}{lll}\mathrm{f}_{\mathrm{DCside}} & \mathrm{DC} \text { side frequencies } & 61\end{array}$

$\begin{array}{lll}\mathrm{i}_{0} & \text { NP current } & 62\end{array}$

$\begin{array}{lll}\overline{\dot{i}_{0}} & \text { NP current mean value } & 62\end{array}$

$\overline{\mathrm{i}}_{\mathrm{DCc} 1} \quad$ capacitor $\mathrm{c}_{1}$ current mean value $\quad 62$

$\begin{array}{lll}\overline{\mathrm{i}}_{\mathrm{DC} 2} & \text { capacitor } \mathrm{c}_{2} \text { current mean value } & 62\end{array}$

K notch filter width coefficient $\quad 69$

$\begin{array}{lll}\mathrm{u}_{\mathrm{DC} 1} & \text { capacitor } \mathrm{c}_{1} \text { voltage } & 62\end{array}$

$\mathrm{u}_{\mathrm{DC} 2} \quad$ capacitor $\mathrm{c}_{2}$ voltage $\quad 62$

$\begin{array}{ll}\mathrm{u}_{\text {DCdiff }} & \text { DC-link voltage difference }\end{array}$

$\begin{array}{ll}u_{\text {DCdiffo }} & \text { DC component of } u_{\text {DCdiff }}\end{array}$ 


\title{
Curriculum Vitae
}

\author{
Nom : André HODDER \\ Date de naissance : 25 mai 1974 \\ Nationalité : Suisse \\ Email : andre.hodder@a3.epfl.ch
}

\section{Formation}

- Gymnase type C, 1990-1993.

- EPFL, section électricité, 1993-1999.

- Assistant doctorant au Laboratoire de Machine Electriques, depuis 1999.

\section{Publications}

- $\quad$ "Double-fed asynchronous motor-generator with a 3-level VSI cascade for applications to pumped storage plants", Soumis à IEEE IAS meeting 2004 Industrial Drives, A. Hodder, J.-J. Simond.

- $\quad$ "Unbalanced DC-link voltage regulation in a back-to-back 3-level PWM converter for a doubly-fed induction motor/generator", Soumis à IEE Electric Power Application Journal, A. Hodder, J.-J. Simond.

- $\quad$ "Test virtuel d'un code de régulation DSP pour réseaux et systèmes d'entraînements électriques", Bulletin AES Electrosuisse 3/2004, A. Hodder, J.-J. Simond.

- $\quad$ Investigation and comparison between classical and state-space control for the entry VSI of a frequency converter", ICEM 2002, A. Hodder, J.-J. Simond, A. Sapin, D. Schafer.

- "Doubly-Fed Asynchronous Machine with 3-Level VSI cascade for Variable Speed Pump Storage", ICEM 2000, A. Sapin, A. Hodder, D. Schafer, J.-J. Simond. 